\title{
Assessing the Vulnerability and Resilience of the Philippines to Disasters
}

by

\section{Rio Yonson}

A thesis

submitted to the Victoria University of Wellington in fulfilment of the requirements for the degree of Doctor of Philosophy in Economics.

Victoria University of Wellington 


\section{Contents}

List of Tables ................................................................................................. vii

List of Figures................................................................................................................. xi

Acknowledgements..............................................................................................................

Abstract .......................................................................................................................... xviii

1 Introduction ...............................................................................................................1

$1.1 \quad$ Background and Context ............................................................... 1

1.2 Chapter Rationale and Objectives..................................................... 3

2 Economic Vulnerability and Economic Resilience .........................................7

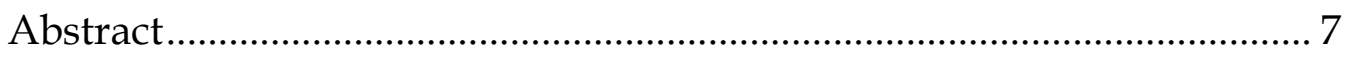

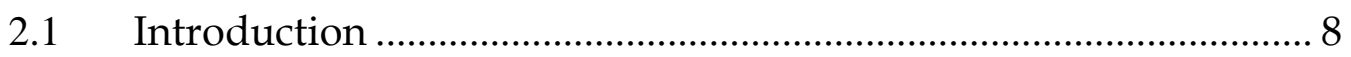

2.2 Definitions and Frameworks on Vulnerability and Resilience ... 10

2.2.1 Vulnerability and Resilience..................................................... 11

2.2.2 Economic Vulnerability and Economic Resilience..................... 14

2.3 Assessment of Economic Vulnerability and Economic Resilience 19

2.3.1 Indices of Vulnerability and Resilience.

2.3.1.1 Vulnerability Index .............................................................. 20

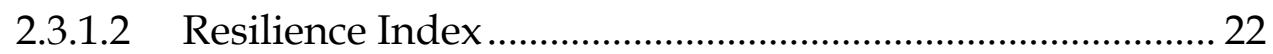


2.3.2.1 Determinants of Economic Vulnerability 23

2.3.2.2 Determinants of Economic Resilience 28

2.4 Synthesis and Implications for Policy 34

3 Measurement of Disaster Risk: An Example from Tropical Cyclones in the Philippines ............................................................................................37

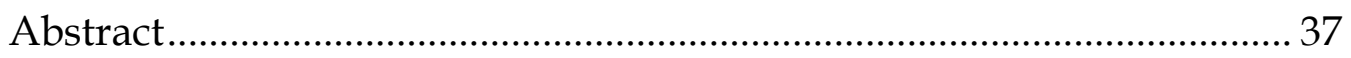

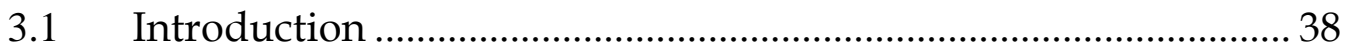

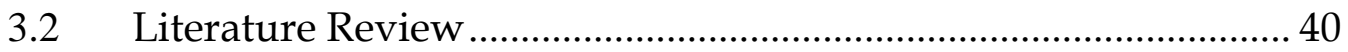

3.2.1 Frameworks on Vulnerability and Disaster Risk Assessment. 40

3.2.2 Determinants of Vulnerability: Identification and Quantification 42

3.3 Philippine Development and Tropical Cyclone Disasters 45

3.4 Model, Dataset, and Descriptive Statistics 49

3.4.1 Risk Framework, Econometric Model and Estimation Method 49

3.4.2 Variables and Sources of Data 50

3.4.2.1 Impact 50

3.4.2.2 Hazard 51

3.4.2.3 Exposed Population, Topography and Geography .... 51

3.4.2.4 Vulnerability 53 
3.5 Results and Discussions ........................................................... 58

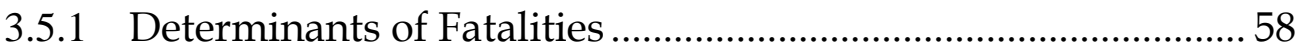

3.5.2 Estimated Fatalities per Province …......................................... 67

3.6 General Conclusions, Policy Implications and Next Steps ......... 72

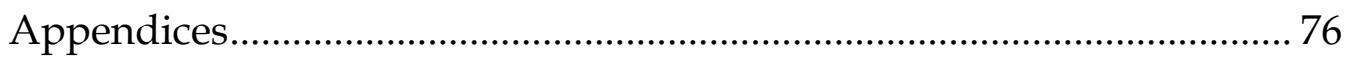

4 Floods and Pestilence: Diseases in Philippine Urban Areas ....................84

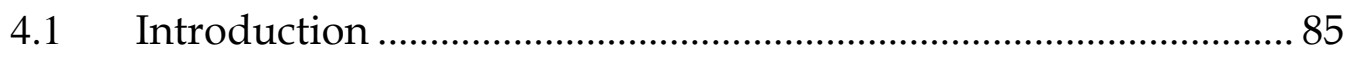

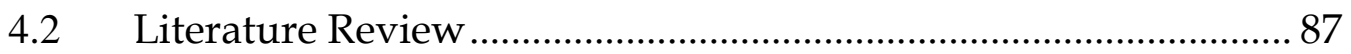

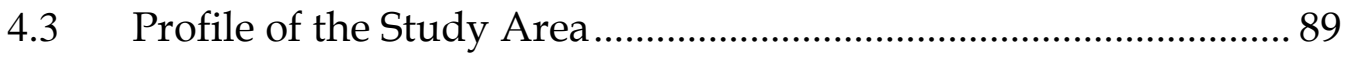

4.4 Model, Dataset, and Descriptive Statistics ................................. 92

4.4.1 Model and Estimation Method ............................................... 92

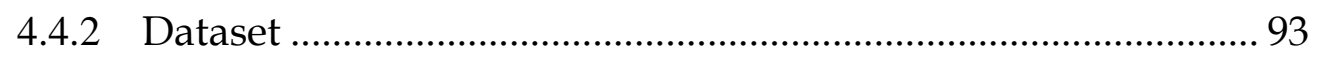

4.4.2.1 Diseases Covered ................................................................. 95

4.4.2.2 Flood Characteristics and Flood Exposure........................ 95

4.4.2.3 Physical, Economic, Social, Demographic Determinants of Diseases 97

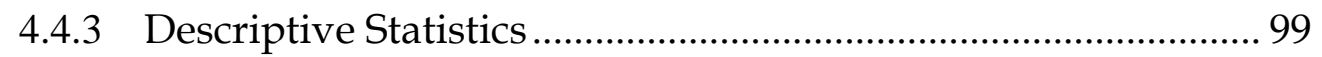

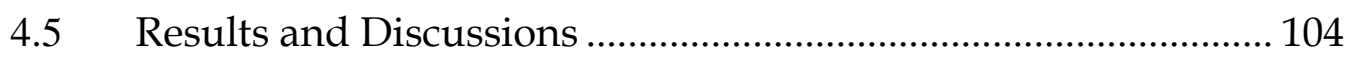

4.5.1 Determinants of the Probability to Get Sick .......................... 104 
4.6 Cost Implications of Flood-Induced Diseases

Appendices

5 Measurement of Economic Welfare Risk and Resilience of the Philippine Regions .......................................................................................................................................137

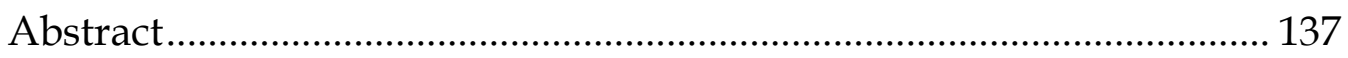

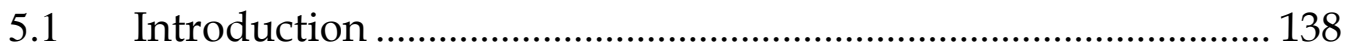

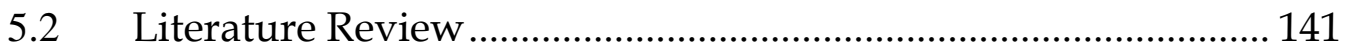

5.3 Philippine Development and Riverine Flood Disasters ............ 146

5.4 Model, Dataset, and Descriptive Statistics ................................ 150

5.4.1 Economic Welfare Disaster Risk Model................................... 150

5.4.2 Data and Assumptions ............................................................. 159

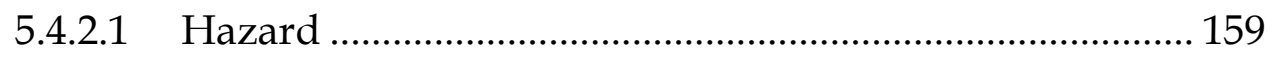

5.4.2.2 Exposure of assets used ................................................ 160

5.4.2.3 Socioeconomic Vulnerability and Resilience .................. 160

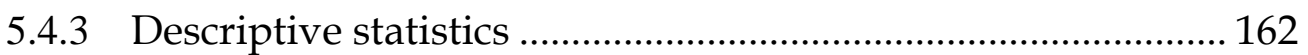

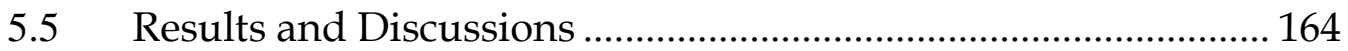

5.5.1 Asset Risk, Welfare Risk, and Resilience ............................... 164

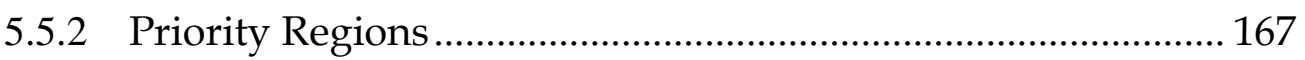


5.5.3.1 Within Each Region ................................................... 175

5.5.3.2 Across Regions .......................................................... 178

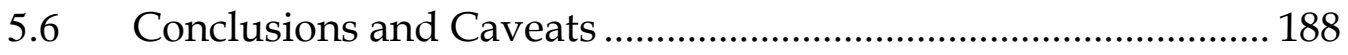

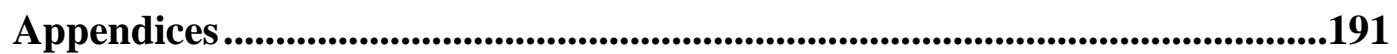

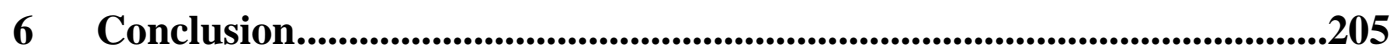

6.1 Determinants of Tropical Cyclone Fatalities ............................. 206

6.2 Relationship of Floods and Diseases in Urban Areas ................ 207

6.3 Resilience of Regions to Riverine Floods ................................... 208

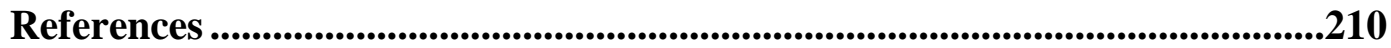




\section{List of Tables}

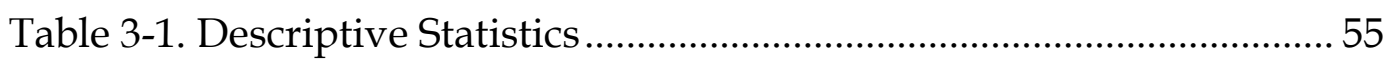

Table 3-2. Results of the Various Specifications of the Full Model .............. 61

Table 3-3. Results of the Various Specifications of the Final Model ............ 62

Table 3-4. Random Effects vs Fixed Effects Using Time-Varying Explanatory Variables Only.

Table 3-5. Monte Carlo Simulation .................................................................. 65

Table 3-6. Relative Importance of the Explanatory Variables ....................... 66

Table 3-7. Number of Tropical Cyclones and Impacts on Population and

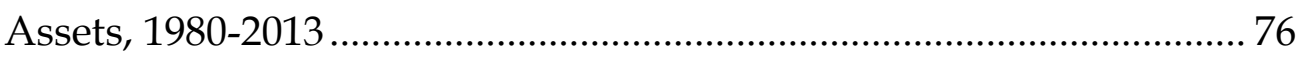

Table 3-8. Variable Sources and Description.................................................. 77

Table 3-9. Correlation of Variables ................................................................. 79

Table 3-10. Preliminary Regressions Set 1: Controls are Either Hazard or Exposure or, Topography and Geography Variables Only .................. 80

Table 3-11. Preliminary Regressions Set 2: Controls are Combinations of Hazard, Exposure, and Topography and Geography Variables.......... 81

Table 3-12. Preliminary Regression Set 3: Controls are Vulnerability Variables Only 82

Table 3-13. Random Effects vs Fixed Effects using Interacted Ground Slope 83

Table 4-1. Categories of Diseases for the Second Set of Regressions. 95 
Table 4-2. Descriptive Statistics 100

Table 4-3. Full Model, by Specific Disease. 108

Table 4-4. Full Model, by Disease Category 109

Table 4-5. Estimated Number of Households that Suffered from FloodInduced Diseases, Floodplains of Cagayan de Oro City 113

Table 4-6. Estimated Number of Households that Suffered from FloodInduced Diseases, All Urban Areas in the Philippines. 113

Table 4-7. Assumptions on Cost Implications of Flood-Induced Diseases 115

Table 4-8. Cost Implications of Flood-Induced Diseases, 2014 (in USD), Floodplains of Cagayan de Oro 116

Table 4-9. Cost Implications of Flood-Induced Diseases, 2014 (in USD), All Urban Areas in the Philippines 116

Table 4-10. Cost of Disease vs Average Household Income of the DiseaseAffected Household, 2014 (in USD), Floodplains of Cagayan de Oro 116

Table 4-11. Cases, Incidence, DALY of Diseases: Philippines, 2012 122

Table 4-12. Pairwise Correlation 123

Table 4-13. Number and Incidence by Disease, and by Flooded and NotFlooded Households, Cagayan de Oro..... 124

Table 4-14. Model with A Proxy for Poverty Based on Housing Structure, by Specific Disease 126 
Table 4-15. Model with A Proxy for Poverty Based on Housing Structure, by Disease Category ........................................................................ 127

Table 4-16. Robustness Check 1, by Specific Disease ............................... 128

Table 4-17. Robustness Check 2, by Specific Disease ................................. 129

Table 4-18. Robustness Check 3, by Specific Disease ................................ 130

Table 4-19. Robustness Checks 1, by Category of Diseases ...................... 131

Table 4-20. Robustness Check 2, by Category of Diseases ........................ 131

Table 4-21. Robustness Check 3, by Category of Diseases ........................ 132

Table 4-22. Robust Determinants by Specific Disease: Flood Exposure, Flood Height, and Flood Duration .............................................................. 133

Table 4-23. Robust Determinants by Category of Diseases: Flood Exposure, Flood Height, and Flood Duration ...................................................... 134

Table 4-24. Summary of Cost Implications of Flood-Induced Diseases, by Scenario and by Specific Disease, 2014 (in PhP), Floodplains of Cagayan de Oro ................................................................................. 135

Table 4-25. Summary of Cost Implications of Flood-Induced Diseases, by Scenario and by Specific Disease, 2014 (in PhP), All Urban Areas in the Philippines. 135

Table 4-26. Average Cost of Disease per Household (for CDO) or Family (for the Philippines), by Disease, 2014 ................................................ 136

Table 5-1. Exposure by Category of Families .......................................... 154

Table 5-2. Asset Losses by Category of Families ...................................... 156 
Table 5-3. NPV of Consumption Losses by Category of Families (without scale-up of protective mechanisms) ....................................................... 157

Table 5-4. NPV of Consumption Losses with Scaled-Up Social Protection by

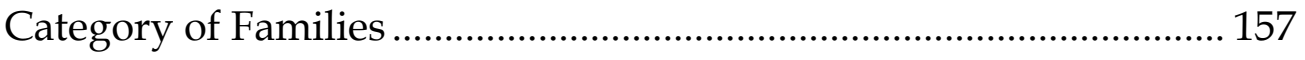

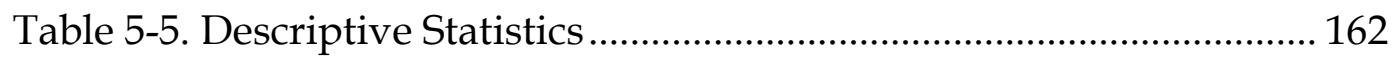

Table 5-6. Asset Risk, Welfare Risk, and Resilience (\%) .............................. 165

Table 5-7. Variables, Parameters, Results ................................................... 192 


\section{List of Figures}

Figure 3-1. The Provinces of the Philippines................................................... 46

Figure 3-2. Tropical Cyclone Tracks, 2005-2010............................................ 56

Figure 3-3. Number of Occurrences: Destructive Tropical Cyclones, 20052010 56

Figure 3-4. Total Number of Fatalities, Destructive Tropical Cyclones, 20052010 56

Figure 3-5. Total Number of Affected Persons, Destructive Tropical Cyclones, 2005-2010 56

Figure 3-6. Predicted Fatalities 69

Figure 3-7. Predicted Fatalities by Scenario 70

Figure 3-8. Summary of Predicted Fatalities by Scenario 72

Figure 4-1. Administrative Map of Cagayan de Oro City...... 91

Figure 4-2. Location of Households in the Dataset 94

Figure 4-3. Incidence of Disease, by Specific Kind and by Household Groupings (\%). 102

Figure 4-4. Incidence of Disease, by Disease Category and by Household Groupings (\%). 102

Figure 4-5. Kernel Density Map of Disease-Affected Households 103

Figure 4-6. Kernel Density Map of Low-Income Households 103 
Figure 4-7. Kernel Density Map of Households Affected by Typhoid Fever 125

Figure 5-1. The 18 Regions of the Philippines............................................... 148

Figure 5-2. Reconstruction Dynamics and Total Output Losses ................ 152

Figure 5-3. Categorization of Regions According to Resilience .................. 172

Figure 5-4. Categorization of Regions According to Welfare Risk ............ 172

Figure 5-5. Prioritization of Regions, Based on Resilience and Welfare Risk 173

Figure 5-6. Hot Spot Analysis of Provincial Level of Poverty Incidence. 173

Figure 5-7. Policy Cards for a High Priority Region: ARMM..................... 177

Figure 5-8. Policy Cards for the Low Priority Regions: NCR ..................... 177

Figure 5-9. Reduction in Exposure by 10\% ............................................... 181

Figure 5-10. Reduction in Asset Vulnerability by 5\% ................................ 182

Figure 5-11. Increase in Family Income by 10\% ......................................... 183

Figure 5-12. Reduction in Poverty Incidence by 1\% .................................. 184

Figure 5-13. Increase in Social Protection by 10\% ....................................... 186

Figure 5-14.Provision of scale-up protection by $15 \%$ of income ................ 187

Figure 5-15. Policy Card: National Capital Region ...................................... 196

Figure 5-16. Policy Card: Cordillera Administrative Region....................... 196

Figure 5-17. Policy Card: Region I - Ilocos Region ....................................... 197 
Figure 5-18. Policy Card: Region II - Cagayan Valley 197

Figure 5-19. Policy Card: Region III - Central Luzon................................... 198

Figure 5-20. Policy Card: Region IVA - CALABARZON ............................ 198

Figure 5-21. Policy Card: Region IVB - MIMAROPA................................... 199

Figure 5-22. Policy Card: Region V - Bicol Region ...................................... 199

Figure 5-23. Policy Card: Region VI - Western Visayas .............................. 200

Figure 5-24. Policy Card: Negros Island Region............................................. 200

Figure 5-25. Policy Card: Region VII - Central Visayas ............................... 201

Figure 5-26. Policy Card: Region VIII - Eastern Visayas............................. 201

Figure 5-27. Policy Card: Region IX - Zamboanga Peninsula ...................... 202

Figure 5-28. Policy Card: Region X- Northern Mindanao........................... 202

Figure 5-29. Policy Card: Region XI - Davao Region.................................... 203

Figure 5-30. Policy Card: Region XII - SOCCSAKARGEN......................... 203

Figure 5-31. Policy Card: Region XIII - CARAGA Region........................... 204

Figure 5-32. Policy Card: ARMM - Autonomous Region of Muslim

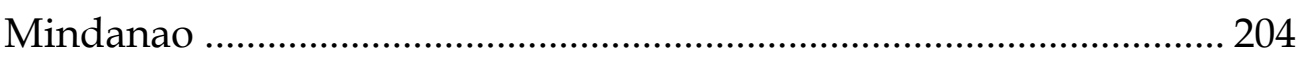




\section{For my Papa}

(who is with me from up there)

$\mathcal{E}$

my Mama

(who is with me here) 


\section{Acknowledgements}

The best part of my journey as a PhD student has to do with my supervisors - I am privileged to have the great tandem of Professor Ilan Noy and Associate Professor JC Gaillard. They mentored me well and closely supervised me, yet gave me a fair amount of independence in doing research. Their suggestions and contributions significantly improved the substance of this thesis. With Ilan, I appreciate the candid exchanges of ideas, his subtle yet effective pressure to deliver, and even his bluntness that I take without offense but with much humor instead. I admire his simplicity and unassuming brilliance. I appreciate JC as much for despite that we are regions apart, he makes himself easily accessible. His inputs mirror his profound passion for his work and advocacies that enriched the interdisciplinary character of this thesis. For the many good things that they made happen for me, I will always be thankful.

I also remain grateful to my past academic mentors at Monash University Dietrich Fausten and Peter Forsyth. At Monash, they made me realize that "pressure makes diamonds"; here at Victoria University of Wellington (VUW), Ilan and JC demonstrated to me how to keep calm and be cool amidst these pressures.

I extend great thanks to Stephane Hallegatte, Mook Bangalore and Adrien Voight-Schilb for the opportunity to work with them on my fifth chapter. Learning programming for me to adjust their code and data was difficult but working with them was not. I am also thankful that this work eventually led to my official engagement with the World Bank to work on a related but separate project with my former colleagues at the Philippines' National Economic and Development Authority (NEDA) and other 
government agencies. I thank Ilan's fraternal twin brother, Dr. Ami Neuberger, for the advice in categorizing the diseases in my fourth chapter.

Researching on the Philippines is quite a tall order as datasets are not always available to the public. I am, therefore, thankful to the following offices for recognizing the value of research and for sharing their data: Climate Change Commission of the Philippines, Philippine Statistics Agency, Philippine Atmospheric Geophysical and Astronomical Services Administration, National Disaster Risk Reduction and Management Council, Department of Agriculture, Department of Environment and Natural Resources, Local Government Units of Cagayan de Oro City and Malaybalay City, Province of Bukidnon, and of course, the NEDA where my interest on the study of natural hazards and disasters all started.

Sincerest thanks to the EQC-MPI Chair in the Economics of Disasters for the fully-funded PhD Scholarship. I am happy that the VUW School of Economics and Finance (SEF) gave me the opportunity to teach and tutor, and to represent the SEF PhD students to the Victoria Business School PhD Students Committee. I give my profound respect to the SEF teaching and administrative personnel for their professionalism and friendliness. Special thanks go to Ingrid for being so pleasant and going the extra mile always.

Many thanks to Jan Feld of SEF-VUW, Stephen Knowles of the Department of Economics of University of Otago, and Paul Raschky of the Department of Economics of Monash University for thoroughly reviewing my thesis, giving me valuable feedback, and encouraging me to submit my chapters in good journals. Special thanks also go to Phil Lester of the School of Biological Sciences of VUW who graciously chaired my thesis oral examination. 
About two weeks prior to my submission of this thesis for examination, I joined Opus International Consultants, Ltd. I thank Opus for all their support, especially to Wendy Turvey and Vivienne Ivory.

My $\mathrm{PhD}$ student-friends have been a big part of my journey. Greatest heartfelt thanks go to Khoa - my buddy who I go the distance (literally) with to unwind and enjoy the good things outside our PhD office walls. With Miles, Tom, Helen, Sodany, Diana, Mona, Cuong, Melissa, Aditya, Ilkin, Tauisi, Olivia, Azreen, Farnaz, Jacob, Tahir, Karam and Hanna, I will cherish either the learning sessions, casual conversations, tramping escapades, or the many nonsense yet blissful moments of laughter. I enjoyed my stay at Vic; I virtually travelled to almost 30 countries around the world by spending time with the amazing SEF staff and PhD students.

My deepest love and gratitude go to family and friends: Mano Iboy who supported me throughout, making me feel like Papa is still around; Mama who is my greatest inspiration and source of strength; Joy for adding spice to my PhD journey; Ate Delia, Auntie Ludy, Joy-Joy, Manang Gaging, Manoy Jun-Jun, Auntie Gaga and their families for taking good care of Mama while I and Mano are away; Evans for the many favours and for the unconditional love; my Philippine DRR teammates - RD Leon, Kyan, Richard, Doods, Jhunles, Manong Jess, Kuya Henry, April, and Jai who have been virtually with me in my journey; and, Kathy, Van, Bob, Pola, Gin, Ate Gina, Kuya Jess, Diana, Antong, Joan and John and their kids Lucy and Charlie for being my family in New Zealand.

I offer everything to the Almighty, for His goodness is infinite, His presence is constant, and His will is truly fair and just. 


\section{Abstract}

Some of the world's most destructive disasters occurred in the Philippines, and a number of these happened in recent years. In 2011, 2012, and 2013, tropical cyclones Washi, Bopha, and Haiyan, respectively, left a staggering trail of over 8,000 deaths, as well as huge damages to assets and livelihoods. In 2009, tropical cyclones Ketsana and Pharma brought massive riverine floods, with a total damage and loss equivalent to $2.7 \%$ of the country's GDP. This dissertation is an endeavour to measure disaster impacts and welfare risk, and to identify factors affecting vulnerability and resilience in different spatial scales in the Philippines. The first of four chapters is an extensive literature survey on the economic vulnerability and economic resilience to disasters. This serves as a prelude to the succeeding three empirical studies contained in Chapters 3 to 5 . Chapter 3 aims to measure tropical cyclone-induced fatalities in the Philippine provinces, and identifies the factors that shape people's vulnerability. It also quantifies the relative importance of hazard, exposure, and socioeconomic vulnerability in influencing fatalities. Chapter 4 is a household level study that quantitatively establishes the linkages between floods and diseases in the floodplains of a highly-urbanized city in the Philippines (Cagayan de Oro), and provides an estimate on the public finance implications of floodinduced diseases to the Philippine urban areas, and on the additional economic burden on affected households. Chapter 5 measures socioeconomic resilience and welfare risk from riverine flood disasters, and systematically quantifies the effectiveness of a menu of region-specific disaster risk reduction and management measures. 


\section{Chapter 1}

\section{Introduction}

\subsection{Background and Context}

The study of the economics of natural hazards and disasters took off in the early 2000s, though the pioneering works of Dacy and Kunreuther (1969) and Albala-Bertrand (1993) came much earlier. The existing empirical studies can be broadly categorized into two strands. The first strand seeks to identify the factors affecting the disaster impacts on people and assets. The second strand aims to measure the follow-on economic effects, and identify the factors that influence these effects. The former strand generates insights about the socioeconomic vulnerabilities of the exposed, while the latter provides insights on economic resilience. In general, economic vulnerability and economic resilience, interacting with the hazard and the exposure of populations and physical assets, are considered critical determinants of the resulting disaster impacts. Indeed, disasters are largely influenced by economic forces so that "the very occurrence of disasters is an economic event" (Cavallo \& Noy, 2011).

The majority of these existing empirical studies are cross-national, but as inputs for decision-making, subnational assessments have a bigger practical 
significance. Many of the institutional and legal structures are identical across areas within a country, and thus the biases introduced by unaccounted differences are less severe and allow one to focus on differences across subnational areas that may be obscured because of these biases. Moreover, a subnational study is of practical usefulness in planning and policy-decisions pertaining to disaster risk reduction and management (DRRM) and climate change adaptation (CCA), and when almost all decisions to allocate scarce resources to subnational areas are undertaken at the national level.

For the reasons cited above, we operationalize the insights from existing empirical literature into a subnational level of assessment. The Philippines, the most exposed country to multiple hazards globally, provides a good case study. The country is located along the Pacific Ring of Fire and along the Pacific typhoon belt, thus making it prone to various geologic and hydrometeorologic hazards. It experienced some of the world's most destructive disasters, several of which occurred in recent years.

The country's decentralized system of governance, the centralized system of allocation of fiscal resources, the integrated nature of development planning, investment programming and budgeting make it a suitable testcase for the questions we address. Furthermore, the Philippines is undergoing urbanization, rapid development, and democratization that are all typical processes for middle-income countries. These are all hypothesized to have a significant influence on disaster vulnerability and resilience.

Particularly with the passage of the Climate Change Act in 2009 and the Disaster Risk Reduction and Management Act in 2010, the Philippines has been intensifying its efforts to integrate DRRM and CCA in development policies and processes. Thus, the aim of this thesis is to contribute towards 
these efforts by undertaking a systematic assessment of disaster impacts and risk, and vulnerability and resilience to disasters. Finally, the hope is that these research outputs can readily be put to practical application.

\subsection{Chapter Rationale and Objectives}

This thesis comprises four main parts that are in Chapters 2 to 5 . Each of these chapters is a separate and complete paper by itself; each has a different focus but with complementary objectives to the other chapters.

At the outset, it is noted that the literature provides numerous definitions of vulnerability and resilience in the context of natural hazards, but despite a myriad of frameworks, a consensus has yet to be reached. For this thesis, vulnerability and resilience are generally considered as:

- Vulnerability is mainly considered as a pre-disaster concern that refers to the conditions that make the confluence of a hazard, and a system's exposure to it, result in a disaster.

- Resilience is largely, but not entirely, a post-disaster concern; it refers to the conditions that make the affected systems withstand and bounce back from the disaster experienced. It is also a pre-disaster concern in as much as a system's ability to withstand adverse disaster impacts is largely influenced by pre-disaster conditions.

These definitions are simplified adaptations of the selected definitions presented in Chapter 2.

Chapter 2 is an extensive literature survey on economic vulnerability and economic resilience specific to the study of natural hazards and disasters. It also serves as a prelude to the three empirical studies contained in the succeeding chapters. It describes the progress made in the conceptualization and measurement of the economic dimensions of 
vulnerability and resilience to natural hazards and disasters. Broad insights are generated from the existing literature for practical applications and policy decision-making.

Chapter 3 aims to answer the question: What determines fatalities from tropical cyclone disasters? It is widely accepted that the level of socioeconomic development, characteristics of urbanization, and quality of local governance influence the resulting impacts of disasters on people, assets, and the economy. These insights from the quantitative cross-national empirical literature are operationalized into a provincial level assessment in this chapter. Apparently, this is the first subnational empirical work that combines the use of panel data econometric estimation methods with GIS tools to systematically answer the question posed within the context of a middle-income country.

A tool is developed to determine the underlying drivers of tropical cycloneinduced fatalities, and to explain the variability of these fatalities across provinces. This involves the construction of a new provincial level panel dataset to assess the influence of socioeconomic vulnerability (i.e. levels of economic and social development, urbanization, governance), exposure (i.e. population, topography and geography), and hazard characteristics (i.e. rainfall and wind speed) on the resulting fatalities from recent tropical cyclones.

The provincial scale of assessment generates results that have direct usefulness into the integration of DRRM into the various stages of the provincial planning cycle. Among others, this study is undertaken in response to the call to contribute in refining the Philippines provincial disaster risk assessment (DRA), which serves as a main input in integrating disaster risk reduction and management (DRRM) into the Provincial Development and Physical Framework Plan (PDPFP). This study hopes to 
add value to the existing DRA methodology through a systematic approach of vulnerability and disaster risk assessment, among others.

Chapter 4 is a city level assessment to answer the question: Do floods affect the probability of urban residents to suffer from diseases? This paper aims to measure the incremental increase in incidence of diseases due to floods in an urban setting, and to quantify some important cost implications to the government and to the households affected by these flood-induced diseases.

The case study is the floodplains of Cagayan de Oro, a highly-urbanized city in the Philippines that exhibits many of the common characteristics of urban areas in middle-income countries. The study uses the city's 2014 Climate and Disaster Risk Exposure Database, covering 13,568 households and 13 diseases. This makes the study the first quantitative assessment for the question posed that simultaneously covers several diseases and uses a large sample of households.

Logistic regression is used to identify the diseases associated with floods, and to quantify the incremental incidence of each disease because of floods. Spatial statistics tools are also used to determine spatial patterns of diseases, and spatial association between floods and diseases.

Using the estimated incremental increase in incidence for each disease under various scenarios, the study proceeds further to estimate the cost implications of flood-induced diseases on public health finance, and the additional economic burden of diseases on affected households. Cost estimation is undertaken for the floodplains of Cagayan de Oro City, and generalized to all urban areas in the Philippines to serve as inputs for discussions on the expansion or redesign of policies aimed at ensuring 
people's safety from disasters, diseases, and impoverishment within a typical urban setting.

Chapter 5 is a regional level study that systematically tackles the questions: 1) How much asset and welfare risks does each region face from riverine flood disasters? 2) How resilient is each region to riverine flood disasters? and 3) What are the available interventions per region to strengthen resilience to riverine flood disasters and what will be their benefit?

Among the follow-on costs of damages to assets due to disasters are losses in output and income that, in turn, result in consumption and welfare losses (Hallegatte, Bangalore, \& Vogt-Schilb, 2016a, 2016c). As observed, these losses in welfare are often not reported, if at all attempted to be quantified. The scant empirical literature on welfare impacts are often cross-national or focused on one specific area within a country (e.g. a city or province or district, etc). Thus, this study aims to fill these gaps by conducting an intranational assessment of the welfare impacts of riverine flood disasters.

The study uses the economic model of Hallegatte (2014) that extends the usual hazard-exposure-vulnerability disaster risk model into economic welfare disaster risk model (Hallegatte et al., 2016a). The model operationalizes the quantification of welfare risk by adding socioeconomic resilience as a fourth component.

The study covers all 18 regions of the Philippines, and demonstrates the channels through which macroeconomic asset and output losses from disasters translate to consumption and welfare losses at the microeconomic level. Apart from a region-specific estimate of the level of socioeconomic resilience and welfare risk, the study proceeds to systematically identify a menu of region-specific policy options ranked by level of effectiveness in increasing resilience and reducing welfare risk from riverine floods. 


\title{
Chapter 2
}

\section{Economic Vulnerability and Economic Resilience}

\begin{abstract}
With the successful shift from a hazard-centred disaster paradigm to one that places emphasis on the influence of vulnerability and resilience, disasters triggered by natural hazards have since been perceived as unnatural occurrences. To date, the theoretical conceptualization and empirical measures of vulnerability and resilience remain subjects of contentions. This survey of the economic literature aims to describe the progress made in the conceptualization, and measurement of the economic dimensions of vulnerability and resilience in the context of natural hazards, and to provide useful insights for policy-making. Economic vulnerability and economic resilience, interacting with the hazard itself and the exposure of populations and physical assets, are considered critical determinants of the resulting impacts of disasters. The empirical evidence provides systematic support for the hypothesis that apart from the characteristics of the hazards, the potential for people and economies to avoid adverse impacts and their capacity to withstand and rebound from a disaster are influenced by a confluence of socio-economic factors.
\end{abstract}




\subsection{Introduction}

Decades ago, the discourse on disasters was largely about natural hazards and their characteristics. Disasters were viewed as products of processes of the geophysical world (Blaikie, Cannon, Davis, \& Wisner, 1994). As such, governments' interventions were mainly structural, such as hazard protection measures as flood defences (Westen \& Kingma, 2009). This paradigm was eventually seen to have failed to tackle the conditions that result in varying impacts of hazards on people (Wisner, Blaikie, Cannon, \& Davis, 2004). Over time, and particularly with the experiences of developing countries, the concept of vulnerability emerged in the disaster discourse. Disasters triggered by natural hazards have since been widely viewed as un-natural occurrences brought about by a confluence of societal factors with these natural hazards (Westen \& Kingma, 2009). This view, that disasters were the result of the interaction between natural hazards and societal factors appeared as early as in the 1970s (see Kates (1971), and O'Keefe, Westgate, and Wisner (1976)), but this view did not readily gain wide acceptance at that time.

Consequent to this paradigm shift is the heightened interest by a multiplicity of disciplines in gaining a deeper understanding of the important underlying factors that allow hazards to become disasters. From this increasing understanding of vulnerability emerged a likewise increasing appreciation of the distinct role of resilience in shaping the consequences that follow from the resulting disasters impacts.

There is a large conceptual and empirical literature on vulnerability and resilience to natural hazards. While the majority of these works are from diverse social sciences, the economic dimension of vulnerability and of resilience is typically covered. Researchers within economics started later, particularly around the year 2000, though the pioneering works on the 
economics of disasters came much earlier through the works of Dacy and Kunreuther (1969) and Albala-Bertrand (1993). ${ }^{1}$ Economic vulnerability and economic resilience, interacting with the hazard itself and the exposure of populations and physical assets, are considered critical determinants of the resulting disaster damages and losses. Indeed, disasters are largely influenced by economic forces so that "the very occurrence of disasters is an economic event" (Cavallo \& Noy, 2011).

This work aims to describe the progress made in the conceptualization, and measurement of the economic dimensions of vulnerability and resilience in the context of natural hazards. We also aim to provide insights for practical applications of these concepts and measurements in policy decisionmaking. Given this specific contextual backdrop, we take off from the widely used three-component risk formulation ${ }^{2}$ of the disaster risk reduction community as follows: Risk = Hazard $x$ Exposure $x$ Vulnerability

The UNISDR (2009) defines these variables: Risk is "The combination of the probability of an event and its negative consequences"; Hazard is "A dangerous phenomenon, substance, human activity or condition that may cause loss of life, injury or other health impacts, property damage, loss of livelihoods and services, social and economic disruption, or environmental damage"; Exposure refers to "People, property, systems, or other elements present in hazard zones that are thereby subject to potential losses"; and, Vulnerability refers to "The characteristics and circumstances of a

\footnotetext{
1 Among others, Dacy and Kunreuther (1969) examine the determinants of long-run recovery, including infrastructure networks, insurance, and public policy. Meanwhile, Albala-Bertrand (1993) develops a framework for the analysis of disasters in developing countries, and argues that while development influences the occurrence of a disaster, disasters are not obstacles towards development.

2 The framework that disaster risk comprises three components namely, hazard, vulnerability and exposure was first presented by the United Nations Disaster Relief Co-ordinator in 1979 as contained in the Report of Expert Group Meeting (UNDRO, 1979) and later contained in their disaster risk training modules (UNDRO, 1992).
} 
community, system or assets that make it susceptible to the damaging effects of a hazard."

We, likewise, adopt the UNISDR's (2009) definition of resilience, which is "the ability of a system, community or society exposed to hazards to resist, absorb, accommodate to and recover from the effects of a hazard in a timely and efficient manner, including through the preservation and restoration of its essential basic structures and functions."

This work is organized as follows: Section 2.2 provides highlights on selected perspectives and conceptualization on vulnerability and resilience across different disciplinary approaches. It then focuses the discussion on economic vulnerability and economic resilience in broad terms, and subsequently, in the specific context of the natural hazard discourse. Section 2.3 presents a selection of empirical works on determinants and measurement tools. Section 2.4 provides a synthesis and implication for policy, including areas needing further research and refinement.

\subsection{Definitions and Frameworks on Vulnerability and Resilience}

A number of comprehensive reviews (e.g., Birkmann (2006), Gaillard (2010), Thywissen (2006), and Villagran de Leon (2006)) reveal the distinct conceptualization of vulnerability and resilience in each of the disciplines and communities involved in the natural hazards discourse. The multiplicity of separate efforts has led to differing understanding, if not confusion, about these concepts (Miller et al., 2010). This is not surprising as each discipline is likely to maintain its specific definitions and disciplinary frameworks when examining natural hazards and disasters, without making the adjustments and contextualization to align with other disciplines. Apart from the separate efforts of the various academic 
disciplines (e.g. sociology, geography, economics, planning, or public health), the definitions and frameworks continue to evolve by their usage within the disaster risk reduction (DRR) community, and the climate change community. Below, we present selected definitions and frameworks that capture some, but not all, of these community- or discipline-specific views.

\subsubsection{Vulnerability and Resilience}

In tracing the evolution of the concept of vulnerability in the context of natural hazards, Birkmann (2007) found that vulnerability started with a narrow definition that focused only on the intrinsic characteristics of elements at risk. This eventually broadened into a human-centred concept that refers to the likelihood for elements to experience harm. Further, the concept widened to refer to both the element's susceptibility and capacity to cope. Further on, exposure of the elements and their capacity to adapt ${ }^{3}$ were likewise considered as separate components of vulnerability. A broadly accepted version of the concept of vulnerability therefore includes that of a multi-dimensional vulnerability, covering economic, social, physical and institutional aspects.

The equation: Risk = Hazard $x$ Vulnerability, is another popular variant of the risk equation, which captures the two opposing components under the Pressure and Release (PAR) framework (Blaikie et al., 1994; Wisner et al., 2004). Focusing on people, vulnerability is defined in this framework as "the characteristics of a person or group in terms of their capacity to anticipate, cope with, resist, and recover from the impact of a natural hazard" (Blaikie et al., 1994). In this conceptualization, it is evident that

\footnotetext{
${ }^{3}$ It is noted here that while coping capacity and adaptive capacity are often used interchangeably, a distinction is made in Cardona et al. (2012) between the two, as follows: "coping focuses on the moment, constraint, and survival; adapting (in terms of human response) focuses on the future, where learning and reinvention are key features and short-term survival is less in question".
} 
vulnerability encompasses exposure. Worthy of note is that this definition captures what generally are considered as components of resilience as defined by UNISDR (2009). However, despite this definition, the framework's three levels of progression of vulnerability trace the channels through which a disaster occurs when a natural hazard affects the vulnerable. 4 The PAR's emphasis is the imperative to reduce vulnerability and through adjustments to the existing economic and political systems, given that these are the underlying causes of rapid urbanization and population growth (Birkmann, 2006).

Apart from that in the PAR, there are several other earlier definitions of vulnerability that subsume either or both exposure and resilience. For instance, Pelling (2003) identifies three components of vulnerability: exposure, resistance (i.e. capacity to withstand adverse impact), and resilience (i.e. capacities to cope and adapt).

In the second Assessment Report of the Intergovernmental Panel on Climate Change (IPCC), vulnerability is presented as a function of sensitivity, exposure, and adaptive capacity (IPCC, 1996). It groups the negative and positive factors that determine vulnerability, into two separate components, namely, sensitivity and resilience. In its third Assessment Report, the IPCC presented the view that resilience is the "flipside of vulnerability" (IPCC, 2001).

At the time that these reports were released, the climate change community and the DRR community each adopts a framework that is lacking in

\footnotetext{
${ }^{4}$ The Progression of Vulnerability Framework (Wisner, Gaillard, \& Kelman, 2012) further elaborates the PAR framework. This framework distinguishes among three levels of progression of vulnerability: "Root causes" include the economic and social structures that influence how resources, wealth, and power are distributed; the ideologies in governance; and, history and culture. "Dynamic pressures" are grouped into the deficiencies of society's economic, social and political processes, and macro-forces, such as rapid population growth and rapid urbanization, deforestation, decline in soil productivity, among other. These serve as the channels through which the root causes result in fragile livelihoods in unsafe locations, which is the final level in the progression (Blaikie et al., 1994; Wisner et al., 2012).
} 
commonality even though these communities tackle some common hazards. Nonetheless, more areas of convergence are observed through time as noted by Cardona et al. (2012).

A major development in this conceptualization was contained in the IPCC's Fifth Assessment Report (IPCC, 2014). It is the adoption of a risk framework that mirrors the three components of the DRR community's Hazard/Exposure/Vulnerability risk equation. In this framework, the IPCC refers to vulnerability as the "propensity or predisposition to be adversely affected" (IPCC, 2014)5, which basically captures only the "sensitivity" component of its earlier vulnerability definition, and which is consistent with the UNISDR (2009) definition. This harmonization by these two key institutions (UNISDR working on DRR and the IPCC on climate change) can be considered a major step towards achieving greater synchronization of efforts between these two communities.

Meanwhile, the evolution of the concept of resilience in the context of natural hazards dates about as far back as that of vulnerability, though, as previously noted, it has been typically subsumed either under vulnerability or other components of risk. ${ }^{6}$ Holling (1973) described resilience to shocks in the context of ecological systems. He refers to resilience as a system's ability to absorb changes and to persist amidst these changes. Meanwhile, in the geosciences disciplines, the concept is interpreted as the ability to withstand the occurrence of the hazard, while incurring only tolerable levels of losses (Mileti, 1999).

\footnotetext{
5 The other two components of this framework are hazards and exposure. Hazard refers to the "potential occurrence of a natural or human-induced physical event or trend or physical impact that may cause loss of life, injury, or other health impacts, as well as damage and loss to property, infrastructure, livelihoods, service provision, ecosystems, and environmental resources"; and Exposure refers to "people, livelihoods, species or ecosystems, environmental functions, services, and resources, infrastructure, or economic, social, or cultural assets in places and setting that could be adversely affected" (IPCC, 2014).

${ }^{6}$ In tracing how the term "resilience" came to be used in DRR, Alexander (2013) finds that the term has a Latin origin. Though a myriad of DRR literature declares Holling (1973) as the first to coin the term, the work of Bacon in 1625 is the first known scientific use of the term in its present form in the English language (Alexander, 2013).
} 
Engineering puts particular attention on the amount of time it takes to recover from the adverse impact of a shock (Correia, Santos, \& Rodrigues, 1987). From an ecological perspective, Pimm (1984) presents a similar definition to that in engineering by referring to resilience as the speed of recovery following a disturbance. Apart from speed of recovery which he refers to as rapidity, Bruneau et al. (2003) posits that robustness, redundancy and resourcefulness also determines the resilience of physical and social systems. These reduce the chances of experiencing shocks, and, if a shock occurs, the affected systems are readily able to absorb it with minimum adverse effects. As a result of this increasing appreciation of the distinct influence of resilience on disaster risk, there are now disaster risk frameworks that include resilience as an additional component of disaster risk (as in Hallegatte (2014) and Rose (2009b))

\subsubsection{Economic Vulnerability and Economic Resilience}

In Economics, the concept of vulnerability is typically applied to four areas of interest, other than disasters: poverty, food security, asset-vulnerability, and sustainable development (Alwang, Siegel, \& Jorgensen, 2001; Moret, 2014). Most often, vulnerability is analysed in the study of the dynamics of poverty, focusing on the "risk of falling into poverty or deeper into poverty" (Moret, 2014). Likewise, resilience is used in three research strands: economic shocks; sustainability; and, institutions (Rose, 2009b).

Briguglio and colleagues (Briguglio, 2004; Briguglio, Cordina, Farrugia, \& Vella, 2009; Briguglio \& Galea, 2003) are among the first to simultaneously study economic vulnerability and economic resilience, and to posit that these two jointly determine a country's risk of being affected by external shocks. Specifically, they refer to economic vulnerability as a country's exposure to external shocks due to its inherent economic characteristics the economic openness, export concentration, and dependence on strategic 
imports of the country in question. These are conceived as structural and therefore difficult to change with deliberate policies (at least in the shortterm). On the other hand, economic resilience refers to the economy's coping ability that can, in contrast, be influenced by policies (Briguglio et al., 2009). Policies that induce and nurture resilience are those that enhance macroeconomic stability, increase market efficiency, improve governance and expand social development.

In an empirical inquiry they undertake, Briguglio et al. (2009) find that GDP per capita is negatively correlated with their index of economic vulnerability and positively correlated with their index of economic resilience. Additionally, they show there is greater responsiveness of GDP per capita to the resilience index than to the vulnerability index. As such, the authors conclude that a country's economic well-being is shaped more by its policies than by its structural economic characteristics (Briguglio et al., 2009).

Rose (2009a), in his review of the economic literature, finds that several important dimensions of economic resilience are not given adequate emphasis in this literature and some are not considered at all in the existing conceptualizations. He argues that, above all, there is a need to distinguish between damages to stocks (i.e. property damage), and damages to flows (i.e. damages to production of goods and services). While damages to stocks are incurred all at once at the time of the shock, the damages to flows, however, also start immediately with the hazard occurring, but continue to be incurred until full recovery is achieved. Thus, Rose (2009) argues that damages to flows are more relevant to the economic resilience concern.

The Damage and Loss Assessment (DALA) methodology introduced by the United Nations-Economic Commission for Latin America and the Caribbean (UN-ECLAC) in 1972 (GFDRR, 2014) and widely used among the 
Development multilaterals (such as the World Bank), also adopts a stockflow typology of disaster impacts (ECLAC \& WB, 2003). In this ECLAC methodology, direct damages refer to the damages to the stock of assets that are incurred at the time of the disaster and immediately after, while indirect losses refer to the reduction in the economic flows due the decrease in the production of goods and services and other macroeconomic effects (ECLAC $\& W B$, 2003). Rose (2004b) argues that the use of 'direct' and 'indirect' labels to refer to stocks and flows impacts is misleading since the impacts on flows begin at time the disaster occurs. Moreover, he argues that both impacts to stocks and flows have corresponding direct and indirect effects. ${ }^{7}$

Other important dimensions of economic resilience proposed by Rose $(2009 b)$ are the behavioural and policy dimensions since the pace of recovery depends critically on the actions of decision-makers. Furthermore, he argues the need to also consider the temporal aspects of resilience. In his work, static resilience refers to the capacity of an exposed element to maintain its functionality when affected by a shock through efficient resource allocation. In contrast, dynamic resilience refers to the speed of recovery of affected elements through repair and reconstruction of the damaged capital stock. Static economic resilience and dynamic economic resilience are considered as the essence of the economic problem in the face of shocks (Rose, 2011). Likewise, he argues that context, capability, market, cost, process and fairness dimensions need to be integrated into the definition of economic resilience. The market dimension refers to supplyside resilience and demand-side resilience, while the cost dimension refers to the cost efficiency of alternative resilience policy measures that can be undertaken. The process dimension refers to the manner in which the action

\footnotetext{
7 It is noted that this stock-flow and direct-indirect typology proposed by (Rose, 2004b) has been adopted in various US National Academy of Sciences reports (in NRC (2005), (2011) and (2012)); and, in economic assessment of disaster consequences as in NMC (2005). These reports provide useful identification of the direct and indirect effects of damages to stocks and flows.
} 
happens and the target of resilience is achieved, while the fairness dimension is usually understood to involve examining whether the implementation of actions and targets is done in an equitable manner (though how one defines equitable is also contentious).

Considering the various dimensions he described, Rose (2009a) defines economic resilience as "The process by which a community develops and efficiently implements its capacity to absorb an initial shock through mitigation and to respond and adapt afterward so as to maintain function and hasten recovery, as well as to be in a better position to reduce losses from future disasters." In terms of interventions, Rose (2004a) states that preventative actions or mitigation measures reduce the magnitude of the hazard and/or the probability of a disaster to occur, as well as reduce vulnerability. Further, he argues that in the absence of mitigation and prevention measures, disaster impacts can be reduced through resilience, particularly through ingenuity, resourcefulness, and speedy repair and reconstruction both during and in the aftermath of a disaster occurrence (Rose, 2004a, 2007).

Hallegatte (2014) proposes an economic framework to guide the assessment of economic resilience. In his framework, resilience refers to the economy's ability to minimize people's welfare losses from a disaster, and the direct damages to assets do not fully capture the adverse impacts on people's welfare. ${ }^{8}$ Any systematic assessment of welfare losses requires the conduct of economic assessment of losses of economic flows (Hallegatte \& Przyluski, 2010). These asset losses lead to consequent losses of output, income, and consumption, which, together with asset losses, better captures

${ }^{8}$ What is referred to in Economics as "welfare" approximates what is referred to as well-being in daily parlance. The Oxford Dictionary of Economics defines welfare as the "state of well-being of an individual or a society. The level of welfare measures the degrees of contentment of an individual or a society" (Black, Hashimzade, \& Myles, 2009). 
the welfare losses resulting from a disaster. In this framework, asset losses and output losses are alternative typologies of economic costs resulting from a disaster that are, to an extent, distinct from the usual direct damage and indirect loss typology used by the ECLAC. Specifically, asset losses here refer to reduction in the value of the stock of assets, while output losses refer to the reduction in the income flow (Hallegatte, 2014). Thus, this typology of economic costs is consistent with the damages to stocks and flows of (Rose, 2004a) rather than with the direct damage and indirect loss typology of the ECLAC framework.

This framework of Hallegatte (2014) extends the risk equation into an "economic welfare disaster risk" with economic resilience as a fourth component, along with hazard, exposure and vulnerability. On the one hand, resilience at the macro level is determined by the economy's ability to limit the immediate losses in income resulting from losses in assets (or the economy's instantaneous resilience), and by the economy's ability to "reconstruct and recover quickly" (referred to as dynamic resilience, as in Rose (2004a)) (Hallegatte, 2014). On the other hand, resilience at the micro level is influenced by the distribution of the losses incurred across the affected households, the household's ability to smooth their consumption and their access to risk sharing schemes (Hallegatte, 2014). This framework can be a useful framework for practical application as it captures both the macroeconomic and microeconomic aspects of resilience. It is noted that a vast majority of the work are at the "macroeconomic level and omits important consideration at the micro level" (Rose and Krausmann, 2013).

Another principal contribution of the framework is that it considers socioeconomic heterogeneity in order to measure the disparity in welfare losses, with a specific focus on losses for the poor. The framework further traces the channels through which asset losses lead to welfare losses. The 
methodologies and economic models in this framework are translated into a set of algorithms and processes that capture these channels. Hallegatte (2014) identifies a corresponding list of indicators as "a first step toward the construction of a meaningful and measurable indicator for economic resilience". Using this framework, he proposes two approaches to reduce 'economic disaster welfare risk.' The first approach is to reduce the direct impacts of disasters on assets, and the second approach is to reduce the output losses resulting from the asset losses. The latter entails increasing the resilience of socio-economic systems, both at the macro and micro levels.

\subsection{Assessment of Economic Vulnerability and Economic Resilience}

Amidst the continuing evolution of the concepts, efforts have been made to translate these conceptual approaches into practical tools to empirically identify the determinants of the various dimensions of economic vulnerability and resilience.

\subsubsection{Indices of Vulnerability and Resilience}

One of the most commonly used methods to assess vulnerability and resilience to natural hazards is the index method. These indices aim to capture the multi-dimensionality of vulnerability and resilience, and therefore include their economic dimensions. The most common economic variables included are on output (GDP or regional production), income, employment, inflation, consumption, expenditures, savings, domestic and international financial transfers, public finance and trade (Angeon \& Bates, 2015; Cutter et al., 2008; Villagran de Leon, 2006).

These indices vary in terms of purpose (e.g. assessment of vulnerability and/or resilience), spatial coverage (e.g. global, regional, local), scale of 
analysis (e.g. governments, local authorities, firm-level, household), and methodological approach (e.g. deductive, inductive, econometric). Many of these indices employ an inductive approach and the identification of indicators are based on relevant conceptual frameworks and/or on identified important indicators in the earlier empirical literature. The aggregation of indicators into a composite index is commonly done through ad-hoc arithmetic or geometric averaging, and standardization is typically done prior to aggregation. Where weights are applied, these are often based on expert judgment, or by participatory approaches, or a combination of both.

A more systematic method to identify relevant variables and assign weights involves econometric algorithms, including data reduction methods as Principal Component Analysis (PCA) and Factor Analysis (FA). The Social Vulnerability Index (SoVI) of Cutter, Boruff, and Shirley (2003) is one of the earliest indices employing the PCA. The SoVI and its descendants is often used in sectoral level studies such as the series of empirical works on risk management and climate change undertaken by of the International Food and Policy Research Institute (IFPRI, 2015).

In the next two sub-sections, we present two global indices. The objective here is to show how indices based on similar frameworks can be designed for a different purpose and employ different approach.

\subsubsection{Vulnerability Index}

The Disaster Risk Index or the DRI is the first index employing a statistical approach that attempts to demonstrate the manner in which development affects human vulnerability and disaster risk (Peduzzi, 2006; Pelling, 2006). The DRI is global in its coverage and has a country-level scale of analysis. It is noted that the DRI was commissioned by the United Nations 
Development Program to be used in guiding decisions by international and national policy-makers (Peduzzi, Dao, Herold, \& Mouton, 2009; UNDPBCPR, 2004). The DRI employs a deductive approach to identify different economic, social, and environmental indicators, which are then examined for their correlation with disaster deaths (Pelling, 2006). The DRI equation mirrors the standard risk equation: $R=H \times P o p \times V u l$; where $R$ is disaster risk, measured in terms of number of deaths, $H$ is the proxy for hazard, measured in terms of frequency of occurrence, Pop is the number of people living in the area exposed to the hazard, and $V u l$ is vulnerability. Vulnerability is considered as the component of risk that explains why people with the same level of exposure face varying levels of risk (Peduzzi, 2006). As noted, the DRI only uses data on deaths to proxy for risk.

A total of 32 socio-economic and environmental variables were tested as potential important vulnerability factors for each hazard type (Peduzzi et al., 2009). The final set of vulnerability variables varies across hazards depending on the results of separate regression specifications. Among the economic variables found to be important are GDP per capita for tropical cyclones, droughts, and floods; and urban growth for earthquakes. The results indicate that indeed development influences vulnerability to natural hazards, but the aspects of development that affect each hazard vary. Vulnerability to hydro-meteorological hazards, for example, is influenced by the level of development as measured by per capita GDP, while vulnerability to earthquakes is influenced by the process of development (in this case, urban population growth). A multiple-hazard composite index is constructed using the estimated risk for each hazard. A final output of the process is a risk map, where the countries covered are depicted in seven DRI classes/categories. 


\subsubsection{Resilience Index}

The Index for Risk Management (InFORM) is designed for a global analysis of humanitarian risk and its target users are humanitarian organizations, donor agencies, country governments, and development stakeholders that have resilience as their key agenda (De Groeve, Poljansek, \& Vernaccini, 2015). Like the DRI, the InFORM takes off from the three-component risk equation. In addition, the InFORM integrates the other factors identified in the PAR, thus adding a fourth component - the lack of coping capacity (De Groeve et al., 2015; JRC-EC, 2014). Also like the DRI, the InFORM takes a multiple hazards approach. However, unlike the DRI that covers only natural hazards, InFORM covers human-made hazards as well. While the DRI employs a deductive approach in indicator selection, the InFORM employs an inductive approach. The InFORM is a composite index of over 50 indicators categorized and computed as follows:

$$
\begin{aligned}
\text { Risk }=\text { Hazard } & \& \text { Exposure } e^{\frac{1}{3}} \times \text { Vulnerability }^{\frac{1}{3}} \\
& \times \text { Lack of coping capacity } \\
&
\end{aligned}
$$

Consistent with UNISDR definition, the InFORM defines vulnerability as people's susceptibility to hazards, and in the construction of the index it is represented in two categories: socio-economic vulnerability and vulnerable groups (JRC-EC, 2014).

Economic vulnerability is captured under the socio-economic category, which is computed as the arithmetic mean of indicators measuring development and deprivation, inequality, and aid dependency. We note that resilience is captured, though not in its entirety, under lack of coping capacity, which refers to the available resources that help people to "absorb the shock" (JRC-EC, 2014). For this component, governance, institutional and infrastructure indicators are used. 
We emphasize that while both indices presented above are at the macro level, there are also micro-level indices designed to assess economic vulnerability or resilience at the household or firm levels. Some useful reviews of macro and micro level indices can be found in Birkmann (2007), Cutter et al. (2008), and Rose and Krausmann (2013).

\subsubsection{Econometric Approach}

\subsubsection{Determinants of Economic Vulnerability}

Within Economics, econometric methods using cross-section or panel data approaches are the most commonly used to systematically identify the underlying factors influencing vulnerability and resilience. Econometric methods are mainly deductive, an approach which Pelling (2006) asserts provides more realism than an inductive approach. Studies on the economics of disasters using these methods belong to two strands.

The first strand seeks to identify the factors affecting the disaster impacts on people and assets. These models generally take the following form:

$Y_{i t}=\alpha_{0}+\beta_{1} \operatorname{Haz}_{i t}+\beta_{2} \operatorname{Exp}_{i t}+\beta_{2} V u l_{i t}+\varepsilon_{i t}$; where $Y_{i t}$ is the measure of actual impacts either on people or on assets in spatial unit $i$ at time $t$; Hazit is a vector of hazard characteristics; Expit is a measure of the exposure of people or assets; $V u l_{i t}$ is the vector of control variables hypothesize to influence vulnerability to the hazard. Y, Haz, Exp, Vul correspond to Risk, Hazard, Exposure and Vulnerability in the standard risk equation discussed earlier. By controlling for hazard characteristics and exposure of people and assets, these empirical models generate insights about the vulnerabilities of the exposed.

The second strand aims to measure the economic effects typically in either the short-run (months to several years) or long-run (at least 3-5 years). 
These studies also attempt to understand the factors that influence these impacts, thereby also providing insights on the determinants of economic resilience. As surveyed by Cavallo and Noy (2011), these models generally take the following form: $Y_{i t}=\alpha+\beta X_{i t}+\gamma D I S_{i t}+\varepsilon_{i t}$; where $Y_{i t}$ is the impact on economic flows, for a spatial unit $i$ at time $t$. These impacts may include GDP (or growth), GDP per capita, human development index, poverty and employment, among others. DIS $i t$ is the immediate disaster impact to assets and/or to population. In some studies, this includes the hazard characteristics. $X_{i t}$ is the vector of control variables affecting $Y_{i t}$ (Cavallo \& Noy, 2011).

As previously argued, resilience can refer to the ability to minimize welfare losses (Hallegatte, 2014). For this purpose, there is a need to decide the appropriate measures of welfare to use. Indicators of production and outputs, such as GDP and its variants, are commonly used as a proxy for welfare, though consumption is arguably a better proxy (Mechler, 2009). ${ }^{9}$ In general, production only indicates how much is made available, while consumption indicates how much is actually used (consumed). It therefore better captures the economic concepts of utility and standard of living. From a Utilitarist perspective, consumption is what matters most, and not output and production (Hallegatte \& Przyluski, 2010).

While the DRI uses a cross sectional dataset, the cross-country econometric empirical works that followed use panel datasets, with the disaster impact data coming mainly from EM-DAT.10 Toya and Skidmore (2007) and Raschky (2008) examined the correlation between several aspects of development. Toya and Skidmore (2007) assess the extent at which disaster

\footnotetext{
9 There is a huge economic literature that discusses the various measures of welfare. Nordhaus and Tobin (1972) present one of the earliest arguments on the limitations of production and growth indicators as measures of welfare.

${ }^{10}$ Besides EM-DAT, other available databases include DesInventar (compiled by UNISDR) and privately held datasets collected by the two re-insurance companies (MunichRe and SwissRe).
} 
fatalities and losses decline as economies grow. Raschky (2008) examines the important influence that institutions have on the vulnerability of people and assets to disasters. Their respective models took a relatively simple form, as they did not have proxies for the characteristics of the hazards studied.

Many of the succeeding studies address the exogeneity concerns pointed out by Noy (2009) by integrating into their models indicators on hazard characteristics. The number of fatalities and cost of damage are the main proxies for disaster risk, or the dependent variables of the econometric model. Some opt to directly use proxies for the hazard such as wind-speed or the magnitude of an earthquake (Felbermayr \& Gröschl, 2014; Strobl, 2012).

Using earthquake fatalities as the dependent variable, Kahn (2005) aimed to examine the presence and extent of correlation between fatalities, and geography, income, and institutional quality. Anbarci (2005) used negative binomial models to examine the influence of inequality on disaster risk, using a political economy model. Kellenberg and Mobarak (2008) investigated the correlation of deaths due to floods, earthquakes, landslides, windstorms and extreme temperature with income level and demonstrated a non-linear correlation between these measures. In their specifications, risk first increases with income, but beyond a certain income threshold, it starts decreasing.

There is consensus in these cross-country empirical studies that indeed a country's level of economic development affects its vulnerability to disasters (Anbarci, Escaleras, \& Register, 2005; Kahn, 2005; Raschky, 2008; Toya \& Skidmore, 2007). However, there is difference in the findings as to the direction of relationship between the level of economic development and disaster (as in Kellenberg and Mobarak 2008), as well as the extent to 
which the level of development influences vulnerability between developed and developing countries and/or regions.

Peduzzi et al. (2009) use GDP per capita as proxy for economic development, and find that it is negatively correlated with the fatalities across tropical cyclone, drought, and flood hazards. Likewise, Kahn (2005) finds that developed countries have fewer fatalities from earthquakes than those of developing countries. He thus concludes that economic development serves as an "implicit insurance" that cushions the adverse disaster impacts on people. Fewer deaths in developed countries may also be due to a deliberate government policy of placing higher priority on the protection of lives. This decision to prioritise life may originate from political pressures that apply everywhere, but this can more readily be done with the abundance of resources and technology in these countries.

Of interest is the finding that while income is also an important predictor of the number of disaster deaths in both developing and developed countries, the magnitude of its effect in the former group of countries is lower than those in the latter. In developing countries, social conditions matter more than the level of income in reducing the number of deaths, and a more educated citizenry are better able to make informed decisions ensuring their safety (Toya \& Skidmore, 2007).

Kellenberg and Mobarak (2008) do not completely refute the findings of a linear disaster-economic development relationship. However, they argue that in the case of developing countries, economic development may actually increase the risk that people face by "changing micro behaviour in such a way so as to increase aggregate exposure to disasters" (Kellenberg \& Mobarak, 2008). They also suggest that risk to disasters is also determined by vulnerabilities that are created or enhanced as consequences of development processes. Urbanization can have varied effects on risk to 
disasters. That is, urbanization may reduce or increase vulnerability depending on the context within which it occurs. They find that countries with comparable levels of income but with different degrees of urbanization can have different risk levels. Competent urban planning, where structures are appropriately designed and where there is adequate capacity to provide economic and social services, urbanization may not necessarily increase vulnerability to disasters. But, where the capacity of urban areas to deliver key services cannot cope with the rapid influx of population (as is the often the case in developing countries), urbanization may lead to increased exposure and vulnerability to disasters. Employment opportunities in dense urban areas attract low-income families, even if relocation to the urban fringe means increased exposure to disasters. Hence, urbanization in this case increasingly entices people with inherent vulnerability into harm's way (because of relatively fewer resources and weaker capacities to adapt and cope in times of disaster).

The effects of aspects of governance on disaster fatalities and damages have likewise been explored. Kahn (2005) finds that democratic countries experience relatively fewer deaths from disasters than those with other forms of governance. Under a democracy, governments adopt intervening measures to mitigate the adverse consequences of hazards (Kahn, 2005). Raschky (2008), as well, finds that a country's institutional framework is a key determinant of vulnerability to disasters. There are fewer fatalities among countries with better institutions because resource allocation is better, and laws and legislations are in place, and effectively enforced (Raschky, 2008).

Anbarci et al. (2005) use inequality, measured in terms of Gini coefficient, as a proxy for the quality of governance and institutions. They argue that a political economy that has low income and high inequality experiences 
difficulty in generating collective action to provide public goods such as disaster preventive measures. Against this backdrop, these economies suffer more deaths from disasters. In like manner, Kahn (2005) finds that, all else equal, countries with higher inequality suffer more fatalities from earthquakes than countries with lower inequality.

An earlier work by Adger (1999) shows similar results. With Vietnam as a case study, which is in transition from a centrally planned economy, he finds that the increasing inequality and the breakdown of collective community action that results from the economic transition have contributed to greater vulnerability. However, he asserts that the resulting institutional change and economic restructuring towards a market system augurs well in terms of reducing vulnerability as informal coping mechanisms have started to re-emerge.

\subsubsection{Determinants of Economic Resilience}

As in the first strand of econometric studies, the second strand likewise finds that countries with higher level of development are more resilient. Using a panel dataset for 109 countries covering the period 1970 - 2003, Noy (2009) pursued a two-fold inquiry. The first is to quantify the short-run impacts of disasters on the macro-economy; and the second is to examine the determinants of these impacts. This paper finds that disaster damage to capital stock results in reduced short-run macroeconomic growth, and that the value of damage is reflected in the extent of growth reduction. He further finds that for a disaster of a given magnitude, the corresponding change in output growth (measured in \% of GDP) among small economies and developing countries are greater than those of big economies and developed countries. Interestingly, the direction of change may also vary between these two types of countries. In developing countries, a one standard deviation increases in asset damage results in a $9 \%$ reduction in 
output growth. In the case of developed countries, there is instead a corresponding increase in output growth, albeit minimal. Meanwhile, disasters, alternatively measured in terms of number of deaths and affected persons, do not result in statistically observable reductions in output growth.

On Noy's (2009) second inquiry, results reveal that countries with higher income per capita, greater trade openness, and higher literacy rates, higher levels of public spending, and better institutions are able to withstand the initial impacts of disasters, and are also able to prevent spillovers. Noy (2009) attributes this to the capacity for resource mobilization to implement the necessary reconstruction. It is worthwhile to note that the above findings already provide preliminary quantitative confirmation that indeed economic vulnerability and economic resilience are both shaped by the same common economic factors.

Unlike the other econometric studies with a similar research question and methodological approach, Hochrainer (2009) establishes a counterfactual to the observed post-disaster GDP. He uses an autoregressive integrated moving average (ARIMA) model to forecast post-disaster GDP levels. He then uses the difference between the forecasted and observed GDP level five years after the disaster as the dependent variable in a multivariate regression analysis to determine the influence of explanatory variables on output levels. Like Noy (2009), he finds evidence of the negative (but small) consequences of the direct disaster impacts on capital stock to macroeconomic output, though his focus is on the medium-term and in the long-term (five years).

Using this approach, he finds that the inflows of remittances and aid reduce the adverse macroeconomic consequences significantly. In this framework, a disaster with damage to capital stock, above a value of $1 \%$ of GDP, would 
overwhelm the internal capacity of the country to self-finance post-disaster reconstruction needs; and hence the importance of aid.

Moreover, that remittances have a significant influence likewise suggests that external sources of finances are also important for individual or household level recovery, perhaps particularly for the affected individuals to go back to productive activities and contribute to output production. Overall, while the direct impacts on capital stock have a strong influence on the follow-on impacts of disasters on output, external funds also have an influence on post-disaster dynamics (Hochrainer, 2009).

In a similar attempt to determine welfare changes due to the occurrences of disasters, Mechler (2009) measures the corresponding changes in consumption, instead of the usual changes in GDP. In a global sample, Mechler (2009) finds that assets losses do not cause significant changes in consumption. However, by narrowing the sample to low-income countries only, he finds that asset losses do adversely alter consumption. In a further inquiry, he finds that inflows of regular and post disaster aid likewise do not result in significant changes in consumption, except among low-income countries.

Noy and $\mathrm{Vu}(2010)$ undertook one of the earliest sub-national empirical inquiries on the impact of disasters on output growth, by looking at the experiences of 61 provinces in Vietnam for 1995-2006. They use output level and output growth rate as dependent variables in separate regressions, and the number of deaths to population ratio and value of damaged assets in proportion to GDP as proxies for direct disaster impacts in separate regressions. They find that direct asset damages impact positively on output growth, estimated at $0.03 \%$ for every percentage point in asset damage as proportion to GDP. In a further inquiry on the heterogeneity of experiences across the eight regions in Vietnam, the results suggest that 
regions with higher levels of development, and that have better access to funds for reconstruction from the central government, experience this 'creative destruction' dynamics, and a consequent short-run growth spurt in the disaster aftermath. The authors claim that this provides support for an earlier observation by Cuaresma, Hlouskova, and Obersteiner (2008) that areas with high levels of development benefit from capital upgrading for assets damaged during a disaster.

The household micro-econometric study of Antilla-Hughes and Hsiang (2013) examines tropical cyclones and study the Philippines by constructing a panel data set from various nationwide household surveys and other datasets. The authors find that consequent to the sharp drop in household income due to disasters are alterations in investment, expenditure and consumption patterns of the households surveyed. There is an evident reduction in investments in human capital, resulting in children dropping out from school, and a reduction in household expenditures on medicine and nutritious foods. Several other papers report similar findings for other case studies (surveyed in Karim and Noy (2016)); but neither of these examines whether these short-term patterns of impact on investment in health and education have any long-term impacts. An exception is Caruso and Miller (2015) that find that these impacts on education persist even in the second generation after a catastrophic event (in their case, an earthquake in Peru in 1970).

Arouri, Nguyen, and Youssef (2015) undertook a household level study on Vietnam to determine the effects of floods, storms and droughts on household welfare, and determine the characteristics of households and communities that made them resilient to the adverse disaster impacts. In their model using commune-level fixed-effect, they ran separate regressions for each of four dependent variables: income per capita, per capita 
consumption expenditure, poverty status of households, and share of income of alternative sources of income. The authors posit that resilient households experience relatively less adverse disaster impacts on their welfare, as proxied by these indicators (Arouri et al., 2015).

For storm-related disasters, their results reveal that those households with fewer members of working age, those with more household members, and those belonging to the ethnic minority groups are all less resilient. The authors' interpretation is that households with fewer members of the working age cannot increase labour supply to generate income to cover the losses in income and consumption. Meanwhile, large households have lower per capita income and minority groups have lower access to services that will help in smoothing their consumption. Internal remittances are found to be an important contributor of resilience to all three hazards. Likewise, access to finance-such as microfinancing, international remittances and social allowances - is found as a significant contributor to resilience. Yet, in communes with either a more equal distribution of expenditure (as measured by a commune's Gini coefficient of expenditures) or higher level of average per capita expenditure, households are found to be more resilient. Furthermore, households with high level of education are also more resilient to the adverse effects of floods and droughts.

The vast majority of the above econometric studies in either research strand focuses on the macroeconomic and national level assessments. Results of global and country-level studies provide general indications on what broadly determines vulnerability and resilience across countries, and how each country fares against others. However, sub-national level assessments are better able to capture context-specific concerns; hence, their findings have greater practical usefulness to any country. 
Moreover, at the time of writing, we find no micro-econometric analysis along the first strand of inquiry on the determinants of deaths, injuries, diseases or property damage at the household or firm levels. The works of Antilla-Hughes and Hsiang (2013) , and Arouri et al. (2015) are two of a few studies along the second strand of inquiry. Results from micro-level analysis would provide insights on other factors that likewise have important influences on economic vulnerability and resilience, and allow for comparison of the relative importance of these factors at the micro and macro levels.

The focus of econometric studies on the macro level of inquiry is likely due to the complexity of using a single econometric model to capture both levels, and, perhaps, to the difficulty of accessing or building a useful micro level dataset. Other useful frameworks for a macro-micro analysis include computable general equilibrium methods (as proposed by (Rose, 2004a); Rose and Krausmann (2013)), partial equilibrium analysis (as in Hallegatte et al. (2016a) which applies the framework introduced first developed by (Hallegatte, 2014), and other mathematical algorithms.

Vulnerability and resilience have typically been studied separately, even within disciplines. However, studying them simultaneously will assist in painting a more comprehensive picture of total disaster impacts. It may also subsequently aid in the identification of a comprehensive package of interventions that addresses the various channels through which vulnerabilities are reduced and resilience enhanced. A deeper appreciation of the channels of causality involved allows for better informed pre- and post-disaster policy. Thus, it is important for vulnerability and resilience to be studied simultaneously, yet measured separately, as one cannot fully address one without addressing the other. 


\subsection{Synthesis and Implications for Policy}

Some broad agreements have been reached towards achieving greater precision in the conceptualization of both vulnerability and resilience. In the context of natural hazards and disasters, vulnerability and resilience are interrelated. Yet, despite having similar underlying factors, they refer to different things. Vulnerability is mainly considered as a pre-disaster concern that refers to the conditions that make the confluence of a hazard, and a system's exposure to it, result in a disaster. Resilience is largely, but not entirely, a post-disaster concern; it refers to the conditions that makes the affected systems withstand and bounce back from the disaster experienced. It is also pre-disaster concern in as much as a system's ability to withstand adverse disaster impacts is largely influenced by pre-disaster conditions.

Likewise, several broad conclusions and useful insights for disaster risk reduction (DRR) policy decisions can be generated from the empirical findings described here. The results provide systematic support for the hypothesis that apart from the characteristics of the hazards, the potential for people and systems to avoid adverse impacts, and their capacity to withstand and rebound from a disaster are influenced by a confluence of socio-economic factors. Hence, DRR measures must include an appropriate mix of structural and non-structural measures that aim to affect these factors. The conceptual and empirical findings imply that in the terms of DRR priorities, vulnerability is typically linked to prevention, preparedness and mitigation; while resilience, to response, rehabilitation, reconstruction, and recovery, as well as mitigation to address future risks.

There is a consensus in the cross-country studies that low-income countries are more vulnerable and less resilient than countries with higher levels of development. What this means in practical terms is that assistance and 
investments in development yield the greatest benefits in terms of lives spared and assets protected from disasters if low income countries, particularly those with high exposure, are favoured. Moreover, the findings that social conditions may matter more than the level of income in reducing the number of deaths, likewise indicates the nature of intervention needed to significantly address vulnerability among these countries.

Moreover, findings consistently suggest that policies that are most effective in minimizing impacts on economic flows and other spillover effects at the macroeconomic level are mostly about the provision of adequate access to funds, including aid, to speed up the reconstruction, rehabilitation, and subsequent economic recovery. External sources of funds, such as aid and remittances, are likewise critical for household-level recovery, particularly among the financially constrained; though internal sources, including saving, are also important. With the apparent critical role of credit and access to funding, more research on financial risk-transfer tools, such as insurance, as a tool for building resilience is still required.

To date, the intensified application of economic theory resulted in important advances in concretizing the concepts of economic vulnerability and resilience, as well as in measuring them. Nonetheless, alongside these advances one can identify some needed refinements including: adopt an integrated approach for the study of both economic vulnerability and economic resilience, covering both macro and micro levels, as well as from short-run to long-run; apply a systematic method in identifying a plausible set of indicators to capture and measure the distinct economic vulnerability and resilience of each element in different contexts and circumstances; determine the relative importance of common underlying factors in influencing economic vulnerability and economic resilience at the macro and micro levels; and, translate the measures and findings into tools for 
systematically identifying and prioritizing a set of policies and actions to reduce vulnerability and strengthen resilience.

The existing empirical studies employ various methods of indicator selection and of construction of indices and other measures. The most appropriate method is likely to vary across different contexts and levels of analysis. What is of concern, however, is that various measures with the same spatial scale, and similar objectives and focus yield differing results either in terms of the set of indicators found important in influencing vulnerability and resilience, or relative importance among the indicators in the set. Given these differences, there will likewise be corresponding differences in policy recommendations. Hence, there is a need to apply a careful and comparative examination, qualitative and quantitative, so that one can successfully and reliably identify a plausible set of indicators that measure and then determine a robust menu of policy options to reduce economic vulnerability and increase resilience.

Overall, the aim is for a sound and widely-accepted set of tools for systematically identifying and prioritizing a set of policies and actions to reduce vulnerability and strengthen resilience in different contexts (e.g. developed and developing countries), timeframes (e.g. long-, medium-, and short-run), levels of assessment and governance (e.g. macro and micro; household community, city, province, country), hazard types (e.g. meteorological and geologic), and elements at risk. 


\title{
Chapter 3
}

\section{Measurement of Disaster Risk: An Example from Tropical Cyclones in the Philippines}

\begin{abstract}
What determines disaster fatalities? We identify the determinants of tropical cyclone-induced fatalities in the Philippine provinces, and to explain the variability of these fatalities across provinces. We construct a new provincial level panel dataset, and use statistical methods to assess the influence of socioeconomic vulnerability (i.e. levels of economic and social development, urbanization, governance), exposure (i.e. population, topography and geography), and hazard characteristics (i.e. rainfall volume and wind speed) on the resulting fatalities from recent tropical cyclones. We find strong evidence that socioeconomic development and good local governance reduces disaster fatalities, while unplanned urbanization is associated with more fatalities. Exposure, including topography, and tropical cyclone strength are likewise important determinants of fatalities. However, disaster fatalities appear to be influenced much more by socioeconomic vulnerability and exposure, than by the hazard itself. We quantify this difference to contribute to policy planning at national and subnational scales.
\end{abstract}




\subsection{Introduction}

We aim to estimate tropical cyclone-induced fatalities in the Philippine provinces, and to explain the variability of these fatalities. It is widely accepted that the level of socioeconomic development, characteristics of urbanization, and quality of local governance influence the resulting impacts of disasters on people, assets and the economy. We operationalize these insights into our measurements, focusing on tropical cyclone fatalities.

The Philippines, the most exposed country to tropical cyclone hazards globally, provides a good test-case of our measurement tool. Tropical cyclones, which are the second most frequently occurring hazards in the world, are the most frequent as well as the most destructive hazards in the Philippines (Jose, 2012). The country's decentralized system of local governance makes it suitable for a subnational level of inquiry. Furthermore, the Philippines is undergoing urbanization, rapid development, and democratization that are all typical processes for middleincome countries. These are all hypothesized to have a significant influence on disaster impacts.

We construct a new provincial level panel dataset, and use econometric methods to assess the influence of socioeconomic vulnerability ${ }^{11}$ (using indicators on levels of economic and social development, urbanization, governance), exposure (using indicators on population exposure, topography and geography), and hazard characteristics (using rainfall

\footnotetext{
${ }^{11}$ We note that the theoretical literature offers numerous definitions of vulnerability in the context of natural hazards, but despite a myriad of frameworks, a consensus has yet to be reached. For the purpose of this study, we refer to factors influencing peoples' vulnerability as those economic, social, political, physical, and environmental factors that increase or reduce their ability to withstand the adverse impacts of natural hazards. This is a simplified adaptation of the selected existing definitions of vulnerability (Blaikie et al., 1994; Bohle, 2001; Cardona et al., 2012; Davidson \& Shah, 1997; UNDP-DHA, 1994; UNISDR, 2005; Wisner et al., 2004). A more thorough discussion of the conceptual differences and the ways in which vulnerability and resilience have been measured is available in Noy and Yonson (2016) and (Beccari, 2016).
} 
volume and wind speed) on the resulting fatalities from recent tropical cyclones. To our knowledge, this study is the first subnational work using a panel dataset and econometric method to determine the underlying contributing factors to tropical cyclone-induced fatalities in the context of a developing country. The flurry of subnational studies that examined human vulnerability, using either qualitative or non-econometric quantitative methods, either focus on a specific disaster or undertake comparative analyses of few disaster events. We adopt a more general approach by looking at experiences across provinces for all tropical cyclones that occurred in recent times.

Existing measurement tools are either inter-country or very local, but as inputs for decision-making, subnational tools have a bigger practical significance. ${ }^{12}$ Specifically, our results enable the prioritization of disaster risk reduction and management (DRRM) policies at the national and subnational levels based on the differing vulnerabilities and disaster fatalities we measure. Moreover, our results can also be considered as establishing a point of reference in assessing the effectiveness of the implementation of recent changes in policy and practice of DRRM at the national and local levels. ${ }^{13}$

As a quick preview of our results, we find strong evidence that the levels of economic and social development provide protection and build human capacities, thereby reducing disaster deaths. ${ }^{14}$ Importantly from a planning

\footnotetext{
12 An example is of an inter-country index is the Disaster Risk Index (DRI), constructed by the United Nations Development Programme (UNDP) to systematically analyse the linkage of vulnerability to development. The DRI is a global index whose purpose is to establish the relative human vulnerability across countries (Peduzzi et al., 2009).

${ }^{13}$ The Philippines passed landmark laws on climate change adaptation (CCA), and on disaster risk reduction and management (DRRM) in 2009 and 2010, respectively. Among others, these laws require the local government to integrate CCA and DRRM into local development decisions. Our results can serve as suitable benchmark against which to compare the future levels of vulnerability and disaster impacts in terms of fatalities across provinces, as well as the outcomes of most recent changes in policy and practice of DRRM.

14 These results are largely consistent with the existing inter-country empirical work adopting a similar quantitative approach (Anbarci et al., 2005; Kahn, 2005; Kellenberg \& Mobarak, 2008; Noy, 2009; Peduzzi et al.,
} 
and policy lens, the characteristics of urbanization and quality of local governance can significantly alter the magnitude of loss of human lives. Unplanned urbanization is positively associated with disaster fatalities. Improved local revenue generation translates to greater availability of resources for an expanded and better provision of services to address disasters. Hazard patterns and exposure, including topography, are important determinants of fatalities. Crucially, we find that tropical cyclone-induced fatalities are influenced more by socioeconomic vulnerability and exposure than by the hazard itself.

The paper is organized as follows: Section 3.2 provides a background on tropical cyclone-related disasters and on development in the Philippines. Section 3.3 briefly presents selected related work across disciplines, and identifies the gap we aim to fill. Section 3.4 presents our econometric model, estimation method, and data we use. Section 3.5 presents our results, while Section 3.6 provides general conclusions, policy implications and next steps.

\subsection{Literature Review}

\subsubsection{Frameworks on Vulnerability and Disaster Risk Assessment}

The Pressure and Release (PAR) framework provides a qualitative depiction of how disasters are generated when a natural hazard affects the vulnerable individual or group of people (Blaikie et al., 1994; Wisner et al., 2004). This framework considers disaster risk as a product of hazard and vulnerability:

Risk $=$ Hazard $x$ Vulnerability

2009; Raschky, 2008; Toya \& Skidmore, 2007). These results are likewise consistent with related in-depth studies on the Philippines using very different methods (Gaillard, Liamzon, \& Villanueva, 2007; Israel \& Briones, 2014). 
Focusing on people, vulnerability is defined in this framework as "the characteristics of a person or group in terms of their capacity to anticipate, cope with, resist, and recover from the impact of a natural hazard" (Blaikie et al., 1994). It describes a progression of vulnerability. The first level of the progression is "root causes," which includes social and economic structures that determine the distribution of resources, wealth, and power; ideologies in governance; and, history and culture. An emphasis is made on the need to determine the historical origin of these structures and to explain the underlying ideologies that give ground for the legitimacy of these structures. This implies that root causes may be distant in space and time relative to the location of present vulnerability (Wisner et al., 2012).

The second level of the progression comprises of "dynamic pressures" (Blaikie et al., 1994; Wisner et al., 2012). These are grouped into the deficiencies of society's social, economic and political processes, and macroforces, such as rapid population growth and rapid urbanization, deforestation, decline in soil productivity, among others. Accordingly, the dynamic pressures serve as channels through which the root causes result in fragile livelihoods and unsafe locations (Blaikie et al., 1994; Wisner et al., 2012).

Another popular framework is the three-component risk formulation as follows:

$$
\text { Risk }=\text { Hazard } x \text { Exposure } x \text { Vulnerability }
$$

The UNISDR (2009) defines these variables: Risk is "The combination of the probability of an event and its negative consequences"; Hazard is "A dangerous phenomenon, substance, human activity or condition that may cause loss of life, injury or other health impacts, property damage, loss of livelihoods and services, social and economic disruption, or environmental 
damage"; Exposure refers to "People, property, systems, or other elements present in hazard zones that are thereby subject to potential losses"; and, Vulnerability refers to "The characteristics and circumstances of a community, system or assets that make it susceptible to the damaging effects of a hazard."

This risk framework has been adopted in probabilistic disaster risk assessment methodologies ${ }^{15}$, such as in the existing Philippine methodology for the provinces (NEDA, 2008). We, likewise, use this framework for this study, but as noted earlier, we use actual data on disaster fatalities, and indicators for the hazard, exposure, and vulnerability components.

\subsubsection{Determinants of Vulnerability: Identification and Quantification}

A number of vulnerability indices have been developed and econometric empirical studies undertaken in the attempt to identify and examine what determines vulnerability and disaster risk. In econometric models, the underlying causes of vulnerability are indirectly determined. For instance, the Disaster Risk Index (DRI), which is designed to assess exposure and vulnerability to disasters (Peduzzi, 2006), adopts a definition of risk that is influenced by hazard, exposure and vulnerability, as in Equation 2. While the DRI adopts a cross-section approach, most of the works that followed adopted a panel data analysis.

The cross-country empirical studies are unanimous in the findings that a country's level of economic development affects its vulnerability to disasters, and likewise determines the extent of disaster impacts on people

\footnotetext{
${ }^{15}$ In these methodologies, Risk is commonly proxied by either the annual expected number of fatalities or affected persons or expected cost of damage per year; Hazard is the probability of occurrence (expressed as the reciprocal of the return period) of a hazard of a given severity; Exposure is the estimated number of people and value of assets exposed to such hazard; and Vulnerability is the degree of loss, expressed from 0 to 100 percent, of the elements at risk to a hazard of given severity (NEDA, 2008; Peduzzi et al., 2009; UNDP-DHA, 1994; UNISDR, 2013).
} 
and assets, such as deaths and costs of damage (Anbarci et al., 2005; Kahn, 2005; Raschky, 2008; Toya \& Skidmore, 2007). However, there is difference in the findings as to the direction of relationship between the level of economic development and disaster impacts, as well as the extent at which the development influences vulnerability and disaster impacts between wealthy and less affluent countries and/or regions. Overall, less affluent countries are more vulnerable and face graver disaster impacts than more wealthy countries.

Using GDP per capita as proxy for economic development, Peduzzi et al. (2009) find that it is negatively correlated with deaths across all types of hazards considered: tropical cyclone, drought, and flood. This finding is supported by Kahn (2005), who finds that more wealthy countries have fewer deaths from earthquakes than those of less affluent countries. Cavallo and Noy (2011) attribute this to the investments made by more wealthy countries on prevention and mitigation measures. These measures are lacking in less affluent countries given the limits of available resources and other social, political and economic constraints that hinder access to available resources (Anbarci et al., 2005; Cavallo \& Noy, 2011).

In a similar light, Toya and Skidmore (2007) find that as economies develop, they experience fewer disaster deaths. This is further confirmed by the lower damage cost-to-GDP ratios among developed countries than those in developing countries (Toya \& Skidmore, 2007). It is interesting to note that while they find that income is also an important factor in determining the number of fatalities among developing countries, the magnitude of effect of income differences is lower than those in developed countries.

While not completely refuting these findings of a linear disaster-economic development relationship, Kellenberg and Mobarak (2008) argued that economic development may actually increase the risk people face by 
"changing micro behaviour in such a way as to increase aggregate exposure to disasters". They suggest that disaster risk is also determined by development processes such as urbanization. ${ }^{16}$ Wamsler (2006) substantiates this argument by asserting that this is largely because urban growth, planned or otherwise, happens without due consideration to reducing disaster risk.

The effects of several aspects of governance on disaster deaths and damages have likewise been explored. Kahn (2005) and Raschky (2008) examined the influence of the form and quality of institutions on disaster fatalities using several proxy measures including the country's level of democracy and good-governance indicators. Kahn (2005) finds that democratic countries experience relatively fewer deaths from disasters than those with other forms of governance. Under a democracy, governments adopt intervening measures to mitigate the adverse consequences of hazards (Kahn, 2005). This is consistent with Raschky's (2008) findings that a country's institutional framework is a determinant of vulnerability and disaster fatalities. There are fewer fatalities among countries with better institutions because resource allocation is better, and relevant laws and regulations are in place, and effectively enforced (Raschky, 2008). Anbarci et al. (2005) examine the influence of income inequality on earthquake fatalities, and argue that a polity that has low income and high inequality experiences

\footnotetext{
${ }^{16}$ Kellenberg and Mobarak (2008) argue that urbanization can, in different contexts, have varied effects on risk to disasters. That is, urbanization may reduce or increase vulnerability depending on the context within which it occurs. Specifically, they found that countries with comparable levels of income but with different degrees of urbanization have different risk levels. On one hand, in contexts with competent urban planning, where structures are appropriately designed and where there is adequate capacity to provide economic and social services, urbanization may not necessarily increase vulnerability to disasters. On the other hand, where the capacity of urban areas to deliver key services cannot cope with the rapid influx of population (as is the usual case in developing countries), urbanization may lead to increased exposure and vulnerability to disasters. They argue that better employment opportunities in dense urban areas attract low income families, even if such transfer means increased exposure to disasters. Hence, urbanization in this case increasingly entices people with existing vulnerability (because of relatively fewer resources and weaker capacities to adapt and cope in times of disaster) into harm's way.
} 
difficulty in generating collective action to undertake preventive measures. ${ }^{17}$

We note that our review of the literature revealed no research at the subnational level that employed panel econometric methods to deduce the underlying causes of vulnerability and disaster impacts. A subnational study has some advantages over a cross-country one, as many of the institutional and legal structures are identical across provinces within a country, and thus the biases introduced by missing variables are less severe and allow one to focus on cross-provincial differences that may be obscured because of these biases. Moreover, as noted earlier, a subnational study is of practical usefulness in planning and policy-decisions pertaining to DRRM when almost all DRRM decisions to allocate scarce resources to regions are undertaken at the national level.

\subsection{Philippine Development and Tropical Cyclone Disasters}

The Philippines is an archipelago comprising of over 7,100 islands that are categorized into three major groups: Luzon, Visayas, and Mindanao (Figure 3-1). It is located within the Pacific Ring of Fire, as well as along the north Pacific typhoon belt. In 2013, the country had 81 provinces, a population of over 92 million as of the 2010 Census, and a population density of 308 persons per square kilometre (PSA, 2012a, 2015c).

\footnotetext{
${ }^{17}$ Earlier work by Adger (1999), on Vietnam, finds that the increasing inequality and the breakdown of collective community action that results from its economic transition have contributed to greater vulnerability. He asserts that the restructuring towards a market system augers well in terms of reducing vulnerability because informal coping mechanisms have re-emerged.
} 
Figure 3-1. The Provinces of the Philippines

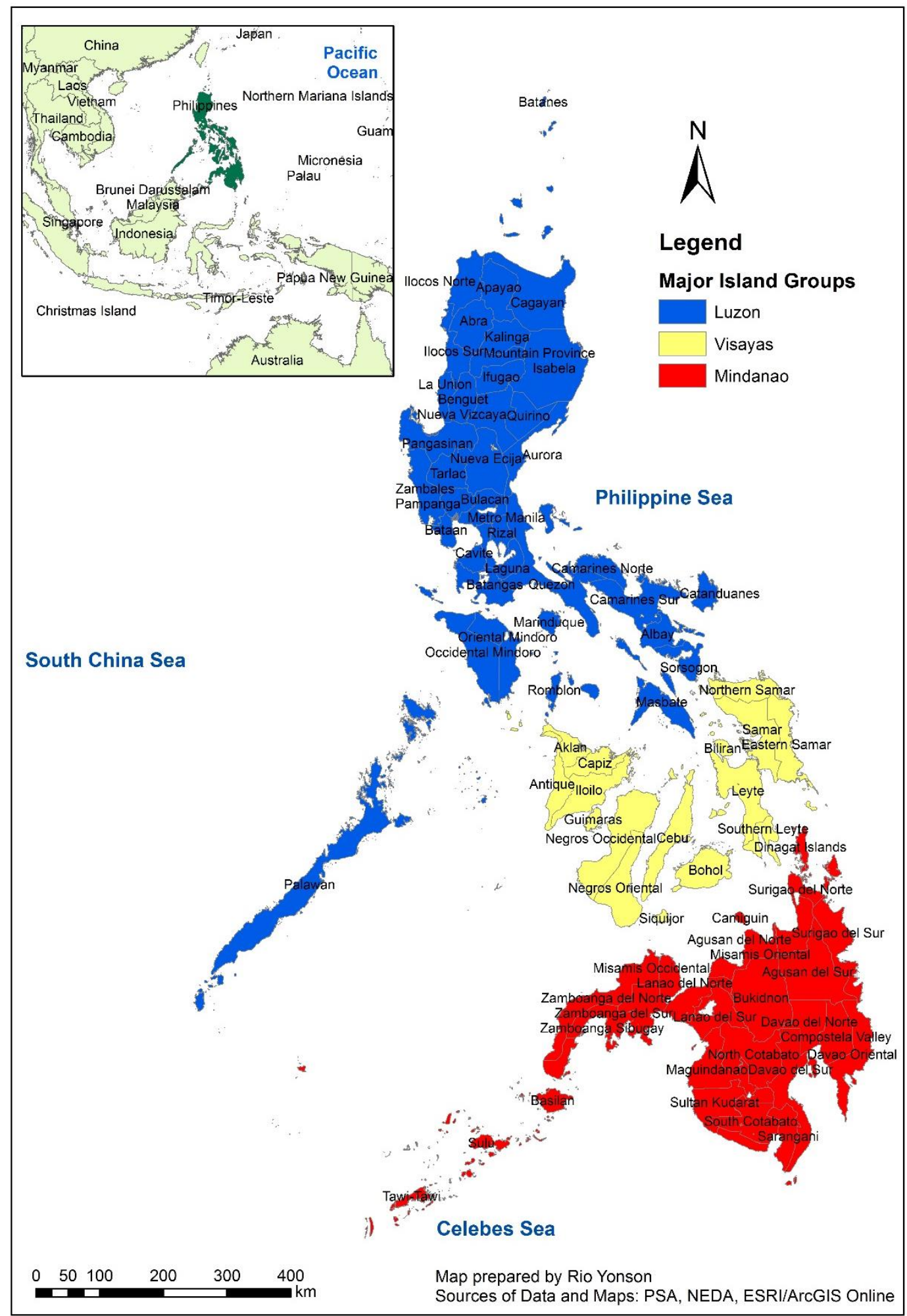


The Philippines passed the Climate Change Act in 2009 and the Disaster Risk Reduction and Management Act in 2010.18 Even before the corresponding institutional mechanisms were fully implemented, these laws were put to the test as the country was hit by a series of lethal tropical cyclones. In 2013, Typhoon Haiyan left a staggering trail of 6,092 deaths, while in 2012 and in 2011, Typhoon Bopha and Tropical Storm (TS) Washi claimed 1,248 and 1,258 lives, respectively (NDRRMC, 2014). ${ }^{19}$ These three tropical cyclones were the most destructive globally during the years 20112013 (Guha-Sapir, Hoyois, \& Below, 2012, 2013, 2014). Moreover, these tropical cyclones were the most costly disaster events in the Philippines in these years (NDRRMC, 2014).

The Philippine Atmospheric, Geophysical, Astronomical Services Administration (PAGASA) reports that there have been no indications of decadal changes in tropical cyclone frequency during the period 1948 to 2010 (PAGASA, 2014). However, there are observed increases in the intensities of recent tropical cyclone occurrences, which are often considered manifestations of the impacts of climate change (PAGASA, 2011; Yang, Wang, Huang, \& Wang, 2015).

A total of 652 tropical cyclones entered the Philippines for the period 19802013 (PAGASA, 2014). About half of these were reported as destructive having had adverse impacts on people (in terms of fatalities, injuries, and disruption in typical daily activities) and on assets. The cumulative death toll from 1980 to 2013 reached over 30,000, while average annual fatalities was 885. For each destructive cyclone, an average of 102 persons die. About

\footnotetext{
18 These laws are "often in advance of so many European countries" (Shepherd et al., 2013). The Special Representative of the UN Secretary-General on DRR has been quoted as saying that these laws are the "best in the world" and indicate a shift from a reactive to a proactive approach in addressing disasters (Ginnetti et al., 2013).

${ }^{19}$ In the Philippines, a typhoon is a tropical cyclone with a maximum wind speed of above $118 \mathrm{~km}$ per hour (kph), while a tropical storm (TS) has a maximum wind speed of $64-118 \mathrm{kph}$. A tropical depression (TD), has a maximum wind speed of $63 \mathrm{kph}$ (PAGASA, undated).
} 
5 million persons were affected annually, and over 570,000 were affected on average per destructive tropical cyclone. Annual average cost was USD355 million. Damage costs were highest in 2012 and 2013, mainly due to Typhoons Bopha and Haiyan, respectively. Average damage per destructive event was USD41 million. ${ }^{20}$

Despite the Philippines' sustained high economic growth rate in recent years, poverty reduction has been disappointing. In 2013, its 7.2\% real GDP growth rate was higher than most of its neighbouring countries and almost on par with that of China (WB, 2014). However, as of 2012, poverty incidence among the population in the Philippines stood at $25.2 \%$, only 1.4 percentage points lower than that in 2006 while the number of poor people increased by 1.1 million (WB, 2014). There is great variation across provinces, with poverty incidence in 2012 ranging from a low of only $3.4 \%$ to a high of $73.8 \%$ (PSA, 2013).

In terms of urbanization, the rapid influx of people into the urban areas has resulted in increased population density in urban poor communities that translate to greater vulnerability, as well as greater hazard exposure as poor communities expanded further in hazard prone areas (ADB, 2009a; Gaillard, 2008; Gaillard et al., 2007; Ginnetti et al., 2013; WB-EASPR, 2003). The encroachment of built-up areas to hazard prone locations has persistently been one of the prevalent land-use conflicts across provinces in the Philippines (Corpuz, 2013). Areas demarcated as hazard-prone are among those with densest human settlements. The consequences of unplanned urbanization, along with the poor enforcement of land-use plans, zoning ordinances and other pertinent policies and laws (such as

${ }^{20}$ Table 3-7 in the Appendix provides annual data on impacts of destructive tropical cyclones on people and assets. 
water, forestry and building codes) combine together in building up exposure and exacerbating vulnerability to disasters (Gaillard, 2011; Liongson, 2000; Porio, 2011).

\subsection{Model, Dataset, and Descriptive Statistics}

\subsubsection{Risk Framework, Econometric Model and Estimation Method}

We use as a framework for our analysis the typical three-component risk formulation in Equation 2. As we are using past observed data for each component, we translate this disaster risk framework into a disaster impact framework. Hence, our econometric disaster impact model is as follows:

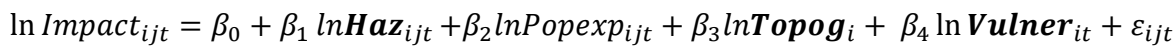

where Impactijt $_{i s}$ a measure of fatalities in province $i$ of a past tropical cyclone $j$, in year $t ; \mathbf{H a z}_{i j t}$ is a vector of physical characteristics that measure the strength of a particular past tropical cyclone $j$ in year $t$ that affected province $i$; Popexp $i j t$, is a measure of the extent of population exposure in $i$ to $j$ in year $t ; \operatorname{Topog}_{i}$ is a vector of time-invariant topographic and geographic characteristics of each province $i$; and, Vulner $i$ is the vector of control variables we hypothesize as either positively or negatively affecting people's vulnerability to tropical cyclones. ${ }^{21}$ By controlling for hazard strength and the exposure to it, we can deduce the factors affecting people's vulnerability.

We built a new provincial-level panel dataset of relevant indicators collected from different sources, and estimate Equation 3 using random effects method, as well as pooled OLS and fixed effects. We justify our use of the random effects method both on technical grounds and practical

\footnotetext{
21 Since both our dependent and independent variables are log-transformed, each coefficient is therefore interpreted as elasticity of the dependent variable with respect to the particular regressor. We note that the logarithmic transformation of the dependent variable addresses its heavy skew and makes its distribution approximately normal.
} 
considerations. We make use of a good set of explanatory variables, including measures of hazard strength and topographic and geographic variables, to represent each component in the disaster framework we use. This allows us to plausibly make the assumption of exogeneity ( $\operatorname{Cov}\left(\mathbf{X}_{\mathrm{ijt}}\right.$, $\left.\mathrm{a}_{\mathrm{i}}\right)=0$ ). That is, the unobserved heterogeneity or the unobserved variation across provinces, $\alpha_{i}$, is uncorrelated with all of the explanatory variables, the vector $\mathbf{X}_{\mathrm{ijt}}$, in all time periods. Hence, $\varepsilon_{\mathrm{ijt}}$ is a composite error term comprising of the unobserved heterogeneity, $\alpha_{i}$, and the idiosyncratic error, $\eta_{\mathrm{ijt}}$. That is, $\varepsilon_{i j t}=\alpha_{i}+\eta_{i j t}$. The use of the random effects estimation method allows us to control for time-invariant topographic variables. Given that one intent of this study is to inform physical and land use planning, topographic and geographic factors are key variables of interest, hence, the need for these to be purposely included in our model.

\subsubsection{Variables and Sources of Data}

Our choice of indicators for each component of the framework is based on the existing related cross-country work, along with the consideration of the specific circumstances of the Philippine provinces. Our dataset covers the period 2005-2010, as dictated by data availability.

\subsubsection{Impact}

Our measure of disaster impact is the number of fatalities (\% of provincial population) in province $i$, that is exposed to tropical cyclone $j$ in year $t^{22}$. By scaling the number of fatalities using total provincial population, we account for the varying sizes of the provinces. We consolidate various

\footnotetext{
22 We use $\ln (1+$ fatality $)$ for our measure of disaster impact and $\ln (1+$ affected persons $)$ for our measure of population exposure. By doing this, the observations with zero values for fatalities and affected persons are not dropped from the sample when the logarithmic transformation is done, but are instead given a value of almost zero.
} 
datasets of fatalities from the Philippines' National Disaster Risk Reduction Council (NDRRMC), including situational reports per tropical cyclone.

\subsubsection{Hazard}

We use two measures of hazard strength. ${ }^{23}$ The first measure is the maximum 24-hour rainfall volume. For a given tropical cyclone, the exposed provinces experienced different strengths of the hazard, depending on whether they are directly under the tropical cyclone path or along the periphery. To account for this, the rainfall volume assigned to each province per tropical cyclone in a given year is based on the maximum 24-hour volume recorded in the nearest rain gauge station to each province. We use the daily rainfall volume recorded in 30 PAGASA stations across the country.

The second measure is the maximum wind speed per tropical cyclone experienced by the province. We use data on the Tropical Cyclone Warning Logs of the PAGASA of the Philippines and the Joint Typhoon Warning Centre (JTWC) of the United States Air Force/Navy. ${ }^{24}$ These logs include details on the location and sustained maximum winds of the tropical cyclone. These rainfall volume and wind speed data are processed using Geographic Information System (GIS) tools to determine their values per province per tropical cyclone. ${ }^{25}$

\subsubsection{Exposed Population, Topography and Geography}

At the time that we conducted this study, the closest available proxy indicator for the exposed population is the number of affected persons (\%

\footnotetext{
${ }^{23}$ This is considering that in the Philippines, tropical cyclones can trigger other hazards: flood, landslide, coastal flooding, and storm surge. While the first three are induced more by heavy downpour of rainwater than by strong winds, the opposite is generally true for storm surges where high wind speeds are a major contributing factor. ${ }^{24}$ Data is downloaded from www.typhoon2000.ph.

25 A number of earlier related inter-country empirical work on tropical cyclones have used the number of occurrences within the country in a given year as the proxy for the hazard magnitude. We consider rainfall volume and wind speed as better measures of tropical cyclone strength, and of its capacity to destroy.
} 
to provincial population). ${ }^{26}$ We note that in a similar study by Raschky (2008), the number of affected persons is used as an explanatory variable "to control for the social magnitude of the disaster".

The geographic control variables commonly found in related empirical work are geo-location and land area (Adger, 1999; Anbarci et al., 2005; Kahn, 2005; Kellenberg \& Mobarak, 2008; Noy, 2009; Peduzzi et al., 2009; Raschky, 2008; Toya \& Skidmore, 2007). Given the distinct and complex topographic and geographic features of the Philippine archipelago, we use several additional control variables obtained with GIS analysis tools. These variables are province-specific and do not change over time.

Instead of using total land area, we disaggregate the provincial land area by slope category: 1) area of relatively flat-sloped land, with a slope range of 0 to $18 \%$; and, 2) area of steeply-sloped land, with a slope of above $18 \% .27$ From a land-use planning perspective and based on the Revised Forestry Code of the Philippines, areas with slope of above $18 \%$ is not suitable for settlements use, and must not be used for such purpose (GOP, 1975; NEDA, 2007). These land use policies are supposed to be embodied in the land use plans of the local government units, and their corresponding zoning ordinances. For location, we use dummy variables indicating the country's major island groups, and for provinces located along the eastern shoreline,

\footnotetext{
${ }^{26}$ While "exposed population" and "affected population" (or affected persons) are used interchangeably in some related work (such as in NEDA (2008), we make the distinction between the two. Exposed population refers to those persons exposed to the hazard but who may not have been adversely affected. Affected population refers to those persons exposed to the hazard and who were adversely affected; that is, affected population is the exposed population who are vulnerable. Nonetheless, in the absence of an actual population exposure dataset, we use the number of affected persons as a proxy. This is a close approximation as the number of affected persons is more often quickly and roughly estimated as the population residing in exposed areas, which then more closely measures the exposed population.

27 There are six slope categories in the Philippines, as follows: (a) 0 to $3 \%$ - level to nearly level; (b) 3 to $8 \%$ - gently sloping; (c) 8 to $18 \%$ - undulating to rolling; (d) 18 to 30\% - rolling to moderately steep; (e) 30 to 50\% - steep; and, (f) above $50 \%$ - very steep. We only make two broad categories here to distinguish between the areas that are suitable for settlements use and those that are not.
} 
as tropical cyclones always arrive from the east. We also use a dummy variable to indicate whether the province is landlocked.

\subsubsection{Vulnerability}

We disaggregate the components of the Human Development Index (HDI) to examine separately the influence of economic development and social development. We use data on real per capita income, average educational attainment (measured in terms of mean years of schooling) of the population, and average life expectancy taken from the Philippine Human Development Reports (PHDN, 2013). We also proxy for the lack of resources using poverty incidence as a proxy. Due to the high correlation coefficient of -0.87 between per capita income and poverty incidence, we enter them into the model one at a time. ${ }^{28}$

For our inquiry on the nature of the influence of urbanization on fatalities, we use both the overall population density in the province, and population density in built-up areas. The former is computed as provincial population divided by the total provincial land area, and the latter, provincial population divided by the total built-up areas in the province.

We also derived an indicator for quality of local governance. Given the provincial resolution of this study and the specific circumstance in the Philippines, we use public finance data of the local government units to construct a governance variable. We use the percentage of locally-generated tax revenues to the total income of local government units (LGU) within the provincial geographic boundary. ${ }^{29}$ The sources of basic data are the annual Statements of Income and Expenditures of LGUs prepared by the Philippine Bureau of Local Government Finance (BLGF, 2014). This

\footnotetext{
${ }^{28}$ Table 3-9 in the Appendix shows the results of the pairwise correlation. As a rule for this paper, we only simultaneously enter into the model variables that have a maximum correlation coefficient of 0.60 .

29 These include the provincial, city, and municipal local government units. We do not have data for the barangays, which is the lowest administrative unit in the Philippines.
} 
indicator determines the level of financial dependence of the provinces to funds provided by the central government. ${ }^{30}$ Given this specific circumstance of the Philippines, this serves as a good indicator of institutional quality. ${ }^{31} \mathrm{~A}$ high value of this variable indicates greater local effort and effectiveness in revenue generation that translate to greater financial resources for the provision of public goods.

\subsubsection{Descriptive Statistics}

Within the period 2005-2010, a total of 104 tropical cyclones passed the Philippine Area of Responsibility (PAGASA, 2014) (see Figure 3-2). Of which, 57 were reported by the NDRRMC as destructive. Together, these destructive tropical cyclones claimed a total of 2,625 lives and affected about 36 million persons. These 57 destructive tropical cyclones make a total of 722 provincial 'hits' in the dataset, indicating that, on average, 13 provinces were affected by each tropical cyclone. During the six-year period, each province, on average, was affected by nine tropical cyclones. Figures 3-3 to 3-5 depict the distributions of the total number of events, number of fatalities, and number of affected persons by province during the period covered. Visual inspection reveals that the number of events, average number of fatalities and average number of affected persons vary across provinces, regions and major island groups. Tropical cyclones typically pass the northern part of the country (the northern part of the Luzon major island group). Of the total number of observations, 550 are for

\footnotetext{
${ }^{30}$ In the Philippines, the Total Current Operating Income of local government units comes from local and external sources. Revenues from external sources comprise mainly of funds provided by the central government, largely in the form of Internal Revenue Allotment or the IRA. The annual provision of IRA seemingly provides disincentive for the LGUs to undertake local revenue generation. "LGUs have generally been unwilling to raise their own revenues, particularly through potentially rich sources such as property tax. The IRA has effectively substituted for own-source revenue generation" (Balisacan \& Hall, 2006).

${ }^{31}$ The Philippines has an indicator of the quality of governance called the Good Governance Index or the GGI (PSA-NSCB). We do not use the GGI as it is basically an average value of socioeconomic indicators, including those that we individually use as proxy for the different aspects of development that we examine in this study. We note, however, that the GGI includes local government finance indicator.
} 
the provinces in the Luzon island group, 118 in the Visayas island group, and the remaining 54, in the Mindanao island group. ${ }^{32}$

Table 3-1 below shows the descriptive statistics of the variables used in the model, covering the period 2005-2010. The variables are presented in their original form in the table but are entered into the model after a logarithmic transformation, except for the dummy variables. Relative to the affected province's population, the highest fatalities recorded is 508 per million population. Meanwhile, the average 24-hour rainfall volume is $101 \mathrm{~mm}$, and average wind speed is 107 kilometres per hour.

Table 3-1. Descriptive Statistics

\begin{tabular}{|c|c|c|c|c|c|}
\hline Variable & Description & Mean & Std. Dev. & Min & Max \\
\hline Fatality & Number of fatalities for every $1,000,000$ population & 7 & 28 & 0 & 508 \\
\hline Rainfall & $\begin{array}{l}\text { Maximum 24-hour rainfall volume per province per } \\
\text { tropical cyclone (in } \mathrm{mm} \text { ) }\end{array}$ & 101 & 97 & 0 & 685 \\
\hline Wind & $\begin{array}{l}\text { Maximum wind speed per tropical cyclone (in } \\
\text { kilometres per hours) }\end{array}$ & 107 & 44 & 45 & 215 \\
\hline $\begin{array}{l}\text { Affected } \\
\text { population }\end{array}$ & $\begin{array}{l}\text { Number of affected persons for every } 1,000,000 \\
\text { population }\end{array}$ & 50,745 & 121,424 & 0 & 976,959 \\
\hline Flat-sloped land & $\begin{array}{l}\text { Area in the province with slope } 0-18 \% \text { (in square } \\
\text { kilometres) }\end{array}$ & 1,178 & 950 & 12 & 3,638 \\
\hline $\begin{array}{l}\text { Steeply-sloped } \\
\text { land }\end{array}$ & $\begin{array}{l}\text { Area in the province with slope above } 18 \% \text { (in square } \\
\text { kilometres) }\end{array}$ & 1,898 & 1,231 & 112 & 6,390 \\
\hline Luzon (dummy) & $\begin{array}{l}\text { Dummy variable with a value of } 1 \text { if a given province is } \\
\text { part of Luzon island group, value of zero (0) otherwise }\end{array}$ & 0.76 & 0.43 & 0 & 1 \\
\hline Visayas (dummy) & $\begin{array}{l}\text { Dummy variable with a value of } 1 \text { if a given province is } \\
\text { part of Visayas island group, value of zero (0) } \\
\text { otherwise }\end{array}$ & 0.16 & 0.37 & 0 & 1 \\
\hline $\begin{array}{l}\text { Eastern province } \\
\text { (dummy) }\end{array}$ & $\begin{array}{l}\text { Dummy variable with a value of } 1 \text { if a given province is } \\
\text { located in the east-most part of the country (along the } \\
\text { eastern shoreline), value of zero (0) otherwise }\end{array}$ & 0.25 & 0.43 & 0 & 1 \\
\hline $\begin{array}{l}\text { Landlocked } \\
\text { province (dummy) }\end{array}$ & $\begin{array}{l}\text { Dummy variable with a value of } 1 \text { if a given province is } \\
\text { landlocked, value of zero }(0) \text { if province is coastal }\end{array}$ & 0.25 & 0.43 & 0 & 1 \\
\hline Income per capita & Real per capita income (in USD) & 1,430 & 465 & 578 & 2710 \\
\hline Poverty incidence & Poverty incidence & 29.08 & 14.93 & 1.84 & 67.5 \\
\hline $\begin{array}{l}\text { Mean years of } \\
\text { schooling }\end{array}$ & $\begin{array}{l}\text { Average years of schooling of the population (in } \\
\text { number of years) }\end{array}$ & 10.03 & 0.71 & 7.1 & 11.99 \\
\hline Life expectancy & Average life expectancy (in number of years) & 68.73 & 3.9 & 52.8 & 76.4 \\
\hline $\begin{array}{l}\% \text { local tax } \\
\text { revenue to total } \\
\text { income }\end{array}$ & Percentage of tax revenue to total LGU income & 11.43 & 9.61 & 0.14 & 43.68 \\
\hline Built-up density & $\begin{array}{l}\text { Population density in built-up areas (persons per } \\
\text { square kilometre) }\end{array}$ & 11,596 & 11,607 & 2,468 & 95,691 \\
\hline Population density & $\begin{array}{l}\text { Population density in the province (persons per square } \\
\text { kilometre) }\end{array}$ & 410 & 444 & 28 & 2,336 \\
\hline
\end{tabular}

32 To date there are 81 provinces in the country. The $81^{\text {st }}$ province, Davao Occidental, was created only in 2013 , while the $80^{\text {th }}$, the province of Dinagat Islands, was created in the last quarter of 2006. During the period 20052010, there are no separate records of disaster impacts, as well as socioeconomic data for Dinagat province. Hence, only 79 of the 81 provinces are included in the dataset for this paper. 
Figure 3-2. Tropical Cyclone Tracks, 2005-2010

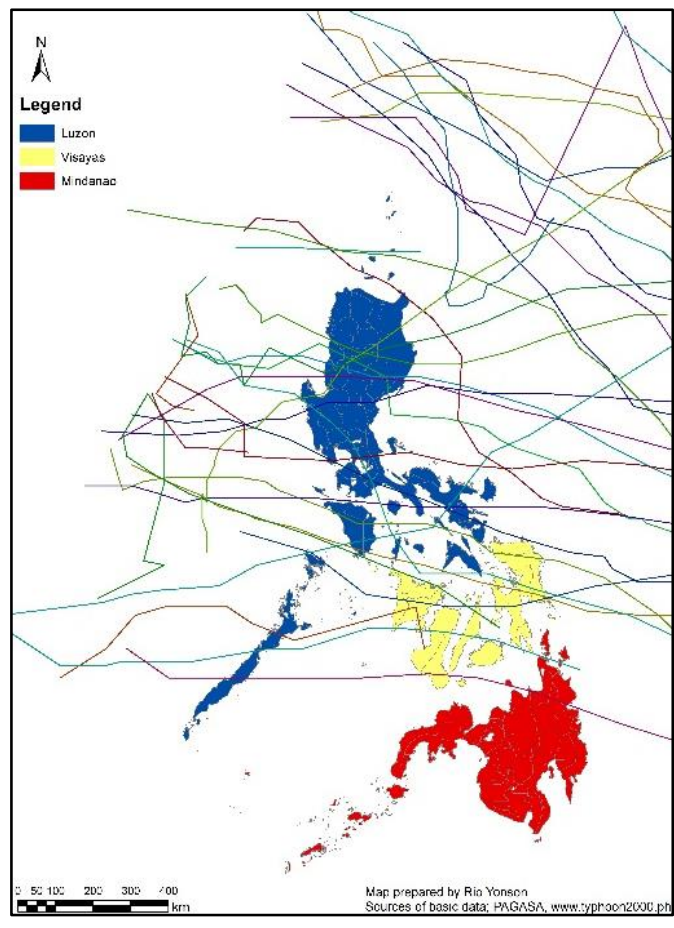

Figure 3-4. Total Number of Fatalities, Destructive Tropical Cyclones, 2005-2010

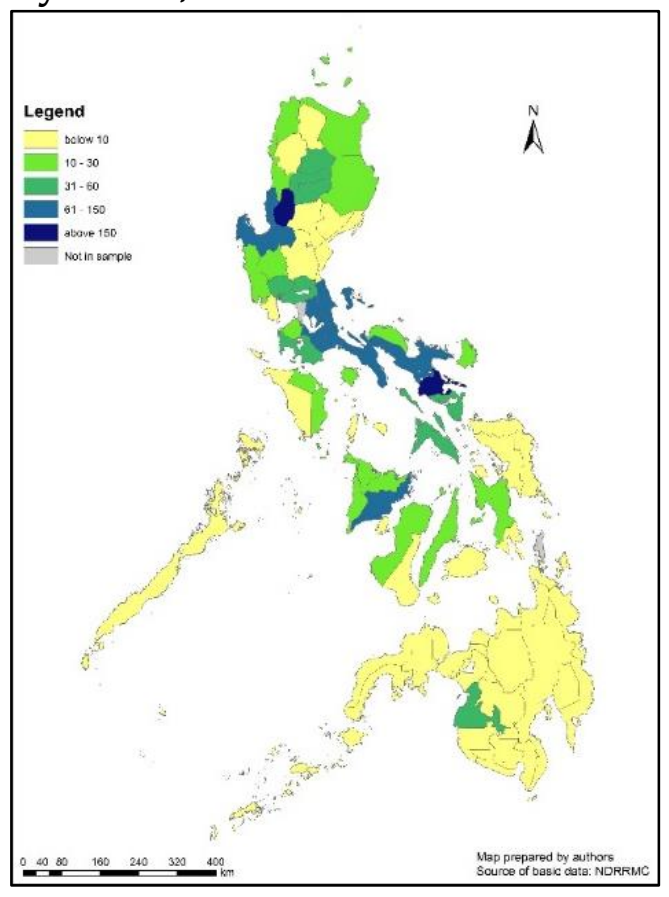

Figure 3-3. Number of Occurrences: Destructive Tropical Cyclones, 2005-2010

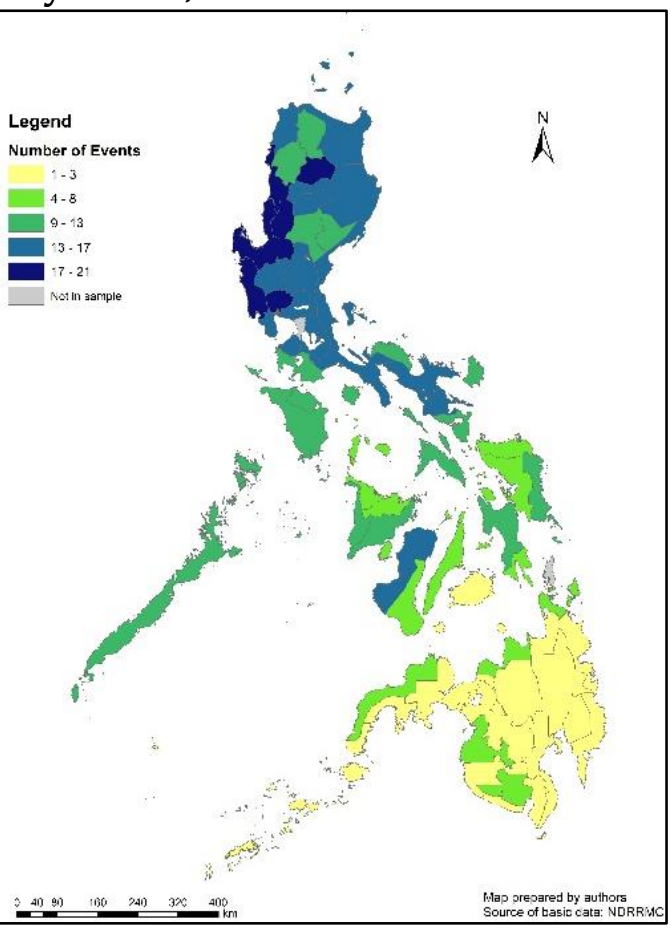

Figure 3-5. Total Number of Affected Persons, Destructive Tropical Cyclones, 2005-2010

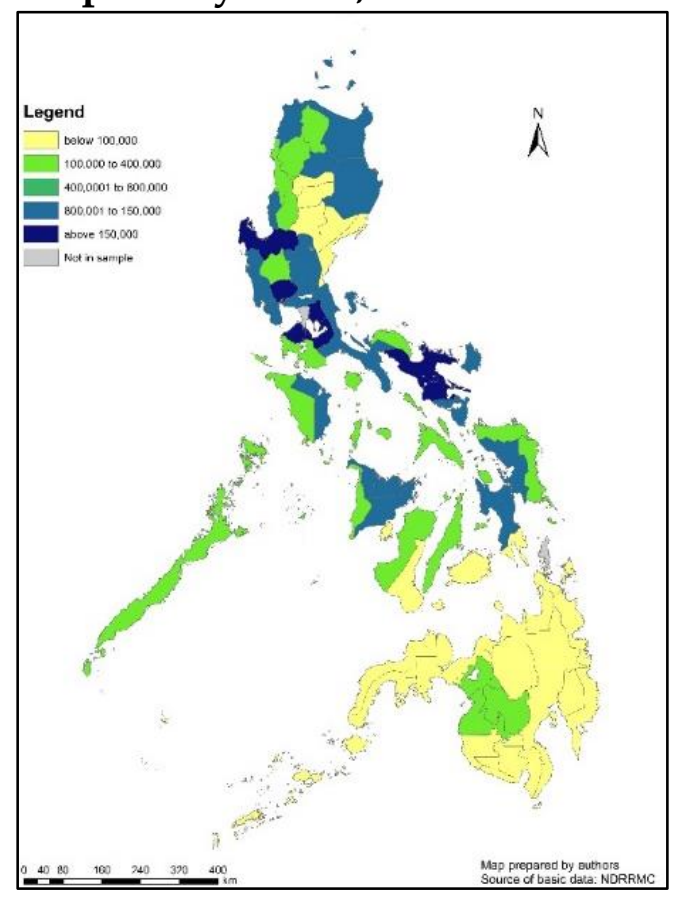


Average real income per capita ranged from a minimum of USD 578 (TawiTawi) to a maximum of USD 2,710 (Benguet Province), and an average of USD 1,430 across provinces. Poverty incidence ranged from a low of $1.84 \%$ (Cavite) to a high of $67.5 \%$ (Zamboanga del Norte); the average incidence at the country level is $29.08 \%$. The lowest average life expectancy is 52.8 years (Tawi-Tawi), while the highest is 76.4 years (La Union). The national life expectancy is 68.73 years. In terms of the average educational attainment (in years) of the population, provincial values range from 7.1 years (Sulu) to 11.99 years (Batanes). The country-level average is 10 years.

Population density in built-up areas range from 2,468 persons per square kilometre (Tarlac) to a high of 95,691 persons per square kilometre (Lanao del Sur), which is over eight times higher than the average of 11,596 per square kilometre. Meanwhile, the ratio of provincial tax revenue to total LGU income range from a high of $43.68 \%$ (Laguna) and a low of less than $1 \%$ (Sulu), which practically indicates a full reliance on the revenue allotment from the central government. The average across provinces is only $11.43 \%$.

Generally, the provinces with the worst socioeconomic and governance indicators (low per capita income, high poverty incidence, etc) are in Mindanao, while the better off provinces are those located in Luzon. Conversely, the provinces in Mindanao, on average, experienced the least number of destructive tropical cyclones. 


\subsection{Results and Discussions ${ }^{33}$}

\subsubsection{Determinants of Fatalities}

Table 3-2 shows the results under five specifications of Equation 3, estimated using the pooled OLS and random effects methods. The standard errors are estimated using the Huber-White estimator to ensure heteroscedasticity-consistent errors. The two methods yield very similar results, but the Breusch-Pagan Lagrange Multiplier test suggests the use of random effects over pooled OLS to estimate the various specifications of the model, except for the fourth specification that focuses on urbanization. Hence, in discussing the results we refer to the random effects estimates, unless otherwise stated.

It can be gleaned from Column 2 that the coefficient of per capita income is negative and highly significant, indicating that fatality is a decreasing function of income. All else constant, a 10 percent increase in per capita income reduces the proportion of fatalities by 11 percent. This is even though more and stronger cyclones hit the higher income provinces of the north. Conversely, from the standpoint of inadequacy, the coefficient of poverty incidence is positive, and significant (Column 4). This quantitatively validates the earlier claims that in the Philippines, poverty is a critical factor in determining vulnerability to disasters (ADB, 2009a; Shepherd et al., 2013). Likewise, social development matters in ensuring people's safety from the adverse impacts of tropical cyclones. We find that high of level of education and good health are inversely associated with fatalities (Column 6).

\footnotetext{
${ }^{33}$ We note again that all variables are entered into the model in their respective logarithmic transformation. For brevity in the analysis, we simply refer to the name of the variables and dispel with repeatedly indicating that they are in logarithmic form.
} 
We next examine the influence of urbanization, which is closely linked with economic growth. In general, urban areas in the Philippines exhibit the benefits from the agglomeration of people and economic activities (Corpuz, 2013). However, our result reveals a positive and significant coefficient of the density in built-up areas, as shown in Column 7 of Table 3-2. This points to the diminishing safety of people as the existing built-up areas become more population-dense. This may partly reflect the burgeoning of settlements in hazard prone areas and the lagging provision of adequate services for the additional population, particularly in areas exhibiting a high population growth rate (WB-EASPR, 2003). ${ }^{34}$ It is interesting to note, however, that population density has a negative and significant coefficient; that is, an increase in overall population density in a province is negatively correlated with fatalities. These results together indicate that the danger of losing lives is increasingly concentrated in the urban areas once a tropical cyclone occurs.

The coefficient for our local governance variable is significant and inversely correlated with fatalities. Our result denotes that good governance, even at the subnational level, is critical in minimizing disaster fatalities. As shown in Column 10 in Table 3-2, all else constant, a 10 percent increase in the proportion of local tax revenues to total provincial income reduces the proportion of fatalities by 4 percent. This likely reflects the fact that more public finance resources translate to greater provision and availability of protective public goods and services.

\footnotetext{
${ }^{34}$ The Philippine population grew at an average of 2.69\% during the period 1950-2010, higher than the averages for South East Asia, the whole of Asia and the World (UN, 2014). Urban population grew much faster, driven mainly by migration of people from rural areas. During the period 1950 - 1990, urban population grew at an annual average of $4.47 \%$, also higher than the averages for South East Asia, the whole of Asia and the World (UN, 2014). Thereafter, urban annual population growth rate slowed down, ranging from $1.12 \%$ to $2.21 \%$ from 1990 to 2010. The country's rate of urbanization has outpaced the provision of adequate services (ADB, 2014; WB-EASPR, 2003).
} 
For the topographic and geographic control variables, the results in Table 3-2 generally reveal that the ground slope categories are important in explaining the fatalities resulting from tropical cyclones. It is noted that while the coefficient for the areas with slope below $18 \%$ is negative and significant, the coefficient for areas with slope above $18 \%$ is positive and also significant. A plausible explanation for these is that areas with slope below $18 \%$, which are legally deemed suited for settlements use, have stronger DRRM measures in place than those in areas with more than $18 \%$ slopes, which are areas officially not appropriate for settlements purposes. It has been noted that in the Philippines, communities in steep slopes are also becoming increasingly dense. Gaillard et al. (2007) find that when the traditional areas for settlement in the lowland are reaching carrying capacity, many poor people resort to taking residence in marginal areas, such as those with steep slopes that are prone to rain-induced landslides.

For the hazard variables, we find that across all five specifications the proportion of fatalities increases with increases in rainfall volume. However, there is no statistically significant result in terms of the link between fatalities and wind speed. This is an interesting finding, as quite a few papers proxy for the strength of cyclone impact with wind speed measures (e.g. Hsiang and Jina, 2014). Our results suggest this may be an inappropriate proxy. In terms of exposure, fatality is an increasing function of exposed people, as proxied for by the proportion of affected persons to provincial population. 
Table 3-2. Results of the Various Specifications of the Full Model

\begin{tabular}{|c|c|c|c|c|c|c|c|c|c|c|}
\hline & \multicolumn{2}{|c|}{ Specification 1} & \multicolumn{2}{|c|}{ Specification 2} & \multicolumn{2}{|c|}{ Specification 3} & \multicolumn{2}{|c|}{ Specification 4} & \multicolumn{2}{|c|}{ Specification 5} \\
\hline & OLS & $\begin{array}{l}\text { RE } \\
\text { (2) }\end{array}$ & OLS & $\begin{array}{l}\text { RE } \\
\text { (4) }\end{array}$ & $\begin{array}{l}\text { OLS } \\
(5)\end{array}$ & $\begin{array}{l}\text { RE } \\
(6)\end{array}$ & $\begin{array}{l}\text { OLS } \\
(7)\end{array}$ & $\begin{array}{l}\text { RE } \\
(8)\end{array}$ & $\begin{array}{l}\text { OLS } \\
\text { (9) }\end{array}$ & $\begin{array}{c}\text { RE } \\
(10)\end{array}$ \\
\hline Rainfall & $\begin{array}{l}0.0713^{*} \\
(2.55)\end{array}$ & $\begin{array}{l}0.0835^{* *} \\
(3.02)\end{array}$ & $\begin{array}{l}0.0713^{*} \\
(2.57)\end{array}$ & $\begin{array}{l}0.0868^{* *} \\
(3.13)\end{array}$ & $\begin{array}{l}0.0693^{* *} \\
(2.59)\end{array}$ & $\begin{array}{l}0.0857^{* *} \\
(3.11)\end{array}$ & $\begin{array}{l}0.0931^{* * *} \\
(3.90)\end{array}$ & $\begin{array}{l}\text { 0.0931*** } \\
(3.61)\end{array}$ & $\begin{array}{l}\text { "0.0859** } \\
(3.22)\end{array}$ & $\begin{array}{l}0.0952^{* * *} \\
(3.58)\end{array}$ \\
\hline Wind & $\begin{array}{l}-0.0375 \\
(-0.46)\end{array}$ & $\begin{array}{l}-0.0451 \\
(-0.53)\end{array}$ & $\begin{array}{l}0.0158 \\
(0.19)\end{array}$ & $\begin{array}{l}0.00885 \\
(0.11)\end{array}$ & $\begin{array}{l}-0.0173 \\
(-0.21)\end{array}$ & $\begin{array}{l}-0.0251 \\
(-0.29)\end{array}$ & $\begin{array}{l}-0.0197 \\
(-0.26)\end{array}$ & $\begin{array}{l}-0.0197 \\
(-0.24)\end{array}$ & $\begin{array}{l}-0.0226 \\
(-0.28)\end{array}$ & $\begin{array}{l}-0.0250 \\
(-0.30)\end{array}$ \\
\hline Affected persons & $\begin{array}{l}0.0800^{* * *} \\
(10.59)\end{array}$ & $\begin{array}{l}0.0816^{* * * *} \\
(9.88)\end{array}$ & $\begin{array}{l}0.0792^{* * *} \\
(10.57)\end{array}$ & $\begin{array}{l}0.0801^{* * *} \\
(9.96)\end{array}$ & $\begin{array}{l}0.0811^{* * *} \\
(10.83)\end{array}$ & $\begin{array}{l}0.0821 * * * \\
(10.16)\end{array}$ & $\begin{array}{l}0.0772^{* * *} \\
(10.78)\end{array}$ & $\begin{array}{l}0.0772 * * * \\
(9.73)\end{array}$ & $\begin{array}{l}0.0773 * * * \\
(10.22)\end{array}$ & $\begin{array}{l}\text { * } 0.0798 * * * \\
(10.00)\end{array}$ \\
\hline Flat-sloped land & $\begin{array}{l}-0.852^{* * *} \\
(-18.10)\end{array}$ & $\begin{array}{l}-0.863^{* * *} \\
(-9.57)\end{array}$ & $\begin{array}{l}-0.761^{* * *} \\
(-15.82)\end{array}$ & $\begin{array}{l}-0.770^{* * *} \\
(-8.18)\end{array}$ & $\begin{array}{l}-0.795 * * * \\
(-16.57)\end{array}$ & $\begin{array}{l}-0.826^{* * *} \\
(-10.32)\end{array}$ & $\begin{array}{l}-0.520^{* * *} \\
(-11.33)\end{array}$ & $\begin{array}{l}-0.520^{* * *} \\
(-10.52)\end{array}$ & $\begin{array}{l}-0.625^{* * *} \\
(-12.62)\end{array}$ & $\begin{array}{l}-0.676^{* * *} \\
(-7.88)\end{array}$ \\
\hline Steeply-sloped land & $\begin{array}{l}0.286 * * * \\
(5.95)\end{array}$ & $\begin{array}{l}0.256^{* * *} \\
(3.35)\end{array}$ & $\begin{array}{l}0.179 * * \\
(3.20)\end{array}$ & $\begin{array}{l}0.131 \\
(1.48)\end{array}$ & $\begin{array}{l}0.333^{* * *} \\
(6.84)\end{array}$ & $\begin{array}{l}0.298^{* * *} \\
(3.49)\end{array}$ & $\begin{array}{l}-0.187^{* * *} \\
(-3.33)\end{array}$ & $\begin{array}{l}-0.187^{* * *} \\
(-3.63)\end{array}$ & $\begin{array}{l}0.246 * * * \\
(4.89)\end{array}$ & $\begin{array}{l}0.238^{* *} \\
(2.94)\end{array}$ \\
\hline Luzon (dummy) & $\begin{array}{l}0.249^{*} \\
(1.98)\end{array}$ & $\begin{array}{l}0.193 \\
(1.29)\end{array}$ & $\begin{array}{l}0.228 \\
(1.76)\end{array}$ & $\begin{array}{l}0.195 \\
(1.17)\end{array}$ & $\begin{array}{l}0.280^{*} \\
(2.25)\end{array}$ & $\begin{array}{l}0.207 \\
(1.48)\end{array}$ & $\begin{array}{l}0.152 \\
(1.27)\end{array}$ & $\begin{array}{l}0.152 \\
(1.33)\end{array}$ & $\begin{array}{l}0.0372 \\
(0.30)\end{array}$ & $\begin{array}{l}0.00748 \\
(0.05)\end{array}$ \\
\hline Visayas (dummy) & $\begin{array}{l}-0.154 \\
(-1.15)\end{array}$ & $\begin{array}{l}-0.156 \\
(-0.93)\end{array}$ & $\begin{array}{l}-0.145 \\
(-1.06)\end{array}$ & $\begin{array}{l}-0.143 \\
(-0.83)\end{array}$ & $\begin{array}{l}-0.113 \\
(-0.82)\end{array}$ & $\begin{array}{l}-0.119 \\
(-0.69)\end{array}$ & $\begin{array}{l}0.0324 \\
(0.26)\end{array}$ & $\begin{array}{l}0.0324 \\
(0.21)\end{array}$ & $\begin{array}{l}-0.156 \\
(-1.12)\end{array}$ & $\begin{array}{l}-0.152 \\
(-0.86)\end{array}$ \\
\hline Eastern province (dummy) & $\begin{array}{l}0.107 \\
(1.20)\end{array}$ & $\begin{array}{l}0.138 \\
(0.93)\end{array}$ & $\begin{array}{l}0.0392 \\
(0.44)\end{array}$ & $\begin{array}{l}0.0642 \\
(0.43)\end{array}$ & $\begin{array}{l}0.192^{*} \\
(2.23)\end{array}$ & $\begin{array}{l}0.198 \\
(1.51)\end{array}$ & $\begin{array}{l}0.0206 \\
(0.25)\end{array}$ & $\begin{array}{l}0.0206 \\
(0.25)\end{array}$ & $\begin{array}{l}0.109 \\
(1.25)\end{array}$ & $\begin{array}{l}0.139 \\
(1.05)\end{array}$ \\
\hline Landlocked province (dummy) & $\begin{array}{l}0.169 \\
(1.88)\end{array}$ & $\begin{array}{l}0.175 \\
(0.99)\end{array}$ & $\begin{array}{l}0.194^{*} \\
(2.14)\end{array}$ & $\begin{array}{l}0.215 \\
(1.15)\end{array}$ & $\begin{array}{l}-0.0694 \\
(-0.76)\end{array}$ & $\begin{array}{l}-0.0134 \\
(-0.08)\end{array}$ & $\begin{array}{l}-0.00753 \\
(-0.09)\end{array}$ & $\begin{array}{l}-0.00753 \\
(-0.10)\end{array}$ & $\begin{array}{l}0.0535 \\
(0.61)\end{array}$ & $\begin{array}{l}0.0564 \\
(0.36)\end{array}$ \\
\hline Income per capita & $\begin{array}{l}-1.245^{* * *} \\
(-8.78)\end{array}$ & $\begin{array}{l}-1.132^{* * *} \\
(-5.82)\end{array}$ & & & & & & & & \\
\hline Poverty incidence & & & $\begin{array}{l}0.553^{* * *} \\
(8.52)\end{array}$ & $\begin{array}{l}0.556 * * * \\
(5.24)\end{array}$ & & & & & & \\
\hline Life expectancy & & & & & $\begin{array}{l}-5.303^{* * *} \\
(-6.73)\end{array}$ & $\begin{array}{l}-4.356^{* * *} \\
(-4.25)\end{array}$ & & & & \\
\hline Mean years of schooling & & & & & $\begin{array}{l}-2.097^{* *} \\
(-3.16)\end{array}$ & $\begin{array}{l}-2.207^{*} \\
(-2.56)\end{array}$ & & & & \\
\hline Built-up density & & & & & & & $\begin{array}{l}0.159 * * \\
(3.30)\end{array}$ & $\begin{array}{l}0.159 * * \\
(3.05)\end{array}$ & & \\
\hline Population density & & & & & & & $\begin{array}{l}-0.724^{* * *} \\
(-14.30)\end{array}$ & $\begin{array}{l}-0.724^{* * *} \\
(-16.61)\end{array}$ & & \\
\hline$\%$ local tax revenues to total income & & & & & & & & & $\begin{array}{l}-0.442^{* * *} \\
(-9.99)\end{array}$ & $\begin{array}{l}-0.375^{* * *} \\
(-6.05)\end{array}$ \\
\hline _cons & $\begin{array}{l}6.519 * * * \\
(5.43)\end{array}$ & $\begin{array}{l}6.035^{* * *} \\
(3.86)\end{array}$ & $\begin{array}{l}-4.298^{* * *} \\
(-7.69)\end{array}$ & $\begin{array}{l}-3.895^{* * *} \\
(-4.63)\end{array}$ & $\begin{array}{l}23.97^{* * *} \\
(8.10)\end{array}$ & $\begin{array}{l}20.72^{* * *} \\
(5.49)\end{array}$ & $\begin{array}{l}1.150 \\
(1.41)\end{array}$ & $\begin{array}{l}1.150 \\
(1.32)\end{array}$ & $\begin{array}{l}-2.813^{* * *} \\
(-5.25)\end{array}$ & $\begin{array}{l}-2.525 * * * \\
(-3.36)\end{array}$ \\
\hline $\mathrm{N}$ & 722 & 722 & 722 & 722 & 722 & 722 & 722 & 722 & 722 & 722 \\
\hline R-sq & 0.4730 & 0.4779 & 0.4700 & 0.4756 & 0.4960 & 0.5004 & 0.5610 & 0.5678 & 0.4900 & 0.4940 \\
\hline
\end{tabular}

t statistic in parentheses; ${ }^{*} \mathrm{p}<0.05 * * \mathrm{p}<0.01 * * * \mathrm{p}<0.001 ;$ OLS reflects adjusted R-sq; RE reflects overall R-sq

Table 3-3 below shows the results of estimating a final form of the model, where we regress the proportion of fatalities only on the significant explanatory variables as shown in Table 3-2. We find that all the explanatory variables retained their respective signs and level of significance. These results provide an initial indication that these explanatory variables are robust to the exclusion of other control variables. 
Table 3-3. Results of the Various Specifications of the Final Model

\begin{tabular}{|c|c|c|c|c|c|c|c|c|c|c|}
\hline & \multicolumn{2}{|c|}{ Specification 1} & \multicolumn{2}{|c|}{ Specification 2} & \multicolumn{2}{|c|}{ Specification 3} & \multicolumn{2}{|c|}{ Specification 4} & \multicolumn{2}{|c|}{ Specification 5} \\
\hline & oLs & RE & OLS & RE & OLS & RE & OLS & RE & oLs & RE \\
\hline & $(1)$ & $(2)$ & (3) & (4) & $(5)$ & (6) & $(7)$ & $(8)$ & (9) & $(10)$ \\
\hline Rainfall & $\begin{array}{l}0.0848^{* *} \\
(3.07)\end{array}$ & $\begin{array}{l}0.0911^{* * *} \\
(3.33)\end{array}$ & $\begin{array}{l}{ }^{*} 0.0867^{* *} \\
(3.15)\end{array}$ & $\begin{array}{l}0.0952^{* * *} \\
(3.45)\end{array}$ & $\begin{array}{l}0.0760^{* *} \\
(2.83)\end{array}$ & $\begin{array}{l}0.0893^{* * *} \\
(3.30)\end{array}$ & $\begin{array}{l}0.0962^{* * *} \\
(4.14)\end{array}$ & $\begin{array}{l}{ }^{*} 0.0962^{* * * *} \\
(3.95)\end{array}$ & $\begin{array}{l}0.0886 * * * \\
(3.38)\end{array}$ & $\begin{array}{l}{ }^{*} 0.0946^{* * *} \\
(3.65)\end{array}$ \\
\hline Affected persons & $\begin{array}{l}0.0817^{* * *} \\
(10.92)\end{array}$ & $\begin{array}{c}{ }^{*} 0.0821^{* * *} \\
(10.46)\end{array}$ & $\begin{array}{l}0.0812^{* * *} \\
(10.96)\end{array}$ & $\begin{array}{l}0.0812^{* * *} \\
(10.75)\end{array}$ & $\begin{array}{l}0.0847^{* * *} \\
(11.34)\end{array}$ & $\begin{array}{l}0.0829 * * * \\
(10.60)\end{array}$ & $\begin{array}{l}0.0781^{* * *} \\
(11.05)\end{array}$ & $\begin{array}{l}\text { * } 0.0781^{* * * *} \\
(10.17)\end{array}$ & $\begin{array}{l}{ }^{*} 0.0782^{* * *} \\
(10.51)\end{array}$ & $\begin{array}{l}\text { * } 0.0798^{* * *} \\
(10.48)\end{array}$ \\
\hline Flat-sloped land & $\begin{array}{l}-0.876 * * * \\
(-19.24)\end{array}$ & $\begin{array}{l}-0.887^{* * *} \\
(-9.72)\end{array}$ & $\begin{array}{l}-0.809 * * * \\
(-17.69)\end{array}$ & $\begin{array}{l}-0.818^{* * *} \\
(-9.22)\end{array}$ & $\begin{array}{l}-0.794^{* * *} \\
(-16.70)\end{array}$ & $\begin{array}{l}-0.831^{* * *} \\
(-10.24)\end{array}$ & $\begin{array}{l}-0.518^{* * *} \\
(-11.50)\end{array}$ & $\begin{array}{l}-0.518^{* * *} \\
(-12.36)\end{array}$ & $\begin{array}{l}-0.627 * * * \\
(-12.58)\end{array}$ & $\begin{array}{l}-0.674^{* * *} \\
(-7.83)\end{array}$ \\
\hline Steeply-sloped land & $\begin{array}{l}0.327^{* * *} \\
(7.21)\end{array}$ & $\begin{array}{l}0.290^{* * *} \\
(3.96)\end{array}$ & $\begin{array}{l}0.242^{* * *} \\
(4.66)\end{array}$ & $\begin{array}{l}0.194^{*} \\
(2.39)\end{array}$ & $\begin{array}{l}0.336^{* * *} \\
(7.21)\end{array}$ & $\begin{array}{l}0.306^{* * *} \\
(4.03)\end{array}$ & $\begin{array}{l}-0.195^{* * *} \\
(-3.46)\end{array}$ & $\begin{array}{l}-0.195^{* * *} \\
(-3.79)\end{array}$ & $\begin{array}{l}0.249 * * * \\
(5.01)\end{array}$ & $\begin{array}{l}0.245^{* *} \\
(3.16)\end{array}$ \\
\hline Income per capita & $\begin{array}{l}-1.040 * * * \\
(-8.20)\end{array}$ & $\begin{array}{l}-0.935^{* * *} \\
(-5.55)\end{array}$ & & & & & & & & \\
\hline Poverty incidence & & & $\begin{array}{l}0.453^{* * *} \\
(7.92)\end{array}$ & $\begin{array}{l}0.450^{* * *} \\
(4.72)\end{array}$ & & & & & & \\
\hline Life expectancy & & & & & $\begin{array}{l}-4.576 * * * \\
(-5.79)\end{array}$ & $\begin{array}{l}-3.892^{* * *} \\
(-3.67)\end{array}$ & & & & \\
\hline Mean years of schooling & & & & & $\begin{array}{l}-2.112^{* * *} \\
(-3.32)\end{array}$ & $\begin{array}{l}-2.018^{*} \\
(-2.35)\end{array}$ & & & & \\
\hline Built-up density & & & & & & & $\begin{array}{l}0.127^{* *} \\
(3.11)\end{array}$ & $\begin{array}{l}0.127^{* *} \\
(2.64)\end{array}$ & & \\
\hline Population density & & & & & & & $\begin{array}{l}-0.733^{* * *} \\
(-15.19)\end{array}$ & $\begin{array}{l}-0.733^{* * *} \\
(-16.53)\end{array}$ & & \\
\hline$\%$ local tax revenues to total income & & & & & & & & & $\begin{array}{l}-0.447^{* * *} \\
(-10.19)\end{array}$ & $\begin{array}{l}-0.384^{* * *} \\
(-6.24)\end{array}$ \\
\hline _cons & $\begin{array}{l}4.919 * * * \\
(4.54)\end{array}$ & $\begin{array}{l}4.487^{* *} \\
(3.26)\end{array}$ & $\begin{array}{l}-3.884 * * * \\
(-10.37)\end{array}$ & $\begin{array}{l}-3.493^{* * *} \\
(-4.65)\end{array}$ & $\begin{array}{l}21.02^{* * *} \\
(7.18)\end{array}$ & $\begin{array}{l}18.33^{* * *} \\
(4.77)\end{array}$ & $\begin{array}{l}1.563^{*} \\
(2.43)\end{array}$ & $\begin{array}{l}1.563^{*} \\
(1.97)\end{array}$ & $\begin{array}{l}-2.884 * * * \\
(-7.57)\end{array}$ & $\begin{array}{l}-2.669 * * * \\
(-3.73)\end{array}$ \\
\hline $\mathrm{N}$ & 722 & 722 & 722 & 722 & 722 & 722 & 722 & 722 & 722 & 722 \\
\hline R-sq & 0.4560 & 0.4579 & 0.4550 & 0.4570 & 0.4810 & 0.4827 & 0.5630 & 0.5662 & 0.4890 & 0.4896 \\
\hline
\end{tabular}

t statistic in parentheses; ${ }^{*} \mathrm{p}<0.05 * * \mathrm{p}<0.01 * * * \mathrm{p}<0.001 ;$ OLS reflects adjusted $\mathrm{R}$-sq; RE reflects overall R-sq

To test the robustness of our time-varying explanatory variables, we compare the estimation results using random effects and fixed effects methods. We regress fatalities on the significant time-varying explanatory variables only to make the results of the two methods directly comparable. It can be seen from Table 3-4 that rainfall and the proportion of affected persons are likewise significant under fixed effects method, but among the socioeconomic variables, only income per capita is significant. However, the results of the Hausman tests reveal that using random effects method provides both consistent and efficient estimates for Specifications 1 to 4 . Under these four specifications, using fixed effects estimation method is not only unable to estimate the coefficients of our time-invariant ground slope variables that are critical considerations for land-use planning, fixed effects 
method also produces less efficient estimates than random effects method. ${ }^{35}$ We note that in Table 3-13 in the appendix, we show the results of another set of regressions where we replaced the vulnerability variables in each of the five specifications with the interacted ground slope variables with the vulnerability variables. Likewise, the Hausman tests indicate the use of random effects method for all specifications, including Specification 5.

Table 3-4. Random Effects vs Fixed Effects Using Time-Varying Explanatory Variables Only

\begin{tabular}{|c|c|c|c|c|c|c|c|c|c|c|}
\hline & \multicolumn{2}{|c|}{ Specification 1} & \multicolumn{2}{|c|}{ Specification 2} & \multicolumn{2}{|c|}{$\underline{\text { Specification } 3}$} & \multicolumn{2}{|c|}{ Specification 4} & \multicolumn{2}{|c|}{ Specification 5} \\
\hline & $\begin{array}{l}\text { RE } \\
(1) \\
\end{array}$ & $\begin{array}{c}\mathrm{FE} \\
(2) \\
\end{array}$ & $\begin{array}{l}\text { RE } \\
\text { (3) } \\
\end{array}$ & $\begin{array}{l}\text { FE } \\
(4) \\
\end{array}$ & $\begin{array}{l}\text { RE } \\
(5) \\
\end{array}$ & $\begin{array}{l}\text { FE } \\
(6) \\
\end{array}$ & $\begin{array}{l}\text { RE } \\
(7) \\
\end{array}$ & $\begin{array}{l}\mathrm{FE} \\
(8) \\
\end{array}$ & $\begin{array}{l}\text { RE } \\
(9) \\
\end{array}$ & $\begin{array}{c}\mathrm{FE} \\
(10) \\
\end{array}$ \\
\hline Rainfall & $\begin{array}{l}0.100^{* * *} \\
(3.50)\end{array}$ & $\begin{array}{l}0.104^{* * *} \\
(3.48)\end{array}$ & $\begin{array}{l}0.103^{* * *} \\
(3.56)\end{array}$ & $\begin{array}{l}0.107^{* * *} \\
(3.58)\end{array}$ & $\begin{array}{l}0.0991^{* * *} \\
(3.42)\end{array}$ & $\begin{array}{l}{ }^{k} 0.105^{* * *} \\
(3.50)\end{array}$ & $\begin{array}{l}0.105^{* * *} \\
(3.62)\end{array}$ & $\begin{array}{l}0.105^{* * *} \\
(3.55)\end{array}$ & $\begin{array}{l}0.106^{* * *} \\
(3.79)\end{array}$ & $\begin{array}{l}0.107^{* * *} \\
(3.56)\end{array}$ \\
\hline Affected persons & $\begin{array}{l}0.0829 * * * \\
(10.54)\end{array}$ & $\begin{array}{l}0.0839 * * * \\
(10.26)\end{array}$ & $\begin{array}{l}0.0821^{* * *} \\
(10.60)\end{array}$ & $\begin{array}{l}{ }^{k} 0.0831^{* * *} \\
(10.26)\end{array}$ & $\begin{array}{l}{ }^{*} 0.0827 * * * \\
(10.45)\end{array}$ & $\begin{array}{l}{ }^{k} 0.0838^{* * *} \\
(10.43)\end{array}$ & $\begin{array}{l}0.0820^{* * *} \\
(10.52)\end{array}$ & $\begin{array}{l}{ }^{k} 0.0842^{* * *} \\
(10.37)\end{array}$ & $\begin{array}{l}{ }^{*} 0.0809 * * * \\
(10.51)\end{array}$ & $\begin{array}{l}{ }^{*} 0.0833^{* * *} \\
(10.35)\end{array}$ \\
\hline Income per capita & $\begin{array}{l}-0.572^{*} \\
(-2.30)\end{array}$ & $\begin{array}{l}-0.610^{*} \\
(-2.26)\end{array}$ & & & & & & & & \\
\hline Poverty incidence & & & $\begin{array}{l}0.348^{* *} \\
(2.99)\end{array}$ & $\begin{array}{l}0.301 \\
(1.23)\end{array}$ & & & & & & \\
\hline Life expectancy & & & & & $\begin{array}{l}-5.912^{* *} \\
(-3.18)\end{array}$ & $\begin{array}{l}-0.860 \\
(-0.25)\end{array}$ & & & & \\
\hline Mean years of schooling & & & & & $\begin{array}{l}0.568 \\
(0.39)\end{array}$ & $\begin{array}{l}-2.779 \\
(-1.88)\end{array}$ & & & & \\
\hline Built-up density & & & & & & & $\begin{array}{l}0.0671 \\
(0.76)\end{array}$ & $\begin{array}{l}-2.167 \\
(-1.90)\end{array}$ & & \\
\hline Population density & & & & & & & $\begin{array}{l}-0.679^{* * *} \\
(-8.55)\end{array}$ & $\begin{array}{l}0 \\
\text { (.) }\end{array}$ & & \\
\hline$\%$ local tax revenues to total income & & & & & & & & & $\begin{array}{l}-0.443^{* * *} \\
(-5.46)\end{array}$ & $\begin{array}{l}-0.0107 \\
(-0.07)\end{array}$ \\
\hline _cons & $\begin{array}{l}-2.325 \\
(-1.33)\end{array}$ & $\begin{array}{l}-2.111 \\
(-1.06)\end{array}$ & $\begin{array}{l}-7.577^{* * *} \\
(-17.34)\end{array}$ & $\begin{array}{l}-7.475^{* * *} \\
(-9.90)\end{array}$ & $\begin{array}{l}17.22^{* *} \\
(2.64)\end{array}$ & $\begin{array}{l}3.520 \\
(0.26)\end{array}$ & $\begin{array}{l}-3.322^{* *} \\
(-2.88)\end{array}$ & $\begin{array}{l}13.10 \\
(1.26)\end{array}$ & $\begin{array}{l}-5.590^{* * *} \\
(-26.25)\end{array}$ & $\begin{array}{l}-6.503^{* * *} \\
(-19.88)\end{array}$ \\
\hline $\mathrm{N}$ & 722 & 722 & 722 & 722 & 722 & 722 & 722 & 722 & 722 & 722 \\
\hline R-sq & 0.1413 & 0.209 & 0.1777 & 0.206 & 0.2605 & 0.206 & 0.3767 & 0.209 & 0.3389 & 0.204 \\
\hline $\begin{array}{l}\text { Prob >chi } 2 \text { of } \\
\text { Hausman Test }\end{array}$ & & $\begin{array}{l}602 \\
\text { e RE } \\
\end{array}$ & & $\begin{array}{l}7617 \\
\text { e RE }\end{array}$ & & $\begin{array}{l}558 \\
\text { e RE } \\
\end{array}$ & & $\begin{array}{l}1458 \\
\text { e RE }\end{array}$ & $\begin{array}{l}0.0 \\
\text { Use }\end{array}$ & $\begin{array}{l}184 \\
\text { e FE }\end{array}$ \\
\hline
\end{tabular}

Having established the appropriateness of using random effects over fixed effects method, and the robustness of our explanatory variables in influencing fatalities, we proceed to establishing the robustness of the estimated coefficients. For this purpose, we perform a Monte Carlo

35 The Hausman test results indicate the use of fixed effects in estimating Specification 5. However, considering the importance and robustness of ground slope variables in determining fatalities as shown in Tables 3-2 and 33 , we decide to likewise estimate the fifth specification using random effects method so that we can purposely control for the ground slope variables. 
Simulation procedure. We generate 10,000 independent datasets or samples, each with 500 randomly drawn observations without replacement ${ }^{36}$ from the 722 observations in our original dataset. This is equivalent to randomly dropping 222 observations from the original dataset. For each of the 10,000 samples, we re-estimate the various specifications using the random effects method, except for Specification 4 where we use pooled OLS. We then get the average of each coefficient estimated over 10,000 samples and compare the average with the corresponding coefficient estimated from using our original dataset.

Table 3-5 shows our Monte Carlo simulation results (labelled as MCS) juxtaposed with the estimation results using our original dataset for each of the five specifications. All the variables retained their sign and significance, except for the level of education. It can be seen from Column 5 that in the Monte Carlo simulation the years of schooling is not significant, though the sign is the same as that in Column 6, which is estimated using the original dataset. On the whole, the average coefficients of the simulations are comparable to those estimated using the original dataset. We note that among the socioeconomic variables, poverty incidence has the lowest difference in estimated coefficients between estimation using MCS and using the original dataset.

In general, the preceding results, including the Monte Carlo simulations, reveal that the relationship between fatalities and explanatory variables is robust, even with the inclusion or exclusion of selected variables, and with sampling.

${ }^{36}$ Each observation from the original dataset can be chosen once or not at all in a newly generated sample. 
Table 3-5. Monte Carlo Simulation

\begin{tabular}{|c|c|c|c|c|c|c|c|c|c|c|}
\hline & \multicolumn{2}{|c|}{ Specification 1} & \multicolumn{2}{|c|}{ Specification 2} & \multicolumn{2}{|c|}{ Specification 3} & \multicolumn{2}{|c|}{ Specification 4} & \multicolumn{2}{|c|}{ Specification 5} \\
\hline & $\begin{array}{l}\text { MCS } \\
\text { (1) }\end{array}$ & $\begin{array}{c}\text { Original } \\
\text { Dataset } \\
(2)\end{array}$ & $\begin{array}{l}\text { MCS } \\
\text { (3) }\end{array}$ & $\begin{array}{c}\text { Original } \\
\text { Dataset } \\
\text { (4) }\end{array}$ & $\begin{array}{l}\text { MCS } \\
(5)\end{array}$ & $\begin{array}{c}\text { Original } \\
\text { Dataset } \\
(6)\end{array}$ & $\begin{array}{l}\text { MCS } \\
(7)\end{array}$ & $\begin{array}{c}\text { Original } \\
\text { Dataset } \\
(8)\end{array}$ & $\begin{array}{l}\text { MCS } \\
\text { (9) }\end{array}$ & $\begin{array}{c}\text { Original } \\
\text { Dataset } \\
(10)\end{array}$ \\
\hline Rainfall & $\begin{array}{l}0.0879 * \\
(2.30)\end{array}$ & $\begin{array}{l}0.0911^{* * *} \\
(3.33)\end{array}$ & $\begin{array}{l}0.0955^{*} \\
(2.51)\end{array}$ & $\begin{array}{l}0.0952^{* * *} \\
(3.45)\end{array}$ & $\begin{array}{l}0.0818^{*} \\
(2.21)\end{array}$ & $\begin{array}{l}0.0893^{* * *} \\
(3.30)\end{array}$ & $\begin{array}{l}0.0906^{* *} \\
(3.23)\end{array}$ & $\begin{array}{l}0.0962^{* * *} \\
(4.14)\end{array}$ & $\begin{array}{l}\text { * } 0.0948^{* *} \\
(2.76)\end{array}$ & $\begin{array}{l}0.0946^{* * *} \\
(3.65)\end{array}$ \\
\hline Affected persons & $\begin{array}{l}0.0855^{* * *} \\
(10.06)\end{array}$ & $\begin{array}{l}0.0821 * * * \\
(10.46)\end{array}$ & $\begin{array}{l}0.0828^{* * *} \\
(10.31)\end{array}$ & $\begin{array}{l}0.0812^{* * *} \\
(10.75)\end{array}$ & $\begin{array}{l}0.0865^{* * *} \\
(9.90)\end{array}$ & $\begin{array}{l}0.0829 * * * \\
(10.60)\end{array}$ & $\begin{array}{l}0.0793^{* * *} \\
(9.34)\end{array}$ & $\begin{array}{l}0.0781^{* * *} \\
(11.05)\end{array}$ & $\begin{array}{l}\text { * } 0.0830 * * * \\
(9.91)\end{array}$ & $\begin{array}{l}0.0798^{* * *} \\
(10.48)\end{array}$ \\
\hline Flat-sloped land & $\begin{array}{l}-0.848 * * * \\
(-8.14)\end{array}$ & $\begin{array}{l}-0.887^{* * *} \\
(-9.72)\end{array}$ & $\begin{array}{l}-0.778^{* * *} \\
(-7.91)\end{array}$ & $\begin{array}{l}-0.818^{* * *} \\
(-9.22)\end{array}$ & $\begin{array}{l}-0.755^{* * *} \\
(-8.18)\end{array}$ & $\begin{array}{l}-0.831 * * * \\
(-10.24)\end{array}$ & $\begin{array}{l}-0.465^{* * *} \\
(-9.51)\end{array}$ & $\begin{array}{l}-0.518^{* * *} \\
(-11.50)\end{array}$ & $\begin{array}{l}-0.608 * * * \\
(-6.23)\end{array}$ & $\begin{array}{l}-0.674 * * * \\
(-7.83)\end{array}$ \\
\hline Steeply-sloped land & $\begin{array}{l}0.244^{* *} \\
(3.15)\end{array}$ & $\begin{array}{l}0.290^{* * *} \\
(3.96)\end{array}$ & $\begin{array}{l}0.153 \\
(1.78)\end{array}$ & $\begin{array}{l}0.194^{*} \\
(2.39)\end{array}$ & $\begin{array}{l}0.252^{* *} \\
(2.86)\end{array}$ & $\begin{array}{l}0.306^{* * *} \\
(4.03)\end{array}$ & $\begin{array}{l}-0.224^{* * *} \\
(-3.67)\end{array}$ & $\begin{array}{l}-0.195^{* * *} \\
(-3.46)\end{array}$ & $\begin{array}{l}0.187^{*} \\
(2.14)\end{array}$ & $\begin{array}{l}0.245^{* *} \\
(3.16)\end{array}$ \\
\hline Income per capita & $\begin{array}{l}-1.004^{* * *} \\
(-5.53)\end{array}$ & $\begin{array}{l}-0.935 * * * \\
(-5.55)\end{array}$ & & & & & & & & \\
\hline Poverty incidence & & & $\begin{array}{l}0.470 * * * \\
(4.50)\end{array}$ & $\begin{array}{l}0.450 * * * \\
(4.72)\end{array}$ & & & & & & \\
\hline Life expectancy & & & & & $\begin{array}{l}-4.994^{* * *} \\
(-4.08)\end{array}$ & $\begin{array}{l}-3.892^{* * *} \\
(-3.67)\end{array}$ & & & & \\
\hline Mean years of schooling & & & & & $\begin{array}{l}-1.531 \\
(-1.56)\end{array}$ & $\begin{array}{l}-2.018^{*} \\
(-2.35)\end{array}$ & & & & \\
\hline Built-up density & & & & & & & $\begin{array}{l}0.151^{* *} \\
(3.21)\end{array}$ & $\begin{array}{l}0.127^{* *} \\
(3.11)\end{array}$ & & \\
\hline Population density & & & & & & & $\begin{array}{l}-0.732^{* * *} \\
(-12.81)\end{array}$ & $\begin{array}{l}-0.733^{* * *} \\
(-15.19)\end{array}$ & & \\
\hline$\%$ local tax revenues to total income & & & & & & & & & $\begin{array}{l}-0.421 * * * \\
(-5.80)\end{array}$ & $\begin{array}{l}-0.384 * * * \\
(-6.24)\end{array}$ \\
\hline _cons & $\begin{array}{l}5.075^{* * *} \\
(3.30)\end{array}$ & $\begin{array}{l}4.487^{* *} \\
(3.26)\end{array}$ & $\begin{array}{l}-3.525^{* * *} \\
(-4.16)\end{array}$ & $\begin{array}{l}-3.493 * * * \\
(-4.65)\end{array}$ & $\begin{array}{l}21.78^{* * *} \\
(4.19)\end{array}$ & $\begin{array}{l}18.33^{* * *} \\
(4.77)\end{array}$ & $\begin{array}{l}1.210 \\
(1.52)\end{array}$ & $\begin{array}{l}1.563^{*} \\
(2.43)\end{array}$ & $\begin{array}{l}-2.623 * * \\
(-3.14)\end{array}$ & $\begin{array}{l}-2.669 * * * \\
(-3.73)\end{array}$ \\
\hline Observations & 500 & 722 & 500 & 722 & 500 & 722 & 500 & 722 & 500 & 722 \\
\hline Monte Carlo Simulations & 10,000 & & 10,000 & & 10,000 & & 10,000 & & 10,000 & \\
\hline R-sq & & 0.4579 & & 0.4570 & & 0.4827 & & 0.563 & & 0.4896 \\
\hline
\end{tabular}

Finally, we run separate regressions using standardized variables to determine which among the significant explanatory variables have a greater influence on fatalities. The absolute value of coefficients of the standardized variables indicate the relative strength of each explanatory variable in determining the fatalities. It can be seen from Table 3-6 that rainfall volume has the lowest coefficient in Specifications 1, 2, 3, and 5; and the second lowest in Specification 4.

For instance, in Specification 2 where we use poverty incidence as the proxy for vulnerability, we find that a 1 standard deviation increase in poverty incidence results in a 0.272 standard deviation increase in the proportion of fatalities, whereas a 1 standard deviation increase in the rainfall volume leads to a lower increase in the proportion of fatalities at 0.097 standard 
deviation. That is, the effect of poverty incidence on fatalities is almost three times that of rainfall volume. Similarly, a 1 standard deviation increase in the proportion of affected persons, which is our proxy for population exposure, leads to a 0.297 standard deviation increase in the proportion of fatalities, likewise higher than the effect of rainfall volume. Similarly, ground slope categories have a much larger average effect than rainfall volume.

\section{Table 3-6. Relative Importance of the Explanatory Variables}

\begin{tabular}{|c|c|c|c|c|c|}
\hline & $\frac{\text { Specification 1 }}{(1)}$ & $\frac{\text { Specification 2 }}{(2)}$ & $\frac{\text { Specification } \mathbf{3}}{(3)}$ & $\frac{\text { Specification } 4}{(4)}$ & $\frac{\text { Specification } 5}{(5)}$ \\
\hline Rainfall & $\begin{array}{l}0.0926^{* * *} \\
(3.33)\end{array}$ & $\begin{array}{l}0.0968^{* * *} \\
(3.45)\end{array}$ & $\begin{array}{l}0.0908^{* * *} \\
(3.30)\end{array}$ & $\begin{array}{l}0.0977^{* * *} \\
(3.95)\end{array}$ & $\begin{array}{l}0.0961^{* * *} \\
(3.65)\end{array}$ \\
\hline Affected population & $\begin{array}{l}0.301^{* * *} \\
(10.46)\end{array}$ & $\begin{array}{l}0.297 * * * \\
(10.75)\end{array}$ & $\begin{array}{l}0.304^{* * *} \\
(10.60)\end{array}$ & $\begin{array}{l}0.286 * * * \\
(10.17)\end{array}$ & $\begin{array}{l}0.292^{* * *} \\
(10.48)\end{array}$ \\
\hline Flat-sloped land & $\begin{array}{l}-0.629 * * * \\
(-9.72)\end{array}$ & $\begin{array}{l}-0.580 * * * \\
(-9.22)\end{array}$ & $\begin{array}{l}-0.590 * * * \\
(-10.24)\end{array}$ & $\begin{array}{l}-0.368^{* * *} \\
(-12.36)\end{array}$ & $\begin{array}{l}-0.478 * * * \\
(-7.83)\end{array}$ \\
\hline Steeply-sloped land & $\begin{array}{l}0.193^{* * *} \\
(3.96)\end{array}$ & $\begin{array}{l}0.129 * \\
(2.39)\end{array}$ & $\begin{array}{l}0.203^{* * *} \\
(4.03)\end{array}$ & $\begin{array}{l}-0.130 * * * \\
(-3.79)\end{array}$ & $\begin{array}{l}0.163^{* *} \\
(3.16)\end{array}$ \\
\hline Income per capita & $\begin{array}{l}-0.234^{* * *} \\
(-5.55)\end{array}$ & & & & \\
\hline Poverty incidence & & $\begin{array}{l}0.272 * * * \\
(4.72)\end{array}$ & & & \\
\hline Life expectancy & & & $\begin{array}{l}-0.180 * * * \\
(-3.67)\end{array}$ & & \\
\hline Mean years of schooling & & & $\begin{array}{l}-0.116^{*} \\
(-2.35)\end{array}$ & & \\
\hline Built-up density & & & & $\begin{array}{l}0.0748^{* *} \\
(2.64)\end{array}$ & \\
\hline Population density & & & & $\begin{array}{l}-0.556 * * * \\
(-16.53)\end{array}$ & \\
\hline$\%$ local tax revenue to total income & & & & & $\begin{array}{l}-0.291^{* * *} \\
(-6.24)\end{array}$ \\
\hline _cons & $\begin{array}{l}-0.00292 \\
(-0.06)\end{array}$ & $\begin{array}{l}-0.00192 \\
(-0.04)\end{array}$ & $\begin{array}{l}-0.00542 \\
(-0.12)\end{array}$ & $\begin{array}{l}2.92 e-09 \\
(0.00)\end{array}$ & $\begin{array}{l}0.00925 \\
(0.21)\end{array}$ \\
\hline $\mathrm{N}$ & 722 & 722 & 722 & 722 & 722 \\
\hline R-sq & 0.4579 & 0.4570 & 0.4827 & 0.563 & 0.4896 \\
\hline
\end{tabular}

Overall, across the five model specifications, the results indicate that in the context of the Philippine provinces, fatalities are not mainly results of the destructive characteristics of tropical cyclones, but more so of the exposure and vulnerability. Such results confirm, we believe for the first time, a 
wealth of related qualitative studies that have argued that people's vulnerability constitutes the main driver of disasters (e.g. Watts and Bohle, 1993; Gaillard, 2011; Lewis, 1999; Bankoff et al., 2004; Wisner et al., 2004).

\subsubsection{Estimated Fatalities per Province}

We use our model to gain an understanding on how fatalities vary across provinces, and insights on the main drivers of fatalities on a per-province basis. ${ }^{37}$ In Figure 3-6, we present the model's predicted fatalities using the mean of actual values of all the significant variables we considered, covering the period 2005-2010. ${ }^{38}$ The inset map shows the mean observed fatalities per province across all tropical cyclones and years. The predicted values are estimated using the random effects method on the final form of Specification 2 where we use poverty incidence as the proxy for vulnerability (shown in Column 4 of Table 3-3). ${ }^{39}$ The mean of observed fatalities is 3.81 per million population, while that of the predicted fatalities is 3.09 per million population. ${ }^{40}$

In general, Figure 3-6 shows that predicted disaster fatalities associated with tropical cyclones vary across provinces. We note that even though there are more and stronger tropical cyclones that hit the provinces in the north, it can be gleaned that there are also provinces in the south with relatively high fatalities. This indicates that indeed socioeconomic factors are important determinants of fatalities. As noted earlier, the provinces with the worst socioeconomic indicators (low per capita income, high poverty

\footnotetext{
${ }^{37}$ Our model may not be appropriate to predict future fatalities, particularly as our dataset is a short panel only, and predicting the future frequency, intensity and trajectories of cyclones is a fraught endeavour.

${ }^{38}$ Nine provinces have a difference between observed and predicted values of more than 2 fatalities per million population

${ }^{39}$ We choose Specification 2 in estimating the predicted values of fatalities given that this specification has lowest differences in estimated coefficients between the Monte Carlo Simulation and the original dataset thereby providing us the relatively greater confidence on the magnitude of the effects of each explanatory variable.

${ }^{40}$ The test of means indicates that the two means not are significantly different.
} 
incidence, etc) are in the southern part of the Philippines, while the better off provinces are those located in the north.

Still using the final form of Specification 2, we also estimate scenarios where we use one at a time in separate regressions the observed minimum and maximum values of the rainfall volume (i.e. variable for hazard strength), proportion of affected persons (i.e. proxy indicator for exposed population), and poverty incidence (i.e. variable for vulnerability) across ijt. Scenarios using these extreme values are not the most plausible assumptions, and therefore the corresponding estimates are not the most likely scenario to occur. However, these scenarios allow us to better appreciate which of the variables have greater influence on the resulting fatalities from tropical cyclones for each province. A practical usefulness of this exercise are the insights on general focus and design of interventions on a per province basis. That is, whether in a particular province these interventions should be focused more on addressing either hazard, exposure or vulnerability, or a combination of these disaster risk components.

In Figure 3-7, we present the results of the six scenarios using the extreme values of the explanatory variables. We use as base case scenario the modelpredicted values presented in Figure 3-6. In Scenario 1, we set the rainfall volume for each province equal to the lowest recorded across all ijt. Having set the rainfall volume uniform across provinces and to the minimum, the intuition behind the results is that the fatalities are due more to a combination of the affected persons, ground slope, poverty incidence, than to rainfall volume. Under this scenario, the mean of the estimates across provinces is 2.14 fatalities per million population.

In Scenario 2, we assign to each province the minimum observed value of the proportion of affected persons. The results under this scenario indicate that the relatively higher fatality rates are due mainly to a combination of 
poverty incidence, ground slope, and rainfall volume, and only to a relatively lesser extent on exposure. This scenario brings the fatalities from 3.09 per million population in the base case scenario to only 1.65. Thus, a changing in the exposure to tropical cyclones almost halves the number of resulting fatalities.

\section{Figure 3-6. Predicted Fatalities}

(Fatalities per million population per province)

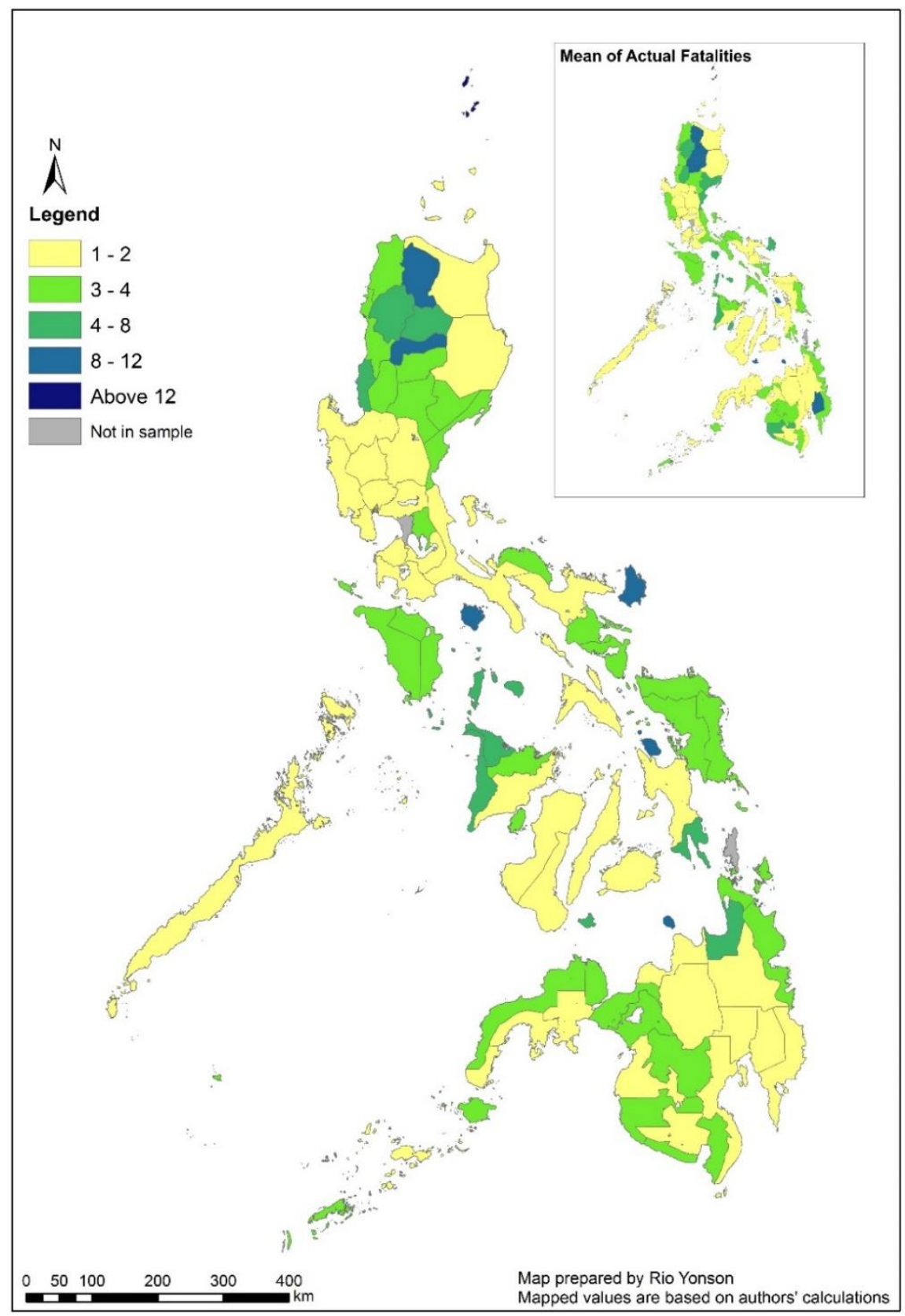


Figure 3-7. Predicted Fatalities by Scenario
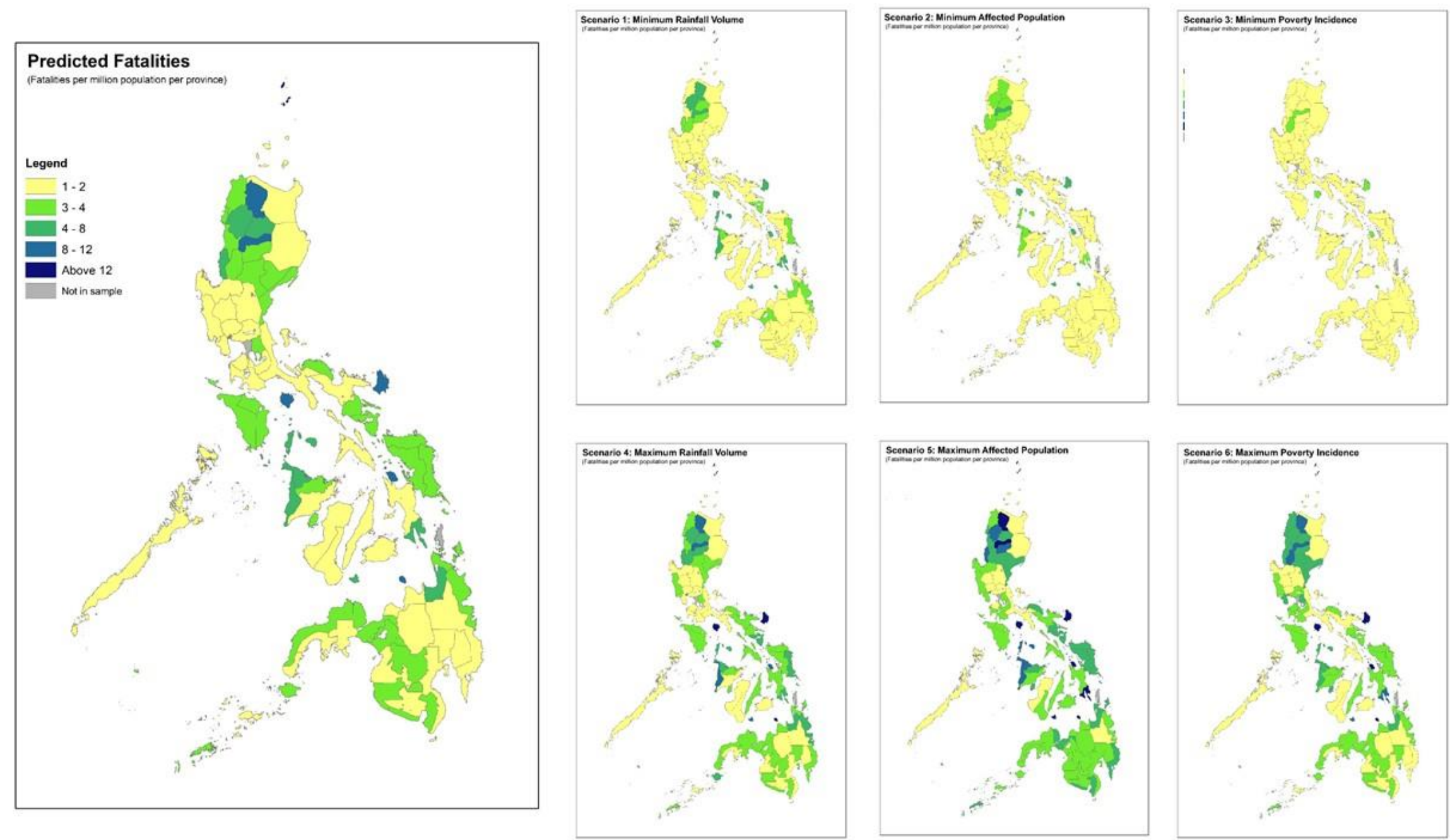
Similarly, for the third scenario, we assign minimum poverty incidence recorded across the provinces and years covered. Among these three scenarios, it can be seen from the maps that it is the third scenario where the estimated fatalities are lowest, and with an overall mean that is substantially lower than that in the base case scenario. Under the third scenario, the average fatalities is only 0.88 persons per million population, compared to 3.09 under the base case scenario.

The important influence of poverty on fatalities in the context of the Philippine provinces is more evident when we compare the results of scenarios using the minimum value of poverty incidence (Scenario 3), on one hand, and the maximum value of poverty incidence (Scenario 6), on the other hand. As can be gleaned, the predicted fatalities vary substantially as the level of poverty incidence is adjusted, pointing to the important influence of human vulnerability on tropical cyclone fatalities. Scenarios 2 and 5 likewise show that the importance of exposure is more than that of hazard strength. ${ }^{41}$ Together, these results mean that despite the Philippines' geographic and topographic setting - one that makes it prone to tropical cyclone hazards - grave impacts on people can be minimized through measures to reduce vulnerability and exposure.

We summarize the overall results of this exercise in Figure 3-8 below. For purposes of comparison, the figure likewise shows the results for scenarios using mean values of rainfall volume, the proportion of affected persons, and poverty incidence. The values going from left to right that correspond to each variable indicate the average estimated fatalities per million population across provinces, estimated using the minimum, mean, and maximum values, respectively, of each variable across provinces and years.

\footnotetext{
${ }^{41}$ Such results confirm several qualitative studies that have argued that people's vulnerability constitutes the main driver of disasters (e.g. Watts and Bohle (1993), Lewis (1999), Bankoff (2004), and Wisner et al. (2004).
} 
As can be seen, changing the values of proportion of affected persons (i.e. our proxy for population exposure), poverty incidence (i.e. the proxy for poverty), alter the resulting fatalities much more than rainfall volume (i.e. the proxy for hazard strength).

Figure 3-8. Summary of Predicted Fatalities by Scenario Using minimum, mean and maximum values of each variable

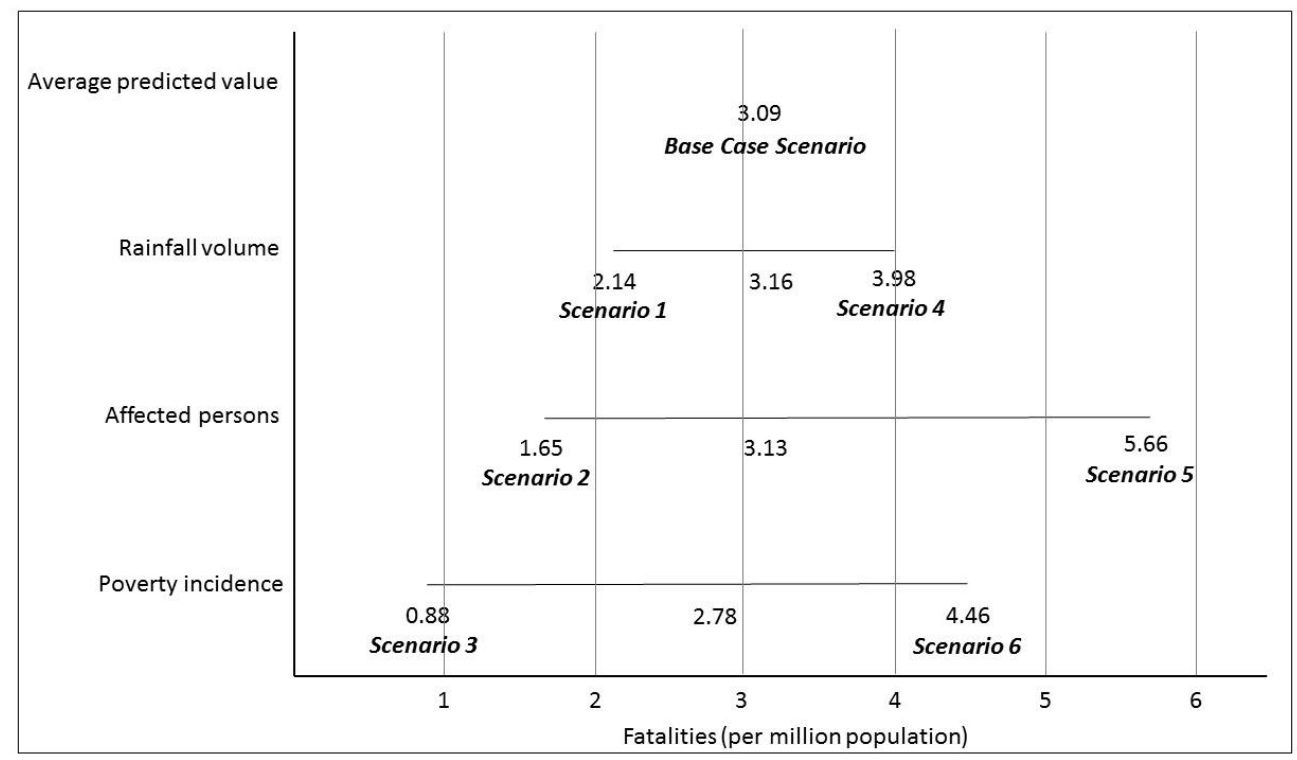

\subsection{General Conclusions, Policy Implications and Next Steps}

Our research is the first subnational empirical work that combines the use of panel data econometric estimation methods with GIS tools to systematically assess the influence of socioeconomic vulnerability, exposure, and hazard characteristics on the resulting fatalities from tropical cyclones in a developing country. Our subnational scale of assessment enables us to generate results that have direct usefulness into the integration of DRRM into the various stages of the provincial planning cycle.

The estimated fatalities per province may serve as baseline values against which succeeding estimates are compared, and as a benchmark for use in the monitoring and evaluation of outcomes resulting from recentlyimplemented landmark DRRM and CCA laws and practices. As we use 
historical data, our results complement and add value to the existing subnational probabilistic disaster risk assessment methodology used in the Philippines and elsewhere. Likewise, our findings on the relative influence of the various factors affecting fatalities provide broad yet systematically derived indications of a number of interventions that may be worthwhile to integrate into an investment programme for DRRM.

We find strong quantitative evidence of the linkage between several aspects of development and disaster-related fatalities, even in a country where the degree of tropical cyclone exposure is high. Broadly, we find that in the case of Philippine provinces, tropical cyclone-induced fatalities are influenced more by socioeconomic conditions and population exposure, than by the hazard itself. For instance, we find that the effect of poverty incidence on fatalities is almost three times that of rainfall volume.

Our results reveal that the level of economic development, as proxied by income per capita, is negatively associated with fatalities. This indicates that adequacy of income allows people to be able to afford to secure themselves from harm. In contrast, poverty, which we find to be positively associated with fatalities, is a manifestation of deprivation of people from building safe dwellings and from acquiring access to settle in hazard-free areas. Poverty also forces people to forgo investments in human capital, particularly health and education, which we likewise found to be critical in building their capacity to survive cyclones.

Good local governance is associated with fewer disaster-related fatalities. Increased effectiveness in generating local revenues means increased ability to provide public goods and services, including the provision of services for public safety (such as early warning systems), as well as access to universal public basic education, and expanded and better quality public health services, particularly among the poor. 
The positive and statistically significant coefficient for built-up density on disaster fatalities indicate that amidst unplanned and rapid urbanization, vulnerabilities are generated and exposure to hazards increased. This finding points to the need for better land use planning that integrates DRRM, along with intensified enforcement of these plans and related laws and systems, such as zoning ordinances, water code, building code, and forestry code, as well as weather forecasting and monitoring, and early warning systems. We note, however, that an additional proxy indicator for urbanization such as floor area per person may provide more robust results and insights for policy.

Overall, our results provide support for national and subnational policy planning through the identification of priority regions and provinces, and critical DRRM interventions within a province. Robust indices, such as the one developed here, equip policy makers with tangible evidence to guide investments and actions. This aids in the deliberate integration of the various components of disaster risk, particularly exposure and vulnerability, in the development process. After all, apart from our findings that the exposure and vulnerability components are found to be relatively more important, they are also the components of disaster risk that can be influenced by policy.

We note some caveats to our findings. Econometric studies alone can hardly capture unequal power relations amongst individuals and the distant (in time and space) causes of vulnerability that facilitate or rather hinder access to resources and means of protection (Wisner et al., 2004). Even studies at the subnational (provincial) scale may mask local inequalities and/or lead to further marginalisation of small vulnerable minorities in provinces and regions deemed less at risk when taken as a whole. 
In the future, we plan to further examine the issues raised here, as additional relevant datasets become available for our use. We also note that due to data limitations, including the absence of maps on areas prone to other hazards induced by tropical cyclones, we are unable to further detail our assessment according to each of these associated hazards. In addition, we are not able to quantitatively explore the impact of environmental degradation on disaster fatalities. Among other data on the environment, vector maps on the state of environmental quality or degradation (i.e. forest cover, etc.) will allow as to undertake such an assessment, using both spatial and statistical analysis tools. We likewise endeavour to cover these as we continue to pursue what we view as an important research agenda. 


\section{Appendices}

Table 3-7. Number of Tropical Cyclones and Impacts on Population and Assets, 1980-2013

\begin{tabular}{|c|c|c|c|c|c|}
\hline Year & $\begin{array}{l}\text { Number of Tropical } \\
\text { Cyclones that Passed } \\
\text { the Philippine Area of } \\
\text { Responsibility* } \\
\text { (1) }\end{array}$ & $\begin{array}{l}\text { Number of } \\
\text { Destructive } \\
\text { Tropical } \\
\text { Cyclones** } \\
\text { (2) }\end{array}$ & $\begin{array}{l}\text { Number of } \\
\text { Fatalities } \\
\text { (3) }\end{array}$ & $\begin{array}{l}\text { Number of } \\
\text { Affected } \\
\text { Persons } \\
\text { (4) }\end{array}$ & $\begin{array}{l}\text { Total Cost of } \\
\text { Damages } \\
\text { (In Million } \\
\text { USD)*** } \\
\text { (5) }\end{array}$ \\
\hline 1980 & 23 & 6 & 143 & $1,666,498$ & 196 \\
\hline 1981 & 23 & 7 & 696 & $1,750,142$ & 161 \\
\hline 1982 & 21 & 8 & 389 & $2,149,167$ & 193 \\
\hline 1983 & 23 & 4 & 126 & 747,155 & 49 \\
\hline 1984 & 20 & 4 & 2,108 & $4,105,133$ & 362 \\
\hline 1985 & 17 & 4 & 211 & $1,643,142$ & 136 \\
\hline 1986 & 21 & 6 & 171 & $1,524,301$ & 92 \\
\hline 1987 & 16 & 6 & 1,020 & $3,691,555$ & 199 \\
\hline 1988 & 20 & 5 & 429 & $6,081,572$ & 412 \\
\hline 1989 & 19 & 7 & 382 & $2,582,822$ & 207 \\
\hline 1990 & 20 & 10 & 706 & $6,092,959$ & 524 \\
\hline 1991 & 19 & 6 & 5,414 & $1,815,989$ & 292 \\
\hline 1992 & 16 & 7 & 118 & $1,755,811$ & 199 \\
\hline 1993 & 32 & 14 & 827 & $7,363,591$ & 739 \\
\hline 1994 & 25 & 12 & 242 & $3,054,232$ & 121 \\
\hline 1995 & 16 & 11 & 1,356 & $7,683,526$ & 590 \\
\hline 1996 & 17 & 10 & 124 & $1,255,289$ & 106 \\
\hline 1997 & 14 & 6 & 95 & $2,399,435$ & 35 \\
\hline 1998 & 11 & 4 & 490 & $7,322,133$ & 563 \\
\hline 1999 & 16 & 9 & 103 & $1,793,742$ & 66 \\
\hline 2000 & 18 & 9 & 345 & $7,284,946$ & 169 \\
\hline 2001 & 17 & 10 & 440 & $3,769,262$ & 135 \\
\hline 2002 & 13 & 5 & 169 & $3,546,469$ & 16 \\
\hline 2003 & 25 & 10 & 139 & $3,362,991$ & 77 \\
\hline 2004 & 25 & 10 & 1,232 & $6,966,136$ & 237 \\
\hline 2005 & 17 & 5 & 54 & $1,019,646$ & 46 \\
\hline 2006 & 20 & 10 & 1,165 & $11,253,211$ & 394 \\
\hline 2007 & 13 & 8 & 124 & $2,998,885$ & 60 \\
\hline 2008 & 21 & 9 & 673 & $7,009,725$ & 452 \\
\hline 2009 & 22 & 16 & 1,140 & $12,250,050$ & 923 \\
\hline 2010 & 11 & 10 & 136 & $2,596,587$ & 275 \\
\hline 2011 & 19 & 19 & 1,557 & $9,884,577$ & 628 \\
\hline 2012 & 17 & 16 & 1,386 & $8,006,126$ & 1064 \\
\hline 2013 & 25 & 11 & 6,389 & $21,381,374$ & 2354 \\
\hline Total & 652 & 294 & 30,099 & $167,808,179$ & 12,072 \\
\hline Average & 19 & $\begin{array}{c}9 \\
\text { (47\% of } \\
\text { annual } \\
\text { average) } \\
\end{array}$ & 885 & $4,935,535$ & 355 \\
\hline \multicolumn{3}{|c|}{ Average per Destructive Tropical Cyclone } & 102 & 570,776 & 41 \\
\hline
\end{tabular}

Sources: Number of Tropical Cyclones that Passed the Philippine Area of Responsibility (PAGASA, 2014). Number of Destructive Tropical Cyclones, Impacts of Tropical cyclones (NDRRMC, 2014). Disaster impacts (i.e. number of fatalities and affected persons) include those resulting from tropical cyclone-induced flooding, landslide, and storm surge.

*The Philippine Area of Responsibility (PAR) is the area designated for PAGASA to monitor and issue bulletins on the formation and occurrence of tropical cyclone.

**Destructive tropical cyclones are those that had adverse impacts on people and assets.

*** Annual average exchange rates used to convert cost in PhP to USD taken from Bangko Sentral ng Pilipinas (Central Bank of the Philippines) website (BSP, 2014). 
Table 3-8. Variable Sources and Description

\begin{tabular}{|c|c|c|}
\hline $\begin{array}{l}\text { Variable } \\
\text { Name }\end{array}$ & $\begin{array}{c}\text { Description of the Variable } \\
\text { Method of } \\
\text { Derivation/Computation }\end{array}$ & Sources \\
\hline Fatality & $\begin{array}{l}\text { Number of fatalities for every } \\
1,000,000 \text { population }\end{array}$ & $\begin{array}{l}\text { National Disaster Risk Reduction } \\
\text { and Management Council } \\
\text { (NDRRMC)/ Office of Civil } \\
\text { Defense (OCD) }\end{array}$ \\
\hline $\begin{array}{l}\text { Affected } \\
\text { persons }\end{array}$ & $\begin{array}{l}\text { Number of affected persons for } \\
\text { every } 1,000,000 \text { population }\end{array}$ & NDRRMC/OCD \\
\hline Rainfall & $\begin{array}{l}\text { Amount of maximum 24-hour } \\
\text { rainfall volume per tropical cyclone } \\
\text { experienced by each the province. }\end{array}$ & $\begin{array}{lr}\text { Philippine } & \text { Atmospheric, } \\
\text { Geophysical, } & \text { Astronomical } \\
\text { Services } & \text { Administration } \\
\text { (PAGASA) } & \end{array}$ \\
\hline Wind & $\begin{array}{l}\text { Maximum wind speed per tropical } \\
\text { cyclone experienced by each the } \\
\text { province (using data from tropical } \\
\text { cyclone logs) }\end{array}$ & $\begin{array}{l}\text { Joint Typhoon Warning Center } \\
\text { (JTWC) of the United States Air } \\
\text { Force/Navy; PAGASA. Data is } \\
\text { downloaded } \\
\text { www.typhoon2000.ph. from }\end{array}$ \\
\hline $\begin{array}{l}\text { Flat-sloped } \\
\text { land }\end{array}$ & $\begin{array}{l}\text { Area of land (in square kilometres) } \\
\text { within a given province with a slope } \\
\text { range of } 0 \text { to } 18 \% \text {. }\end{array}$ & Department of Agriculture (DA) \\
\hline $\begin{array}{l}\text { Steeply- } \\
\text { sloped land }\end{array}$ & $\begin{array}{l}\text { Area of land (in square kilometres) } \\
\text { within a given province with a slope } \\
\text { above } 18 \%\end{array}$ & DA \\
\hline $\begin{array}{l}\text { Luzon } \\
\text { (dummy) }\end{array}$ & $\begin{array}{l}\text { Dummy variable with a value of } 1 \text { if } \\
\text { a given province is part of Luzon } \\
\text { island group, value of zero (0) } \\
\text { otherwise }\end{array}$ & $\begin{array}{l}\text { Based on the List of Regions and } \\
\text { Provinces in the Philippines, } \\
\text { Philippine Statistics Agency } \\
\text { (PSA) }\end{array}$ \\
\hline $\begin{array}{l}\text { Visayas } \\
\text { (dummy) }\end{array}$ & $\begin{array}{l}\text { Dummy variable with a value of } 1 \text { if } \\
\text { a given province is part of Visayas } \\
\text { island group, value of zero (0) } \\
\text { otherwise }\end{array}$ & $\begin{array}{l}\text { Based on the List of Regions and } \\
\text { Provinces in the Philippines, } \\
\text { Philippine Statistics Agency } \\
\text { (PSA) }\end{array}$ \\
\hline $\begin{array}{l}\text { Eastern } \\
\text { province } \\
\text { (dummy) }\end{array}$ & $\begin{array}{l}\text { Dummy variable with a value of } 1 \text { if } \\
\text { a given province is located in the } \\
\text { east-most part of the country (along } \\
\text { the eastern shoreline), value of zero } \\
\text { (0) otherwise }\end{array}$ & $\begin{array}{l}\text { GIS-generated using Philippine } \\
\text { Administrative Map }\end{array}$ \\
\hline $\begin{array}{l}\text { Landlocked } \\
\text { province } \\
\text { (dummy) }\end{array}$ & $\begin{array}{l}\text { Dummy variable with a value of } 1 \text { if } \\
\text { a given province is landlocked, } \\
\text { value of zero }(0) \text { if province is } \\
\text { coastal }\end{array}$ & $\begin{array}{l}\text { GIS-generated using Philippine } \\
\text { Administrative Map }\end{array}$ \\
\hline $\begin{array}{l}\text { Income per } \\
\text { capita }\end{array}$ & Real per capita income (in USD) & $\begin{array}{l}\text { 2012/2013 Philippine Human } \\
\text { Development Report (PHDR), } \\
\text { Philippine Human Development } \\
\text { Network (PHDN) }\end{array}$ \\
\hline
\end{tabular}




\begin{tabular}{|c|c|c|}
\hline $\begin{array}{l}\text { Variable } \\
\text { Name }\end{array}$ & $\begin{array}{c}\text { Description of the Variable } \\
\text { Method of } \\
\text { Derivation/Computation }\end{array}$ & Sources \\
\hline $\begin{array}{l}\text { Poverty } \\
\text { incidence }\end{array}$ & Poverty incidence & PSA \\
\hline $\begin{array}{l}\text { Mean years } \\
\text { of schooling }\end{array}$ & $\begin{array}{l}\text { Average years of schooling of the } \\
\text { population (in number of years) }\end{array}$ & $2012 / 2013$ PHDR of the PHDN \\
\hline $\begin{array}{l}\text { Life } \\
\text { expectancy }\end{array}$ & $\begin{array}{l}\text { Average life expectancy (in number } \\
\text { of years) }\end{array}$ & $2012 / 2013$ PHDR of the PHDN \\
\hline $\begin{array}{l}\% \text { local tax } \\
\text { revenue to } \\
\text { total income }\end{array}$ & $\begin{array}{l}\text { Percentage of the local tax revenue } \\
\text { to the total income from all sources. } \\
\text { Local tax revenue is the sum of tax } \\
\text { revenues of the provincial, city and } \\
\text { municipal local government units } \\
\text { within the provincial boundary. } \\
\text { Local tax revenues comprise of real } \\
\text { property tax, tax on business, and } \\
\text { other taxes. The total annual } \\
\text { income of these local government } \\
\text { units (LGUs) comes from two major } \\
\text { sources: 1) incomes from local } \\
\text { sources earned through the efforts } \\
\text { of the LGU; and 2) incomes } \\
\text { provided by the central } \\
\text { government, mainly in the form of } \\
\text { Internal Revenue Allotment. }\end{array}$ & $\begin{array}{l}\text { Statement of Income and } \\
\text { Expenditures (SIE)of Local } \\
\text { Government Units from the } \\
\text { Bureau of Local Government } \\
\text { Finance (BLGF) }\end{array}$ \\
\hline $\begin{array}{l}\text { Built-up } \\
\text { density }\end{array}$ & $\begin{array}{l}\text { Population density in built-up areas } \\
\text { (persons per square kilometre) }\end{array}$ & $\begin{array}{l}\text { GIS generated using data from } \\
\text { PSA and DA }\end{array}$ \\
\hline $\begin{array}{l}\text { Population } \\
\text { density }\end{array}$ & $\begin{array}{l}\text { Population density in the province } \\
\text { (persons per square kilometre) }\end{array}$ & $\begin{array}{l}\text { GIS generated using data from } \\
\text { PSA and DA }\end{array}$ \\
\hline
\end{tabular}


Table 3-9. Correlation of Variables

\begin{tabular}{|c|c|c|c|c|c|c|c|c|c|c|c|c|c|c|c|c|c|}
\hline & Fatality & Rainfall & Wind & $\begin{array}{l}\text { Affected } \\
\text { persons }\end{array}$ & $\begin{array}{l}\text { Flat-sloped } \\
\text { land }\end{array}$ & $\begin{array}{l}\text { Steeply- } \\
\text { sloped land }\end{array}$ & $\begin{array}{c}\text { Luzon } \\
\text { (dummy) }\end{array}$ & $\begin{array}{l}\text { Visayas } \\
\text { (dummy) }\end{array}$ & $\begin{array}{l}\text { Eastern } \\
\text { province } \\
\text { (dummy) }\end{array}$ & $\begin{array}{c}\text { Landlocked } \\
\text { (dummy) }\end{array}$ & $\begin{array}{c}\text { Income per } \\
\text { capita }\end{array}$ & $\begin{array}{l}\text { Poverty } \\
\text { incidence }\end{array}$ & $\begin{array}{c}\text { Life } \\
\text { expectancy }\end{array}$ & $\begin{array}{l}\text { Mean years } \\
\text { of schooling }\end{array}$ & $\begin{array}{l}\text { Built-up } \\
\text { density }\end{array}$ & $\begin{array}{l}\text { Population } \\
\text { density }\end{array}$ & $\begin{array}{l}\text { \% local tax } \\
\text { revenue to } \\
\text { total } \\
\text { income }\end{array}$ \\
\hline Fatality & 1.0000 & & & & & & & & & & & & & & & & \\
\hline Rainfall & $\begin{array}{l}0.1461^{*} \\
0.0001\end{array}$ & 1.0000 & & & & & & & & & & & & & & & \\
\hline Wind & $\begin{array}{l}0.1098^{*} \\
0.0031\end{array}$ & $\begin{array}{l}0.1289^{*} \\
0.0005\end{array}$ & 1.0000 & & & & & & & & & & & & & & \\
\hline Affected persons & $\begin{array}{l}0.3143^{*} \\
0.0000\end{array}$ & $\begin{array}{l}0.2137^{*} \\
0.0000\end{array}$ & $\begin{array}{l}0.1724^{*} \\
0.0000\end{array}$ & 1.0000 & & & & & & & & & & & & & \\
\hline Flat-sloped land & $\begin{array}{l}-0.4754^{*} \\
0.0000\end{array}$ & $\begin{array}{l}-0.0508 \\
0.1728\end{array}$ & $\begin{array}{l}-0.1081^{*} \\
0.0036\end{array}$ & $\begin{array}{l}-0.014 \\
0.7072\end{array}$ & 1.0000 & & & & & & & & & & & & \\
\hline Steeply-sloped land & $\begin{array}{l}0.0423 \\
0.2558\end{array}$ & $\begin{array}{l}-0.0707 \\
0.0575\end{array}$ & $\begin{array}{l}-0.0348 \\
0.3511\end{array}$ & $\begin{array}{l}-0.0443 \\
0.2343\end{array}$ & $\begin{array}{l}0.4202^{*} \\
0.0000\end{array}$ & 1.0000 & & & & & & & & & & & \\
\hline Luzon (dummy) & $\begin{array}{l}0.0985^{*} \\
0.0081\end{array}$ & $\begin{array}{l}0.1489^{*} \\
0.0001\end{array}$ & $\begin{array}{l}0.1661^{*} \\
0.0000\end{array}$ & $\begin{array}{l}0.1089^{*} \\
0.0034\end{array}$ & $\begin{array}{l}-0.0966^{*} \\
0.0094\end{array}$ & $\begin{array}{l}-0.1091^{*} \\
0.0033\end{array}$ & 1.0000 & & & & & & & & & & \\
\hline Visayas (dummy) & $\begin{array}{l}-0.0705 \\
0.0584\end{array}$ & $\begin{array}{l}-0.0276 \\
0.4588\end{array}$ & $\begin{array}{l}-0.1069 * \\
0.004\end{array}$ & $\begin{array}{l}-0.0784^{*} \\
0.0351\end{array}$ & $\begin{array}{l}0.0285 \\
0.4442\end{array}$ & $\begin{array}{l}0.0987^{*} \\
0.008\end{array}$ & $\begin{array}{l}-0.7904^{*} \\
0.0000\end{array}$ & 1.0000 & & & & & & & & & \\
\hline Eastern province (dummy) & $\begin{array}{l}0.0456 \\
0.2209\end{array}$ & $\begin{array}{l}-0.0295 \\
0.4282\end{array}$ & $\begin{array}{l}-0.0166 \\
0.6553\end{array}$ & $\begin{array}{l}0.0293 \\
0.4321\end{array}$ & $\begin{array}{l}0.1370^{*} \\
0.0002\end{array}$ & $\begin{array}{l}0.1664^{*} \\
0.0000\end{array}$ & $\begin{array}{l}-0.0234 \\
0.5294\end{array}$ & $\begin{array}{l}0.0483 \\
0.1946\end{array}$ & 1.0000 & & & & & & & & \\
\hline Landlocked (dummy) & $\begin{array}{l}0.1958^{*} \\
0.0000\end{array}$ & $\begin{array}{l}0.1155^{*} \\
0.0018\end{array}$ & $\begin{array}{l}0.0636 \\
0.0879\end{array}$ & $\begin{array}{l}-0.0517 \\
0.1649\end{array}$ & $\begin{array}{l}-0.2731^{*} \\
0.0000\end{array}$ & $\begin{array}{l}0.0905^{*} \\
0.015\end{array}$ & $\begin{array}{l}0.2922^{*} \\
0.0000\end{array}$ & $\begin{array}{l}-0.2547^{*} \\
0.0000\end{array}$ & $\begin{array}{l}-0.3321^{*} \\
0.0000\end{array}$ & 1.0000 & & & & & & & \\
\hline Income per capita & $\begin{array}{l}-0.1874^{*} \\
0.0000\end{array}$ & $\begin{array}{l}0.07777^{*} \\
0.0368\end{array}$ & $\begin{array}{l}0.0575 \\
0.1225\end{array}$ & $\begin{array}{l}0.0102 \\
0.785\end{array}$ & $\begin{array}{l}-0.2429^{*} \\
0.0000\end{array}$ & $\begin{array}{l}-0.4040^{*} \\
0.0000\end{array}$ & $\begin{array}{l}0.3778^{*} \\
0.0000\end{array}$ & $\begin{array}{l}-0.2511^{*} \\
0.0000\end{array}$ & $\begin{array}{l}-0.2457^{*} \\
0.0000\end{array}$ & $\begin{array}{l}0.1988^{*} \\
0.0000\end{array}$ & 1.0000 & & & & & & \\
\hline Poverty incidence & $\begin{array}{l}0.2644^{*} \\
0.0000\end{array}$ & $\begin{array}{l}-0.0849^{*} \\
0.0225\end{array}$ & $\begin{array}{l}-0.0927 * \\
0.0127\end{array}$ & $\begin{array}{l}-0.0104 \\
0.7808\end{array}$ & $\begin{array}{l}0.1435^{*} \\
0.0001\end{array}$ & $\begin{array}{l}0.5170^{*} \\
0.0000\end{array}$ & $\begin{array}{l}-0.3473^{*} \\
0.0000\end{array}$ & $\begin{array}{l}0.2407 * \\
0.0000\end{array}$ & $\begin{array}{l}0.3179^{*} \\
0.0000\end{array}$ & $\begin{array}{l}-0.1592^{*} \\
0.0000\end{array}$ & $\begin{array}{l}-0.8709^{*} \\
0.0000\end{array}$ & 1.0000 & & & & & \\
\hline Life expectancy & $\begin{array}{l}-0.3989^{*} \\
0.0000\end{array}$ & $\begin{array}{l}0.0092 \\
0.8042\end{array}$ & $\begin{array}{l}0.0225 \\
0.5466\end{array}$ & $\begin{array}{l}0.026 \\
0.4862\end{array}$ & $\begin{array}{l}0.1582^{*} \\
0.0000\end{array}$ & $\begin{array}{l}-0.1744^{*} \\
0.0000\end{array}$ & $\begin{array}{l}0.2052^{*} \\
0.0000\end{array}$ & $\begin{array}{l}-0.1058^{*} \\
0.0044\end{array}$ & $\begin{array}{l}0.0746^{*} \\
0.0452\end{array}$ & $\begin{array}{l}-0.2152^{*} \\
0.0000\end{array}$ & $\begin{array}{l}0.5596^{*} \\
0.0000\end{array}$ & $\begin{array}{l}-0.5186^{*} \\
0.0000\end{array}$ & 1.0000 & & & & \\
\hline Mean years of schooling & $\begin{array}{l}-0.1253^{*} \\
0.0007\end{array}$ & $\begin{array}{l}0.0678 \\
0.0688\end{array}$ & $\begin{array}{l}0.0752^{2} \\
0.0433\end{array}$ & $\begin{array}{l}0.0407 \\
0.2752\end{array}$ & $\begin{array}{l}-0.2945^{*} \\
0.0000\end{array}$ & $\begin{array}{l}-0.3113^{*} \\
0.0000\end{array}$ & $\begin{array}{l}0.3094^{*} \\
0.0000\end{array}$ & $\begin{array}{l}-0.1878^{*} \\
0.0000\end{array}$ & $\begin{array}{l}-0.2194^{*} \\
0.0000\end{array}$ & $\begin{array}{l}0.1137^{*} \\
0.0022\end{array}$ & $\begin{array}{l}0.7613^{*} \\
0.0000\end{array}$ & $\begin{array}{l}-0.6505^{*} \\
0.0000\end{array}$ & $\begin{array}{l}0.5561^{*} \\
0.0000\end{array}$ & 1.0000 & & & \\
\hline Built-up density & $\begin{array}{l}0.1249^{*} \\
0.0008\end{array}$ & $\begin{array}{l}-0.1214^{*} \\
0.0011\end{array}$ & $\begin{array}{l}-0.1113^{*} \\
0.0027\end{array}$ & $\begin{array}{l}0.0037 \\
0.9217\end{array}$ & $\begin{array}{l}0.014 \\
0.7068\end{array}$ & $\begin{array}{l}0.1192^{*} \\
0.0013\end{array}$ & $\begin{array}{l}-0.4678^{*} \\
0.0000\end{array}$ & $\begin{array}{l}0.2742^{*} \\
0.0000\end{array}$ & $\begin{array}{l}0.2076^{*} \\
0.0000\end{array}$ & $\begin{array}{l}-0.2495^{*} \\
0.0000\end{array}$ & $\begin{array}{l}-0.5960^{*} \\
0.0000\end{array}$ & $\begin{array}{l}0.49755^{*} \\
0.0000\end{array}$ & $\begin{array}{l}-0.3107^{*} \\
0.0000\end{array}$ & $\begin{array}{l}-0.4953^{*} \\
0.0000\end{array}$ & 1.0000 & & \\
\hline Population density & $\begin{array}{l}-0.5102^{*} \\
0.0000\end{array}$ & $\begin{array}{l}0.0568 \\
0.1274\end{array}$ & $\begin{array}{l}-0.0267 \\
0.4743\end{array}$ & $\begin{array}{l}0.0073 \\
0.8456\end{array}$ & $\begin{array}{l}0.0818^{*} \\
0.028\end{array}$ & $\begin{array}{l}-0.6071^{*} \\
0.0000\end{array}$ & $\begin{array}{l}-0.0108 \\
0.772\end{array}$ & $\begin{array}{l}0.0343 \\
0.3568\end{array}$ & $\begin{array}{l}-0.1539^{*} \\
0.0000\end{array}$ & $\begin{array}{l}-0.2299 * \\
0.0000\end{array}$ & $\begin{array}{l}0.5080^{*} \\
0.0000\end{array}$ & $\begin{array}{l}-0.6154^{*} \\
0.0000\end{array}$ & $\begin{array}{l}0.6110^{*} \\
0.0000\end{array}$ & $\begin{array}{l}0.4496^{*} \\
0.0000\end{array}$ & $\begin{array}{l}-0.1468^{*} \\
0.0001\end{array}$ & 1.0000 & \\
\hline$\%$ local tax revenue to total income & $\begin{array}{l}-0.5035^{*} \\
0.0000\end{array}$ & $\begin{array}{l}0.0474 \\
0.2034\end{array}$ & $\begin{array}{l}-0.0229 \\
0.5388\end{array}$ & $\begin{array}{l}-0.0283 \\
0.4478\end{array}$ & $\begin{array}{l}0.2701^{*} \\
0.0000\end{array}$ & $\begin{array}{l}-0.2444^{*} \\
0.00000\end{array}$ & $\begin{array}{l}0.0691 \\
0.0633 \\
\end{array}$ & $\begin{array}{l}-0.028 \\
0.4524\end{array}$ & $\begin{array}{l}-0.1315^{*} \\
0.0004\end{array}$ & $\begin{array}{l}-0.1294^{*} \\
0.0005\end{array}$ & $\begin{array}{l}0.6047^{*} \\
0.0000\end{array}$ & $\begin{array}{l}-0.6591^{*} \\
0.0000\end{array}$ & $\begin{array}{l}0.6574^{*} \\
0.0000\end{array}$ & $\begin{array}{l}0.5450^{*} \\
0.0000\end{array}$ & $\begin{array}{l}-0.3367^{*} \\
0.0000\end{array}$ & $\begin{array}{l}0.7616^{*} \\
0.0000\end{array}$ & 1.0000 \\
\hline
\end{tabular}


Table 3-10. Preliminary Regressions Set 1: Controls are Either Hazard or Exposure or, Topography and Geography Variables Only

\begin{tabular}{|c|c|c|c|c|c|c|c|c|c|c|c|c|}
\hline & $\begin{array}{l}\text { OLS } \\
\text { (1) }\end{array}$ & $\begin{array}{l}\mathrm{RE} \\
(2)\end{array}$ & $\begin{array}{c}\mathrm{FE} \\
(3)\end{array}$ & $\begin{array}{l}\text { OLS } \\
(4)\end{array}$ & $\begin{array}{l}\text { RE } \\
(5)\end{array}$ & $\begin{array}{l}\mathrm{FE} \\
(6)\end{array}$ & $\begin{array}{l}\text { OLS } \\
\text { (7) }\end{array}$ & $\begin{array}{l}\mathrm{RE} \\
(8)\end{array}$ & $\begin{array}{l}\mathrm{FE} \\
(9)\end{array}$ & $\begin{array}{l}\text { OLS } \\
\text { (10) }\end{array}$ & $\begin{array}{c}\mathrm{RE} \\
(11)\end{array}$ & $\begin{array}{c}\mathrm{FE} \\
(12)\end{array}$ \\
\hline$\overline{\text { Rainfall }}$ & $\begin{array}{l}0.132^{* * *} \\
(3.39)\end{array}$ & $\begin{array}{l}0.161^{* * *} \\
(4.19)\end{array}$ & $\begin{array}{l}0.171^{* * *} \\
(4.21)\end{array}$ & & & & & & & & & \\
\hline Wind & $\begin{array}{l}0.266^{*} \\
(2.42)\end{array}$ & $\begin{array}{l}0.122 \\
(1.30)\end{array}$ & $\begin{array}{l}0.100 \\
(1.07)\end{array}$ & & & & & & & & & \\
\hline Affected persons & & & & $\begin{array}{l}0.0858^{* * *} \\
(9.17)\end{array}$ & $\begin{array}{l}0.0880^{* * *} \\
(10.63)\end{array}$ & $\begin{array}{l}0.0891^{* * *} \\
(10.37)\end{array}$ & & & & & & \\
\hline Flat-sloped land & & & & & & & & & & $\begin{array}{l}-0.848^{* * *} \\
(-17.53)\end{array}$ & $\begin{array}{l}-0.855^{* * *} \\
(-9.92)\end{array}$ & $\begin{array}{l}0 \\
\text { (.) }\end{array}$ \\
\hline Steeply-sloped land & & & & & & & & & & $\begin{array}{l}0.433^{* * *} \\
(8.12)\end{array}$ & $\begin{array}{l}0.340^{* *} \\
(3.18)\end{array}$ & $\begin{array}{l}0 \\
\text { (.) }\end{array}$ \\
\hline Mean slope & & & & & & & $\begin{array}{l}1.555^{* * *} \\
(13.29)\end{array}$ & $\begin{array}{l}1.319^{* * *} \\
(5.33)\end{array}$ & $\begin{array}{l}0 \\
\text { (.) }\end{array}$ & & & \\
\hline Luzon (dummy) & & & & & & & $\begin{array}{l}0.371^{*} \\
(2.54)\end{array}$ & $\begin{array}{l}0.333 \\
(1.66)\end{array}$ & $\begin{array}{l}0 \\
\text { (.) }\end{array}$ & $\begin{array}{l}0.0373 \\
(0.28)\end{array}$ & $\begin{array}{l}0.0339 \\
(0.20)\end{array}$ & $\begin{array}{l}0 \\
\text { (.) }\end{array}$ \\
\hline Visayas (dummy) & & & & & & & $\begin{array}{l}0.134 \\
(0.78)\end{array}$ & $\begin{array}{l}0.192 \\
(0.70)\end{array}$ & $\begin{array}{l}0 \\
\text { (.) }\end{array}$ & $\begin{array}{l}-0.244 \\
(-1.60)\end{array}$ & $\begin{array}{l}-0.214 \\
(-1.04)\end{array}$ & $\begin{array}{l}0 \\
\text { (.) }\end{array}$ \\
\hline Eastern province (dummy) & & & & & & & $\begin{array}{l}0.198^{*} \\
(1.98)\end{array}$ & $\begin{array}{l}0.159 \\
(0.75)\end{array}$ & $\begin{array}{l}0 \\
(.)\end{array}$ & $\begin{array}{l}0.252^{* *} \\
(2.67)\end{array}$ & $\begin{array}{l}0.216 \\
(1.54)\end{array}$ & $\begin{array}{l}0 \\
(.)\end{array}$ \\
\hline Landlocked province (dummy) & & & & & & & $\begin{array}{l}0.0672 \\
(0.66)\end{array}$ & $\begin{array}{l}0.0540 \\
(0.25)\end{array}$ & $\begin{array}{l}0 \\
(.)\end{array}$ & $\begin{array}{l}0.0354 \\
(0.34)\end{array}$ & $\begin{array}{l}0.0289 \\
(0.13)\end{array}$ & $\begin{array}{l}0 \\
(.)\end{array}$ \\
\hline _cons & $\begin{array}{l}-7.883^{* * *} \\
(-15.96)\end{array}$ & $\begin{array}{l}-7.256 * * * \\
(-16.90)\end{array}$ & $\begin{array}{l}-7.283^{* * *} \\
(-17.14)\end{array}$ & $\begin{array}{l}-6.084^{* * *} \\
(-135.03)\end{array}$ & $\begin{array}{l}-6.008^{* * *} \\
(-58.12)\end{array}$ & $\begin{array}{l}-6.082^{* * *} \\
(-1639.52)\end{array}$ & $\begin{array}{l}-10.14^{* * *} \\
(-31.89)\end{array}$ & $\begin{array}{l}-9.466^{* * *} \\
(-15.67)\end{array}$ & $\begin{array}{l}-6.121 * * * \\
(-1.87 e+17)\end{array}$ & $\begin{array}{l}-3.298^{* * *} \\
(-8.05)\end{array}$ & $\begin{array}{l}-2.524^{* * *} \\
(-3.48)\end{array}$ & $\begin{array}{l}-6.121^{* * *} \\
(-1.87 \mathrm{e}+17)\end{array}$ \\
\hline $\mathrm{N}$ & 722 & 722 & 722 & 722 & 722 & 722 & 722 & 722 & 722 & 722 & 722 & 722 \\
\hline adj. R-sq & 0.027 & 0.027 & 0.048 & 0.098 & 0.099 & 0.189 & 0.238 & 0.243 & 0.000 & 0.305 & 0.307 & 0.000 \\
\hline
\end{tabular}


Table 3-11. Preliminary Regressions Set 2: Controls are Combinations of Hazard, Exposure, and Topography and Geography Variables

\begin{tabular}{|c|c|c|c|c|c|c|c|c|c|c|c|c|c|c|c|c|c|c|}
\hline & $\begin{array}{l}\text { OLS } \\
\text { (1) }\end{array}$ & $\begin{array}{l}\text { RE } \\
(2) \\
\end{array}$ & $\begin{array}{l}\mathrm{FE} \\
(3) \\
\end{array}$ & $\begin{array}{l}\text { OLS } \\
\text { (4) }\end{array}$ & $\begin{array}{l}\text { RE } \\
(5) \\
\end{array}$ & $\begin{array}{l}\mathrm{FE} \\
(6) \\
\end{array}$ & $\begin{array}{l}\text { OLS } \\
\text { (7) }\end{array}$ & $\begin{array}{l}\text { RE } \\
(8) \\
\end{array}$ & $\begin{array}{l}\mathrm{FE} \\
(9) \\
\end{array}$ & $\begin{array}{l}\text { OLS } \\
(10) \\
\end{array}$ & $\begin{array}{l}\text { RE } \\
\text { (11) } \\
\end{array}$ & $\begin{array}{c}\mathrm{FE} \\
\text { (12) }\end{array}$ & $\begin{array}{l}\text { OLS } \\
\text { (13) }\end{array}$ & $\begin{array}{c}\text { RE } \\
\text { (14) }\end{array}$ & $\begin{array}{c}\mathrm{FE} \\
(15) \\
\end{array}$ & $\begin{array}{l}\text { OLS } \\
(16) \\
\end{array}$ & $\begin{array}{c}\text { RE } \\
\text { (17) }\end{array}$ & $\begin{array}{c}\mathrm{FE} \\
(18) \\
\end{array}$ \\
\hline Rainfall & $\begin{array}{l}0.136 * * * \\
(3.87)\end{array}$ & $\begin{array}{l}0.161^{* * *} \\
(4.11)\end{array}$ & $\begin{array}{l}0.171^{* * *} \\
(4.21)\end{array}$ & $\begin{array}{l}0.135^{* * *} \\
(4.41)\end{array}$ & $\begin{array}{l}0.156^{* * *} \\
(4.26)\end{array}$ & $\begin{array}{l}0.171^{* * *} \\
(4.21)\end{array}$ & & & & & & & $\begin{array}{l}0.0752^{*} \\
(2.29)\end{array}$ & $\begin{array}{l}0.0994 * * * \\
(3.39)\end{array}$ & $\begin{array}{l}\text { *0.107*** } \\
(3.57)\end{array}$ & $\begin{array}{l}0.0764^{* *} \\
(2.69)\end{array}$ & $\begin{array}{l}0.0962 * * * \\
(3.43)\end{array}$ & $\begin{array}{l}0.107^{* * *} \\
(3.57)\end{array}$ \\
\hline Wind & $\begin{array}{l}0.161 \\
(1.66)\end{array}$ & $\begin{array}{l}0.114 \\
(1.22)\end{array}$ & $\begin{array}{l}0.100 \\
(1.07)\end{array}$ & $\begin{array}{l}0.0957 \\
(1.04)\end{array}$ & $\begin{array}{l}0.101 \\
(1.09)\end{array}$ & $\begin{array}{l}0.100 \\
(1.07)\end{array}$ & & & & & & & $\begin{array}{l}0.0365 \\
(0.39)\end{array}$ & $\begin{array}{l}-0.0141 \\
(-0.17)\end{array}$ & $\begin{array}{l}-0.0273 \\
(-0.32)\end{array}$ & $\begin{array}{l}-0.0248 \\
(-0.29)\end{array}$ & $\begin{array}{l}-0.0220 \\
(-0.26)\end{array}$ & $\begin{array}{l}-0.0273 \\
(-0.32)\end{array}$ \\
\hline Affected persons & & & & & & & $\begin{array}{l}0.0889 * * * \\
(10.69)\end{array}$ & 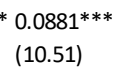 & $\begin{array}{l}{ }^{*} 0.0891^{* * *} \\
(10.37)\end{array}$ & $\begin{array}{l}\text { *0.0863*** } \\
(10.68)\end{array}$ & $\begin{array}{l}0.0872 * * * \\
(10.46)\end{array}$ & $\begin{array}{l}0.0891 * * * \\
(10.37)\end{array}$ & $\begin{array}{l}0.0840^{* * *} \\
(10.31)\end{array}$ & $\begin{array}{l}0.0828^{* * *} \\
(10.25)\end{array}$ & 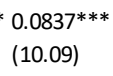 & $\begin{array}{l}0.0823^{* * *} \\
(10.60)\end{array}$ & $\begin{array}{l}0.0821 * * * \\
(10.19)\end{array}$ & $\begin{array}{l}0.0837 * * * \\
(10.09)\end{array}$ \\
\hline Flat-sloped land & & & & $\begin{array}{l}-0.851^{* * *} \\
(-17.02)\end{array}$ & $\begin{array}{l}-0.867^{* * *} \\
(-9.20)\end{array}$ & $\begin{array}{l}0 \\
\text { (.) }\end{array}$ & & & & $\begin{array}{l}-0.839 * * * \\
(-18.49)\end{array}$ & $\begin{array}{l}-0.845^{* * *} \\
(-9.70)\end{array}$ & $\begin{array}{l}0 \\
\text { (.) }\end{array}$ & & & & $\begin{array}{l}-0.845^{* * *} \\
(-18.17)\end{array}$ & $\begin{array}{l}-0.857^{* * *} \\
(-9.29)\end{array}$ & $\begin{array}{l}0 \\
\text { (.) }\end{array}$ \\
\hline Steeply-sloped land & & & & $\begin{array}{l}0.450^{* * *} \\
(8.53)\end{array}$ & $\begin{array}{l}0.357^{* * *} \\
(3.36)\end{array}$ & $\begin{array}{l}0 \\
\text { (.) }\end{array}$ & & & & $\begin{array}{l}0.440^{* * *} \\
(8.73)\end{array}$ & $\begin{array}{l}0.317^{* *} \\
(2.95)\end{array}$ & $\begin{array}{l}0 \\
\text { (.) }\end{array}$ & & & & $\begin{array}{l}0.450^{* * *} \\
(8.98)\end{array}$ & $\begin{array}{l}0.331^{* *} \\
(3.11)\end{array}$ & $\begin{array}{l}0 \\
\text { (.) }\end{array}$ \\
\hline Mean slope & $\begin{array}{l}1.567 * * * \\
(13.62)\end{array}$ & $\begin{array}{l}1.336^{* * *} \\
(5.47)\end{array}$ & $\begin{array}{l}0 \\
\text { (.) }\end{array}$ & & & & $\begin{array}{l}1.557^{* * *} \\
(14.58)\end{array}$ & $\begin{array}{l}1.295^{* * *} \\
(5.26)\end{array}$ & $\begin{array}{l}0 \\
\text { (.) }\end{array}$ & & & & $\begin{array}{l}1.567^{* * *} \\
(14.75)\end{array}$ & $\begin{array}{l}1.311^{* * *} \\
(5.37)\end{array}$ & $\begin{array}{l}0 \\
\text { (.) }\end{array}$ & & & \\
\hline Luzon (dummy) & $\begin{array}{l}0.210 \\
(1.40)\end{array}$ & $\begin{array}{l}0.143 \\
(0.68)\end{array}$ & $\begin{array}{l}0 \\
\text { (.) }\end{array}$ & $\begin{array}{l}-0.107 \\
(-0.80)\end{array}$ & $\begin{array}{l}-0.141 \\
(-0.81)\end{array}$ & $\begin{array}{l}0 \\
\text { (.) }\end{array}$ & $\begin{array}{l}0.232 \\
(1.65)\end{array}$ & $\begin{array}{l}0.184 \\
(0.95)\end{array}$ & $\begin{array}{l}0 \\
\text { (.) }\end{array}$ & $\begin{array}{l}-0.0934 \\
(-0.73)\end{array}$ & $\begin{array}{l}-0.107 \\
(-0.65)\end{array}$ & $\begin{array}{l}0 \\
\text { (.) }\end{array}$ & $\begin{array}{l}0.162 \\
(1.11)\end{array}$ & $\begin{array}{l}0.0916 \\
(0.45)\end{array}$ & $\begin{array}{l}0 \\
\text { (.) }\end{array}$ & $\begin{array}{l}-0.153 \\
(-1.16)\end{array}$ & $\begin{array}{l}-0.192 \\
(-1.14)\end{array}$ & $\begin{array}{l}0 \\
\text { (.) }\end{array}$ \\
\hline Visayas (dummy) & $\begin{array}{l}0.00854 \\
(0.05)\end{array}$ & $\begin{array}{l}0.0373 \\
(0.14)\end{array}$ & $\begin{array}{l}0 \\
\text { (.) }\end{array}$ & $\begin{array}{l}-0.367^{*} \\
(-2.44)\end{array}$ & $\begin{array}{l}-0.364 \\
(-1.81)\end{array}$ & $\begin{array}{l}0 \\
\text { (.) }\end{array}$ & $\begin{array}{l}0.118 \\
(0.72)\end{array}$ & $\begin{array}{l}0.198 \\
(0.74)\end{array}$ & $\begin{array}{l}0 \\
\text { (.) }\end{array}$ & $\begin{array}{l}-0.257 \\
(-1.75)\end{array}$ & $\begin{array}{l}-0.209 \\
(-1.07)\end{array}$ & $\begin{array}{l}0 \\
\text { (.) }\end{array}$ & $\begin{array}{l}0.0538 \\
(0.33)\end{array}$ & $\begin{array}{l}0.107 \\
(0.40)\end{array}$ & $\begin{array}{l}0 \\
\text { (.) }\end{array}$ & $\begin{array}{l}-0.321^{*} \\
(-2.17)\end{array}$ & $\begin{array}{l}-0.297 \\
(-1.51)\end{array}$ & $\begin{array}{l}0 \\
\text { (.) }\end{array}$ \\
\hline Eastern province (dummy) & $\begin{array}{l}0.201^{*} \\
(2.03)\end{array}$ & $\begin{array}{l}0.175 \\
(0.81)\end{array}$ & $\begin{array}{l}0 \\
\text { (.) }\end{array}$ & $\begin{array}{l}0.249^{* *} \\
(2.65)\end{array}$ & $\begin{array}{l}0.217 \\
(1.49)\end{array}$ & $\begin{array}{l}0 \\
\text { (.) }\end{array}$ & $\begin{array}{l}0.196^{*} \\
(2.08)\end{array}$ & $\begin{array}{l}0.172 \\
(0.80)\end{array}$ & $\begin{array}{l}0 \\
\text { (.) }\end{array}$ & $\begin{array}{l}0.247^{* *} \\
(2.81)\end{array}$ & $\begin{array}{l}0.226 \\
(1.59)\end{array}$ & $\begin{array}{l}0 \\
\text { (.) }\end{array}$ & $\begin{array}{l}0.197^{*} \\
(2.09)\end{array}$ & $\begin{array}{l}0.181 \\
(0.82)\end{array}$ & $\begin{array}{l}0 \\
\text { (.) }\end{array}$ & $\begin{array}{l}0.244^{* *} \\
(2.77)\end{array}$ & $\begin{array}{l}0.227 \\
(1.56)\end{array}$ & $\begin{array}{l}0 \\
\text { (.) }\end{array}$ \\
\hline Landlocked province (dummy) & $\begin{array}{l}0.0275 \\
(0.27)\end{array}$ & $\begin{array}{l}0.0166 \\
(0.07)\end{array}$ & $\begin{array}{l}0 \\
\text { (.) }\end{array}$ & $\begin{array}{l}-0.00737 \\
(-0.07)\end{array}$ & $\begin{array}{l}-0.0207 \\
(-0.09)\end{array}$ & $\begin{array}{l}0 \\
\text { (.) }\end{array}$ & $\begin{array}{l}0.151 \\
(1.61)\end{array}$ & $\begin{array}{l}0.152 \\
(0.75)\end{array}$ & $\begin{array}{l}0 \\
\text { (.) }\end{array}$ & $\begin{array}{l}0.119 \\
(1.23)\end{array}$ & $\begin{array}{l}0.133 \\
(0.60)\end{array}$ & $\begin{array}{l}0 \\
\text { (.) }\end{array}$ & $\begin{array}{l}0.124 \\
(1.32)\end{array}$ & $\begin{array}{l}0.124 \\
(0.60)\end{array}$ & $\begin{array}{l}0 \\
\text { (.) }\end{array}$ & $\begin{array}{l}0.0898 \\
(0.92)\end{array}$ & $\begin{array}{l}0.0965 \\
(0.43)\end{array}$ & $\begin{array}{l}0 \\
\text { (.) }\end{array}$ \\
\hline _cons & $\begin{array}{l}-11.31^{* * *} \\
(-23.10)\end{array}$ & $\begin{array}{l}-10.50^{* * *} \\
(-15.45)\end{array}$ & $\begin{array}{l}-7.283^{* * *} \\
(-17.14)\end{array}$ & $\begin{array}{l}-4.258^{* * *} \\
(-6.96)\end{array}$ & $\begin{array}{l}-3.493^{* * *} \\
(-4.23)\end{array}$ & $\begin{array}{l}-7.283^{* * *} \\
(-17.14)\end{array}$ & $\begin{array}{l}-10.02^{* * *} \\
(-33.90)\end{array}$ & $\begin{array}{l}-9.280^{* * * *} \\
(-15.49)\end{array}$ & $\begin{array}{l}-6.082^{* * *} \\
(-1639.52)\end{array}$ & $\begin{array}{l}-3.293^{* * *} \\
(-8.09) \\
1\end{array}$ & $\begin{array}{l}-2.316^{* *} \\
(-3.11)\end{array}$ & $\begin{array}{l}-6.082^{* * *} \\
(-1639.52)\end{array}$ & $\begin{array}{l}-10.45^{* * *} \\
(-21.85)\end{array}$ & $\begin{array}{l}-9.568 * * * \\
(-14.26)\end{array}$ & $\begin{array}{l}-6.401 * * * \\
(-16.51)\end{array}$ & $\begin{array}{l}-3.466^{* * * *} \\
(-6.02)\end{array}$ & $\begin{array}{l}-2.531^{* *} \\
(-3.14)\end{array}$ & $\begin{array}{l}-6.401^{* * *} \\
(-16.51)\end{array}$ \\
\hline $\mathrm{N}$ & 722 & 722 & 722 & 722 & 722 & 722 & 722 & 722 & 722 & 722 & 722 & 722 & 722 & 722 & 722 & 722 & 722 & 722 \\
\hline adj. R-sq & 0.259 & 0.263 & 0.048 & 0.323 & 0.326 & 0.048 & 0.342 & 0.344 & 0.189 & 0.403 & 0.402 & 0.189 & 0.345 & 0.348 & 0.205 & 0.407 & 0.407 & 0.205 \\
\hline
\end{tabular}


Table 3-12. Preliminary Regression Set 3: Controls are Vulnerability Variables Only

\begin{tabular}{|c|c|c|c|c|c|c|c|c|c|c|c|c|c|c|c|}
\hline & $\begin{array}{l}\text { OLS } \\
(1)\end{array}$ & $\begin{array}{l}\text { RE } \\
(2) \\
\end{array}$ & $\begin{array}{l}\mathrm{FE} \\
(3) \\
\end{array}$ & $\begin{array}{l}\text { OLS } \\
\text { (4) }\end{array}$ & $\begin{array}{l}\mathrm{RE} \\
(5) \\
\end{array}$ & $\begin{array}{l}\mathrm{FE} \\
(6) \\
\end{array}$ & $\begin{array}{l}\text { OLS } \\
(7)\end{array}$ & $\begin{array}{l}\text { RE } \\
(8) \\
\end{array}$ & $\begin{array}{l}\mathrm{FE} \\
(9) \\
\end{array}$ & $\begin{array}{l}\text { OLS } \\
(10) \\
\end{array}$ & $\begin{array}{c}\text { RE } \\
(11) \\
\end{array}$ & $\begin{array}{c}\mathrm{FE} \\
(12) \\
\end{array}$ & $\begin{array}{l}\text { OLS } \\
(13) \\
\end{array}$ & $\begin{array}{l}\text { RE } \\
(14) \\
\end{array}$ & $\begin{array}{l}\mathrm{FE} \\
(15) \\
\end{array}$ \\
\hline Income per capita & $\begin{array}{l}-0.749 * * * \\
(-4.70)\end{array}$ & $\begin{array}{l}-0.501 \\
(-1.86)\end{array}$ & $\begin{array}{l}-0.544 \\
(-1.75)\end{array}$ & & & & & & & & & & & & \\
\hline Poverty incidence & & & & $\begin{array}{l}0.438^{* * *} \\
(7.69)\end{array}$ & $\begin{array}{l}0.340^{* *} \\
(2.69)\end{array}$ & $\begin{array}{l}0.367 \\
(1.14)\end{array}$ & & & & & & & & & \\
\hline Life expectancy & & & & & & & $\begin{array}{l}-10.29 * * * \\
(-10.68)\end{array}$ & $\begin{array}{l}-6.579 * * * \\
(-3.62)\end{array}$ & $\begin{array}{l}0.647 \\
(0.17)\end{array}$ & & & & & & \\
\hline Mean years of schooling & & & & & & & $\begin{array}{l}2.427^{* *} \\
(2.99)\end{array}$ & $\begin{array}{l}1.328 \\
(0.92)\end{array}$ & $\begin{array}{l}-2.750 \\
(-1.66)\end{array}$ & & & & & & \\
\hline Built-up density & & & & & & & & & & $\begin{array}{l}0.0867 \\
(1.66)\end{array}$ & $\begin{array}{l}0.0348 \\
(0.40)\end{array}$ & $\begin{array}{l}-1.615 \\
(-1.28)\end{array}$ & & & \\
\hline Population density & & & & & & & & & & $\begin{array}{l}-0.664^{* * *} \\
(-16.38)\end{array}$ & $\begin{array}{l}-0.668^{* * *} \\
(-8.31)\end{array}$ & $\begin{array}{l}0 \\
\text { (.) }\end{array}$ & & & \\
\hline$\%$ local tax revenue to total incon & & & & & & & & & & & & & $\begin{array}{l}-0.664^{* * *} \\
(-14.49)\end{array}$ & $\begin{array}{l}-0.490^{* * *} \\
(-5.66)\end{array}$ & $\begin{array}{l}-0.0630 \\
(-0.40)\end{array}$ \\
\hline _cons & $\begin{array}{l}-0.715 \\
(-0.62)\end{array}$ & $\begin{array}{l}-2.503 \\
(-1.32)\end{array}$ & $\begin{array}{l}-2.197 \\
(-0.98)\end{array}$ & $\begin{array}{l}-7.504^{* * *} \\
(-40.34)\end{array}$ & $\begin{array}{l}-7.206^{* * *} \\
(-16.30)\end{array}$ & $\begin{array}{l}-7.282^{* * *} \\
(-7.14)\end{array}$ & $\begin{array}{l}31.81^{* * *} \\
(8.98)\end{array}$ & $\begin{array}{l}18.63^{* *} \\
(2.87)\end{array}$ & $\begin{array}{l}-2.525 \\
(-0.17)\end{array}$ & $\begin{array}{l}-3.209^{* * *} \\
(-5.77)\end{array}$ & $\begin{array}{l}-2.725 * \\
(-2.51)\end{array}$ & $\begin{array}{l}8.492 \\
(0.74)\end{array}$ & $\begin{array}{l}-4.759^{* * *} \\
(-47.83)\end{array}$ & $\begin{array}{l}-5.139 * * * \\
(-26.22)\end{array}$ & $\begin{array}{l}-5.992^{* * *} \\
(-18.41)\end{array}$ \\
\hline $\mathrm{N}$ & 722 & 722 & 722 & 722 & 722 & 722 & 722 & 722 & 722 & 722 & 722 & 722 & 722 & 722 & 722 \\
\hline adj. R-sq & 0.034 & 0.035 & 0.002 & 0.069 & 0.070 & 0.002 & 0.170 & 0.172 & -0.000 & 0.261 & 0.262 & 0.001 & 0.252 & 0.254 & -0.001 \\
\hline
\end{tabular}


Table 3-13. Random Effects vs Fixed Effects using Interacted Ground Slope

\begin{tabular}{|c|c|c|c|c|c|c|c|c|c|c|}
\hline & \multirow{2}{*}{\multicolumn{2}{|c|}{$\mathrm{RE}_{\mathrm{RE}}^{\text {Specification 1 }}$}} & \multicolumn{2}{|c|}{ Specification 2 } & \multirow{2}{*}{\multicolumn{2}{|c|}{$\mathrm{RE}_{\mathrm{RE}}^{\text {Specification 3 }}$}} & \multicolumn{2}{|c|}{ Specification 4} & \multicolumn{2}{|c|}{ Specification 5} \\
\hline & & & $\begin{array}{l}\text { RE } \\
(3)\end{array}$ & $\begin{array}{l}\text { FE } \\
(4)\end{array}$ & & & $\begin{array}{l}\text { RE } \\
(7)\end{array}$ & $\begin{array}{l}\mathrm{FE} \\
(8)\end{array}$ & $\begin{array}{l}\text { RE } \\
\text { (9) }\end{array}$ & $\begin{array}{c}\mathrm{FE} \\
(10)\end{array}$ \\
\hline $\begin{array}{l}\text { Rainfall } \\
\end{array}$ & $\begin{array}{l}0.0892^{* * *} \\
(3.32)\end{array}$ & $\begin{array}{l}0.104^{* * *} \\
(3.66)\end{array}$ & $\begin{array}{l}0.0985^{* * *} \\
(3.60)\end{array}$ & $\begin{array}{l}0.104^{* * *} \\
(3.66)\end{array}$ & $\begin{array}{l}.0896^{* * *} \\
(3.33)\end{array}$ & $\begin{array}{l}0.108^{* * *} \\
(3.79)\end{array}$ & $\begin{array}{l}0.0948^{* * *} \\
(3.72)\end{array}$ & $\begin{array}{l}0.104^{* * *} \\
(3.68)\end{array}$ & $\begin{array}{l}0.106^{* * *} \\
(3.91)\end{array}$ & $\begin{array}{l}0.107^{* * *} \\
(3.75)\end{array}$ \\
\hline Affected persons & $\begin{array}{l}0.0820^{* * *} \\
(11.35)\end{array}$ & $\begin{array}{l}0.0839^{* * *} \\
(11.43)\end{array}$ & $\begin{array}{l}0.0821^{* * *} \\
(11.37)\end{array}$ & $\begin{array}{l}0.0832^{* * *} \\
(11.37)\end{array}$ & $\begin{array}{l}0.0829^{* * *} \\
(11.48)\end{array}$ & $\begin{array}{l}0.0835 * * * \\
(11.38)\end{array}$ & $\begin{array}{l}0.0790^{* * *} \\
(11.28)\end{array}$ & $\begin{array}{l}0.0841^{* * *} \\
(11.46)\end{array}$ & $\begin{array}{l}0.0811^{* * *} \\
(11.27)\end{array}$ & $\begin{array}{l}0.0833 * * * \\
(11.30)\end{array}$ \\
\hline $\begin{array}{l}\text { Interacted: } \\
\text { Income per capita, flat-sloped land }\end{array}$ & $\begin{array}{l}-0.122^{* * *} \\
(-13.69)\end{array}$ & $\begin{array}{l}-0.00284 \\
(-0.01)\end{array}$ & & & & & & & & \\
\hline $\begin{array}{l}\text { Interacted: } \\
\text { Income per capita, steeply-sloped land }\end{array}$ & $\begin{array}{l}0.0382^{* * *} \\
(3.81)\end{array}$ & $\begin{array}{l}-0.0838 \\
(-0.24)\end{array}$ & & & & & & & & \\
\hline $\begin{array}{l}\text { Interacted: } \\
\text { Poverty incidence, flat-sloped land }\end{array}$ & & & $\begin{array}{l}-0.188^{* * *} \\
(-5.67)\end{array}$ & $\begin{array}{l}-0.368^{*} \\
(-2.15)\end{array}$ & & & & & & \\
\hline $\begin{array}{l}\text { Interacted: } \\
\text { Poverty incidence, steeply-sloped land }\end{array}$ & & & $\begin{array}{l}0.188^{* * *} \\
(5.81)\end{array}$ & $\begin{array}{l}0.435^{*} \\
(2.42)\end{array}$ & & & & & & \\
\hline $\begin{array}{l}\text { Interacted: } \\
\text { Life expectancy, flat-sloped land }\end{array}$ & & & & & $\begin{array}{l}0.331 \\
(0.63)\end{array}$ & $\begin{array}{l}-8.713^{*} \\
(-2.22)\end{array}$ & & & & \\
\hline $\begin{array}{l}\text { Interacted: } \\
\text { Life expectancy, steeply-sloped land }\end{array}$ & & & & & $\begin{array}{l}-0.237 \\
(-0.47)\end{array}$ & $\begin{array}{l}8.233^{*} \\
(2.17)\end{array}$ & & & & \\
\hline $\begin{array}{l}\text { Interacted: } \\
\text { Mean years of schooling, flat-sloped land }\end{array}$ & & & & & $\begin{array}{l}-1.009 \\
(-1.04)\end{array}$ & $\begin{array}{l}5.128 \\
(1.76)\end{array}$ & & & & \\
\hline $\begin{array}{l}\text { Interacted: } \\
\text { Mean years of schooling, steeply-sloped land }\end{array}$ & & & & & $\begin{array}{l}0.570 \\
(0.61)\end{array}$ & $\begin{array}{l}-5.201 \\
(-1.89)\end{array}$ & & & & \\
\hline $\begin{array}{l}\text { Interacted: } \\
\text { Built-up density, flat-sloped land }\end{array}$ & & & & & & & $\begin{array}{l}0.0454^{*} \\
(2.04)\end{array}$ & $\begin{array}{l}0 \\
(.)\end{array}$ & & \\
\hline $\begin{array}{l}\text { Interacted: } \\
\text { Built-up density, steeply-sloped land }\end{array}$ & & & & & & & $\begin{array}{l}-0.0496^{*} \\
(-2.13)\end{array}$ & $\begin{array}{l}0.599 \\
(0.53)\end{array}$ & & \\
\hline $\begin{array}{l}\text { Interacted: } \\
\text { Population density, flat-sloped land }\end{array}$ & & & & & & & $\begin{array}{l}-0.157 * * \\
(-4.61)\end{array}$ & $\begin{array}{l}-0.935 \\
(-0.81)\end{array}$ & & \\
\hline $\begin{array}{l}\text { Interacted: } \\
\quad \text { Population density, steeply-sloped land }\end{array}$ & & & & & & & $\begin{array}{l}0.0410 \\
(1.30)\end{array}$ & $\begin{array}{l}0 \\
(.)\end{array}$ & & \\
\hline $\begin{array}{l}\text { Interacted: } \\
\% \text { local tax revenues to total income, flat-sloped land }\end{array}$ & & & & & & & & & $\begin{array}{l}-0.195 * * * \\
(-4.86)\end{array}$ & $\begin{array}{l}0.0154 \\
(0.07)\end{array}$ \\
\hline $\begin{array}{l}\text { Interacted: } \\
\quad \% \text { local tax revenues to toal income, stee ply-sloped land }\end{array}$ & & & & & & & & & $\begin{array}{l}0.130^{* *} \\
(3.12)\end{array}$ & $\begin{array}{l}-0.0145 \\
(-0.07)\end{array}$ \\
\hline _cons & $\begin{array}{l}-2.007 * * * \\
(-3.82)\end{array}$ & $\begin{array}{l}-1.972 \\
(-0.82)\end{array}$ & $\begin{array}{l}-6.531^{* * *} \\
(-18.11)\end{array}$ & $\begin{array}{l}-8.340^{* * *} \\
(-9.59)\end{array}$ & $\begin{array}{l}-2.160^{* * *} \\
(-3.77)\end{array}$ & $\begin{array}{l}5.445 \\
(0.42)\end{array}$ & $\begin{array}{l}-1.544^{* * *} \\
(-3.97)\end{array}$ & $\begin{array}{l}-8.889 \\
(-0.30)\end{array}$ & $\begin{array}{l}-5.563^{* * *} \\
(-29.21)\end{array}$ & $\begin{array}{l}-6.539^{* * *} \\
(-14.89)\end{array}$ \\
\hline $\begin{array}{l}n \\
\text { R-sq }\end{array}$ & $\begin{array}{l}722 \\
0.4436\end{array}$ & $\begin{array}{l}722 \\
0.112 \\
\end{array}$ & $\begin{array}{l}722 \\
0.3541 \\
\end{array}$ & $\begin{array}{l}722 \\
0.116 \\
\end{array}$ & $\begin{array}{l}722 \\
4391 \\
\end{array}$ & $\begin{array}{l}722 \\
0.115\end{array}$ & $\begin{array}{l}722 \\
0.5524 \\
\end{array}$ & $\begin{array}{l}722 \\
0.113\end{array}$ & $\begin{array}{l}722 \\
0.4437\end{array}$ & $\begin{array}{l}722 \\
0.106 \\
\end{array}$ \\
\hline $\begin{array}{l}\text { Prob >chi2 of } \\
\text { Hausman Test }\end{array}$ & & $\begin{array}{l}.2257 \\
\text { se RE }\end{array}$ & & $\begin{array}{l}.1159 \\
\text { se RE }\end{array}$ & & $\begin{array}{ll}0.115 \\
\text { e RE }\end{array}$ & & $\begin{array}{ll}0.115 \\
\text { e RE }\end{array}$ & & $\begin{array}{l}10.09 \\
\text { e RE }\end{array}$ \\
\hline
\end{tabular}




\title{
Chapter 4
}

\section{Floods and Pestilence: Diseases in Philippine Urban Areas}

\begin{abstract}
Do floods affect the probability for urban households to suffer from diseases? We study Cagayan de Oro, a highly-urbanized city in the Philippines that exhibits many of the common characteristics of urban areas in middle-income countries. We use the 2014 Climate and Disaster Risk Exposure Database for the city's floodplains, and cover 13,568 households and 13 diseases. Bronchitis, respiratory tract infection, influenza, chicken pox, measles, typhoid fever, diarrhoea, leptospirosis, dengue, hypertension, and heart diseases are each associated with either one or a combination of the flood variables: exposure, height, or duration. We quantify their incremental incidence due to flood exposure, and provide indicative estimates on their cost implications both to the government and to the disease-affected households. In general, we find that flood-induced diseases cause large cost to the government as well as heavy financial burden on affected families, particularly among the economically disadvantaged. Cost estimation is undertaken for the floodplains of Cagayan de Oro City, and expanded to all urban areas in the Philippines to serve as inputs for discussions on the expansion or redesign of policies aimed at ensuring people's safety from disasters, diseases, and impoverishment within a typical urban setting.
\end{abstract}




\subsection{Introduction}

The Sendai Framework for Disaster Risk Reduction (SFDRR) 2015-2030 calls for a "more explicit focus on people and their health" (UN, 2015a). Of the seven global targets in the framework, four are directly linked to health (UNISDR, 2015b). Likewise, the 17 Sustainable Development Goals (SDGs) places "Good health and well-being", including in times of disasters, as one of the imperatives in transforming the world (UN, 2015b). ${ }^{42}$ Together, these reflect the fact that aside from disaster-related deaths and injuries, the increased incidences of diseases and occurrences of outbreaks are also critical impacts on people in the aftermath of disasters. ${ }^{43}$

This paper attempts to quantitatively examine the association between floods and diseases in an urban setting, and to make broad estimates of the implications on public health finance and household income and wellbeing. We see this as an important research undertaking given that disasters and diseases both have important economic consequences. Among others, disasters bring damage to capital and disrupt economic activities that may ultimately translate to long-term adverse impacts, including welfare losses among affected households (Hallegatte, Vogt-Schilb, Bangalore, \& Rozenberg, 2017; Noy \& duPont, 2016) . Diseases cause loss of worker productivity, output loss, and increased public health expenditure. At the microeconomic level, disease-affected individuals suffer, incur unexpected medical expenses, and forego earning incomes (Goerg, Patterson-Lomba, Hébert-Dufresne, \& Althouse, 2014; Ruger, Jamison, Bloom, \& Canning, 2012; WHO, 2009). Also, either the impacts of flood disasters or of diseases can lead to poverty traps (Bonds, Keenan, Rohani, \& Sachs, 2010; Carter, Little, Mogues, \& Negatu, 2007; Hallegatte et al., 2016a).

${ }^{42}$ Ten of the 17 SDGs have targets associated with disaster risk reduction (UNISDR, 2015a).

${ }^{43}$ Climate change is foreseen to increase the frequency and intensity of some natural hazards, including floods (IPCC, 2014). Likewise, the World Health Organization pronounces climate change as an additional challenge in attaining improvements in human health (WHO, 2003). 
We first study the floodplains of Cagayan de Oro City, and then broaden the analysis to cover all urban areas in the Philippines. The city exhibits many of the typical characteristics of urban areas in the country, and in other middle-income countries elsewhere. It is characterized by limited public resources that are thinly spread across many competing development needs; rapid and unplanned urbanization; and, expansion of settlements with increased poverty concentration in hazard-prone areas. ${ }^{44}$ Meanwhile, the Philippines is one of the most at-risk countries to tropical cyclones in the east and southeast regions of Asia (Pelling, 2012), and experiences massive destructions from the associated floods, landslides, and storm surges. ${ }^{45}$

As a quick preview to our results, we find that bronchitis, respiratory tract infection, influenza, chicken pox, measles, typhoid fever, diarrhoea, leptospirosis, dengue, hypertension, and heart diseases are each associated with either flood exposure, flood height, or flood duration, or a combination of these flood-related variables. However, we find no such significant association between any of the flood-related variables and either tuberculosis or malaria. Our estimates on the cost implications of diseases reveal very large opportunity costs both to the government and to the disease-affected households; and, among the affected households, falling into poverty or extreme poverty are likely adverse consequent effects of these costs.

This paper is organized as follows: Section 4.2 presents a review of literature with greater focus on the quantitative empirical studies on floods and diseases. Section 4.3 profiles our study area, highlighting the characteristics

\footnotetext{
44 These characteristics are among the critical contributory factors to the magnitude of disasters, including those brought by floods, in the Philippine urban areas (Ballesteros, 2010).

45 The rapid influx of people resulted in densely populated urban poor communities, many of which are experiencing greater hazard vulnerability and exposure due to encroachment on areas prone to hazards (ADB, 2009b; Gaillard et al., 2007; Ginnetti et al., 2013; WB-EASPR, 2003), and greater health issues resulting from overcrowding and poor living conditions.
} 
typical of urban areas in the Philippines. Section 4.4 presents the model, estimation method, and dataset we use. Section 4.5 discusses the results on the linkage of floods and diseases, while Section 4.6 presents the cost implications of flood-induced diseases. Section 4.7 provides general conclusions, broad policy implications, and some caveats.

\subsection{Literature Review}

In the Economics discipline, there is a growing number of empirical quantitative inquiry on the socioeconomic determinants of disaster impacts on fatalities (such as in Anbarci et al. (2005), Kahn (2005), Peduzzi (2006), Raschky (2008), and Toya and Skidmore (2007)). ${ }^{46}$. However, we find no quantitative economic literature that attempts to establish the link between floods and diseases. There is a broad consensus among the wide empirical economic literature that health is a key factor in increasing welfare, as well as a "form of human capital that promotes economic development" (Ruger et al., 2012). As argued, good health directly increases welfare as rational individuals prefer to be healthy than otherwise; it also indirectly increases welfare as a person's marginal utility from consuming goods and services is influenced by his or her health condition (WHO, 2009). Also, as healthy individuals are able to undertake productive activities, they are also able to consume goods and services they desire (WHO, 2009).

In the fields of medicine and social sciences (outside economics), the effort to systematically and quantitatively establish the link between floods and diseases is growing, though not yet very extensive. We present the key

\footnotetext{
46 There is a general consensus among existing cross-country empirical studies that a country's level of economic development is inversely related to people's vulnerability to disasters (Anbarci et al., 2005; Kahn, 2005; Peduzzi, 2006; Raschky, 2008; Toya \& Skidmore, 2007). Kahn (2005) asserts that economic development serves as an "implicit insurance" that cushions the adverse disaster impacts on people. Social conditions, particularly education, matter more than the level of income in reducing disaster deaths in less affluent countries (Toya \& Skidmore, 2007), and unplanned and mismanaged urbanization either create or enhance people's vulnerabilities to disaster impacts (Kellenberg \& Mobarak, 2008). Likewise, there are fewer fatalities among countries with better institutions (Adger, 1999; Kahn, 2005; Raschky, 2008). Yonson, Gaillard, and Noy (2016) find that in the context of the Philippine provinces, poverty and people's exposure matter more than the hazard itself in determining deaths from tropical cyclone disasters.
} 
results of studies using quantitative methods here, with the aim of identifying some gaps that our current research attempts to fill. ${ }^{47}$

Del Ninno, Dorosh, Smith, and Roy (2001) studied the health impacts of the 1998 floods in Bangladesh. They find that the various levels of flood severity positively determine the probability for an individual to be sick with either diarrhoea, respiratory illnesses, or fever. The probability to contract any of these illnesses increases as the level of flood severity increases. These findings are supported by those found in a similar study conducted by Kunii, Nakamura, Abdur, and Wakai (2002) among 517 individuals in two districts that were exposed to the same 1998 Bangladesh floods. The results reveal water storages consequent to the floods, absence of water purification tablets, and poverty significantly increases the probability of experiencing diarrhoea.

A few quantitative empirical studies have likewise explored the long-term health impacts of floods. In the case of the 1998-1999 floods in the province of Hunan in China, Liu et al. (2006) find that both the type and severity of flood increase the probability for individuals to suffer post-traumatic stress disorder (PTSD). In addition, they find that PTSD incidence is greater among women than among men, and that there is greater probability for individuals 18 years and above to suffer from the disorder.

While the above studies are in the context of a developing country, similar empirical and quantitative studies have also been undertaken in developed countries. For instance, Lamond, Joseph, and Proverbs (2015) conducted a household study related to the 2007 flood event in England. Flood severity, household income, and duration of relocation are found to be significant factors associated with deterioration of mental health. Thus, whether in an

\footnotetext{
47 We note however that there are numerous related work on floods and diseases but which are not within the economics discipline. Ahern, Kovats, Wilkinson, Few, and Matthies (2005) undertook a review on the large body of published empirical literature that present epidemiologic evidence of the health impacts of floods in various parts of the world.
} 
affluent or less affluent country, floods have adverse health impacts, including those that are more long-term in nature such as post-traumatic stress disorder and other mental illness.

The above studies provide some robust quantitative evidence of the association between floods and diseases. We aim to add value to this strand of research by approaching the inquiry from an economic standpoint. Similar to the above studies, we undertake a quantitative inquiry but, unlike these studies, we simultaneously cover several diseases and we use a very large number of households. We also proceed further to quantify some important cost implications to the government and to the affected households. We focus on urban areas, given the greater concentration of economic activities that may be disrupted by natural hazard and health shocks.

\subsection{Profile of the Study Area}

Cagayan de Oro City is the regional centre of Northern Mindanao (or Region X), the second largest regional economy in the Mindanao island of the Philippines ${ }^{48}$ (PSA, 2015b). As early as 1983, the city was classified as "highly urbanized"49 (GOP, 1983), and has continued to undergo rapid urbanization even after more than three decades. Its population growth rate for the period $2010-2015$ is $2.23 \%$, which is higher than the national average but is comparable to other Philippine urban areas. ${ }^{50}$ Based on the result of the 2015 Census, Cagayan de Oro is the ninth most populous city in the country, with a total population of 675,950 and population density of 1,383 persons per square kilometre (PSA, 2016b).

\footnotetext{
${ }^{48}$ The Philippines is divided into three major island groups: Luzon, Visayas, and Mindanao

${ }^{49}$ This is based on population and city income criteria stipulated in the Local Government Code of 1983 (GOP, 1983). The Local Government Code of 1983 was repealed by Republic Act No. 7160, otherwise known as the Local Government Code of 1991 (GOP, 1991).

${ }^{50}$ Author's computation based on data from PSA (2016a) and PSA (2016c).
} 
As in other urban areas in the country, the city's hazard-prone areas are becoming more densely populated because of its rapid and unplanned urbanization. Living conditions in informal settlements in flood-prone coastal areas and riverbanks worsen as they become more crowded (NEDA, 2012). Poverty incidence city-wide is lower than the national average $(7.7 \%$ vs $19.7 \%$ in 2012), but those in the city's pockets of poverty are much higher.

Several geographic characteristics of the city make it susceptible to coastal, riverine, and urban floods. As can be gleaned in Figure 4-1, Cagayan de Oro is a coastal city located along the Macajalar Bay. It is traversed by two major rivers, Cagayan de Oro and Iponan Rivers that comprise a network of rivers, creeks, and tributaries that drain into the bay. The city's floodplains have a high concentration of institutional, industrial, and commercial establishments, as well as residential areas. Urban floods are typically experienced during the rainy season when heavy rainfall saturates the city's drainage system (LGU-CDO, 2016). Often, these urban floods only worsen traffic congestion in the main thoroughfares without necessarily causing damage to various productive assets. Inundation typically subsides in less than three hours, with depths of up to half a meter only (LGU-CDO, 2016). 


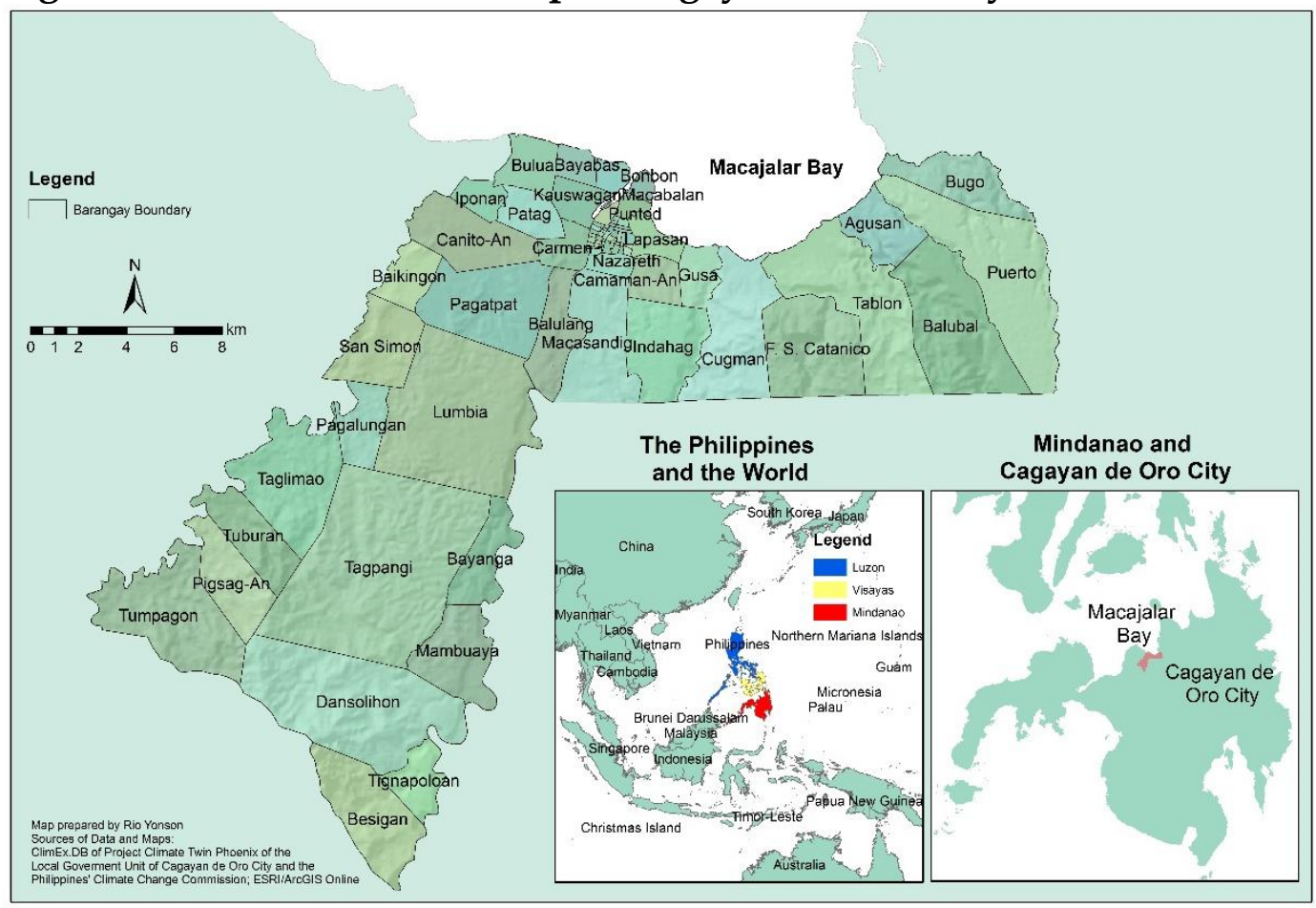

Apart from climate change, the city's 2016 Vulnerability and Adaptation Assessment Report (LGU-CDO, 2016) identifies the following factors, among others, that worsen the magnitude and impacts of floods: denuded forest in upland areas; intensive land cultivation of large plantation areas; and, illegal and unsustainable mining activities within the Cagayan de Oro Watershed. In recent years, the city has experienced destructive flash flood and riverine flood disasters. The worst among these occurred on 16 December 2011; the combined effects of the excessive rainfall volume brought by Tropical Storm Washi ${ }^{51}$ in the headwaters of the city's major rivers, and the high tidal level of the Macajalar Bay brought widespread flooding (Ginnetti et al., 2013; Guha-Sapir et al., 2012; NDRRMC, 2012a; NEDA, 2012). The rampaging waters carrying debris and mud wiped out the burgeoning settlements along these rivers, particularly on former

\footnotetext{
51 A month's worth of rain fell within 24 hours (NEDA, 2012). Analysis of historical data on rainfall indicate that the volume brought by TS Washi has a return period of 35 years under a log-normal distribution, and 75 years under an exponential distribution (TCAGP, 2014). Meanwhile, it is projected that in 2050 the city will be affected by increased frequency of extreme events, higher temperature, and changes in the amount of rainfall within each season (PAGASA, 2011). With the projected increase in the amount of rainfall, tropical storms with characteristics and associated floods such as those of TS Washi are foreseen to occur more often in a few years (TCAGP, 2014).
} 
riverbeds, and on sandbars and deltas that formed as result of silt accumulation (Ginnetti et al., 2013; LGU-CDO, 2016; NEDA, 2012).

On top of about 700 fatalities, there were 400,000 persons affected, and 19,134 houses either completely or partially damaged in the city (LGUCDO, 2016; NDRRMC, 2014). Apart from the strength of TS Washi and the unsustainable upland production and forest practices (LGU-CDO, 2016; NEDA, 2012), the massive adverse consequences of the flood are also largely attributed to the urban expansion in areas along the rivers (Grünewald \& Boyer, 2013), and failure of governance (Ginnetti et al., 2013). As reported, the displaced population in the aftermath of the Washi disaster brought were those "living in extremely high-risk informal settlements prior to the disaster" (Ginnetti et al., 2013).

TS Washi likewise left serious consequences to the city's health sector. The damage to the equipment and supplies in the health centres compromised the centres' capacity to deliver the immediate health services to the floodexposed areas (LGU-CDO, 2016). Although there were no declared outbreaks of diseases, there was an observed increase in water-borne diseases.

\subsection{Model, Dataset, and Descriptive Statistics}

\subsubsection{Model and Estimation Method}

Our primary aim here is to demonstrate the effect of flood exposure and flood characteristics on the probability of contracting a disease. We adopt the United Nations framework where disaster impact on people is influenced by the characteristics of the hazard, the exposure people to the hazard, and the existing physical, economic, social, and demographic conditions that determines people's vulnerability and/or resilience to disasters (UNISDR, 2009, 2015b). In this study, the disaster impact we study is morbidity resulting from the experience of households to floods. 
We estimate a binary response model using the logistic regression method, as follows:

$P(y=1 \mid \boldsymbol{H}, E, \boldsymbol{V})=\frac{\exp \left(\beta_{1} \boldsymbol{H}_{i}+\beta_{2} E_{i}+\beta_{3} \boldsymbol{V}_{i}+u_{i}\right)}{\left[1+\exp \left(\beta_{1} \boldsymbol{H}_{i}+\beta_{2} E_{i}+\beta_{3} \boldsymbol{V}_{i}+u_{i}\right)\right]} \quad$ Equation 1

where $y$ takes on a value of one (1) when the household experienced a given disease, and zero (0) otherwise; $\boldsymbol{H}$ is the vector of variables that serve as proxies for the characteristics of the hazard, i.e. flood height and flood duration; $E$ is our indicator of household exposure to floods, i.e. whether or not the household had been flooded; and, $V$ is vector of other control variables that may affect the probability of getting sick from a given disease (i.e. factors that affect a household's vulnerability and resilience to diseases).

We run two sets of regressions. In the first set, we run regressions by specific disease, while in the second set, we run regressions by disease categories. We group the diseases into categories in the second set of regressions given that individuals or households may imperfectly distinguish among specific diseases with similar symptoms.

\subsubsection{Dataset}

We use the 2014 Climate and Disaster Risk Exposure Database (ClimEx.db) for the floodplains of Cagayan de Oro City. It is a survey of 15,942 households. ClimEx.db was first implemented in the cities of Cagayan de Oro and Iligan in the Northern Mindanao Region of the Philippines that were devastated by TS Washi. ClimEx.db for the Cagayan de Oro City's floodplains covers 23 of the city's 80 barangays ${ }^{52}$. Within each barangay, the areas most at risk to floods were delineated for coverage in the database. ${ }^{52}$ A barangay is the lowest administrative unit in the Philippines. It serves as the primary planning and
implementing body of the government at the community level (GOP, 1991) 
The household population in the database comprise approximately $20 \%$ of the total population in the covered barangays

\section{Figure 4-2. Location of Households in the Dataset}

(on Climate-adjusted Flood Hazard Map; Return period of rainfall volume: 100 years)

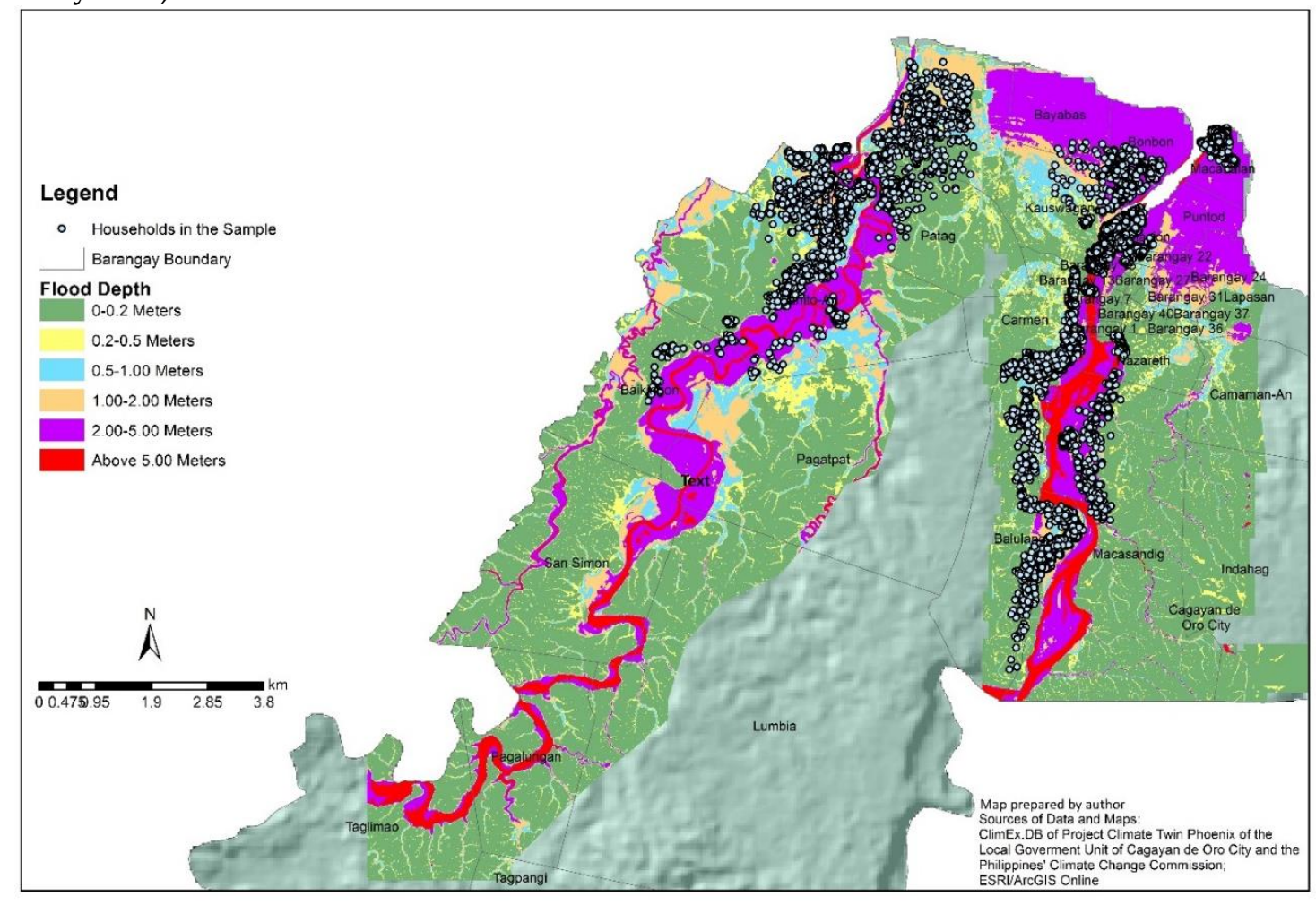

We use only 13,568 households as our dataset. We dropped 747 households that did not have information on whether they experienced flooding. Likewise, we dropped all 1,625 households in three barangays where there were no incidences of any disease; we suspect an error either in the enumeration or recording of survey responses as it is unlikely that households in these barangays were not affected at all by any of the several common diseases we cover. We also drop the only 2 household respondents in another barangay. Figure 4-2 shows the location of households in our dataset overlain on the climate-adjusted flood hazard map for a rainfall volume with a 100-year return period. 


\subsubsection{Diseases Covered}

We study 13 diseases that caused morbidity among the households approximately within the period $2011-2014^{53}$. We note that the information in our dataset is based on self-reporting. This implies that household responses to the question on what diseases they experienced may not necessarily be based on earlier diagnosis by health and/or medical practitioners. At the time that we conducted this study in 2016, it is the only quantitative study that both had a large number of households, and several diseases covered. Table 4-1 below shows the 13 diseases we cover, and the categorization we use for the second set of regressions.

Table 4-1. Categories of Diseases for the Second Set of Regressions

\begin{tabular}{|l|l|}
\hline \multicolumn{1}{|c|}{ Category } & \multicolumn{1}{c|}{ Specific Diseases Included } \\
\hline Any Disease & $\begin{array}{l}\text { Bronchitis, respiratory tract infection, tuberculosis, influenza, } \\
\text { chicken pox, measles, typhoid fever, diarrhoea, leptospirosis, } \\
\text { dengue, malaria, hypertension, heart diseases }\end{array}$ \\
\hline Respiratory-related & Bronchitis, respiratory tract infection, tuberculosis \\
\hline Air-borne & Influenza, chicken pox, measles \\
\hline Water or Food-borne & Typhoid fever, diarrhoea, leptospirosis \\
\hline Vector-borne & Dengue, malaria \\
\hline $\begin{array}{l}\text { Non-communicable } \\
\text { diseases }\end{array}$ & Hypertension and heart diseases \\
\hline
\end{tabular}

We run a total of 18 separate regressions: 1 for each of the 12 specific diseases, ${ }^{54}$ and 1 for each of the 6 categories of diseases.

\subsubsection{Flood Characteristics and Flood Exposure}

We use two hazard characteristics as proxies of $\mathrm{H}$ in Equation 1. These are the flood height (expressed in meters) and the flood duration (expressed in hours) that each household experienced. For E in Equation 1, we use a dummy variable that takes on a value of one (1) if the household was exposed to a flood, and zero (0) otherwise. We hypothesize that each flood

\footnotetext{
${ }^{53}$ The survey for the database was undertaken in May 2014 and asked the households the diseases that they experienced in the last 3 years.

${ }^{54}$ In the first set of regressions, malaria is not included. Only 16 households in our sample experienced malaria, all were flood-exposed.
} 
variable bears a positive coefficient in regressions where it is significantly associated with a given disease.

There are various channels through which floods might increase the incidence of different diseases. Areas exposed to floods become breeding areas for pathogens that result in the spread of various diseases in these areas (Del Ninno et al., 2001; Maryam et al., 2012). The most common resulting diseases are vector-borne diseases, such as dengue and malaria.

Massive floods may lead to displacement and prolonged stay of a large number of affected households in evacuation centres. Respiratory-related, as well as water, food, vector-, and air-borne diseases are likely to spread amidst crowding, poor hygiene, lack of access to clean water, and lack of disease prevention measures in these centres (Kouadio, Aljunid, Kamigaki, Hammad, \& Oshitani, 2012; Maryam et al., 2012; Matthew et al., 2016; John T. Watson, Michelle Gayer, \& Maire A. Connolly, 2007). Stress and fatigue from flood exposure and the difficult circumstances that the affected households may experience in the aftermath can also lead to psychological distress and morbidity (Carroll, Balogh, Morbey, \& Araoz, 2010; Lamond et al., 2015).

The damage to or contamination of drinking water facilities with dirty water is another channel though floods increase the incidence of diseases (Kondo et al., 2002; Kunii et al., 2002). These diseases typically include diarrhoea and typhoid fever. Flood waters may also carry animal waste that are harmful to people. Infection from diseases happens when open wounds of people come in contact with the urine of infected rodents carried by floods (Vijayachari, Sugunan, \& Shriram, 2008; John T. Watson et al., 2007).

We note that the households in our dataset face similar level of flood risk. By the time that the survey for the dataset we use was conducted, the households that face greater risk from floods in the floodplains of Cagayan 
de Oro had been displaced and eventually transferred to various resettlement sites. The massive floods brought by TS Washi in December 2011 wrecked houses and communities nearest to the banks of the Iponan and Cagayan de Oro rivers. In the aftermath of this disaster, Red Zones were declared, thereby forcing households out of the areas with the highest susceptibility to floods.

\subsubsection{Physical, Economic, Social, Demographic Determinants of Diseases}

Our spatial and geocoded datasets allow us to measure the distance from each household dwelling to the shoreline. Apart from greater exposure to coastal floods, households that are closer to the shoreline experience greater relative humidity. With distance to shoreline as our proxy indicator for relative humidity, we would expect a negative coefficient of this variable, indicating that the probability to suffer from a disease decreases the farther a household is from the shoreline.

We also control for household water service connection, i.e. the source of drinking water among the households. Exposure to contaminated waters is one of the most common channels through which floods lead to diseases. We use a dummy variable where one (1) indicates that the household has a piped water service connection within their household dwelling or uses bottled water as source of drinking water, and zero (0) otherwise.

Earlier empirical works also find that social conditions, such as education, reduces the magnitude of disaster impacts (Noy, 2009; Raschky, 2008; Toya \& Skidmore, 2007). They assert that individuals with high level of education are better able to make informed decisions, including along ensuring their safety. Thus, we also control for level of education using the proportion of household members who have completed at least a high school education. 
Likewise, we also use household demographic variables typically used in the empirical literature. We control for household size given that, all else the same, larger households simply by having more number of members have higher probability of experiencing a disease than smaller households. We also control for household composition in terms of percentage of members by age-group in order to determine who are most susceptible to each disease and/ or category of diseases. Age is known to be a determinant of certain diseases (Jacobsen, 2008; Nomura et al., 2016). For instance, heart disease and hypertension are more common among older than younger individuals, while measles and chicken pox are typically experienced among children and youth. To avoid multicollinearity, we drop the percentage of household members with ages 19 to 59 years old, which is the population age-group that may be considered as relatively less vulnerable to diseases.

We recognize that income or poverty variable is a key control variable that is associated with the probability of households to experience diseases (Leal Filho, 2016; Nomura et al., 2016). However, over 3,000 households in our dataset did not report their income levels. Thus, controlling for income or using a poverty variable (computed based on an income threshold) means losing 3,000 observations in our dataset. This could also potentially lead to selection bias. However, omitting an important control variable could also potentially lead to bias.

Thus, we run another regression where we use an alternative measure of poverty, which is based on housing structure. We use a dummy variable to indicate whether or not the household is poor. We then compare the results with those of regressions where we do not control for income or incomebased poverty measure.

We note that there is a whole host of other variables found to be important determinants of diseases. These include lifestyle, access to health care and 
health insurance, and genetic and biological factors (Nomura et al., 2016). We do not discount the importance of these variables, but given the limits of the information available in the household level datasets, we are not able to control for these. Nonetheless, we have good control variables on flood exposure and flood characteristics that are suitable to one of the purposes of our inquiry, i.e. to examine whether floods and their characteristics are determinants of the probability of getting ill.

\subsubsection{Descriptive Statistics}

Being in the floodplains, $89.67 \%$ of the households in our dataset have been exposed to floods. Across households, the average flood height and flood duration experienced are 1.67 meters and 6.72 hours, respectively. Over $42 \%$ have experienced at least one of the 13 diseases. As can be seen from Table 4-2, the most common disease among the households is influenza, with an incidence of $19.21 \%$. Typhoid fever is the second top cause of morbidity (9.27\% incidence), followed by hypertension $(9.21 \%)$, and diarrhoea $(8.92 \%)$. Diseases with the least incidence are malaria $(0.12 \%)$, tuberculosis $(0.26 \%)$, leptospirosis $(1.60 \%)$, and chicken pox $(1.65 \%)$. 
Table 4-2. Descriptive Statistics

\begin{tabular}{lcccr}
\hline \multicolumn{1}{c}{ Variable } & Mean & Std. Dev. & Min & Max \\
\hline Bronchitis & 0.0657 & 0.2478 & 0 & 1 \\
Respiratory tract infection & 0.0644 & 0.2455 & 0 & 1 \\
Tuberculosis & 0.0026 & 0.0507 & 0 & 1 \\
Influenza & 0.1921 & 0.3939 & 0 & 1 \\
Chicken pox & 0.0165 & 0.1274 & 0 & 1 \\
Measles & 0.0261 & 0.1594 & 0 & 1 \\
Typhoid fever & 0.0927 & 0.2900 & 0 & 1 \\
Diarrhoea & 0.0892 & 0.2850 & 0 & 1 \\
Leptospirosis & 0.0160 & 0.1255 & 0 & 1 \\
Dengue & 0.0315 & 0.1748 & 0 & 1 \\
Malaria & 0.0012 & 0.0343 & 0 & 1 \\
Hypertension & 0.0921 & 0.2891 & 0 & 1 \\
Heart disease & 0.0214 & 0.1449 & 0 & 1 \\
Any disease & 0.4248 & 0.4943 & 0 & 1 \\
Respiratory diseases & 0.1310 & 0.3374 & 0 & 1 \\
Air-borne diseases & 0.2181 & 0.4130 & 0 & 1 \\
Water or Food-borne diseases & 0.1725 & 0.3778 & 0 & 1 \\
Vector-borne diseases & 0.0327 & 0.1777 & 0 & 1 \\
Non-communicable diseases & 0.0996 & 0.2995 & 0 & 1 \\
Flood exposed households & 0.8967 & 0.3043 & 0 & 1 \\
Flood height (in meters) & 1.6723 & 1.3474 & 0 & 5 \\
Flood duration (in number of hours) & 6.7168 & 5.3616 & 0 & 24 \\
Distance of household dwelling to shoreline (in km) & 2.6180 & 1.5509 & 0.0175 & 7.8530 \\
Literacy rate (high school) & 0.3543 & 0.3134 & 0 & 4 \\
Water service connection & 0.8203 & 0.3839 & 0 & 1 \\
Number of household members & 4.4577 & 2.0900 & 1 & 20 \\
Members 0 - 5 years olds & 0.1201 & 0.1668 & 0 & 1 \\
Members 6 - 14 years old & 0.1432 & 0.1771 & 0 & 1 \\
Members 15 - 18 years old & 0.0604 & 0.1213 & 0 & 1 \\
Members 19- 60 years old & 0.6030 & 0.2505 & 0 & 1 \\
Members above 60 years old & 0.0734 & 0.1946 & 0 & 1 \\
\hline & & & & \\
\hline
\end{tabular}

Figure 4-3 shows the comparative incidences of the diseases between floodexposed and not flood-exposed households ${ }^{55}$, where the former has consistently higher incidence than the latter for each of the 13 diseases. Interestingly, the incidences of typhoid fever, diarrhoea, bronchitis, dengue, measles, chicken pox, and leptospirosis among flood-exposed households are more than double those of the not flood-exposed. These differences provide initial indications on the magnitude of the incremental effects of floods on the incidence of each disease, and which diseases are likely to cause outbreaks in the aftermath of flood disasters. The initial Chi-square tests we conduct reveal that these differences in disease incidence between ${ }^{55}$ Table $4-13$ in the appendix shows both the incidence and the number of households affected per disease and
per category of diseases, disaggregated into flood-exposed and not flood-exposed households. 
the two household groups are statistically significant except for tuberculosis and malaria, which have the lowest incidence among the various diseases.

Similarly, it can be seen from Figure 4-4 that the incidence of diseases among the flood exposed households is substantially higher than those not flood-exposed, at $44.44 \%$ against $25.48 \%$. On a per disease category basis, air-borne related diseases are the most prevalent among both groupings of households. Consistent with the results by specific disease, we find that the incidences of water- or food-borne diseases, respiratory-related diseases, and vector-borne diseases among flood-exposed households are more than double those of the not flood-exposed.

The georeferenced dwellings of households in our dataset allows us to generate descriptive spatial statistics. Specifically, we use the Kernel Density in the Spatial Analyst tool in ArcGIS to determine areas with the highest density of households affected by any of the 13 diseases. ${ }^{56}$ We show the results in Figure 4-5, overlain on the two highest flood levels of the climate-adjusted flood hazard map that approximate the path of the Cagayan de Oro and Iponan Rivers and the most frequently-flooded areas. It can be seen that Barangay Consolacion and the surrounding barangays have the highest density of disease-affected households. Located in these barangays are some settlements that are among Cagayan de Oro City's pockets of poverty, or where low-income households have relatively high density (refer to Figure 4-6). Further, all five of the islets that formed from silt, but which are nonetheless have growing communities, are located in these barangays. ${ }^{57}$ Furthermore, it can be gleaned from Figure $4-5$ that areas relatively likely to experience floods also have high density of diseases.

\footnotetext{
${ }^{56}$ We use household size as weight for each point data (or each household in the sample). ArcGIS uses a quadratic kernel function.

57 In the aftermath of TS Washi, seven areas were proclaimed non-habitable due to high exposure to riverine floods (NEDA, 2012). Apart from these 5 islets are 2 areas in Barangay Macasandig, which is one of the worstaffected barangays by TS Washi
} 
Figure 4-3. Incidence of Disease, by Specific Kind and by Household Groupings (\%)

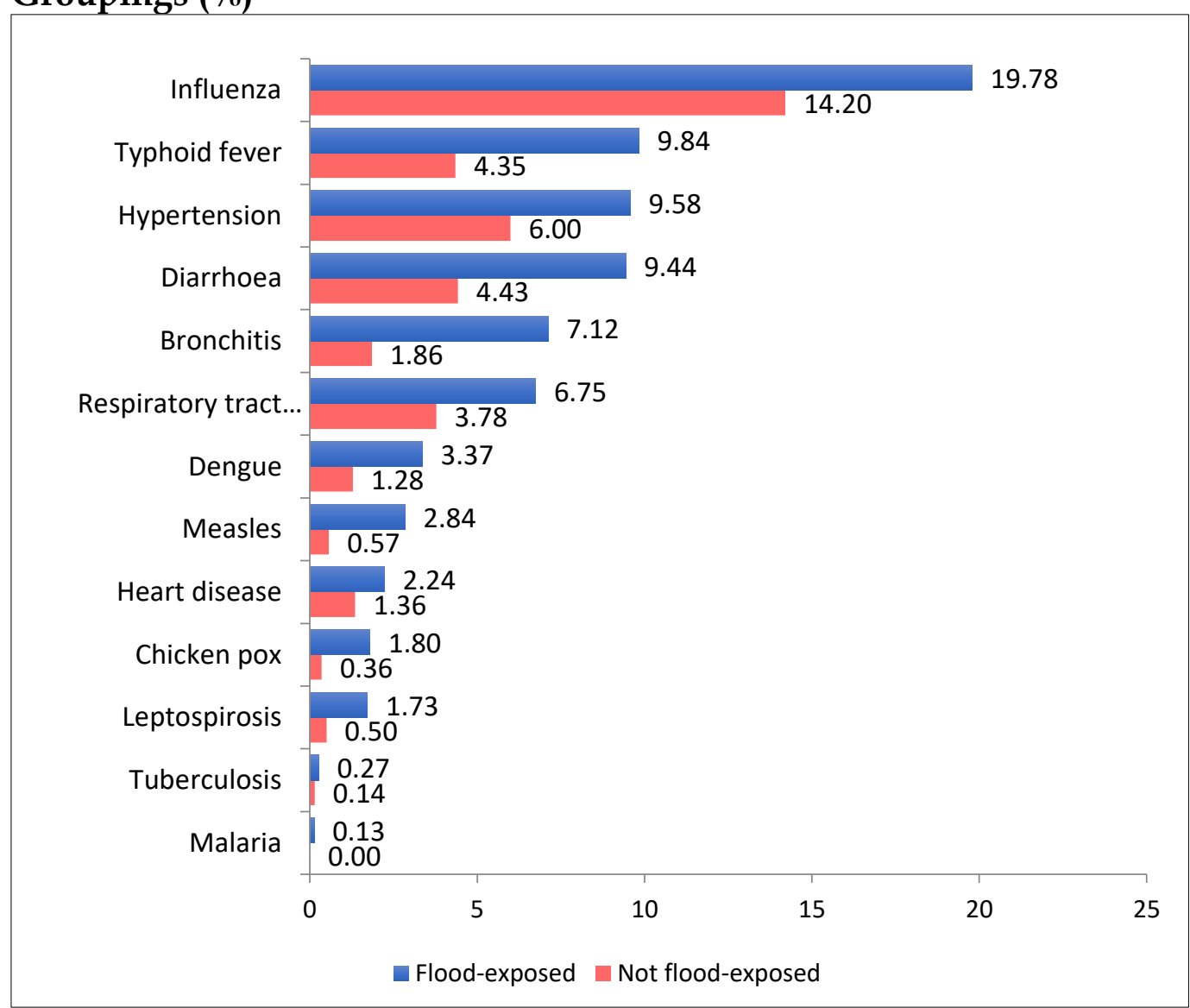

Figure 4-4. Incidence of Disease, by Disease Category and by Household Groupings (\%)

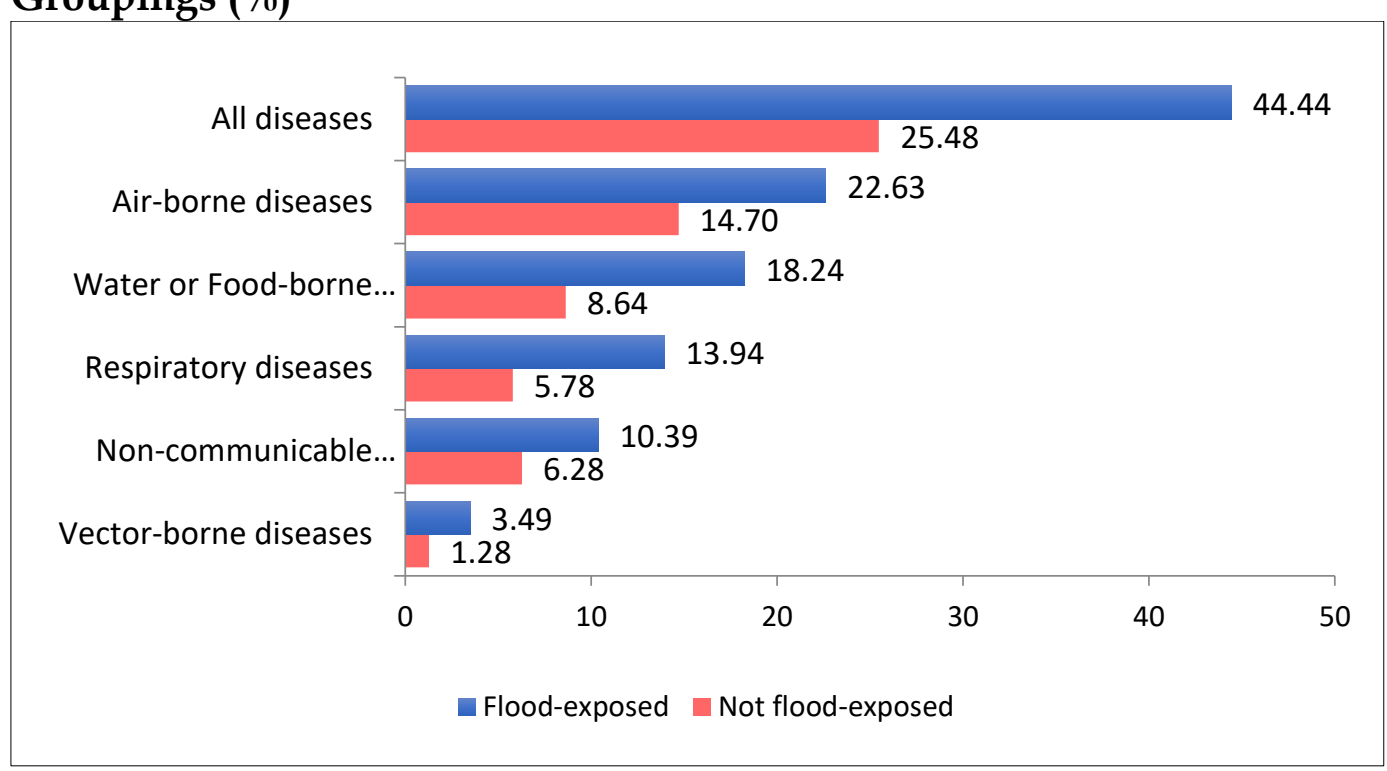


Figure 4-5. Kernel Density Map of Disease-Affected Households

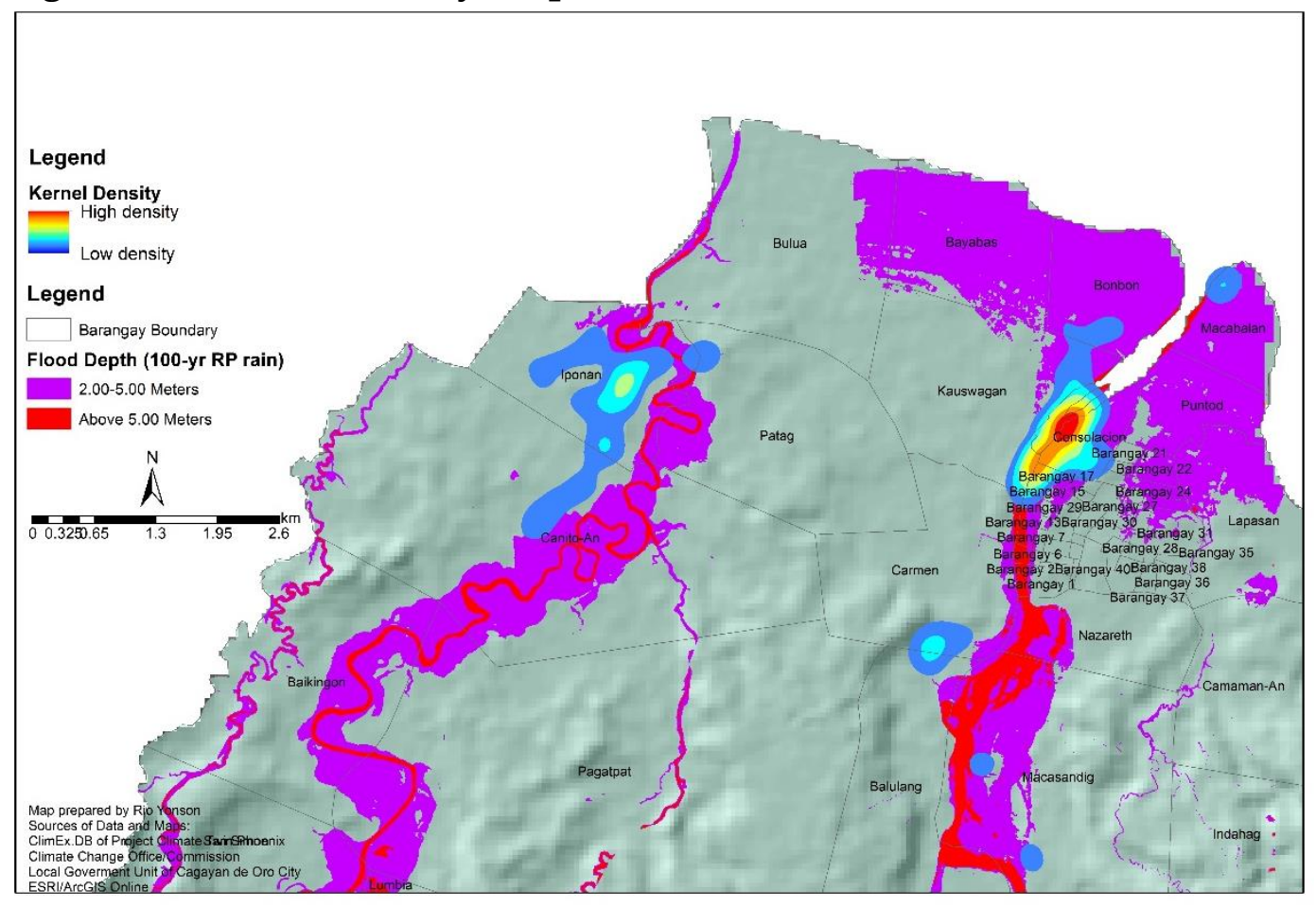

Figure 4-6. Kernel Density Map of Low-Income Households

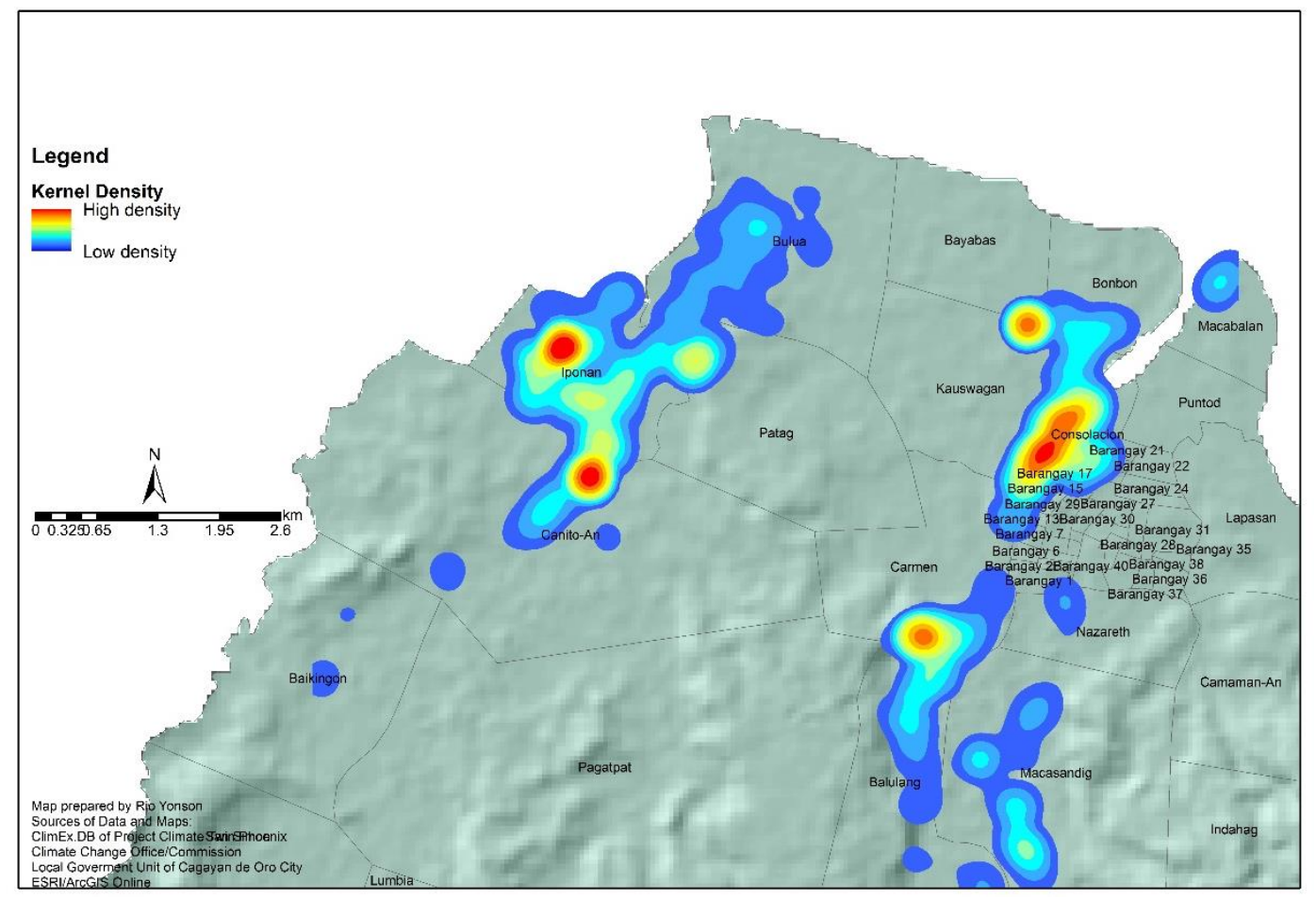




\subsection{Results and Discussions}

\subsubsection{Determinants of the Probability to Get Sick}

Table 4-3 shows the results under the full model specification. For ease in the interpretation of results, we present the marginal effects of a particular explanatory variable on the probability of morbidity from a disease. We note that we do not include malaria in the analysis by specific disease. Eleven of the diseases we cover are significantly associated either flood exposure, flood height, or flood duration, or a combination of these floodrelated variables. These diseases are bronchitis, respiratory tract infection, influenza, chicken pox, measles, typhoid fever, diarrhoea, leptospirosis, dengue, hypertension, and heart disease. We find no significant association between any of the three flood-related variables and tuberculosis.

Bronchitis is linked to all three flood-related variables. All else held constant, the probability for an average household to contract bronchitis increases by 6.19 percentage points if said household was exposed to a flood. Moreover, the probability to contract such a disease increases by 0.35 percentage points for each meter of increase in flood height, and by 0.13 percentage points for an additional hour of flood duration.

Diarrhoea is likewise associated with all flood-related variables. An average household is 8.95 percentage points more probable to suffer from diarrhoea when flood-exposed. This increment is the highest in terms of response to flood exposure across diseases. Surprisingly, flood height and flood duration each has a negative and significant coefficient, indicating that the probability to suffer from diarrhoea decreases as flood height or flood duration increases. Meanwhile, each of the flood-related variables also has a significant association with the probability for dengue. However, we likewise find an unexpected negative sign for the coefficient of flood height. Given that we would expect a positive link between any of the flood 
variables and a given disease, we take another look at these rather counterintuitive results for diarrhoea and dengue in the sensitivity check later in Section 4.5.2.

The probability to contract either respiratory tract infection, chicken pox, or leptospirosis is significantly linked to flood exposure and flood height. Leptospirosis responds positively to both these flood variables. For respiratory tract infection and chicken pox, results show that the higher the flood height, the lower is the probability to suffer from either of these diseases. We likewise check the robustness of these unexpected results for respiratory tract infection and chicken pox later in Section 4.5.2.

Typhoid fever is associated with both flood exposure and flood duration. Influenza, which is the most prevalent disease across households, is positively associated with both flood height and flood duration. Meanwhile, measles, hypertension, and heart disease are positively associated with flood exposure only. The positive and significant coefficient of flood exposure on the probability of suffering from either hypertension or heart disease is likely due to the stress experienced by the exposed household during and in the aftermath of the disaster. Recovering from a disaster is stressful not only financially, but also emotionally and mentally. 58

Table 4-4 shows the results of our second set of regressions on all 13 diseases combined including malaria (Column 1), and on disease categories (Columns 2 - 6) using the same explanatory variables as in our first set of regressions. All else constant, there is 19.6 percentage points increase in the probability to experience at least one of the 13 diseases if the household is

\footnotetext{
${ }^{58}$ Given the above result, it may be worthwhile to conduct an inquiry on post-traumatic disorder and mental health conditions on flood-affected households in the city. Symptoms of these conditions may not be readily observed in the immediate disaster aftermath yet may have long-term consequences. As presented in Section 4.2, Liu et al. (2006) found positive association between the probability for an individual to suffer from post-traumatic stress disorder and flood exposure. Similarly, Lamond et al. (2015) find evidence on the significant link between mental health deterioration and the depth of flood experienced by households.
} 
exposed to a flood. Likewise, the probability of getting ill also increases with increases in flood duration.

Noteworthy is the very strong positive association between air-borne diseases and all three flood-related variables (Column 3 of Table 4-4). It may be worthwhile to investigate the underlying channels through which airborne-related diseases are linked to water-related disasters such as floods. For instance, data-permitting, it is interesting to assess the link between the probability of diseases and the experience of being in evacuation centres where overcrowding is usually a problem. ${ }^{59}$ It has been argued that post disaster disease outbreaks are mainly associated with the displacement of the affected population (J. T. Watson, M. Gayer, \& M. A. Connolly, 2007).

Column 2 of Table 4-4 shows that flood exposure and flood duration increase the probability for households to be affected with respiratoryrelated diseases. Similarly, flood exposure is positively associated with water- or food-borne, vector-borne, and non-communicable diseases. As in the case for dengue, the coefficient for flood height under vector-borne diseases is negative and significant - another counterintuitive result that we check for robustness in Section 4.5.2.

As to the other control variables, Table 4-3 also shows that the more distant the household dwelling is from the shoreline, the lower is the probability for the household to get sick from respiratory tract infection, measles, typhoid fever, and, diarrhoea. Households with a higher proportion of members who have completed at least a high school education have a lower probability to experience bronchitis, influenza, chicken pox, measles, and diarrhoea. ${ }^{59}$ As discussed in Section 4.3, the extended stay in evacuation centres affected the physical and mental health of
those displaced in the aftermath of TS Washi (LGU-CDO, 2014b). 
Access to household water service connection reduces the probability of experiencing bronchitis, respiratory tract infection, and diarrhoea. Surprisingly, Table 4-3 shows that access to water service connection increases the probability of contracting measles and typhoid fever. Likewise, Table 4-4 shows that household water service connection increases the probability of experiencing water- and food-borne diseases. These results warrant further inquiry as access to safe drinking water is supposed to prevent water- and food-borne diseases. Initially, the density map for typhoid fever (Figure 4-7 in the appendix) reveals that households affected by the disease have a seemingly higher density in settlements along the riverbanks of Barangay Consolacion, and neighbouring areas. Some of these settlements are also among the pockets of poverty in the city where living conditions, including access to water and sanitation, are inferior compared to those in other parts of the barangays where they are located, and in the city, in general.60 It may be that the poor conditions in these settlements exacerbate their susceptibility to diseases during flood events.

As for household demographics, we find a highly significant and positive association between household size and several individual diseases, and disease categories. Also, the associated diseases per age group are as would be expected. ${ }^{60}$ We note that $81.6 \%$ of households in our sample have household water connection. City-wide access is higher
at $91.40 \%$ in 2014 (LGU-CDO, 2014a). 
Table 4-3. Full Model, by Specific Disease

\begin{tabular}{|c|c|c|c|c|c|c|c|c|c|c|c|c|}
\hline & Bronchitis & $\begin{array}{l}\text { Respiratory } \\
\text { Tract Infection }\end{array}$ & Tuberculosis & Influenza & Chicken Pox & Measles & Typhoid Fever & Diarrhoea & Leptospirosis & Dengue & Hypertension & Heart Diseases \\
\hline & (1) & (2) & (3) & (4) & (5) & (6) & (7) & (8) & (9) & $(10)$ & (11) & (12) \\
\hline Flood exposure (binary) & $\begin{array}{l}0.0619^{* * *} \\
(5.55)\end{array}$ & $\begin{array}{l}0.0561^{* * *} \\
(6.33)\end{array}$ & $\begin{array}{l}0.000865 \\
(0.76)\end{array}$ & $\begin{array}{l}0.0154 \\
(1.12)\end{array}$ & $\begin{array}{l}0.0253^{* * *} \\
(4.41)\end{array}$ & $\begin{array}{l}0.0405^{* * *} \\
(5.61)\end{array}$ & $\begin{array}{l}0.0667^{* * *} \\
(6.35)\end{array}$ & $\begin{array}{l}0.0895^{* * *} \\
(8.15)\end{array}$ & $\begin{array}{l}0.0132^{*} \\
(2.41)\end{array}$ & $\begin{array}{l}0.0294^{* * *} \\
(4.29)\end{array}$ & $\begin{array}{l}0.0409^{* * *} \\
(4.16)\end{array}$ & $\begin{array}{l}0.0104^{*} \\
(2.12)\end{array}$ \\
\hline Flood height (meter) & $\begin{array}{l}0.00348^{*} \\
(2.30)\end{array}$ & $\begin{array}{l}-0.00900 * * * \\
(-5.99)\end{array}$ & $\begin{array}{l}0.0000295 \\
(0.20)\end{array}$ & $\begin{array}{l}0.0160^{* * *} \\
(6.07)\end{array}$ & $\begin{array}{l}-0.00136^{*} \\
(-2.09)\end{array}$ & $\begin{array}{l}-0.00136 \\
(-1.77)\end{array}$ & $\begin{array}{l}0.000459 \\
(0.28)\end{array}$ & $\begin{array}{l}-0.00766^{* * *} \\
(-4.30)\end{array}$ & $\begin{array}{l}0.00256^{* * *} \\
(4.17)\end{array}$ & $\begin{array}{l}-0.00359 * * \\
(-3.04)\end{array}$ & $\begin{array}{l}0.000422 \\
(0.23)\end{array}$ & $\begin{array}{l}-0.000752 \\
(-0.85)\end{array}$ \\
\hline Flood duration (hour) & $\begin{array}{l}0.00127^{* * *} \\
(3.59)\end{array}$ & $\begin{array}{l}-0.000217 \\
(-0.63)\end{array}$ & $\begin{array}{l}0.0000734 \\
(1.81)\end{array}$ & $\begin{array}{l}0.00277^{* * *} \\
(4.40)\end{array}$ & $\begin{array}{l}0.0000398 \\
(0.26)\end{array}$ & $\begin{array}{l}0.0000905 \\
(0.48)\end{array}$ & $\begin{array}{l}0.00159 * * * \\
(3.99)\end{array}$ & $\begin{array}{l}-0.00102^{*} \\
(-2.33)\end{array}$ & $\begin{array}{l}-0.0000743 \\
(-0.49)\end{array}$ & $\begin{array}{l}0.000475^{*} \\
(1.99)\end{array}$ & $\begin{array}{l}-0.000418 \\
(-1.05)\end{array}$ & $\begin{array}{l}0.00000654 \\
(0.03)\end{array}$ \\
\hline Distance to shore $(\mathrm{km})$ & $\begin{array}{l}0.000988 \\
(0.80)\end{array}$ & $\begin{array}{l}-0.00437^{* * *} \\
(-4.07)\end{array}$ & $\begin{array}{l}-0.000296 \\
(-1.83)\end{array}$ & $\begin{array}{l}0.000673 \\
(0.33)\end{array}$ & $\begin{array}{l}-0.000978 \\
(-1.83)\end{array}$ & $\begin{array}{l}-0.00277^{* * *} \\
(-3.69)\end{array}$ & $\begin{array}{l}-0.00783^{* * *} \\
(-5.74)\end{array}$ & $\begin{array}{l}-0.00670^{* * *} \\
(-4.85)\end{array}$ & $\begin{array}{l}-0.000533 \\
(-0.87)\end{array}$ & $\begin{array}{l}0.00125 \\
(1.54)\end{array}$ & $\begin{array}{l}-0.000956 \\
(-0.70)\end{array}$ & $\begin{array}{l}0.000281 \\
(0.47)\end{array}$ \\
\hline Literacy rate (high school) & $\begin{array}{l}-0.0574^{* * *} \\
(-8.10)\end{array}$ & $\begin{array}{l}0.00536 \\
(0.81)\end{array}$ & $\begin{array}{l}0.000287 \\
(0.39)\end{array}$ & $\begin{array}{l}-0.0797^{* * *} \\
(-6.68)\end{array}$ & $\begin{array}{l}-0.0154^{* * *} \\
(-4.43)\end{array}$ & $\begin{array}{l}-0.0131^{*} \\
(-2.49)\end{array}$ & $\begin{array}{l}-0.00508 \\
(-0.65)\end{array}$ & $\begin{array}{l}-0.0317^{* * *} \\
(-3.40)\end{array}$ & $\begin{array}{l}-0.00268 \\
(-0.86)\end{array}$ & $\begin{array}{l}-0.00448 \\
(-0.95)\end{array}$ & $\begin{array}{l}-0.0134 \\
(-1.77)\end{array}$ & $\begin{array}{l}-0.00281 \\
(-0.76)\end{array}$ \\
\hline Water service connection (binary) & $\begin{array}{l}-0.0366 * * * \\
(-8.35)\end{array}$ & $\begin{array}{l}-0.0344 * * * \\
(-7.71)\end{array}$ & $\begin{array}{l}-0.000973 \\
(-1.59)\end{array}$ & $\begin{array}{l}-0.0140 \\
(-1.60)\end{array}$ & $\begin{array}{l}-0.00137 \\
(-0.58)\end{array}$ & $\begin{array}{l}0.00755^{*} \\
(2.23)\end{array}$ & $\begin{array}{l}0.0966^{* * *} \\
(11.59)\end{array}$ & $\begin{array}{l}-0.0129^{*} \\
(-2.19)\end{array}$ & $\begin{array}{l}-0.00343 \\
(-1.46)\end{array}$ & $\begin{array}{l}-0.000660 \\
(-0.19)\end{array}$ & $\begin{array}{l}0.00925 \\
(1.50)\end{array}$ & $\begin{array}{l}0.000548 \\
(0.19)\end{array}$ \\
\hline Household size & $\begin{array}{l}0.00209^{*} \\
(2.18)\end{array}$ & $\begin{array}{l}0.00204^{*} \\
(2.08)\end{array}$ & $\begin{array}{l}0.000363^{* * *} \\
(3.62)\end{array}$ & $\begin{array}{l}-0.00355^{*} \\
(-2.00)\end{array}$ & $\begin{array}{l}0.000691 \\
(1.65)\end{array}$ & $\begin{array}{l}0.000876 \\
(1.53)\end{array}$ & $\begin{array}{l}0.00168 \\
(1.55)\end{array}$ & $\begin{array}{l}0.00269 * \\
(2.33)\end{array}$ & $\begin{array}{l}0.00212 * * * \\
(5.46)\end{array}$ & $\begin{array}{l}0.00317^{* * *} \\
(6.02)\end{array}$ & $\begin{array}{l}0.0114^{* * *} \\
(11.47)\end{array}$ & $\begin{array}{l}0.00266 * * * \\
(6.37)\end{array}$ \\
\hline $0-5$ years old & $\begin{array}{l}-0.0201 \\
(-1.59)\end{array}$ & $\begin{array}{l}-0.0294^{*} \\
(-2.18)\end{array}$ & $\begin{array}{l}-0.00629 * * \\
(-2.87)\end{array}$ & $\begin{array}{l}-0.00421 \\
(-0.19)\end{array}$ & $\begin{array}{l}0.00431 \\
(0.73)\end{array}$ & $\begin{array}{l}0.0336^{* * *} \\
(4.71)\end{array}$ & $\begin{array}{l}-0.00950 \\
(-0.62)\end{array}$ & $\begin{array}{l}-0.00625 \\
(-0.41)\end{array}$ & $\begin{array}{l}-0.0156^{*} \\
(-2.37)\end{array}$ & $\begin{array}{l}0.0126 \\
(1.39)\end{array}$ & $\begin{array}{l}-0.183 * * * \\
(-10.71)\end{array}$ & $\begin{array}{l}-0.0343^{* * *} \\
(-4.13)\end{array}$ \\
\hline $6-14$ years old & $\begin{array}{l}-0.0111 \\
(-0.92)\end{array}$ & $\begin{array}{l}-0.0394^{* *} \\
(-3.07)\end{array}$ & $\begin{array}{l}0.000586 \\
(0.38)\end{array}$ & $\begin{array}{l}0.0522^{*} \\
(2.54)\end{array}$ & $\begin{array}{l}0.00335 \\
0.67)\end{array}$ & $\begin{array}{l}0.0129 \\
(1.80)\end{array}$ & $\begin{array}{l}0.0176 \\
(1.32)\end{array}$ & $\begin{array}{l}-0.0136 \\
(-0.92)\end{array}$ & $\begin{array}{l}-0.0158^{*} \\
(-2.56)\end{array}$ & $\begin{array}{l}0.0208^{*} \\
(2.54)\end{array}$ & $\begin{array}{l}-0.123 * * * \\
(-8.19)\end{array}$ & $\begin{array}{l}-0.0307 * * * \\
(-4.05)\end{array}$ \\
\hline $15-18$ years old & $\begin{array}{l}0.00877 \\
(0.53)\end{array}$ & $\begin{array}{l}-0.0342 \\
(-1.85)\end{array}$ & $\begin{array}{l}-0.00114 \\
(-0.44)\end{array}$ & $\begin{array}{l}0.0575 * \\
(2.07)\end{array}$ & $\begin{array}{l}0.0102 \\
(1.58)\end{array}$ & $\begin{array}{l}0.0108 \\
(1.18)\end{array}$ & $\begin{array}{l}0.0915^{* * *} \\
(5.67)\end{array}$ & $\begin{array}{l}0.0139 \\
(0.74)\end{array}$ & $\begin{array}{l}-0.0113 \\
(-1.19)\end{array}$ & $\begin{array}{l}0.0253^{*} \\
(2.53)\end{array}$ & $\begin{array}{l}-0.0488^{*} \\
(-2.41)\end{array}$ & $\begin{array}{l}-0.0170 \\
(-1.57)\end{array}$ \\
\hline 60 years old and above & $\begin{array}{l}0.00176 \\
(0.16)\end{array}$ & $\begin{array}{l}-0.00242 \\
(-0.24)\end{array}$ & $\begin{array}{l}0.00366^{* * *} \\
(3.66)\end{array}$ & $\begin{array}{l}-0.0567 * * \\
(-2.91)\end{array}$ & $\begin{array}{l}-0.0136^{*} \\
(-1.96)\end{array}$ & $\begin{array}{l}0.00136 \\
(0.18)\end{array}$ & $\begin{array}{l}-0.0296^{*} \\
(-1.99)\end{array}$ & $\begin{array}{l}-0.0482^{* *} \\
(-3.08)\end{array}$ & $\begin{array}{l}-0.00137 \\
(-0.25)\end{array}$ & $\begin{array}{l}-0.0114 \\
(-1.14)\end{array}$ & $\begin{array}{l}0.106 * * * \\
(11.66)\end{array}$ & $\begin{array}{l}0.0249 * * * \\
(6.46)\end{array}$ \\
\hline $\mathbf{N}$ & 13568 & 13568 & 13568 & 13568 & 13568 & 13568 & 13568 & 13568 & 13568 & 13568 & 13568 & 13568 \\
\hline Psuedo R-s & 0.0346 & 0.021 & 0.0778 & 8079 & 0.0126 & 0.0299 & 0.0372 & 0.0162 & 0.025 & 0.0271 & 0.0503 & 0.0332 \\
\hline
\end{tabular}


Table 4-4. Full Model, by Disease Category

\begin{tabular}{|c|c|c|c|c|c|c|}
\hline & $\begin{array}{c}\text { Any Disease } \\
\text { (1) }\end{array}$ & $\begin{array}{c}\text { Respiratory- } \\
\text { Related } \\
\text { (2) }\end{array}$ & $\begin{array}{c}\text { Air-Borne } \\
\text { (3) }\end{array}$ & $\begin{array}{l}\text { Water- or Food- } \\
\text { Borne } \\
\text { (4) }\end{array}$ & $\begin{array}{c}\text { Vector-Borne } \\
\text { (5) }\end{array}$ & $\begin{array}{c}\text { Non- } \\
\text { Communicable } \\
\text { Diseases } \\
\text { (6) }\end{array}$ \\
\hline Flood exposure & $\begin{array}{l}0.196^{* * *} \\
(11.02)\end{array}$ & $\begin{array}{l}0.110^{* * * *} \\
(8.10)\end{array}$ & $\begin{array}{l}0.0494^{* * *} \\
(3.33)\end{array}$ & $\begin{array}{l}0.135^{* * *} \\
(9.22)\end{array}$ & $\begin{array}{l}0.0315^{* * *} \\
(4.47)\end{array}$ & $\begin{array}{l}0.0451^{* * *} \\
(4.35)\end{array}$ \\
\hline Flood height & $\begin{array}{l}0.00342 \\
(0.97)\end{array}$ & $\begin{array}{l}-0.00387 \\
(-1.71)\end{array}$ & $\begin{array}{l}0.0143^{* * *} \\
(5.15)\end{array}$ & $\begin{array}{l}-0.00267 \\
(-1.09)\end{array}$ & $\begin{array}{l}-0.00378^{* *} \\
(-3.14)\end{array}$ & $\begin{array}{l}0.000597 \\
(0.32)\end{array}$ \\
\hline Flood duration & $\begin{array}{l}0.00269 * * \\
(3.23)\end{array}$ & $\begin{array}{l}0.00134 * * \\
(2.62)\end{array}$ & $\begin{array}{l}0.00300 * * * \\
(4.58)\end{array}$ & $\begin{array}{l}0.00107 \\
(1.80)\end{array}$ & $\begin{array}{l}0.000470 \\
(1.92)\end{array}$ & $\begin{array}{l}0.0000267 \\
(0.06)\end{array}$ \\
\hline Distance to shore & $\begin{array}{l}-0.00718^{*} \\
(-2.51)\end{array}$ & $\begin{array}{l}-0.00408^{*} \\
(-2.41)\end{array}$ & $\begin{array}{l}-0.00216 \\
(-0.99)\end{array}$ & $\begin{array}{l}-0.0129 * * * \\
(-6.57)\end{array}$ & $\begin{array}{l}0.00149 \\
(1.81)\end{array}$ & $\begin{array}{l}-0.00110 \\
(-0.77)\end{array}$ \\
\hline Literacy rate & $\begin{array}{l}-0.0687^{* * *} \\
(-4.61)\end{array}$ & $\begin{array}{l}-0.0496 * * * \\
(-4.94)\end{array}$ & $\begin{array}{l}-0.0979 * * * \\
(-7.69)\end{array}$ & $\begin{array}{l}-0.0131 \\
(-1.13)\end{array}$ & $\begin{array}{l}-0.00433 \\
(-0.90)\end{array}$ & $\begin{array}{l}-0.0136 \\
(-1.68)\end{array}$ \\
\hline Water service connection & $\begin{array}{l}-0.00836 \\
(-0.74)\end{array}$ & $\begin{array}{l}-0.0773 * * * \\
(-12.09)\end{array}$ & $\begin{array}{l}-0.0125 \\
(-1.35)\end{array}$ & $\begin{array}{l}0.0337^{* * * *} \\
(3.83)\end{array}$ & $\begin{array}{l}0.000185 \\
(0.05)\end{array}$ & $\begin{array}{l}0.00768 \\
(1.20)\end{array}$ \\
\hline Household size & $\begin{array}{l}0.0102^{* * *} \\
(4.45)\end{array}$ & $\begin{array}{l}0.00458^{* *} \\
(3.26)\end{array}$ & $\begin{array}{l}-0.00258 \\
(-1.38)\end{array}$ & $\begin{array}{l}0.00496 * * \\
(3.11)\end{array}$ & $\begin{array}{l}0.00315^{* * * *} \\
(5.82)\end{array}$ & $\begin{array}{l}0.0124^{* * *} \\
(11.82)\end{array}$ \\
\hline $0-5$ years old & $\begin{array}{l}-0.138^{* * *} \\
(-4.74)\end{array}$ & $\begin{array}{l}-0.0572 * * \\
(-3.04)\end{array}$ & $\begin{array}{l}0.0205 \\
(0.88)\end{array}$ & $\begin{array}{l}-0.00333 \\
(-0.16)\end{array}$ & $\begin{array}{l}0.0163 \\
(1.77)\end{array}$ & $\begin{array}{l}-0.190^{* * *} \\
(-10.65)\end{array}$ \\
\hline $6-14$ years old & $\begin{array}{l}-0.0593^{*} \\
(-2.17)\end{array}$ & $\begin{array}{l}-0.0484^{* *} \\
(-2.72)\end{array}$ & $\begin{array}{l}0.0468^{*} \\
(2.16)\end{array}$ & $\begin{array}{l}-0.00259 \\
(-0.13)\end{array}$ & $\begin{array}{l}0.0223 * * \\
(2.68)\end{array}$ & $\begin{array}{l}-0.128^{* * *} \\
(-8.20)\end{array}$ \\
\hline $15-18$ years old & $\begin{array}{l}0.0310 \\
(0.83)\end{array}$ & $\begin{array}{l}-0.0349 \\
(-1.39)\end{array}$ & $\begin{array}{l}0.0653^{*} \\
(2.23)\end{array}$ & $\begin{array}{l}0.0862^{* * *} \\
(3.38)\end{array}$ & $\begin{array}{l}0.0254^{*} \\
(2.47)\end{array}$ & $\begin{array}{l}-0.0557^{* *} \\
(-2.62)\end{array}$ \\
\hline 60 years old and above & $\begin{array}{l}0.0458 \\
(1.95)\end{array}$ & $\begin{array}{l}0.00871 \\
(0.58)\end{array}$ & $\begin{array}{l}-0.0702 * * * \\
(-3.37)\end{array}$ & $\begin{array}{l}-0.0498^{*} \\
(-2.50)\end{array}$ & $\begin{array}{l}-0.00987 \\
(-1.00)\end{array}$ & $\begin{array}{l}0.117^{* * *} \\
(12.19)\end{array}$ \\
\hline $\mathrm{N}$ & 13568 & 13568 & 13568 & 13568 & 13568 & 13568 \\
\hline Psuedo R-sq & 0.015 & 0.0251 & 0.0141 & 0.0155 & 0.027 & 0.0502 \\
\hline Correctly classified & 57.26 & 86.9 & 78.19 & 82.75 & 96.73 & 90.03 \\
\hline
\end{tabular}

\subsubsection{Robustness Checks}

As noted in Section 4.4.2.3, we run regressions where we use an alternative measure of poverty that is based on the structure of the household's dwelling. The results are presented in Table 4-14 and 4-15 in the appendix. Overall, the comparison of results between the set of regressions with and without a proxy for poverty does not indicate a potential omitted variable bias if we do not control for poverty in the case of the floodplains of Cagayan de Oro City.

We conduct sensitivity checks to assess the robustness of our results, particularly on our three flood-related variables. These checks involve varying the set of control variables. In the first robustness check, we drop the flood characteristics variables (i.e. height and duration), while in the second check, we drop flood exposure. In the third set of checks, we only control for flood exposure or flood characteristics or a combination of these, and dropped all other explanatory variables. 
Table 4-16 shows the estimation results where flood height and flood duration variables are both dropped. Flood exposure retained its positive sign and is now also significantly associated with influenza. In Table 4-17, we show the results where the flood exposure variable is dropped. We find that under Column 5, the coefficient for flood height remains negative but is no longer significant in influencing the probability for a household to experience chicken pox. However, Column 2 shows that the coefficient for flood height remains negative and significant in the case for respiratory tract infection.

In terms of flood duration, we find under Table 4-17 Column 8 that the coefficient for flood duration remains negative but it is no longer significant in influencing the probability for a household to experience diarrhoea. This likewise nullifies another surprising result discussed earlier under the full model.

Table 4-18 shows a set of regression results where we regress only on one or a combination of the flood exposure and flood characteristics variables. Overall, the comparison of results between the full model and each of the various checks reveal that flood exposure is a robust and positive determinant of the probability for an average household to experience any of the following diseases: bronchitis, respiratory tract infection, chicken pox, measles, typhoid fever, diarrhoea, dengue, leptospirosis, hypertension, and heart disease. Flood height is a robust determinant of the probability to suffer from bronchitis, influenza, and leptospirosis; and, flood duration is a robust determinant for bronchitis, influenza, and typhoid fever. A rather unexpected result that warrants further inquiry is that under respiratory tract infection, coefficient for flood height is consistently negative and significant across various regression specifications. While this may be partly attributed to the imperfect diagnosis of this disease by the household, it is 
nonetheless, worthwhile to conduct a further inquiry. In such an enquiry, it would be appropriate to further disaggregate the disease into the lower and upper respiratory tract infections; these two are not coded separately in the dataset we use in this study.

We run the same set of additional robustness checks for the second set of regressions where we use the disease categories as dependent variable. The comparison of results between the full model (shown in Table 4-4), and the results of each of the various checks reveal that flood exposure is a robust determinant of the probability for a household to experience any of the disease categories. Flood duration is a robust determinant for "Any disease", respiratory-related diseases, and air-borne diseases. Meanwhile, flood height is a robust determinant for air-borne diseases. Interestingly, when all the respiratory-related diseases are categorized into one, we find that the coefficient is also negative but is not significant.

Overall, we find that the three flood-related variables (namely, flood exposure, flood height, and flood duration) are robust and positive determinants of 11 individual diseases. We find that among these three flood-related variables, it is flood exposure that is found to be robust in determining the probability of more number of diseases, and disease categories. While we use a cross-sectional dataset only, the results of our analysis are, however, largely consistent with established knowledge and results of related empirical qualitative and quantitative studies.

\subsection{Cost Implications of Flood-Induced Diseases}

We make indicative estimates on some of the major costs of diseases to the government and to the affected households. ${ }^{61}$ We start with the floodplains

${ }^{61}$ Other macroeconomic costs we did not include are loss of worker productivity and output loss, which are beyond the scope of this paper 
of Cagayan de Oro City, and then broaden the analysis to cover all the urban areas in the Philippines. We consider three scenarios that vary mainly in terms of the assumed percentage used in estimating the number of households affected by flood-induced diseases. ${ }^{62}$ In Scenario 1, we use the coefficient of flood exposure in the initial model with only flood exposure as the regressor, while in Scenario 2, we use the coefficient of flood exposure in the full model. We note that we only use flood exposure in our estimation given that it is the only flood-related variable that consistently has the expected sign across model specifications and across diseases. In Scenario 3 , we use the difference of the incidence per disease between the floodexposed and the not flood-exposed households. Each of these percentages in the different scenario is multiplied to the total number of flood-exposed households to get the estimated number of households that suffered from flood-induced diseases under each scenario.

Tables 4-5 and 4-6 show the estimated number of households affected by flood-induced diseases for the floodplains of Cagayan de Oro and for all urban areas in the Philippines, respectively. For the floodplains for Cagayan de Oro City, the number of flood-exposed households of 12,167 is based on the responses of the households in our dataset.

For all urban areas in the Philippines, the estimated number of floodexposed households for 2014 of 366,497 is estimated using the following assumptions:

a. $75 \%$ of the annual average number of families affected by tropical cyclones for the period 1980-2013 were assumed to had been exposed to the associated flood hazards.

b. Projected percentage of urban population for 2014 is estimated using the projected 2014 total population and projected 2014 urban population of the Philippines.

62 We make several scenarios that vary in terms of the estimated number of households that suffered from floodinduced diseases given the limits of using cross-sectional data in establishing a causal relationship. 
c. The 2014 projected number of flood-exposed households in all urban areas in the Philippines is the product of the results in items $a$. and $b$. above.

Table 4-5. Estimated Number of Households that Suffered from FloodInduced Diseases, Floodplains of Cagayan de Oro City

\begin{tabular}{|c|c|c|c|c|c|c|c|}
\hline \multirow{3}{*}{ Scenario } & \multirow{3}{*}{$\begin{array}{c}\text { Flood- } \\
\text { Exposed } \\
\text { Households }\end{array}$} & \multicolumn{3}{|c|}{$\begin{array}{l}\text { Assumed Percentage of Households that } \\
\text { Suffered from Flood-Induced Diseases (\%) }\end{array}$} & \multicolumn{3}{|c|}{$\begin{array}{l}\text { Estimated Number of Households that } \\
\text { Suffered from Flood-Induced Diseases }\end{array}$} \\
\hline & & Scenario 1 & Scenario 2 & Scenario 3 & \multirow[b]{2}{*}{ Scenario 1} & \multirow[b]{2}{*}{ Scenario 2} & \multirow[b]{2}{*}{ Scenario 3} \\
\hline & & $\begin{array}{l}\text { coefficient of flood } \\
\text { exposure in simple } \\
\text { regression model } \\
\text { with flood } \\
\text { exposure as the } \\
\text { regressor }\end{array}$ & $\begin{array}{l}\text { coefficient of flood } \\
\text { exposure in the } \\
\text { full model }\end{array}$ & $\begin{array}{c}\text { difference of the } \\
\text { disease incidence } \\
\text { between the flood- } \\
\text { exposed and the } \\
\text { not flood-exposed } \\
\text { households }\end{array}$ & & & \\
\hline Bronchitis & 12,167 & 8.16 & 6.19 & 5.26 & 993 & 753 & 640 \\
\hline Respiratory tract infection & 12,167 & 3.63 & 5.61 & 2.96 & 442 & 683 & 361 \\
\hline Influenza & 12,167 & 6.17 & 1.54 & 5.58 & 751 & 187 & 679 \\
\hline Chicken pox & 12,167 & 2.45 & 2.53 & 1.44 & 298 & 308 & 176 \\
\hline Measles & 12,167 & 3.84 & 4.05 & 2.27 & 467 & 493 & 277 \\
\hline Typhoid fever & 12,167 & 7.21 & 6.67 & 5.48 & 877 & 812 & 667 \\
\hline Diarrhoea & 12,167 & 6.47 & 8.95 & 5.01 & 787 & 1,089 & 610 \\
\hline Leptospirosis & 12,167 & 1.87 & 1.32 & 1.23 & 228 & 161 & 149 \\
\hline Dengue & 12,167 & 2.92 & 2.94 & 2.08 & 355 & 358 & 254 \\
\hline Hypertension & 12,167 & 4.21 & 4.09 & 3.58 & 512 & 498 & 436 \\
\hline Heart Diseases & 12,167 & 1.06 & 1.04 & 0.88 & 129 & 127 & 107 \\
\hline Total & & & & & 5,839 & 5,467 & 4,354 \\
\hline
\end{tabular}

Table 4-6. Estimated Number of Households that Suffered from FloodInduced Diseases, All Urban Areas in the Philippines

\begin{tabular}{|c|c|c|c|c|c|c|c|}
\hline \multirow[b]{3}{*}{ Scenario } & \multirow{3}{*}{$\begin{array}{c}\text { Estimated } \\
\text { Flood- } \\
\text { Exposed } \\
\text { Households }\end{array}$} & \multicolumn{3}{|c|}{$\begin{array}{l}\text { Assumed Percentage of Households that } \\
\text { Suffered from Flood-Induced Diseases (\%) }\end{array}$} & \multicolumn{3}{|c|}{$\begin{array}{c}\text { Estimated Number of Households } \\
\text { that Suffered from Flood-Induced } \\
\text { Diseases }\end{array}$} \\
\hline & & Scenario 1 & Scenario 2 & Scenario 3 & & & \\
\hline & & $\begin{array}{c}\text { coefficient of flood } \\
\text { exposure in simple } \\
\text { regression model } \\
\text { with flood } \\
\text { exposure as the } \\
\text { regressor }\end{array}$ & $\begin{array}{c}\text { coefficient of flood } \\
\text { exposure in the } \\
\text { full model }\end{array}$ & \begin{tabular}{|c|} 
difference of the \\
disease incidence \\
between the flood- \\
exposed and the \\
not flood-exposed \\
households
\end{tabular} & Scenario 1 & Scenario 2 & Scenario 3 \\
\hline Bronchitis & 366,497 & 8.16 & 6.19 & 5.26 & 29,906 & 22,686 & 19,284 \\
\hline Respiratory tract infect & 366,497 & 3.63 & 5.61 & 2.96 & 13,304 & 20,560 & 10,866 \\
\hline Influenza & 366,497 & 6.17 & 1.54 & 5.58 & 22,613 & 5,644 & 20,446 \\
\hline Chicken pox & 366,497 & 2.45 & 2.53 & 1.44 & 8,979 & 9,272 & 5,289 \\
\hline Measles & 366,497 & 3.84 & 4.05 & 2.27 & 14,073 & 14,843 & 8,330 \\
\hline Typhoid fever & 366,497 & 7.21 & 6.67 & 5.48 & 26,424 & 24,445 & 20,099 \\
\hline Diarrhoea & 366,497 & 6.47 & 8.95 & 5.01 & 23,712 & 32,801 & 18,361 \\
\hline Leptospirosis & 366,497 & 1.87 & 1.32 & 1.23 & 6,853 & 4,838 & 4,494 \\
\hline Dengue & 366,497 & 2.92 & 2.94 & 2.08 & 10,702 & 10,775 & 7,641 \\
\hline Hypertension & 366,497 & 4.21 & 4.09 & 3.58 & 15,430 & 14,990 & 13,118 \\
\hline Heart Diseases & 366,497 & 1.06 & 1.04 & 0.88 & 3,885 & 3,812 & 3,223 \\
\hline Total & & & & & 175,882 & 164,667 & 131,152 \\
\hline
\end{tabular}

Table 4-7 summarizes the rest of the assumptions we make per cost item. We note that we adopt several simplifying assumptions in cases where actual data is not available. The aim here is to demonstrate the practical 
usefulness of the quantified impacts of floods on the incidence of diseases estimated in Section 4.5 on household level and public health financing. The cost estimates can be updated upon availability of better data.

Tables 4-8 and 4-9 show the results for the floodplains of Cagayan de Oro City, and for all urban areas in the Philippines, respectively. We cover 11 diseases that we earlier found to be associated with flood exposure in either the simple regression model or full model per disease ${ }^{63}$. The cost estimates are in 2014 values, which is the year the ClimEx.db survey was conducted.

The computed additional cost due to floods of the government's provision of social health insurance for the floodplains of Cagayan de Oro ranges from USD 0.99 million to USD1.37 million across scenarios; that for all urban areas in the Philippines ranges from USD 29.86 million to USD41.14 million. These may be considered as conservative estimates given that we made the simplifying assumption that there is only one flood experienced by each household, and only one member per household got sick to a given disease (who is either a hospital in-patient or out-patient).

Meanwhile, among the disease-affected households in the floodplains of $\mathrm{CDO}$, the total out-of-pocket medical cost and foregone earnings ranges from USD 275.10 thousand to USD 378.73 thousand. For all urban areas in the country, the cost to affected households ranges from USD 8.21 million to USD 11.30 million.

\footnotetext{
${ }^{63}$ In the simple regression model, flood exposure is a significant determinant of 11 diseases. In the full model, flood exposure is likewise found to be a significant determinant of the same diseases except influenza. Nonetheless, we use the coefficient of flood exposure in the full model for influenza, which is less than a third of that in the simple regression model. Thus, it gives a conservative estimate of the number of households affected by flood-induced diseases.
} 
Table 4-7. Assumptions on Cost Implications of Flood-Induced Diseases

\begin{tabular}{|c|c|c|}
\hline $\begin{array}{l}\text { Cost to the Government from the } \\
\text { Provision of Social Health Insurance } \\
\text { (SHI) }\end{array}$ & Out-of-Pocket Cost: In-Patient and Out-Patient & Foregone Earnings \\
\hline $\begin{array}{l}\text { - Flood exposure is in terms of } \\
\text { number of families. SHI coverage } \\
\text { is by member. We make the } \\
\text { simplifying assumption that only } \\
\text { one member of each flood- } \\
\text { exposed household gets sick to a } \\
\text { given disease. } \\
\text { SHI benefit rate per disease is the } \\
\text { computed average of the rates of } \\
\text { diseases within disease groupings. } \\
\text { There is maximum availment of } \\
\text { SHI benefits by each hospital in- } \\
\text { patient } \\
\text { Number of in-patients is } 50 \% \text { of } \\
\text { the estimated number of } \\
\text { households affected by flood- } \\
\text { induced diseases. }\end{array}$ & $\begin{array}{l}\text { In-Patient } \\
\text { - } \text { humber of in-patients is } 50 \% \text { of the estimated number of } \\
\text { Hospital cost per day is based on the } 2007 \text { average unit cost } \\
\text { per bed day in all hospitals covered in the Costing Study for } \\
\text { Selected Hospital in the Philippines (Tsilaajav, 2007). The } \\
\text { cost was adjusted to } 2014 \text { values using the annual Consumer } \\
\text { Price Index (CPI) for health (country average) from 2007- } \\
2014 \text {. } \\
\text { - In the absence of actual data, the number of hospital days is } \\
\text { approximated based on the SHI benefit for each disease, } \\
\text { with } 2 \text { and } 5 \text { days as the minimum and maximum number of } \\
\text { days of hospitalization. } \\
\text { Cost in excess of SHI benefits is set to zero if the computed } \\
\text { difference between the Total Hospital Cost per Discharge } \\
\text { and the maximum SHI benefit per disease is negative. } \\
\text { Out-of-pocket cost of medicine is set at } 20 \% \text { of the SHI case } \\
\text { rate for medicine for in-patients. } \\
\text { Out-Patient } \\
\text { - Number of out-patients is } 50 \% \text { of the estimated number of } \\
\text { disease-affected families due to floods. } \\
\text { Out-patient consultation fee is set at } 20 \% \text { of professional fee } \\
\text { covered by the SHI for in-patients. } \\
\text { Cost of medicine is set at } 30 \% \text { of the SHI case rate for } \\
\text { medicine for in-patients. }\end{array}$ & $\begin{array}{l}\text { - Percent of Working-Age Population } \\
\text { For the floodplains of Cagayan de Oro City: based } \\
\text { on the percentage of household members aged } \\
15 \text { to } 60 \text { years old among the households in our } \\
\text { dataset (Refer to Table 2. Descriptive Statistics). } \\
\text { For all urban areas in the Philippines: derived } \\
\text { from the Dependency Ratio for the entire } \\
\text { Philippines, taken from the } 2015 \text { Philippines in } \\
\text { Figures published by the Philippine Statistics } \\
\text { Authority (PSA). } \\
\text { Labour Force Participation Rate and Employment Rate } \\
\text { (taken from } 2014 \text { Labor Force Survey (LFS) of the PSA } \\
\text { For the floodplains of Cagayan de Oro City: based } \\
\text { on the rates for Region X } \\
\text { For all urban areas in the Philippines: based on } \\
\text { the data for the entire Philippines } \\
\text { Wage rate is set at the average daily basic pay of wage } \\
\text { and salary for non-agriculture workers. This value was } \\
\text { computed from the average results of the quarterly LFS } \\
\text { in 2014. } \\
\text { Number of work days lost is equal to the number of } \\
\text { hospital days. }\end{array}$ \\
\hline
\end{tabular}


Table 4-8. Cost Implications of Flood-Induced Diseases, 2014 (in USD), Floodplains of Cagayan de Oro

\begin{tabular}{|l|r|r|r|r|r|r|}
\hline \multirow{2}{*}{ Scenario } & \multicolumn{1}{|c|}{$\begin{array}{c}\text { Cost to } \\
\text { Government }\end{array}$} & \multicolumn{3}{c|}{ Cost to Affected Households } & \multirow{2}{*}{ Total } \\
\cline { 2 - 7 } & $\begin{array}{c}\text { Provision of Social } \\
\text { Health Insurance }\end{array}$ & $\begin{array}{c}\text { Out-of-Pocket } \\
\text { Cost of Hospital In } \\
\text { Patient }\end{array}$ & $\begin{array}{c}\text { Out-of-Pocket } \\
\text { Cost of Hospital } \\
\text { Out-Patient }\end{array}$ & $\begin{array}{c}\text { Foregone } \\
\text { Earnings }\end{array}$ & Sub-total & \\
\hline Scenario 1 & $1,365,844$ & 116,937 & 184,389 & 77,401 & 378,727 & $1,744,571$ \\
\hline Scenario 2 & $1,281,709$ & 109,617 & 173,031 & 72,858 & 355,506 & $1,637,215$ \\
\hline Scenario 3 & 991,077 & 85,253 & 133,795 & 56,049 & 275,098 & $1,266,175$ \\
\hline
\end{tabular}

Table 4-9. Cost Implications of Flood-Induced Diseases, 2014 (in USD), All Urban Areas in the Philippines

\begin{tabular}{|l|r|r|r|r|r|r|}
\hline \multirow{2}{*}{ Scenario } & \multicolumn{1}{|c|}{$\begin{array}{c}\text { Cost to } \\
\text { Government }\end{array}$} & \multicolumn{4}{|c|}{ Cost to Affected Households } & \multirow{2}{*}{ Total } \\
\cline { 2 - 7 } & $\begin{array}{c}\text { Provision of Social } \\
\text { Health Insurance }\end{array}$ & $\begin{array}{c}\text { Out-of-Pocket } \\
\text { Cost of Hospital In } \\
\text { Patient }\end{array}$ & $\begin{array}{c}\text { Out-of-Pocket } \\
\text { Cost of Hospital } \\
\text { Out-Patient }\end{array}$ & $\begin{array}{c}\text { Foregone } \\
\text { Earnings }\end{array}$ & Sub-total & \\
\hline Scenario 1 & $41,142,233$ & $3,522,407$ & $5,554,201$ & $2,226,363$ & $11,302,971$ & $52,445,204$ \\
\hline Scenario 2 & $38,607,900$ & $3,301,903$ & $5,212,067$ & $2,095,696$ & $10,609,666$ & $49,217,566$ \\
\hline Scenario 3 & $29,853,414$ & $2,568,022$ & $4,030,211$ & $1,612,209$ & $8,210,441$ & $38,063,855$ \\
\hline
\end{tabular}

In Table 4-10 below, we compare the cost of disease to the affected household and the average monthly income of households by household classification. For the households in the floodplains of Cagayan de Oro, the cost of disease can range from USD37 to USD157, with an average of USD74.

For an average household, the minimum and maximum costs of disease are $9 \%$ and $39 \%$, respectively, of monthly income; average cost is $18 \%$ of monthly income.

Table 4-10. Cost of Disease vs Average Household Income of the DiseaseAffected Household, 2014 (in USD), Floodplains of Cagayan de Oro

\begin{tabular}{|c|c|c|c|c|c|c|c|}
\hline \multirow[t]{2}{*}{ Household Classification } & \multirow{2}{*}{$\begin{array}{l}\text { Average } \\
\text { Monthy } \\
\text { Income }\end{array}$} & \multicolumn{3}{|c|}{ Cost of Disease } & \multicolumn{3}{|c|}{$\begin{array}{l}\text { \% of Cost of Disease to Average Monthly } \\
\text { Income }\end{array}$} \\
\hline & & Min & Max & Mean & Min & Max & Mean \\
\hline \multicolumn{8}{|l|}{ Floodplains of CDO } \\
\hline Subsistence Poor & 68 & 37 & 157 & 74 & 54 & 231 & 108 \\
\hline Poor & 98 & 37 & 157 & 74 & 38 & 160 & 75 \\
\hline Non-poor & 634 & 37 & 157 & 74 & 6 & 25 & 12 \\
\hline Average & 407 & 37 & 157 & 74 & 9 & 39 & 18 \\
\hline \multicolumn{8}{|l|}{ Philippines } \\
\hline Bottom $10 \%$ & 129 & 37 & 157 & 73 & 23 & 97 & 45 \\
\hline Bottom 30\% & 168 & 37 & 157 & 73 & 18 & 75 & 35 \\
\hline Top 70\% & 557 & 37 & 157 & 73 & 6 & 25 & 12 \\
\hline Average & 440 & 37 & 157 & 73 & 7 & 31 & 15 \\
\hline
\end{tabular}

Note: The average monthly income for the Philippines is estimated from the 2012 and 2015 results of the Family Income and Expenditure Survey (PSA, 2012b, 2015a).

A grave situation is seen when the poor and subsistence poor households are affected. For a poor household, the average cost of disease of USD74 is 
a hefty $75 \%$ of their average monthly income, and can go as high as $160 \%$. Meanwhile, a subsistence poor household, on average, simply cannot afford the medical costs even if they forego all other expenditures. The average cost of disease of USD74 is $108 \%$ of their average monthly income. The minimum cost of USD37 is already more than half of their monthly income, and the maximum cost of USD157 is more than double their income. ${ }^{64}$

We note that the estimated poverty incidence and subsistence incidence in the floodplains are $42.41 \%$ and $24.99 \%$, respectively, indicating greater concentration of poor people than elsewhere in the city. 65 These households typically do not have savings. This means that if these households are affected with a disease, their subsequent attempts to smooth consumption and provide for the medical needs of sick members, such as borrowing and selling of productive assets, may eventually make them significantly poorer.

For the Philippine urban areas in general, the average cost of disease of USD73 is $15 \%$ of the average monthly income. For the Bottom $10 \%$ and Bottom $30 \% 66,45 \%$ and $35 \%$ respectively, of the corresponding average income.

The above results point to the imperative for outside support designed to directly benefit the households, along with specific initiatives targeted to specific groups and areas. As the poor are the most vulnerable and least resilient to floods (or to any hazard in general) and to diseases, the provision of social health insurance with increased benefits during disasters among

\footnotetext{
${ }^{64}$ To put this cost in the context of the household subsistence needs, USD 74 can feed a household of 5 members for about half a month.

${ }_{65}$ Author's computation based on data on household income from the 10,505 households in our sample that reported incomes. These computed incidences are compared to the poverty and subsistence thresholds for Misamis Oriental (i.e. the province where Cagayan de Oro is geographically located).

${ }^{66}$ The Bottom $10 \%$ and the Bottom 30\% may be a considered rough approximation of the subsistence poor and poor families, respectively.
} 
the poor will be crucial. ${ }^{67}$ Likewise, the Philippines' existing conditional cash transfers, called the $4 \mathrm{Ps}^{68}$, for the poor may be expanded such that adequate additional cash support are provided for the treatment of disasterinduced diseases. ${ }^{69}$

Overall, the above estimates reveal large opportunity costs of diseases both to the government and to the disease-affected households. These estimates may serve as starting point for public policy discussions on health, disasters, and poverty; and, towards a more comprehensive assessment of cost implications of diseases brought by floods. ${ }^{70}$

\subsection{Conclusion, Broad Policy Implications, and Caveats}

This empirical work quantitatively explores the link between floods and diseases in a typical urban setting in the Philippines. Using a large household level dataset from the 2014 Climate and Disaster Risk Exposure Database (ClimEx.db) for the floodplains of Cagayan de Oro, we find robust evidence of the positive and significant association between floods and 11 of the diseases we cover. Flood exposure has a positive and statistically significant empirical association with bronchitis, respiratory tract infection, chicken pox, measles, typhoid fever, diarrhoea, leptospirosis, dengue, hypertension, and heart diseases. Flood height is positively associated with

\footnotetext{
${ }^{67}$ It has been argued that the marginal productivity of good health is higher in poorer sectors of society (Ruger et al., 2012), thereby providing the basis for government policies and actions on its provision (WHO, 2009).

${ }^{68}$ The 4Ps, which stands for Pantawid Pamilyang Pilipino Program (Bridging Program for Filipino Families), is a Philippine national government's program implemented in 2010 to reduce intergenerational poverty through public investment on the health and education of the children of the poorest households across all cities and municipalities in the country. The cash grants to beneficiary households are provided upon compliance to the conditions that children of specific age-groups are either dewormed, undergo preventive vaccines and regular health checks, or have 85\% school attendance (GOP). In 2012, the Modified Conditional Cash Transfer, which is a prototype of the 4 Ps, was implemented to provide cash grants for children's education and health needs of families in difficult situations including those affected by disasters (DSWD, 2013).

${ }^{69} \mathrm{In}$ a review on the economic determinants of resilience to disasters, external sources of funds, such as aid and remittances, are deemed critical for household-level recovery, particularly among the financially constrained (Noy \& Yonson, 2016).

${ }^{70}$ Other macroeconomic costs we did not include are loss of worker productivity and output loss, which are beyond the scope of this paper
} 
bronchitis, influenza, and leptospirosis; and, flood duration, with bronchitis, influenza, and typhoid fever.

Unlike the existing related studies, we simultaneously cover several diseases for a large number of households. Thus, our results necessarily provide insights on diseases that are expected to have a relatively greater incremental increase in incidence in the aftermath of flood disasters. These insights may serve as useful bases for the prioritization of diseases to be addressed ex ante and ex post a disaster. Moreover, we show that the density of diseases varies across areas, indicating that flood exposure and flood characteristics combine with area-specific socioeconomic conditions that may generate same impacts yet with different incidence and/or severity. Together, these results may guide the prioritization of interventions, and identification of spatially-focused interventions.

Also unlike the existing literature, we proceeded to provide indicative estimates of the cost implications of diseases. This inquiry reveals the opportunity costs of diseases both to the government and to the diseaseaffected households. The cost incurred by the government could have been used for other development needs, particularly as flood-induced diseases can be largely avoided.

The analysis of the cost of disease to households relative to their average monthly income suggests some important implications on the household well-being. Among those below or just above the poverty line and who have no means to smooth consumption, they may need to forego other consumption needs to prioritize their food needs and at the same time afford the medical expenses. Among those already in subsistence poverty, their subsequent attempts to smooth consumption and provide for the medical needs of sick members, such as borrowing and selling of productive assets, may eventually make them extremely poor, or even fall 
into a poverty trap. Among the non-poor, the combined consequences of foregone earnings and out-of-pocket medical costs may cause some of them to fall into poverty.

These estimates can serve as initial reference for the evaluation of the costs and benefits of alternative intervening measures to avert disaster-induced diseases. Further, these may also serve as useful inputs for discussions on the expansion and/or redesign of the current social welfare program and social health insurance, and other policies aimed at ensuring people's safety from disasters, diseases, and poverty.

In the context of our study area, the qualitative literature indicates that rapid urbanization, improper urban land use, and previous failures in urban governance that resulted in the expansion of communities in areas highly prone to floods are contributory factors to the occurrences of flood disasters (Ginnetti et al., 2013; LGU-CDO, 2014b, 2016; NEDA, 2005). These and our quantitative results on the linkage of flood disasters and diseases point to the need for the integration of disaster risk reduction and management, climate change adaptation, and urban health in urban landuse planning and in urban governance. As climate change is expected to result in increased occurrences of extreme events, it is also crucial to avert the existing unsustainable economic production and environment practices to avoid massive flooding.

It is also an imperative to strengthen the capacity of the health sector of the city, including reducing its exposure and increasing its resilience to disasters, in order to adequately provide both preventive and curative interventions. As discussed in Section 4.3, the floods brought by TS Washi brought huge damage to the health centres, thus compromising their capacity to deliver the immediate health services within their respective service areas. 
The above standard top-down measures need to be complemented with measures based on the households' expressed needs. Participatory approaches in the identification of measures will provide an in-depth understanding on the underlying factors of people's exposure to floods, as well as their vulnerability and resilience to disasters and diseases. This is particularly important among the urban poor who may not have the same level of access to some basic social and economic services, and who often do not have enough influence on top-down decisions.

Upon availability of reliable dataset, we intend to go further with a comprehensive assessment on flood impacts on the population (deaths, injuries, diseases, and welfare impacts both in the short- and long-term), and on the cost implications of flood-induced diseases. 


\section{Appendices}

Table 4-11. Cases, Incidence, DALY of Diseases: Philippines, 2012

\begin{tabular}{|l|r|r|r|}
\hline \multicolumn{1}{|c|}{ Disease } & \multicolumn{1}{c|}{$\begin{array}{c}\text { DALY } \\
\text { (in '000) } \\
\text { (1) }\end{array}$} & \multicolumn{1}{c|}{$\begin{array}{c}\text { Number of } \\
\text { Cases } \\
\text { (2) }\end{array}$} & $\begin{array}{c}\text { Incidence } \\
\text { (per 100,000) } \\
\text { (3) }\end{array}$ \\
\hline Bronchitis & No data & 338,789 & \multicolumn{1}{c|}{$352.2(4)$} \\
\hline Influenza & No data & 232,584 & 241.8 (7) \\
\hline Respiratory infections & 2,236 & $2,793,066$ & $2,903.9$ (1) \\
\hline Lower respiratory infections & 2,126 & 569,122 & $591.7(2)$ \\
\hline Upper respiratory infections & 50 & No data & No data \\
\hline Tuberculosis & 1,381 & 93,094 & $96.8(8)$ \\
\hline Chicken pox & No data & No data & No data \\
\hline Hypertension & No data & 512,604 & $532.99(3)$ \\
\hline Heart Diseases & $5,664 *$ & No data & No data \\
\hline Rheumatic heart disease & 214 & No data & No data \\
\hline Hypertensive heart disease & 613 & No data & No data \\
\hline Ischaemic heart disease & 2,644 & No data & No data \\
\hline Measles & 51 & 2,673 & 2.38 \\
\hline Typhoid Fever & No data & 12,511 & 13 \\
\hline Diarrhoea & 694 & 235,110 & $244.4(6)$ \\
\hline Leptospirosis & No data & 793 & 0.8 \\
\hline Dengue & 95 & 44,172 & $45.9(10)$ \\
\hline
\end{tabular}

Note: Italicized numbers in parentheses under column 3 indicate the rank in terms of top 10 causes of diseases in 2012 , with 1 as top cause. 
Table 4-12. Pairwise Correlation

(Independent Variables Only)

\begin{tabular}{|c|c|c|c|c|c|c|c|c|c|c|c|}
\hline & Flood exposure & Flood height & Flood duration & $\begin{array}{c}\text { Distance to } \\
\text { shore }\end{array}$ & Literacy rate & $\begin{array}{c}\text { Water service } \\
\text { connection }\end{array}$ & Household size & $0-5$ years old & $6-14$ years old & $\begin{array}{c}15-18 \text { years } \\
\text { old }\end{array}$ & $\begin{array}{c}60 \text { years olc } \\
\text { and above }\end{array}$ \\
\hline Flood exposure & 1.0000 & & & & & & & & & & \\
\hline \multirow[t]{2}{*}{ Flood height } & $0.4212^{*}$ & 1.0000 & & & & & & & & & \\
\hline & 0.0000 & & & & & & & & & & \\
\hline \multirow[t]{2}{*}{ Flood duration } & $0.2847^{*}$ & $0.2225^{*}$ & 1.0000 & & & & & & & & \\
\hline & 0.0000 & 0.0000 & & & & & & & & & \\
\hline \multirow[t]{2}{*}{ Distance to shore } & $0.2251^{*}$ & $0.2351^{*}$ & $0.0620^{*}$ & 1.0000 & & & & & & & \\
\hline & 0.0000 & 0.0000 & 0.0000 & & & & & & & & \\
\hline \multirow[t]{2}{*}{ Literacy rate } & 0.0012 & 0.0077 & $0.0195 *$ & $-0.0437 *$ & 1.0000 & & & & & & \\
\hline & 0.8867 & 0.3719 & 0.023 & 0.0000 & & & & & & & \\
\hline \multirow[t]{2}{*}{ Water service connection } & -0.008 & 0.0149 & $0.0255^{*}$ & 0.016 & $-0.0761^{*}$ & 1.0000 & & & & & \\
\hline & 0.3491 & 0.083 & 0.003 & 0.0627 & 0.0000 & & & & & & \\
\hline \multirow[t]{2}{*}{ Household size } & 0.0019 & $-0.0312^{*}$ & 0.0015 & 0.0159 & $-0.1559 *$ & $0.0370^{*}$ & 1.0000 & & & & \\
\hline & 0.8266 & 0.0003 & 0.8608 & 0.0636 & 0.0000 & 0.0000 & & & & & \\
\hline \multirow[t]{2}{*}{$0-5$ years old } & -0.0126 & -0.0066 & -0.0042 & $-0.0276^{*}$ & $-0.1386^{*}$ & $-0.0246 *$ & $0.1721^{*}$ & 1.0000 & & & \\
\hline & 0.1417 & 0.4409 & 0.6232 & 0.0013 & 0.0000 & 0.0042 & 0.0000 & & & & \\
\hline \multirow[t]{2}{*}{$6-14$ years old } & 0.0057 & -0.0098 & 0.0102 & 0.0036 & $-0.1933^{*}$ & -0.0108 & $0.2931^{*}$ & $-0.1622^{*}$ & 1.0000 & & \\
\hline & 0.5036 & 0.254 & 0.2354 & 0.6708 & 0.0000 & 0.2072 & 0.0000 & 0.0000 & & & \\
\hline \multirow[t]{2}{*}{$15-18$ years old } & 0.0035 & -0.0108 & 0.003 & 0.0011 & -0.0023 & 0.0134 & $0.1753^{*}$ & $-0.1901 *$ & $-0.0192^{*}$ & 1.0000 & \\
\hline & 0.6877 & 0.2068 & 0.7233 & 0.9006 & 0.7895 & 0.1196 & 0.0000 & 0.0000 & 0.0257 & & \\
\hline \multirow[t]{2}{*}{60 years old and above } & -0.003 & 0.0131 & -0.0063 & -0.0029 & $0.0169 *$ & -0.0023 & $-0.2077^{*}$ & $-0.2037 *$ & $-0.1870^{*}$ & $-0.1014^{*}$ & 1.0000 \\
\hline & 0.7249 & 0.1274 & 0.4597 & 0.7324 & 0.0495 & 0.7874 & 0.0000 & 0.0000 & 0.0000 & 0.0000 & \\
\hline
\end{tabular}


Table 4-13. Number and Incidence by Disease, and by Flooded and Not-Flooded Households, Cagayan de Oro

\begin{tabular}{|c|c|c|c|c|c|c|c|c|c|}
\hline \multirow[b]{2}{*}{ Disease/Category of Diseases } & \multicolumn{3}{|c|}{ Number of Households } & \multicolumn{3}{|c|}{ Number of Disease-Affected Households } & \multicolumn{3}{|c|}{ \% Disease-Affected Households } \\
\hline & $\begin{array}{l}\text { Not flood- } \\
\text { exposed }\end{array}$ & Flood-exposed & Total & $\begin{array}{l}\text { Not flood- } \\
\text { exposed }\end{array}$ & $\begin{array}{l}\text { Flood- } \\
\text { exposed }\end{array}$ & Total & $\begin{array}{l}\text { Not flood- } \\
\text { exposed }\end{array}$ & $\begin{array}{l}\text { Flood- } \\
\text { exposed }\end{array}$ & Total \\
\hline Bronchitis & 1,401 & 12,167 & 13,568 & 26 & 866 & 892 & 1.86 & 7.12 & 6.57 \\
\hline Respiratory tract infection & 1,401 & 12,167 & 13,568 & 53 & 821 & 874 & 3.78 & 6.75 & 6.44 \\
\hline Tuberculosis & 1,401 & 12,167 & 13,568 & 2 & 33 & 35 & 0.14 & 0.27 & 0.26 \\
\hline Influenza & 1,401 & 12,167 & 13,568 & 199 & 2,407 & 2,606 & 14.20 & 19.78 & 19.21 \\
\hline Chicken pox & 1,401 & 12,167 & 13,568 & 5 & 219 & 224 & 0.36 & 1.80 & 1.65 \\
\hline Measles & 1,401 & 12,167 & 13,568 & 8 & 346 & 354 & 0.57 & 2.84 & 2.61 \\
\hline Typhoid fever & 1,401 & 12,167 & 13,568 & 61 & 1,197 & 1,258 & 4.35 & 9.84 & 9.27 \\
\hline Diarrhoea & 1,401 & 12,167 & 13,568 & 62 & 1,148 & 1,210 & 4.43 & 9.44 & 8.92 \\
\hline Leptospirosis & 1,401 & 12,167 & 13,568 & 7 & 210 & 217 & 0.50 & 1.73 & 1.60 \\
\hline Dengue & 1,401 & 12,167 & 13,568 & 18 & 410 & 428 & 1.28 & 3.37 & 3.15 \\
\hline Malaria & 1,401 & 12,167 & 13,568 & - & 16 & 16 & 0.00 & 0.13 & 0.12 \\
\hline Hypertension & 1,401 & 12,167 & 13,568 & 84 & 1,165 & 1,249 & 6.00 & 9.58 & 9.21 \\
\hline Heart disease & 1,401 & 12,167 & 13,568 & 19 & 272 & 291 & 1.36 & 2.24 & 2.14 \\
\hline Any of the 13 diseases & 1,401 & 12,167 & 13,568 & 357 & 5,407 & 5,764 & 25.48 & 44.44 & 42.48 \\
\hline Respiratory diseases & 1,401 & 12,167 & 13,568 & 81 & 1,696 & 1,777 & 5.78 & 13.94 & 13.10 \\
\hline Air-borne diseases & 1,401 & 12,167 & 13,568 & 206 & 2,753 & 2,959 & 14.70 & 22.63 & 21.81 \\
\hline Water or Food-borne diseases & 1,401 & 12,167 & 13,568 & 121 & 2,219 & 2,340 & 8.64 & 18.24 & 17.25 \\
\hline Vector-borne diseases & 1,401 & 12,167 & 13,568 & 18 & 425 & 443 & 1.28 & 3.49 & 3.27 \\
\hline Non-communicable diseases & 1,401 & 12,167 & 13,568 & 88 & 1,264 & 1,352 & 6.28 & 10.39 & 9.96 \\
\hline
\end{tabular}


Figure 4-7. Kernel Density Map of Households Affected by Typhoid Fever

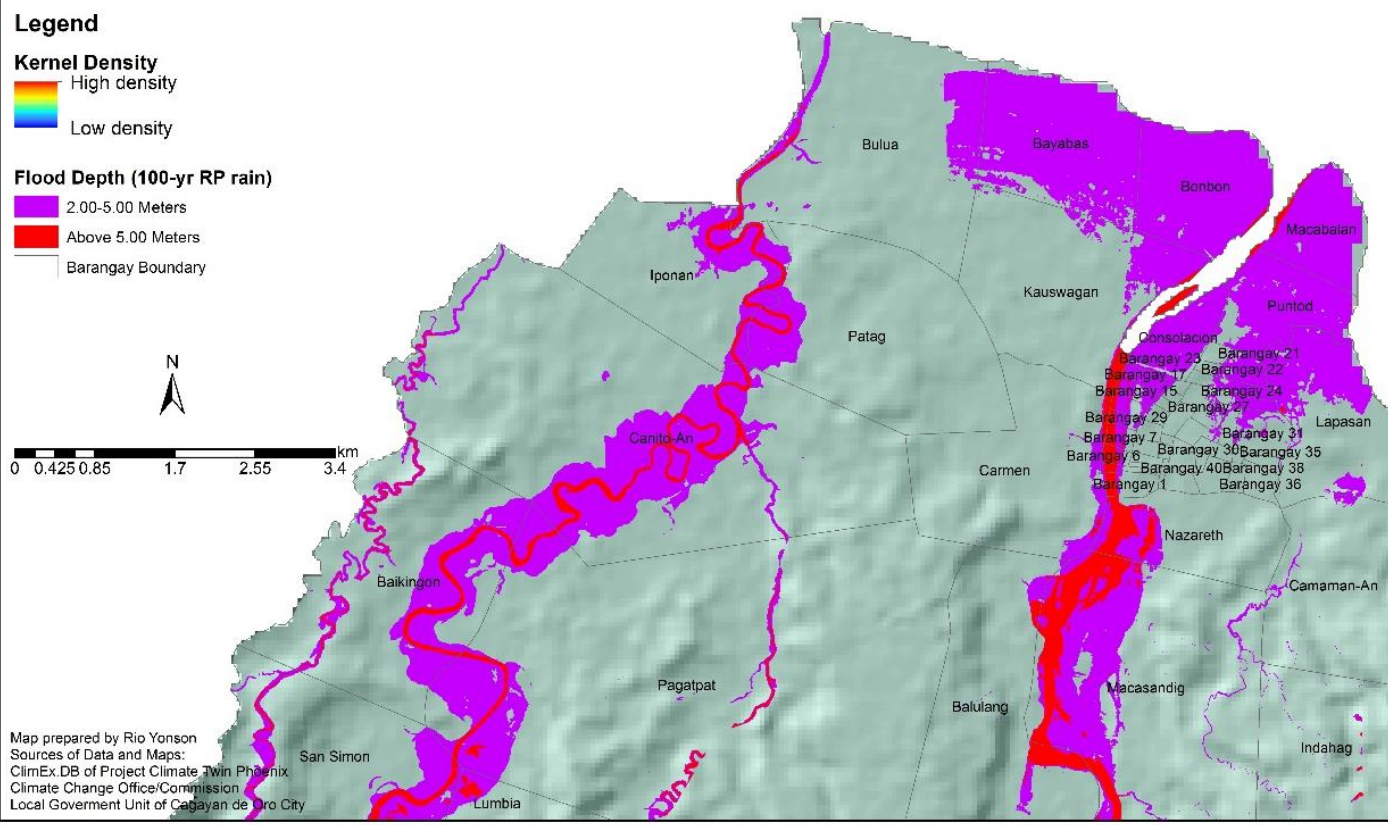


Table 4-14. Model with A Proxy for Poverty Based on Housing Structure, by Specific Disease

\begin{tabular}{|c|c|c|c|c|c|c|c|c|c|c|c|c|}
\hline & Bronchitis & $\begin{array}{l}\text { Respiratory Tract } \\
\text { Infection }\end{array}$ & Tuberculosis & Influenza & Chicken Pox & Measles & Typhoid Fever & Diarrhea & Leptospirosis & Dengue & Hypertension & Heart Diseases \\
\hline & (1) & (2) & (3) & (4) & (5) & (6) & (7) & (8) & (9) & (10) & (11) & \\
\hline Flood exposure & $\begin{array}{l}.0619^{* * *} \\
(5.55)\end{array}$ & $\begin{array}{l}0.0561^{* * *} \\
(6.33)\end{array}$ & $\begin{array}{l}0.000863 \\
(0.76)\end{array}$ & $\begin{array}{l}0.0152 \\
(1.10)\end{array}$ & $\begin{array}{l}0.0252^{* * *} \\
(4.40)\end{array}$ & $\begin{array}{l}0.0403^{* * *} \\
(5.61)\end{array}$ & $\begin{array}{l}0.0667^{* * *} \\
(6.35)\end{array}$ & $\begin{array}{l}0.0895^{* * *} \\
(8.15)\end{array}$ & $\begin{array}{l}0.0131^{*} \\
(2.40)\end{array}$ & $\begin{array}{l}0.0292^{* * *} \\
(4.27)\end{array}$ & $\begin{array}{l}0.0409^{* * *} \\
(4.17)\end{array}$ & $\begin{array}{l}0.0104^{*} \\
(2.12)\end{array}$ \\
\hline Flood height & $\begin{array}{l}0.00357^{*} \\
(2.36)\end{array}$ & $\begin{array}{l}-0.00903^{* * *} \\
(-5.99)\end{array}$ & $\begin{array}{l}0.0000322 \\
(0.22)\end{array}$ & $\begin{array}{l}0.0154^{* * *} \\
(5.82)\end{array}$ & $\begin{array}{l}-0.00131^{*} \\
(-2.05)\end{array}$ & $\begin{array}{l}-0.00127 \\
(-1.66)\end{array}$ & $\begin{array}{l}0.000415 \\
(0.25)\end{array}$ & $\begin{array}{l}-0.00760^{* * *} \\
(-4.27)\end{array}$ & $\begin{array}{l}0.00253^{* * *} \\
(4.11)\end{array}$ & $\begin{array}{l}-0.00350 * * \\
(-2.98)\end{array}$ & $\begin{array}{l}0.000660 \\
(0.37)\end{array}$ & $\begin{array}{l}-0.000733 \\
(-0.83)\end{array}$ \\
\hline Flood duration & $\begin{array}{l}0.00130^{* * *} \\
(3.68)\end{array}$ & $\begin{array}{l}-0.000222 \\
(-0.65)\end{array}$ & $\begin{array}{l}0.0000749 \\
(1.86)\end{array}$ & $\begin{array}{l}0.00258^{* * *} \\
(4.10)\end{array}$ & $\begin{array}{l}0.0000492 \\
(0.32)\end{array}$ & $\begin{array}{l}0.000108 \\
(0.58)\end{array}$ & $\begin{array}{l}0.00158^{* * *} \\
(3.96)\end{array}$ & $\begin{array}{l}-0.00101^{*} \\
(-2.29)\end{array}$ & $\begin{array}{l}-0.0000843 \\
(-0.56)\end{array}$ & $\begin{array}{l}0.000496^{*} \\
(2.07)\end{array}$ & $\begin{array}{l}-0.000343 \\
(-0.86)\end{array}$ & $\begin{array}{l}0.0000123 \\
(0.06)\end{array}$ \\
\hline Distance to shore & $\begin{array}{l}0.000632 \\
(0.50)\end{array}$ & $\begin{array}{l}-0.00430 * * * \\
(-3.95)\end{array}$ & $\begin{array}{l}-0.000312 \\
(-1.87)\end{array}$ & $\begin{array}{l}0.00288 \\
(1.39)\end{array}$ & $\begin{array}{l}-0.00109 * \\
(-2.06)\end{array}$ & $\begin{array}{l}-0.00301 * * * \\
(-3.96)\end{array}$ & $\begin{array}{l}-0.00769 * * * \\
(-5.54)\end{array}$ & $\begin{array}{l}-0.00686^{* * *} \\
(-4.89)\end{array}$ & $\begin{array}{l}-0.000401 \\
(-0.65)\end{array}$ & $\begin{array}{l}0.000993 \\
(1.20)\end{array}$ & $\begin{array}{l}-0.00180 \\
(-1.30)\end{array}$ & $\begin{array}{l}0.000219 \\
(0.36)\end{array}$ \\
\hline Poor & $\begin{array}{l}-0.00693 \\
(-1.67)\end{array}$ & $\begin{array}{l}0.00123 \\
(0.29)\end{array}$ & $\begin{array}{l}-0.000278 \\
(-0.50)\end{array}$ & $\begin{array}{l}0.0401^{* * *} \\
(5.75)\end{array}$ & $\begin{array}{l}-0.00210 \\
(-1.10)\end{array}$ & $\begin{array}{l}-0.00419 \\
(-1.67)\end{array}$ & $\begin{array}{l}0.00222 \\
(0.47)\end{array}$ & $\begin{array}{l}-0.00279 \\
(-0.56)\end{array}$ & $\begin{array}{l}0.00228 \\
(1.16)\end{array}$ & $\begin{array}{l}-0.00469 \\
(-1.60)\end{array}$ & $\begin{array}{l}-0.0154^{* *} \\
(-3.14)\end{array}$ & $\begin{array}{l}-0.00113 \\
(-0.47)\end{array}$ \\
\hline Literacy rate & $\begin{array}{l}-0.0573 * * * \\
(-8.09)\end{array}$ & $\begin{array}{l}0.00534 \\
(0.81)\end{array}$ & $\begin{array}{l}0.000282 \\
(0.39)\end{array}$ & $\begin{array}{l}-0.0804 * * * \\
(-6.74)\end{array}$ & $\begin{array}{l}-0.0153^{* * *} \\
(-4.42)\end{array}$ & $\begin{array}{l}-0.0129^{*} \\
(-2.47)\end{array}$ & $\begin{array}{l}-0.00512 \\
(-0.65)\end{array}$ & $\begin{array}{l}-0.0316^{* * *} \\
(-3.39)\end{array}$ & $\begin{array}{l}-0.00271 \\
(-0.88)\end{array}$ & $\begin{array}{l}-0.00443 \\
(-0.94)\end{array}$ & $\begin{array}{l}-0.0132 \\
(-1.74)\end{array}$ & $\begin{array}{l}-0.00280 \\
(-0.76)\end{array}$ \\
\hline Water service connection & $\begin{array}{l}-0.0372 * * * \\
(-8.49)\end{array}$ & $\begin{array}{l}-0.0342 * * * \\
(-7.65)\end{array}$ & $\begin{array}{l}-0.000989 \\
(-1.62)\end{array}$ & $\begin{array}{l}-0.0102 \\
(-1.17)\end{array}$ & $\begin{array}{l}-0.00156 \\
(-0.67)\end{array}$ & $\begin{array}{l}0.00719^{*} \\
(2.12)\end{array}$ & $\begin{array}{l}0.0968 * * * \\
(11.62)\end{array}$ & $\begin{array}{l}-0.0132^{*} \\
(-2.22)\end{array}$ & $\begin{array}{l}-0.00323 \\
(-1.37)\end{array}$ & $\begin{array}{l}-0.00108 \\
(-0.31)\end{array}$ & $\begin{array}{l}0.00783 \\
(1.27)\end{array}$ & $\begin{array}{l}0.000444 \\
(0.15)\end{array}$ \\
\hline Household size & $\begin{array}{l}0.00200^{*} \\
(2.09)\end{array}$ & $\begin{array}{l}0.00205^{*} \\
(2.09)\end{array}$ & $\begin{array}{l}0.000359^{* * *} \\
(3.59)\end{array}$ & $\begin{array}{l}-0.00311 \\
(-1.75)\end{array}$ & $\begin{array}{l}0.000672 \\
(1.61)\end{array}$ & $\begin{array}{l}0.000836 \\
(1.46)\end{array}$ & $\begin{array}{l}0.00170 \\
(1.57)\end{array}$ & $\begin{array}{l}0.00267^{*} \\
(2.30)\end{array}$ & $\begin{array}{l}0.00214^{* * *} \\
(5.54)\end{array}$ & $\begin{array}{l}0.00312^{* * *} \\
(5.98)\end{array}$ & $\begin{array}{l}0.0113^{* * *} \\
(11.29)\end{array}$ & $\begin{array}{l}0.00265^{* * *} \\
(6.37)\end{array}$ \\
\hline $0-5$ years old & $\begin{array}{l}-0.0192 \\
(-1.52)\end{array}$ & $\begin{array}{l}-0.0296^{*} \\
(-2.19)\end{array}$ & $\begin{array}{l}-0.00622^{* *} \\
(-2.82)\end{array}$ & $\begin{array}{l}-0.00962 \\
(-0.43)\end{array}$ & $\begin{array}{l}0.00457 \\
(0.78)\end{array}$ & $\begin{array}{l}0.0340^{* * *} \\
(4.79)\end{array}$ & $\begin{array}{l}-0.00981 \\
(-0.64)\end{array}$ & $\begin{array}{l}-0.00589 \\
(-0.39)\end{array}$ & $\begin{array}{l}-0.0158^{*} \\
(-2.41)\end{array}$ & $\begin{array}{l}0.0132 \\
(1.46)\end{array}$ & $\begin{array}{l}-0.181^{* * *} \\
(-10.58)\end{array}$ & $\begin{array}{l}-0.0341 * * * \\
(-4.11)\end{array}$ \\
\hline $6-14$ years old & $\begin{array}{l}-0.0103 \\
(-0.86)\end{array}$ & $\begin{array}{l}-0.0395 * * \\
(-3.08)\end{array}$ & $\begin{array}{l}0.000611 \\
(0.39)\end{array}$ & $\begin{array}{l}0.0482^{*} \\
(2.35)\end{array}$ & $\begin{array}{l}0.00355 \\
(0.72)\end{array}$ & $\begin{array}{l}0.0133 \\
(1.86)\end{array}$ & $\begin{array}{l}0.0174 \\
(1.31)\end{array}$ & $\begin{array}{l}-0.0133 \\
(-0.91)\end{array}$ & $\begin{array}{l}-0.0159 * * \\
(-2.59)\end{array}$ & $\begin{array}{l}0.0212 * * \\
(2.60)\end{array}$ & $\begin{array}{l}-0.121^{* * *} \\
(-8.10)\end{array}$ & $\begin{array}{l}-0.0306 * * * \\
(-4.04)\end{array}$ \\
\hline $15-18$ years old & $\begin{array}{l}0.00902 \\
(0.55)\end{array}$ & $\begin{array}{l}-0.0342 \\
(-1.85)\end{array}$ & $\begin{array}{l}-0.00113 \\
(-0.44)\end{array}$ & $\begin{array}{l}0.0566^{*} \\
(2.04)\end{array}$ & $\begin{array}{l}0.0103 \\
(1.59)\end{array}$ & $\begin{array}{l}0.0109 \\
(1.19)\end{array}$ & $\begin{array}{l}0.0915 * * * \\
(5.66)\end{array}$ & $\begin{array}{l}0.0140 \\
(0.74)\end{array}$ & $\begin{array}{l}-0.0113 \\
(-1.19)\end{array}$ & $\begin{array}{l}0.0254^{*} \\
(2.54)\end{array}$ & $\begin{array}{l}-0.0482^{*} \\
(-2.38)\end{array}$ & $\begin{array}{l}-0.0170 \\
(-1.56)\end{array}$ \\
\hline 60 years old and above & $\begin{array}{l}0.00184 \\
0.17)\end{array}$ & $\begin{array}{l}-0.00241 \\
(-0.24)\end{array}$ & $\begin{array}{l}0.00365 * * * \\
(3.65)\end{array}$ & $\begin{array}{l}-0.0568^{* *} \\
(-2.92)\end{array}$ & $\begin{array}{l}-0.0135 \\
(-1.95)\end{array}$ & $\begin{array}{l}0.00142 \\
(0.19)\end{array}$ & $\begin{array}{l}-0.0296^{*} \\
(-1.99)\end{array}$ & $\begin{array}{l}-0.0482^{* *} \\
(-3.08)\end{array}$ & $\begin{array}{l}-0.00134 \\
(-0.25)\end{array}$ & $\begin{array}{l}-0.0114 \\
(-1.14)\end{array}$ & $\begin{array}{l}0.106 * * * \\
(11.67)\end{array}$ & $\begin{array}{l}0.0249^{* * *} \\
(6.46)\end{array}$ \\
\hline $\mathrm{N}$ & 13568 & 13568 & 13568 & 13568 & 13568 & 13568 & 13568 & 13568 & 13568 & 13568 & 13568 & 13568 \\
\hline
\end{tabular}


Table 4-15. Model with A Proxy for Poverty Based on Housing Structure, by Disease Category

\begin{tabular}{|c|c|c|c|c|c|c|}
\hline & $\begin{array}{c}\text { Any Disease } \\
\text { (1) }\end{array}$ & $\begin{array}{c}\text { Respiratory- } \\
\text { Related } \\
(2) \\
\end{array}$ & (3) & $\begin{array}{c}\text { Water- or } \\
\text { Food-Borne } \\
\text { (4) }\end{array}$ & (5) & $\begin{array}{c}\text { Non- } \\
\text { Communicable } \\
\text { Diseases } \\
(6)\end{array}$ \\
\hline Flood exposure & $\begin{array}{l}0.196 * * * \\
(11.02)\end{array}$ & $\begin{array}{l}0.110^{* * *} \\
(8.10)\end{array}$ & $\begin{array}{l}0.0492^{* * *} \\
(3.32)\end{array}$ & $\begin{array}{l}0.135^{* * *} \\
(9.22)\end{array}$ & $\begin{array}{l}0.0313^{* * *} \\
(4.45)\end{array}$ & $\begin{array}{l}0.0451^{* * *} \\
(4.36)\end{array}$ \\
\hline Flood height & $\begin{array}{l}0.00321 \\
(0.91)\end{array}$ & $\begin{array}{l}-0.00376 \\
(-1.66)\end{array}$ & $\begin{array}{l}0.0137^{* * *} \\
(4.94)\end{array}$ & $\begin{array}{l}-0.00260 \\
(-1.07)\end{array}$ & $\begin{array}{l}-0.00368^{* *} \\
(-3.09)\end{array}$ & $\begin{array}{l}0.000830 \\
(0.45)\end{array}$ \\
\hline Flood duration & $\begin{array}{l}0.00263^{* *} \\
(3.16)\end{array}$ & $\begin{array}{l}0.00137 * * \\
(2.67)\end{array}$ & $\begin{array}{l}0.00284^{* * *} \\
(4.33)\end{array}$ & $\begin{array}{l}0.00108 \\
(1.82)\end{array}$ & $\begin{array}{l}0.000492^{*} \\
(2.01)\end{array}$ & $\begin{array}{l}0.0000990 \\
(0.24)\end{array}$ \\
\hline Distance to shore & $\begin{array}{l}-0.00649 * \\
(-2.24)\end{array}$ & $\begin{array}{l}-0.00444^{*} \\
(-2.56)\end{array}$ & $\begin{array}{l}-0.000195 \\
(-0.09)\end{array}$ & $\begin{array}{l}-0.0131 * * * \\
(-6.57)\end{array}$ & $\begin{array}{l}0.00122 \\
(1.44)\end{array}$ & $\begin{array}{l}-0.00193 \\
(-1.33)\end{array}$ \\
\hline Poor & $\begin{array}{l}0.0127 \\
(1.39)\end{array}$ & $\begin{array}{l}-0.00686 \\
(-1.14)\end{array}$ & $\begin{array}{l}0.0355^{* * *} \\
(4.82)\end{array}$ & $\begin{array}{l}-0.00350 \\
(-0.51)\end{array}$ & $\begin{array}{l}-0.00494 \\
(-1.65)\end{array}$ & $\begin{array}{l}-0.0152^{* *} \\
(-2.96)\end{array}$ \\
\hline Literacy rate & $\begin{array}{l}-0.0689 * * * \\
(-4.62)\end{array}$ & $\begin{array}{l}-0.0495^{* * *} \\
(-4.93)\end{array}$ & $\begin{array}{l}-0.0985^{* * *} \\
(-7.73)\end{array}$ & $\begin{array}{l}-0.0130 \\
(-1.12)\end{array}$ & $\begin{array}{l}-0.00427 \\
(-0.90)\end{array}$ & $\begin{array}{l}-0.0134 \\
(-1.66)\end{array}$ \\
\hline Water service connection & $\begin{array}{l}-0.00718 \\
(-0.63)\end{array}$ & $\begin{array}{l}-0.0779 * * * \\
(-12.16)\end{array}$ & $\begin{array}{l}-0.00912 \\
(-0.99)\end{array}$ & $\begin{array}{l}0.0334^{* * *} \\
(3.79)\end{array}$ & $\begin{array}{l}-0.000259 \\
(-0.07)\end{array}$ & $\begin{array}{l}0.00629 \\
(0.98)\end{array}$ \\
\hline Household size & $\begin{array}{l}0.0103^{* * *} \\
(4.51)\end{array}$ & $\begin{array}{l}0.00450 * * \\
(3.19)\end{array}$ & $\begin{array}{l}-0.00219 \\
(-1.17)\end{array}$ & $\begin{array}{l}0.00492 * * \\
(3.09)\end{array}$ & $\begin{array}{l}0.00311^{* * *} \\
(5.78)\end{array}$ & $\begin{array}{l}0.0122^{* * *} \\
(11.66)\end{array}$ \\
\hline 0 - 5 years old & $\begin{array}{l}-0.140 * * * \\
(-4.80)\end{array}$ & $\begin{array}{l}-0.0564^{* *} \\
(-2.99)\end{array}$ & $\begin{array}{l}0.0158 \\
(0.68)\end{array}$ & $\begin{array}{l}-0.00289 \\
(-0.14)\end{array}$ & $\begin{array}{l}0.0170 \\
(1.85)\end{array}$ & $\begin{array}{l}-0.188 * * * \\
(-10.53)\end{array}$ \\
\hline $6-14$ years old & $\begin{array}{l}-0.0605^{*} \\
(-2.21)\end{array}$ & $\begin{array}{l}-0.0478^{* *} \\
(-2.69)\end{array}$ & $\begin{array}{l}0.0434^{*} \\
(2.00)\end{array}$ & $\begin{array}{l}-0.00226 \\
(-0.11)\end{array}$ & $\begin{array}{l}0.0227^{* *} \\
(2.74)\end{array}$ & $\begin{array}{l}-0.127 * * * \\
(-8.11)\end{array}$ \\
\hline $15-18$ years old & $\begin{array}{l}0.0308 \\
(0.82)\end{array}$ & $\begin{array}{l}-0.0347 \\
(-1.39)\end{array}$ & $\begin{array}{l}0.0646^{*} \\
(2.21)\end{array}$ & $\begin{array}{l}0.0863^{* * *} \\
(3.38)\end{array}$ & $\begin{array}{l}0.0255^{*} \\
(2.48)\end{array}$ & $\begin{array}{l}-0.0551^{* *} \\
(-2.60)\end{array}$ \\
\hline 60 years old and above & $\begin{array}{l}0.0458 \\
(1.95)\end{array}$ & $\begin{array}{l}0.00872 \\
(0.58)\end{array}$ & $\begin{array}{l}-0.0703^{* * *} \\
(-3.38)\end{array}$ & $\begin{array}{l}-0.0498^{*} \\
(-2.50)\end{array}$ & $\begin{array}{l}-0.00985 \\
(-1.00)\end{array}$ & $\begin{array}{l}0.117^{* * *} \\
(12.21)\end{array}$ \\
\hline $\mathrm{N}$ & 13568 & 13568 & 13568 & 13568 & 13568 & 13568 \\
\hline
\end{tabular}


Table 4-16. Robustness Check 1, by Specific Disease

\begin{tabular}{|c|c|c|c|c|c|c|c|c|c|c|c|c|}
\hline & $\begin{array}{c}\text { Bronchitis } \\
\text { (1) }\end{array}$ & $\begin{array}{l}\text { Respiratory Tract } \\
\text { Infection } \\
\text { (2) }\end{array}$ & $\begin{array}{c}\text { Tuberculosis } \\
\text { (3) }\end{array}$ & $\begin{array}{l}\text { Influenza } \\
\text { (4) }\end{array}$ & $\begin{array}{c}\text { Chicken Pox } \\
\text { (5) }\end{array}$ & $\begin{array}{c}\text { Measles } \\
\text { (6) }\end{array}$ & $\begin{array}{l}\text { Typhoid Fever } \\
\text { (7) }\end{array}$ & $\begin{array}{c}\text { Diarrhea } \\
\text { (8) }\end{array}$ & $\begin{array}{c}\text { Leptospirosis } \\
\text { (9) }\end{array}$ & $\begin{array}{l}\text { Dengue } \\
(10)\end{array}$ & $\begin{array}{c}\text { Hypertension } \\
\text { (11) }\end{array}$ & $\begin{array}{c}\text { Heart Diseases } \\
\text { (12) }\end{array}$ \\
\hline Flood exposure & $\begin{array}{l}0.0752^{* * *} \\
(7.02)\end{array}$ & $\begin{array}{l}0.0415^{* * * *} \\
(4.82)\end{array}$ & $\begin{array}{l}0.00138 \\
(1.20)\end{array}$ & $\begin{array}{l}0.0581^{* * *} \\
(4.54)\end{array}$ & $\begin{array}{l}0.0235^{* * *} \\
(4.12)\end{array}$ & $\begin{array}{l}0.0389^{* * *} \\
(5.51)\end{array}$ & $\begin{array}{l}0.0764^{* * *} \\
(7.50)\end{array}$ & $\begin{array}{l}0.0725^{* * *} \\
(6.78)\end{array}$ & $\begin{array}{l}0.0179^{* * *} \\
(3.31)\end{array}$ & $\begin{array}{l}0.0262^{* * *} \\
(3.90)\end{array}$ & $\begin{array}{l}0.0395^{* * *} \\
(4.27)\end{array}$ & $\begin{array}{l}0.00918^{*} \\
(1.99)\end{array}$ \\
\hline Distance to shore & $\begin{array}{l}0.00131 \\
(1.12)\end{array}$ & $\begin{array}{l}-0.00571 * * * \\
(-5.22)\end{array}$ & $\begin{array}{l}-0.000307^{*} \\
(-2.07)\end{array}$ & $\begin{array}{l}0.00279 \\
(1.42)\end{array}$ & $\begin{array}{l}-0.00120^{*} \\
(-2.27)\end{array}$ & $\begin{array}{l}-0.00302 * * * \\
(-4.15)\end{array}$ & $\begin{array}{l}-0.00779 * * * \\
(-5.87)\end{array}$ & $\begin{array}{l}-0.00786^{* * *} \\
(-5.74)\end{array}$ & $\begin{array}{l}-0.000104 \\
(-0.18)\end{array}$ & $\begin{array}{l}0.000813 \\
(0.98)\end{array}$ & $\begin{array}{l}-0.000882 \\
(-0.66)\end{array}$ & $\begin{array}{l}0.000186 \\
(0.31)\end{array}$ \\
\hline Literacy rate & $\begin{array}{l}-0.0572^{* * *} \\
(-8.01)\end{array}$ & $\begin{array}{l}0.00478 \\
(0.71)\end{array}$ & $\begin{array}{l}0.000298 \\
(0.40)\end{array}$ & $\begin{array}{l}-0.0777^{* * *} \\
(-6.50)\end{array}$ & $\begin{array}{l}-0.0156^{* * *} \\
(-4.46)\end{array}$ & $\begin{array}{l}-0.0131^{*} \\
(-2.50)\end{array}$ & $\begin{array}{l}-0.00379 \\
(-0.48)\end{array}$ & $\begin{array}{l}-0.0329 * * * \\
(-3.51)\end{array}$ & $\begin{array}{l}-0.00268 \\
(-0.85)\end{array}$ & $\begin{array}{l}-0.00449 \\
(-0.93)\end{array}$ & $\begin{array}{l}-0.0135 \\
(-1.78)\end{array}$ & $\begin{array}{l}-0.00286 \\
(-0.77)\end{array}$ \\
\hline Water service connection & $\begin{array}{l}-0.0360^{* * *} \\
(-8.20)\end{array}$ & $\begin{array}{l}-0.0354^{* * *} \\
(-7.88)\end{array}$ & $\begin{array}{l}-0.000968 \\
(-1.54)\end{array}$ & $\begin{array}{l}-0.0116 \\
(-1.33)\end{array}$ & $\begin{array}{l}-0.00143 \\
(-0.60)\end{array}$ & $\begin{array}{l}0.00750^{*} \\
(2.21)\end{array}$ & $\begin{array}{l}0.0978^{* * *} \\
(11.70)\end{array}$ & $\begin{array}{l}-0.0137^{*} \\
(-2.31)\end{array}$ & $\begin{array}{l}-0.00336 \\
(-1.40)\end{array}$ & $\begin{array}{l}-0.000592 \\
(-0.17)\end{array}$ & $\begin{array}{l}0.00912 \\
(1.48)\end{array}$ & $\begin{array}{l}0.000503 \\
(0.17)\end{array}$ \\
\hline Household size & $\begin{array}{l}0.00199^{*} \\
(2.05)\end{array}$ & $\begin{array}{l}0.00223^{*} \\
(2.27)\end{array}$ & $\begin{array}{l}0.000378^{* * *} \\
(3.69)\end{array}$ & $\begin{array}{l}-0.00399 * \\
(-2.22)\end{array}$ & $\begin{array}{l}0.000719 \\
(1.71)\end{array}$ & $\begin{array}{l}0.000899 \\
(1.57)\end{array}$ & $\begin{array}{l}0.00166 \\
(1.52)\end{array}$ & $\begin{array}{l}0.00285 * \\
(2.47)\end{array}$ & $\begin{array}{l}0.00211^{* * *} \\
(5.30)\end{array}$ & $\begin{array}{l}0.00327^{* * *} \\
(6.16)\end{array}$ & $\begin{array}{l}0.0114^{* * *} \\
(11.48)\end{array}$ & $\begin{array}{l}0.00268^{* * *} \\
(6.43)\end{array}$ \\
\hline $0-5$ years old & $\begin{array}{l}-0.0193 \\
(-1.52)\end{array}$ & $\begin{array}{l}-0.0303^{*} \\
(-2.23)\end{array}$ & $\begin{array}{l}-0.00648^{* *} \\
(-2.86)\end{array}$ & $\begin{array}{l}-0.00150 \\
(-0.07)\end{array}$ & $\begin{array}{l}0.00417 \\
(0.71)\end{array}$ & $\begin{array}{l}0.0335^{* * *} \\
(4.69)\end{array}$ & $\begin{array}{l}-0.00907 \\
(-0.59)\end{array}$ & $\begin{array}{l}-0.00734 \\
(-0.48)\end{array}$ & $\begin{array}{l}-0.0157^{*} \\
(-2.32)\end{array}$ & $\begin{array}{l}0.0124 \\
(1.35)\end{array}$ & $\begin{array}{l}-0.183^{* * *} \\
(-10.71)\end{array}$ & $\begin{array}{l}-0.0343^{* * *} \\
(-4.14)\end{array}$ \\
\hline $6-14$ years old & $\begin{array}{l}-0.0103 \\
(-0.84)\end{array}$ & $\begin{array}{l}-0.0403^{* *} \\
(-3.10)\end{array}$ & $\begin{array}{l}0.000620 \\
(0.39)\end{array}$ & $\begin{array}{l}0.0544^{* *} \\
(2.64)\end{array}$ & $\begin{array}{l}0.00329 \\
(0.66)\end{array}$ & $\begin{array}{l}0.0129 \\
(1.80)\end{array}$ & $\begin{array}{l}0.0188 \\
(1.40)\end{array}$ & $\begin{array}{l}-0.0144 \\
(-0.98)\end{array}$ & $\begin{array}{l}-0.0161^{*} \\
(-2.54)\end{array}$ & $\begin{array}{l}0.0211^{*} \\
(2.55)\end{array}$ & $\begin{array}{l}-0.123^{* * *} \\
(-8.20)\end{array}$ & $\begin{array}{l}-0.0308 * * * \\
(-4.05)\end{array}$ \\
\hline $15-18$ years old & $\begin{array}{l}0.00895 \\
(0.54)\end{array}$ & $\begin{array}{l}-0.0344 \\
(-1.83)\end{array}$ & $\begin{array}{l}-0.00121 \\
(-0.46)\end{array}$ & $\begin{array}{l}0.0574^{*} \\
(2.06)\end{array}$ & $\begin{array}{l}0.0103 \\
(1.59)\end{array}$ & $\begin{array}{l}0.0109 \\
(1.19)\end{array}$ & $\begin{array}{l}0.0920^{* * *} \\
(5.69)\end{array}$ & $\begin{array}{l}0.0140 \\
(0.74)\end{array}$ & $\begin{array}{l}-0.0116 \\
(-1.19)\end{array}$ & $\begin{array}{l}0.0257^{*} \\
(2.54)\end{array}$ & $\begin{array}{l}-0.0488^{*} \\
(-2.41)\end{array}$ & $\begin{array}{l}-0.0170 \\
(-1.56)\end{array}$ \\
\hline 60 years old and above & $\begin{array}{l}0.00219 \\
(0.20)\end{array}$ & $\begin{array}{l}-0.00304 \\
(-0.30)\end{array}$ & $\begin{array}{l}0.00381^{* * *} \\
(3.74)\end{array}$ & $\begin{array}{l}-0.0556^{* *} \\
(-2.84)\end{array}$ & $\begin{array}{l}-0.0138^{*} \\
(-1.98)\end{array}$ & $\begin{array}{l}0.00126 \\
(0.17)\end{array}$ & $\begin{array}{l}-0.0300^{*} \\
(-2.01)\end{array}$ & $\begin{array}{l}-0.0490^{* *} \\
(-3.12)\end{array}$ & $\begin{array}{l}-0.00114 \\
(-0.20)\end{array}$ & $\begin{array}{l}-0.0120 \\
(-1.18)\end{array}$ & $\begin{array}{l}0.106 * * * \\
(11.66)\end{array}$ & $\begin{array}{l}0.0249 * * * \\
(6.44)\end{array}$ \\
\hline $\mathbf{N}$ & 13568 & 13568 & 13568 & 13568 & 13568 & 13568 & 13568 & 13568 & 13568 & 13568 & 13568 & 13568 \\
\hline
\end{tabular}

${\text { t statistic in parentheses; }{ }^{*} p<0.05}^{* *} p<0.01{ }^{* * *} p<0.001$ 
Table 4-17. Robustness Check 2, by Specific Disease

\begin{tabular}{|c|c|c|c|c|c|c|c|c|c|c|c|c|}
\hline & $\begin{array}{c}\text { Bronchitis } \\
\text { (1) }\end{array}$ & $\begin{array}{l}\text { Respiratory Tract } \\
\text { Infection } \\
\text { (2) }\end{array}$ & $\begin{array}{l}\text { Tuberculosis } \\
\text { (3) }\end{array}$ & $\begin{array}{l}\text { Influenza } \\
\text { (4) }\end{array}$ & $\begin{array}{l}\text { Chicken Pox } \\
\text { (5) }\end{array}$ & $\begin{array}{l}\text { Measles } \\
\text { (6) }\end{array}$ & $\begin{array}{l}\text { Typhoid Fever } \\
\text { (7) }\end{array}$ & $\begin{array}{l}\text { Diarrhea } \\
\text { (8) }\end{array}$ & $\begin{array}{l}\text { Leptospirosis } \\
\text { (9) }\end{array}$ & $\begin{array}{c}\text { Dengue } \\
\text { (10) }\end{array}$ & $\begin{array}{l}\text { Hypertension } \\
\text { (11) }\end{array}$ & $\begin{array}{l}\text { Heart Diseases } \\
\text { (12) }\end{array}$ \\
\hline Flood height & $\begin{array}{l}0.00624^{* * *} \\
(4.34)\end{array}$ & $\begin{array}{l}-0.00481^{* * *} \\
(-3.51)\end{array}$ & $\begin{array}{l}0.0000802 \\
(0.54)\end{array}$ & $\begin{array}{l}0.0170^{* * *} \\
(6.75)\end{array}$ & $\begin{array}{l}-0.000175 \\
(-0.29)\end{array}$ & $\begin{array}{l}0.000536 \\
(0.74)\end{array}$ & $\begin{array}{l}0.00428^{* *} \\
(2.76)\end{array}$ & $\begin{array}{l}-0.00180 \\
(-1.11)\end{array}$ & $\begin{array}{l}0.00314^{* * *} \\
(5.28)\end{array}$ & $\begin{array}{l}-0.00184 \\
(-1.75)\end{array}$ & $\begin{array}{l}.00309 \\
(1.85)\end{array}$ & $\begin{array}{l}-0.0000591 \\
(-0.07)\end{array}$ \\
\hline Flood duration & $\begin{array}{l}0.00167 * * * \\
(4.93)\end{array}$ & $\begin{array}{l}0.000372 \\
(1.19)\end{array}$ & $\begin{array}{l}0.0000803^{*} \\
(2.04)\end{array}$ & $\begin{array}{l}0.00291 * * * \\
(4.77)\end{array}$ & $\begin{array}{l}0.000222 \\
(1.51)\end{array}$ & $\begin{array}{l}0.000384^{*} \\
(2.15)\end{array}$ & $\begin{array}{l}0.00211^{* * *} \\
(5.50)\end{array}$ & $\begin{array}{l}-0.000117 \\
(-0.29)\end{array}$ & $\begin{array}{l}0.0000160 \\
(0.11)\end{array}$ & $\begin{array}{l}0.000695 * * \\
(3.06)\end{array}$ & $\begin{array}{l}-0.0000100 \\
(-0.03)\end{array}$ & $\begin{array}{l}0.000105 \\
(0.58)\end{array}$ \\
\hline Distance to shore & $\begin{array}{l}0.00189 \\
(1.55)\end{array}$ & $\begin{array}{l}-0.00310^{* *} \\
(-3.01)\end{array}$ & $\begin{array}{l}-0.000277 \\
(-1.74)\end{array}$ & $\begin{array}{l}0.00101 \\
(0.50)\end{array}$ & $\begin{array}{l}-0.000620 \\
(-1.13)\end{array}$ & $\begin{array}{l}-0.00222^{* *} \\
(-2.85)\end{array}$ & $\begin{array}{l}-0.00644^{* * *} \\
(-4.84)\end{array}$ & $\begin{array}{l}-0.00473^{* * *} \\
(-3.54)\end{array}$ & $\begin{array}{l}-0.000314 \\
(-0.52)\end{array}$ & $\begin{array}{l}0.00181^{*} \\
(2.31)\end{array}$ & $\begin{array}{l}0.00000909 \\
(0.01)\end{array}$ & $\begin{array}{l}0.000516 \\
0.91)\end{array}$ \\
\hline Literacy rate & $\begin{array}{l}-0.0593^{* * *} \\
(-8.12)\end{array}$ & $\begin{array}{l}0.00508 \\
(0.75)\end{array}$ & $\begin{array}{l}0.000274 \\
(0.37)\end{array}$ & $\begin{array}{l}-0.0797 * * * \\
(-6.68)\end{array}$ & $\begin{array}{l}-0.0166^{* * *} \\
(-4.41)\end{array}$ & $\begin{array}{l}-0.0143^{*} \\
(-2.53)\end{array}$ & $\begin{array}{l}-0.00532 \\
(-0.66)\end{array}$ & $\begin{array}{l}-0.0329^{* * *} \\
(-3.45)\end{array}$ & $\begin{array}{l}-0.00279 \\
(-0.87)\end{array}$ & $\begin{array}{l}-0.00474 \\
(-0.97)\end{array}$ & $\begin{array}{l}-0.0137 \\
(-1.80)\end{array}$ & $\begin{array}{l}-0.00291 \\
(-0.78)\end{array}$ \\
\hline Water service connection & $\begin{array}{l}-0.0386 * * * \\
(-8.56)\end{array}$ & $\begin{array}{l}-0.0360^{* * *} \\
(-8.02)\end{array}$ & $\begin{array}{l}-0.00101 \\
(-1.63)\end{array}$ & $\begin{array}{l}-0.0142 \\
(-1.63)\end{array}$ & $\begin{array}{l}-0.00180 \\
(-0.70)\end{array}$ & $\begin{array}{l}0.00766^{*} \\
(2.08)\end{array}$ & $\begin{array}{l}0.0973^{* * *} \\
(11.47)\end{array}$ & $\begin{array}{l}-0.0145 * \\
(-2.41)\end{array}$ & $\begin{array}{l}-0.00368 \\
(-1.52)\end{array}$ & $\begin{array}{l}-0.00105 \\
(-0.29)\end{array}$ & $\begin{array}{l}0.00868 \\
(1.40)\end{array}$ & $\begin{array}{l}0.000388 \\
(0.13)\end{array}$ \\
\hline Household size & $\begin{array}{l}0.00223^{*} \\
(2.27)\end{array}$ & $\begin{array}{l}0.00213^{*} \\
(2.14)\end{array}$ & $\begin{array}{l}0.000367^{* * *} \\
(3.64)\end{array}$ & $\begin{array}{l}-0.00353^{*} \\
(-1.98)\end{array}$ & $\begin{array}{l}0.000776 \\
(1.72)\end{array}$ & $\begin{array}{l}0.000977 \\
(1.60)\end{array}$ & $\begin{array}{l}0.00177 \\
(1.62)\end{array}$ & $\begin{array}{l}0.00285^{*} \\
(2.43)\end{array}$ & $\begin{array}{l}0.00211^{* * *} \\
(5.61)\end{array}$ & $\begin{array}{l}0.00329 * * * \\
(6.05)\end{array}$ & $\begin{array}{l}0.0115 * * * \\
(11.58)\end{array}$ & $\begin{array}{l}0.00266^{* * *} \\
(6.44)\end{array}$ \\
\hline $0-5$ years old & $\begin{array}{l}-0.0214 \\
(-1.63)\end{array}$ & $\begin{array}{l}-0.0307^{*} \\
(-2.22)\end{array}$ & $\begin{array}{l}-0.00639 * * \\
(-2.93)\end{array}$ & $\begin{array}{l}-0.00445 \\
(-0.20)\end{array}$ & $\begin{array}{l}0.00440 \\
(0.69)\end{array}$ & $\begin{array}{l}0.0363 * * * \\
(4.68)\end{array}$ & $\begin{array}{l}-0.0108 \\
(-0.69)\end{array}$ & $\begin{array}{l}-0.00757 \\
(-0.49)\end{array}$ & $\begin{array}{l}-0.0162^{*} \\
(-2.39)\end{array}$ & $\begin{array}{l}0.0126 \\
(1.34)\end{array}$ & $\begin{array}{l}-0.185^{* * *} \\
(-10.76)\end{array}$ & $\begin{array}{l}-0.0348^{* * *} \\
(-4.17)\end{array}$ \\
\hline $6-14$ years old & $\begin{array}{l}-0.0114 \\
(-0.92)\end{array}$ & $\begin{array}{l}-0.0403^{* *} \\
(-3.08)\end{array}$ & $\begin{array}{l}0.000590 \\
(0.38)\end{array}$ & $\begin{array}{l}0.0522^{*} \\
(2.54)\end{array}$ & $\begin{array}{l}0.00359 \\
(0.67)\end{array}$ & $\begin{array}{l}0.0140 \\
(1.80)\end{array}$ & $\begin{array}{l}0.0178 \\
(1.31)\end{array}$ & $\begin{array}{l}-0.0141 \\
(-0.94)\end{array}$ & $\begin{array}{l}-0.0162^{*} \\
(-2.58)\end{array}$ & $\begin{array}{l}0.0215^{* *} \\
(2.58)\end{array}$ & $\begin{array}{l}-0.123^{* * *} \\
(-8.20)\end{array}$ & $\begin{array}{l}-0.0309 * * * \\
(-4.05)\end{array}$ \\
\hline $15-18$ years old & $\begin{array}{l}0.00948 \\
(0.56)\end{array}$ & $\begin{array}{l}-0.0344 \\
(-1.82)\end{array}$ & $\begin{array}{l}-0.00115 \\
(-0.44)\end{array}$ & $\begin{array}{l}0.0576^{*} \\
(2.07)\end{array}$ & $\begin{array}{l}0.0112 \\
(1.61)\end{array}$ & $\begin{array}{l}0.0121 \\
(1.22)\end{array}$ & $\begin{array}{l}0.0933^{* * *} \\
(5.71)\end{array}$ & $\begin{array}{l}0.0149 \\
(0.77)\end{array}$ & $\begin{array}{l}-0.0115 \\
(-1.18)\end{array}$ & $\begin{array}{l}0.0262^{*} \\
(2.55)\end{array}$ & $\begin{array}{l}-0.0488^{*} \\
(-2.40)\end{array}$ & $\begin{array}{l}-0.0171 \\
(-1.56)\end{array}$ \\
\hline 60 years old and above & $\begin{array}{l}0.00181 \\
(0.16)\end{array}$ & $\begin{array}{l}-0.00300 \\
(-0.29)\end{array}$ & $\begin{array}{l}0.00369 * * * \\
(3.64)\end{array}$ & $\begin{array}{l}-0.0568 * * \\
(-2.91)\end{array}$ & $\begin{array}{l}-0.0149 * \\
(-1.98)\end{array}$ & $\begin{array}{l}0.00130 \\
(0.16)\end{array}$ & $\begin{array}{l}-0.0306 * \\
(-2.03)\end{array}$ & $\begin{array}{l}-0.0499 * * \\
(-3.11)\end{array}$ & $\begin{array}{l}-0.00147 \\
(-0.26)\end{array}$ & $\begin{array}{l}-0.0118 \\
(-1.15)\end{array}$ & $\begin{array}{l}0.107 * * * \\
(11.60)\end{array}$ & $\begin{array}{l}0.0250 * * * \\
(6.43)\end{array}$ \\
\hline $\mathrm{N}$ & 13568 & 13568 & 13568 & 13568 & 13568 & 13568 & 13568 & 13568 & 13568 & 13568 & 13568 & 13568 \\
\hline
\end{tabular}


Table 4-18. Robustness Check 3, by Specific Disease

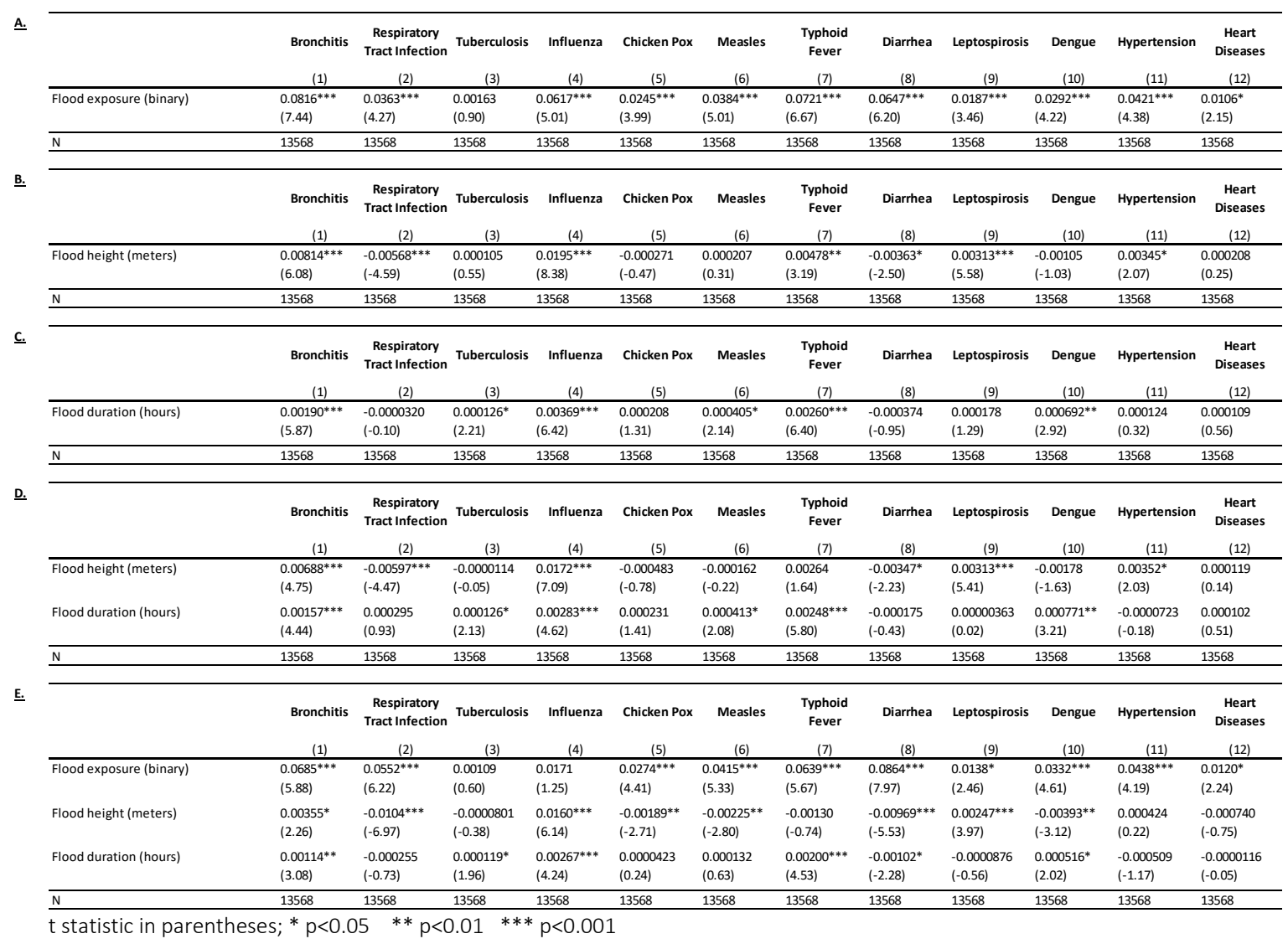


Table 4-19. Robustness Checks 1, by Category of Diseases

\begin{tabular}{|c|c|c|c|c|c|c|}
\hline & $\begin{array}{c}\text { Any Disease } \\
\text { (1) }\end{array}$ & $\begin{array}{c}\text { Respiratory- } \\
\text { Related } \\
(2)\end{array}$ & $\begin{array}{c}\text { Air-Borne } \\
\text { (3) }\end{array}$ & $\begin{array}{l}\text { Water- or Food- } \\
\text { Borne } \\
\text { (4) }\end{array}$ & $\begin{array}{c}\text { Vector-Borne } \\
\text { (5) } \\
\end{array}$ & $\begin{array}{c}\text { Non- } \\
\text { Communicable } \\
\text { Diseases } \\
(6)\end{array}$ \\
\hline Flood exposure & $\begin{array}{l}0.215^{* * *} \\
(13.07)\end{array}$ & $\begin{array}{l}0.111^{* * *} \\
(8.54)\end{array}$ & $\begin{array}{l}0.0899^{* * * *} \\
(6.51)\end{array}$ & $\begin{array}{l}0.136^{* * *} \\
(9.70)\end{array}$ & $\begin{array}{l}0.0280^{* * *} \\
(4.05)\end{array}$ & $\begin{array}{l}0.0463^{* * *} \\
(4.75)\end{array}$ \\
\hline Distance to shore & $\begin{array}{l}-0.00679^{*} \\
(-2.42)\end{array}$ & $\begin{array}{l}-0.00475^{* *} \\
(-2.88)\end{array}$ & $\begin{array}{l}-0.000266 \\
(-0.13)\end{array}$ & $\begin{array}{l}-0.0134^{* * *} \\
(-6.97)\end{array}$ & $\begin{array}{l}0.00104 \\
(1.23)\end{array}$ & $\begin{array}{l}-0.00102 \\
(-0.73)\end{array}$ \\
\hline Literacy rate & $\begin{array}{l}-0.0673^{* * *} \\
(-4.52)\end{array}$ & $\begin{array}{l}-0.0494^{* * *} \\
(-4.92)\end{array}$ & $\begin{array}{l}-0.0956^{* * * *} \\
(-7.51)\end{array}$ & $\begin{array}{l}-0.0127 \\
(-1.09)\end{array}$ & $\begin{array}{l}-0.00435 \\
(-0.89)\end{array}$ & $\begin{array}{l}-0.0135 \\
(-1.68)\end{array}$ \\
\hline Water service connection & $\begin{array}{l}-0.00695 \\
(-0.62)\end{array}$ & $\begin{array}{l}-0.0769 * * * \\
(-12.02)\end{array}$ & $\begin{array}{l}-0.0101 \\
(-1.10)\end{array}$ & $\begin{array}{l}0.0341^{* * *} \\
(3.87)\end{array}$ & $\begin{array}{l}0.000244 \\
(0.07)\end{array}$ & $\begin{array}{l}0.00772 \\
(1.21)\end{array}$ \\
\hline Household size & $\begin{array}{l}0.0101 * * * \\
(4.41)\end{array}$ & $\begin{array}{l}0.00465^{* * *} \\
(3.30)\end{array}$ & $\begin{array}{l}-0.00295 \\
(-1.57)\end{array}$ & $\begin{array}{l}0.00500^{* *} \\
(3.13)\end{array}$ & $\begin{array}{l}0.00326^{* * * *} \\
(5.95)\end{array}$ & $\begin{array}{l}0.0124 * * * \\
(11.83)\end{array}$ \\
\hline 0 - 5 years old & $\begin{array}{l}-0.137^{* * *} \\
(-4.71)\end{array}$ & $\begin{array}{l}-0.0571^{* *} \\
(-3.03)\end{array}$ & $\begin{array}{l}0.0230 \\
(0.99)\end{array}$ & $\begin{array}{l}-0.00334 \\
(-0.16)\end{array}$ & $\begin{array}{l}0.0162 \\
(1.73)\end{array}$ & $\begin{array}{l}-0.190 * * * \\
(-10.65)\end{array}$ \\
\hline $6-14$ years old & $\begin{array}{l}-0.0578^{*} \\
(-2.12)\end{array}$ & $\begin{array}{l}-0.0480^{* *} \\
(-2.70)\end{array}$ & $\begin{array}{l}0.0490^{*} \\
(2.26)\end{array}$ & $\begin{array}{l}-0.00209 \\
(-0.10)\end{array}$ & $\begin{array}{l}0.0226^{* *} \\
(2.69)\end{array}$ & $\begin{array}{l}-0.128^{* * *} \\
(-8.20)\end{array}$ \\
\hline $15-18$ years old & $\begin{array}{l}0.0313 \\
(0.84)\end{array}$ & $\begin{array}{l}-0.0345 \\
(-1.37)\end{array}$ & $\begin{array}{l}0.0652^{*} \\
(2.23)\end{array}$ & $\begin{array}{l}0.0866 * * * \\
(3.39)\end{array}$ & $\begin{array}{l}0.0258^{*} \\
(2.47)\end{array}$ & $\begin{array}{l}-0.0557^{* *} \\
(-2.62)\end{array}$ \\
\hline 60 years old and above & $\begin{array}{l}0.0459 \\
(1.96)\end{array}$ & $\begin{array}{l}0.00852 \\
(0.57)\end{array}$ & $\begin{array}{l}-0.0692^{* * *} \\
(-3.31)\end{array}$ & $\begin{array}{l}-0.0501^{*} \\
(-2.51)\end{array}$ & $\begin{array}{l}-0.0104 \\
(-1.04)\end{array}$ & $\begin{array}{l}0.117 * * * \\
(12.20)\end{array}$ \\
\hline $\mathbf{N}$ & 13568 & 13568 & 13568 & 13568 & 13568 & 13568 \\
\hline
\end{tabular}

t statistic in parentheses; ${ }^{*} p<0.05 \quad * * p<0.01 \quad * * * p<0.001$

Table 4-20. Robustness Check 2, by Category of Diseases

\begin{tabular}{|c|c|c|c|c|c|c|}
\hline & $\begin{array}{c}\text { Any Disease } \\
\text { (1) }\end{array}$ & $\begin{array}{c}\text { Respiratory- } \\
\text { Related } \\
\text { (2) }\end{array}$ & $\begin{array}{c}\text { Air-Borne } \\
\text { (3) }\end{array}$ & $\begin{array}{l}\text { Water- or Food- } \\
\text { Borne } \\
\text { (4) }\end{array}$ & $\begin{array}{c}\text { Vector-Borne } \\
\text { (5) }\end{array}$ & $\begin{array}{c}\text { Non- } \\
\text { Communicable } \\
\text { Diseases } \\
\text { (6) }\end{array}$ \\
\hline Flood height & $\begin{array}{l}0.0173^{* * *} \\
(5.23)\end{array}$ & $\begin{array}{l}0.00257 \\
(1.23)\end{array}$ & $\begin{array}{l}0.0174^{* * *} \\
(6.63)\end{array}$ & $\begin{array}{l}0.00564^{*} \\
(2.49)\end{array}$ & $\begin{array}{l}-0.00193 \\
(-1.80)\end{array}$ & $\begin{array}{l}0.00350^{*} \\
(2.01)\end{array}$ \\
\hline Flood duration & $\begin{array}{l}0.00470 * * * \\
(5.80)\end{array}$ & $\begin{array}{l}0.00227 * * * \\
(4.74)\end{array}$ & $\begin{array}{l}0.00345^{* * *} \\
(5.46)\end{array}$ & $\begin{array}{l}0.00228 * * * \\
(4.04)\end{array}$ & $\begin{array}{l}0.000703 * * \\
(3.03)\end{array}$ & $\begin{array}{l}0.000457 \\
(1.17)\end{array}$ \\
\hline Distance to shore & $\begin{array}{l}-0.00247 \\
(-0.90)\end{array}$ & $\begin{array}{l}-0.00194 \\
(-1.19)\end{array}$ & $\begin{array}{l}-0.00108 \\
(-0.51)\end{array}$ & $\begin{array}{l}-0.00989 * * * \\
(-5.22)\end{array}$ & $\begin{array}{l}0.00208^{* *} \\
(2.61)\end{array}$ & $\begin{array}{l}-0.0000552 \\
(-0.04)\end{array}$ \\
\hline Literacy rate & $\begin{array}{l}-0.0684 * * * \\
(-4.59)\end{array}$ & $\begin{array}{l}-0.0506^{* * *} \\
(-4.96)\end{array}$ & $\begin{array}{l}-0.0979 * * * \\
(-7.68)\end{array}$ & $\begin{array}{l}-0.0136 \\
(-1.16)\end{array}$ & $\begin{array}{l}-0.00458 \\
(-0.92)\end{array}$ & $\begin{array}{l}-0.0139 \\
(-1.71)\end{array}$ \\
\hline Water service connection & $\begin{array}{l}-0.0113 \\
(-1.01)\end{array}$ & $\begin{array}{l}-0.0799 * * * \\
(-12.40)\end{array}$ & $\begin{array}{l}-0.0132 \\
(-1.43)\end{array}$ & $\begin{array}{l}0.0320^{* * *} \\
(3.60)\end{array}$ & $\begin{array}{l}-0.000198 \\
(-0.05)\end{array}$ & $\begin{array}{l}0.00703 \\
(1.09)\end{array}$ \\
\hline Household size & $\begin{array}{l}0.0104^{* * *} \\
(4.57)\end{array}$ & $\begin{array}{l}0.00477 * * * \\
(3.35)\end{array}$ & $\begin{array}{l}-0.00250 \\
(-1.34)\end{array}$ & $\begin{array}{l}0.00513^{* *} \\
(3.20)\end{array}$ & $\begin{array}{l}0.00328^{* * *} \\
(5.85)\end{array}$ & $\begin{array}{l}0.0125^{* * *} \\
(11.95)\end{array}$ \\
\hline $0-5$ years old & $\begin{array}{l}-0.140^{* * *} \\
(-4.83)\end{array}$ & $\begin{array}{l}-0.0593^{* *} \\
(-3.09)\end{array}$ & $\begin{array}{l}0.0198 \\
(0.85)\end{array}$ & $\begin{array}{l}-0.00523 \\
(-0.24)\end{array}$ & $\begin{array}{l}0.0165 \\
(1.72)\end{array}$ & $\begin{array}{l}-0.193^{* * *} \\
(-10.71)\end{array}$ \\
\hline $6-14$ years old & $\begin{array}{l}-0.0586 * \\
(-2.16)\end{array}$ & $\begin{array}{l}-0.0491^{* *} \\
(-2.73)\end{array}$ & $\begin{array}{l}0.0468^{*} \\
(2.16)\end{array}$ & $\begin{array}{l}-0.00283 \\
(-0.14)\end{array}$ & $\begin{array}{l}0.0231^{* *} \\
(2.73)\end{array}$ & $\begin{array}{l}-0.129 * * * \\
(-8.20)\end{array}$ \\
\hline $15-18$ years old & $\begin{array}{l}0.0320 \\
(0.86)\end{array}$ & $\begin{array}{l}-0.0345 \\
(-1.35)\end{array}$ & $\begin{array}{l}0.0657^{*} \\
(2.24)\end{array}$ & $\begin{array}{l}0.0877^{* * *} \\
(3.41)\end{array}$ & $\begin{array}{l}0.0263^{*} \\
(2.49)\end{array}$ & $\begin{array}{l}-0.0557^{* *} \\
(-2.61)\end{array}$ \\
\hline 60 years old and above & $\begin{array}{l}0.0439 \\
(1.88)\end{array}$ & $\begin{array}{l}0.00830 \\
(0.54)\end{array}$ & $\begin{array}{l}-0.0705^{* * *} \\
(-3.38)\end{array}$ & $\begin{array}{l}-0.0513^{*} \\
(-2.55)\end{array}$ & $\begin{array}{l}-0.0103 \\
(-1.01)\end{array}$ & $\begin{array}{l}0.117 * * * \\
(12.12)\end{array}$ \\
\hline $\mathbf{N}$ & 13568 & 13568 & 13568 & 13568 & 13568 & 13568 \\
\hline
\end{tabular}

t statistic in parentheses; ${ }^{*} p<0.05 \quad * * p<0.01 \quad{ }^{* * *} p<0.001$ 
Table 4-21. Robustness Check 3, by Category of Diseases

\begin{tabular}{|c|c|c|c|c|c|c|}
\hline & $\begin{array}{c}\text { Any Disease } \\
\text { (1) }\end{array}$ & $\begin{array}{l}\text { Respiratory- } \\
\text { Related } \\
\text { (2) }\end{array}$ & $\begin{array}{c}\text { Air-Borne } \\
\text { (3) }\end{array}$ & $\begin{array}{l}\text { Water- or Food- } \\
\text { Borne } \\
\text { (4) }\end{array}$ & $\begin{array}{c}\text { Vector-Borne } \\
\text { (5) }\end{array}$ & $\begin{array}{c}\text { Non- } \\
\text { Communicable } \\
\text { Diseases } \\
\text { (6) }\end{array}$ \\
\hline Flood exposure (binary) & $\begin{array}{l}0.207^{* * *} \\
(13.31)\end{array}$ & $\begin{array}{l}0.108^{* * *} \\
(8.49)\end{array}$ & $\begin{array}{l}0.0898^{* * *} \\
(6.77)\end{array}$ & $\begin{array}{l}0.121^{* * *} \\
(8.92)\end{array}$ & $\begin{array}{l}0.0312^{* * *} \\
(4.40)\end{array}$ & $\begin{array}{l}0.0488^{* * *} \\
(4.85)\end{array}$ \\
\hline $\mathrm{N}$ & 13568 & 13568 & 13568 & 13568 & 13568 & 13568 \\
\hline & $\begin{array}{c}\text { Any Disease } \\
\text { (1) }\end{array}$ & $\begin{array}{c}\text { Respiratory- } \\
\text { Related } \\
\text { (2) }\end{array}$ & $\begin{array}{c}\text { Air-Borne } \\
\text { (3) }\end{array}$ & $\begin{array}{l}\text { Water- or Food- } \\
\text { Borne } \\
\text { (4) }\end{array}$ & $\begin{array}{c}\text { Vector-Borne } \\
\text { (5) }\end{array}$ & $\begin{array}{c}\text { Non- } \\
\text { Communicable } \\
\text { Diseases } \\
(6) \\
\end{array}$ \\
\hline Flood height (binary) & $\begin{array}{l}0.0202^{* * *} \\
(6.51)\end{array}$ & $\begin{array}{l}0.00349 \\
(1.86)\end{array}$ & $\begin{array}{l}0.0197^{* * *} \\
(8.12)\end{array}$ & $\begin{array}{l}0.00466^{*} \\
(2.27)\end{array}$ & $\begin{array}{l}-0.00106 \\
(-1.02)\end{array}$ & $\begin{array}{l}0.00424^{*} \\
(2.46)\end{array}$ \\
\hline $\mathrm{N}$ & 13568 & 13568 & 13568 & 13568 & 13568 & 13568 \\
\hline & $\begin{array}{c}\text { Any Disease } \\
\text { (1) }\end{array}$ & $\begin{array}{l}\text { Respiratory- } \\
\text { Related } \\
\text { (2) }\end{array}$ & $\begin{array}{c}\text { Air-Borne } \\
\text { (3) }\end{array}$ & $\begin{array}{l}\text { Water- or Food- } \\
\text { Borne } \\
\text { (4) }\end{array}$ & $\begin{array}{c}\text { Vector-Borne } \\
\text { (5) }\end{array}$ & $\begin{array}{c}\text { Non- } \\
\text { Communicable } \\
\text { Diseases } \\
\text { (6) }\end{array}$ \\
\hline Flood duration (hours) & $\begin{array}{l}0.00546^{* * * *} \\
(6.99)\end{array}$ & $\begin{array}{l}0.00214^{* * *} \\
(4.69)\end{array}$ & $\begin{array}{l}0.00421^{* * * *} \\
(7.02)\end{array}$ & $\begin{array}{l}0.00249 * * * \\
(4.55)\end{array}$ & $\begin{array}{l}0.000699 * * \\
(2.89)\end{array}$ & $\begin{array}{l}0.000625 \\
(1.57)\end{array}$ \\
\hline $\mathrm{N}$ & 13568 & 13568 & 13568 & 13568 & 13568 & 13568 \\
\hline & $\begin{array}{c}\text { Any Disease } \\
\text { (1) }\end{array}$ & $\begin{array}{l}\text { Respiratory- } \\
\text { Related } \\
\text { (2) }\end{array}$ & $\begin{array}{c}\text { Air-Borne } \\
\text { (3) }\end{array}$ & $\begin{array}{l}\text { Water- or Food- } \\
\text { Borne } \\
\text { (4) }\end{array}$ & $\begin{array}{c}\text { Vector-Borne } \\
\text { (5) }\end{array}$ & $\begin{array}{c}\text { Non- } \\
\text { Communicable } \\
\text { Diseases } \\
(6)\end{array}$ \\
\hline Flood height (binary) & $\begin{array}{l}0.0162^{* * *} \\
(5.08)\end{array}$ & $\begin{array}{l}0.00170 \\
(0.84)\end{array}$ & $\begin{array}{l}0.0170^{* * *} \\
(6.69)\end{array}$ & $\begin{array}{l}0.00261 \\
(1.20)\end{array}$ & $\begin{array}{l}-0.00180 \\
(-1.62)\end{array}$ & $\begin{array}{l}0.00389^{*} \\
(2.17)\end{array}$ \\
\hline Flood duration (hours) & $\begin{array}{l}0.00458^{* * *} \\
(5.68)\end{array}$ & $\begin{array}{l}0.00205^{* * *} \\
(4.24)\end{array}$ & $\begin{array}{l}0.00336^{* * *} \\
(5.28)\end{array}$ & $\begin{array}{l}0.00236^{* * *} \\
(4.11)\end{array}$ & $\begin{array}{l}0.000780 * * \\
(3.18)\end{array}$ & $\begin{array}{l}0.000416 \\
(0.99)\end{array}$ \\
\hline $\mathrm{N}$ & 13568 & 13568 & 13568 & 13568 & 13568 & 13568 \\
\hline & $\begin{array}{c}\text { Any Disease } \\
\text { (1) }\end{array}$ & $\begin{array}{l}\text { Respiratory- } \\
\text { Related } \\
\text { (2) }\end{array}$ & $\begin{array}{c}\text { Air-Borne } \\
\text { (3) }\end{array}$ & $\begin{array}{l}\text { Water- or Food- } \\
\text { Borne } \\
\text { (4) }\end{array}$ & $\begin{array}{c}\text { Vector-Borne } \\
\text { (5) }\end{array}$ & $\begin{array}{c}\text { Non- } \\
\text { Communicable } \\
\text { Diseases } \\
(6)\end{array}$ \\
\hline Flood exposure (binary) & $\begin{array}{l}0.192^{* * *} \\
(11.13)\end{array}$ & $\begin{array}{l}0.112^{* * *} \\
(8.26)\end{array}$ & $\begin{array}{l}0.0489 * * * \\
(3.36)\end{array}$ & $\begin{array}{l}0.125^{* * *} \\
(8.72)\end{array}$ & $\begin{array}{l}0.0355^{* * *} \\
(4.80)\end{array}$ & $\begin{array}{l}0.0479 * * * \\
(4.38)\end{array}$ \\
\hline Flood height (binary) & $\begin{array}{l}0.00144 \\
(0.42)\end{array}$ & $\begin{array}{l}-0.00547^{*} \\
(-2.44)\end{array}$ & $\begin{array}{l}0.0136^{* * *} \\
(4.95)\end{array}$ & $\begin{array}{l}-0.00580^{*} \\
(-2.42)\end{array}$ & $\begin{array}{l}-0.00407^{* *} \\
(-3.18)\end{array}$ & $\begin{array}{l}0.000562 \\
(0.28)\end{array}$ \\
\hline Flood duration (hours) & $\begin{array}{l}0.00262^{* *} \\
(3.16)\end{array}$ & $\begin{array}{l}0.00114^{*} \\
(2.21)\end{array}$ & $\begin{array}{l}0.00291 * * * \\
(4.43)\end{array}$ & $\begin{array}{l}0.00129^{*} \\
(2.14)\end{array}$ & $\begin{array}{l}0.000508 \\
(1.94)\end{array}$ & $\begin{array}{l}-0.0000379 \\
(-0.08)\end{array}$ \\
\hline $\mathrm{N}$ & 13568 & 13568 & 13568 & 13568 & 13568 & 13568 \\
\hline
\end{tabular}


Table 4-22. Robust Determinants by Specific Disease: Flood Exposure, Flood Height, and Flood Duration

\begin{tabular}{|c|c|c|c|c|c|c|c|c|c|c|c|c|}
\hline & Bronchitis & $\begin{array}{c}\text { Respiratory } \\
\text { Tract } \\
\text { Infection }\end{array}$ & Tuberculosis & Influenza & Chicken Pox & Measles & $\begin{array}{l}\text { Typhoid } \\
\text { Fever }\end{array}$ & Diarrhoea & Leptospirosis & Dengue & Hypertension & $\begin{array}{c}\text { Heart } \\
\text { Diseases }\end{array}$ \\
\hline & (1) & & (3) & (4) & (5) & & & (8) & (9) & (10) & (11) & (12) \\
\hline \multicolumn{13}{|l|}{ Flood exposure } \\
\hline Full model & $\checkmark$ & $\checkmark$ & & & $\checkmark$ & $\checkmark$ & $\checkmark$ & $\checkmark$ & $\checkmark$ & $\checkmark$ & $\checkmark$ & $\checkmark$ \\
\hline Robustness 1: all controls except flood height and duration & $\checkmark$ & $\checkmark$ & & $\checkmark$ & $\checkmark$ & $\checkmark$ & $\checkmark$ & $\checkmark$ & $\checkmark$ & $\checkmark$ & $\checkmark$ & $\checkmark$ \\
\hline \multirow{2}{*}{\multicolumn{13}{|c|}{ Robustness 3: only flood exposure, height, duration, or combination }} \\
\hline & & & & & & & & & & & & \\
\hline A. Flood exposure only & $\checkmark$ & $\checkmark$ & & $\checkmark$ & $\checkmark$ & $\checkmark$ & $\checkmark$ & $\checkmark$ & $\checkmark$ & $\checkmark$ & $\checkmark$ & $\checkmark$ \\
\hline B. Flood height only & na & na & na & na & na & na & na & na & na & na & na & na \\
\hline C. Flood duration only & na & na & na & na & na & na & na & na & na & na & na & na \\
\hline D. Flood height and duration only & na & na & na & na & na & na & na & na & na & na & na & na \\
\hline E. Flood exposure, height, and duration only & $\checkmark$ & $\checkmark$ & & (1) & $\checkmark$ & $\checkmark$ & $\checkmark$ & $\checkmark$ & $\checkmark$ & $\checkmark$ & $\checkmark$ & $\checkmark$ \\
\hline \multicolumn{13}{|l|}{ Flood height } \\
\hline Full model & $\checkmark$ & $\checkmark$ & & $\checkmark$ & $\checkmark$ & & & $\checkmark$ & $\checkmark$ & $\checkmark$ & & \\
\hline Robustness 1: all controls except flood height and duration & na & na & na & na & na & na & na & na & na & na & na & na \\
\hline Robustness 2: all controls except flood exposure & $\checkmark$ & $\checkmark$ & & $\checkmark$ & & & $\checkmark$ & & $\checkmark$ & & $\checkmark$ & \\
\hline \multicolumn{13}{|l|}{ Robustness 3: only flood exposure, height, duration, or combination } \\
\hline A. Flood exposure only & na & na & na & na & na & na & na & na & na & na & na & na \\
\hline B. Flood height only & $\checkmark$ & $\checkmark$ & & $\checkmark$ & & & $\checkmark$ & $\checkmark$ & $\checkmark$ & & $\checkmark$ & 然 \\
\hline C. Flood duration only & na & na & na & na & na & na & na & na & na & na & na & na \\
\hline D. Flood height and duration only & $\checkmark$ & $\checkmark$ & & $\checkmark$ & & & & $\checkmark$ & $\checkmark$ & & $\checkmark$ & \\
\hline E. Flood exposure, height, and duration only & $\checkmark$ & $\checkmark$ & & $\checkmark$ & $\checkmark$ & $\checkmark$ & & $\checkmark$ & $\checkmark$ & $\checkmark$ & & \\
\hline \multicolumn{13}{|l|}{ Flood duration } \\
\hline Full model & $\checkmark$ & & & $\checkmark$ & & & $\checkmark$ & $\checkmark$ & & $\checkmark$ & & \\
\hline Robustness 1: all controls except flood height and duration & na & na & na & na & na & na & na & na & na & na & na & na \\
\hline Robustness 2: all controls except flood exposure & $\checkmark$ & & $\checkmark$ & $\checkmark$ & & $\checkmark$ & $\checkmark$ & & & $\checkmark$ & & \\
\hline \multicolumn{13}{|c|}{ Robustness 3: only flood exposure, height, duration, or combination } \\
\hline A. Flood exposure only & na & na & na & & na & na & & na & na & na & na & na \\
\hline B. Flood hight only & na & na & na & & na & na & & na & na & na & na & na \\
\hline C. Flood duration only & $\checkmark$ & & $\checkmark$ & $\checkmark$ & & $\checkmark$ & $\checkmark$ & & & $\checkmark$ & & \\
\hline D. Flood height and duration only & $\checkmark$ & & $\checkmark$ & $\checkmark$ & & $\checkmark$ & $\checkmark$ & & & $\checkmark$ & & \\
\hline E. Flood exposure, height and duration onll & $\checkmark$ & & $\checkmark$ & $\checkmark$ & & & $\checkmark$ & $\checkmark$ & & $\checkmark$ & & \\
\hline
\end{tabular}




\section{Table 4-23. Robust Determinants by Category of Diseases: Flood Exposure, Flood Height, and Flood Duration}

\begin{tabular}{|c|c|c|c|c|c|c|}
\hline & $\begin{array}{c}\text { All Diseases } \\
\text { (1) }\end{array}$ & $\begin{array}{c}\text { Respiratory-Related } \\
\text { (2) } \\
\end{array}$ & $\begin{array}{c}\text { Air-Borne } \\
\text { (3) }\end{array}$ & $\begin{array}{l}\text { Water- or Food-Borne } \\
\text { (4) } \\
\end{array}$ & $\begin{array}{c}\text { Vector-Borne } \\
(5) \\
\end{array}$ & $\begin{array}{c}\text { Non-Communicable } \\
\text { Diseases } \\
(6) \\
\end{array}$ \\
\hline \multicolumn{7}{|l|}{ Flood exposure } \\
\hline Full model & $\checkmark$ & $\checkmark$ & $\checkmark$ & $\checkmark$ & $\checkmark$ & $\checkmark$ \\
\hline Robustness 1: all controls except flood height and duration & $\checkmark$ & $\checkmark$ & $\checkmark$ & $\checkmark$ & $\checkmark$ & $\checkmark$ \\
\hline Robustness 2: all controls except flood exposure & na & na & na & na & na & na \\
\hline \multicolumn{7}{|c|}{ Robustness 3: only flood exposure, height, duration, or combination } \\
\hline A. Flood exposure only & $\checkmark$ & $\checkmark$ & $\checkmark$ & $\checkmark$ & $\checkmark$ & $\checkmark$ \\
\hline B. Flood height only & na & na & na & na & na & na \\
\hline C. Flood duration only & na & na & na & na & na & na \\
\hline D. Flood height and duration only & na & na & na & na & na & na \\
\hline E. Flood exposure, height, and duration only & $\checkmark$ & $\checkmark$ & $\checkmark$ & $\checkmark$ & $\checkmark$ & $\checkmark$ \\
\hline \multicolumn{7}{|l|}{ Flood height } \\
\hline Full model & $\checkmark$ & & $\checkmark$ & & & $\checkmark$ \\
\hline Robustness 1: all controls except flood height and duration & na & na & na & na & na & na \\
\hline Robustness 2: all controls except flood exposure & $\checkmark$ & $\checkmark$ & $\checkmark$ & $\checkmark$ & & $\checkmark$ \\
\hline \multicolumn{7}{|c|}{ Robustness 3: only flood exposure, height, duration, or combination } \\
\hline A. Flood exposure only & na & na & na & na & na & na \\
\hline B. Flood height only & $\checkmark$ & & $\checkmark$ & $\checkmark$ & & $\checkmark$ \\
\hline C. Flood duration only & na & na & na & na & na & na \\
\hline D. Flood height and duration only & $\checkmark$ & & $\checkmark$ & & & $\checkmark$ \\
\hline E. Flood exposure, height, and duration only & & $\checkmark$ & $\checkmark$ & $\checkmark$ & $\checkmark$ & \\
\hline \multicolumn{7}{|l|}{ Flood duration } \\
\hline Full model & $\checkmark$ & $\checkmark$ & $\checkmark$ & & & \\
\hline Robustness 1: all controls except flood height and duration & na & na & na & na & na & na \\
\hline Robustness 2: all controls except flood exposure & $\checkmark$ & $\checkmark$ & $\checkmark$ & $\checkmark$ & $\checkmark$ & \\
\hline \multicolumn{7}{|c|}{ Robustness 3: only flood exposure, height, duration, or combination } \\
\hline A. Flood exposure only & na & na & na & na & na & na \\
\hline B. Flood height only & na & na & na & na & na & na \\
\hline C. Flood duration only & $\checkmark$ & $\checkmark$ & $\checkmark$ & $\checkmark$ & $\checkmark$ & \\
\hline D. Flood height and duration only & $\checkmark$ & $\checkmark$ & $\checkmark$ & $\checkmark$ & $\checkmark$ & \\
\hline E. Flood exposure, height, and duration only & $\checkmark$ & $\checkmark$ & $\checkmark$ & $\checkmark$ & & \\
\hline
\end{tabular}


Table 4-24. Summary of Cost Implications of Flood-Induced Diseases, by Scenario and by Specific Disease, 2014 (in PhP), Floodplains of Cagayan de Oro

\begin{tabular}{|c|c|c|c|c|c|c|c|c|c|c|c|c|c|c|c|}
\hline \multirow[b]{2}{*}{ Disease } & \multicolumn{5}{|c|}{ Scenario 1} & \multicolumn{5}{|c|}{ Scenario 2} & \multicolumn{5}{|c|}{ Scenario 2} \\
\hline & $\begin{array}{c}\text { Cost to } \\
\text { Government: } \\
\text { Provision of } \\
\text { Social } \\
\text { Insurance }\end{array}$ & $\begin{array}{l}\text { Out-of-Pocket } \\
\text { cost of } \\
\text { Hospital In- } \\
\text { Patients }\end{array}$ & $\begin{array}{c}\text { Out-of-Pocket } \\
\text { Cost of Out- } \\
\text { Patients }\end{array}$ & $\begin{array}{c}\text { Foregone } \\
\text { Earnings }\end{array}$ & TOTAL COST & $\begin{array}{c}\text { Cost to } \\
\text { Government: } \\
\text { Provision of } \\
\text { Social } \\
\text { Insurance }\end{array}$ & $\begin{array}{l}\text { Out-of-Pocket } \\
\text { Cost of } \\
\text { Hospital In- } \\
\text { Patients }\end{array}$ & $\begin{array}{l}\text { Out-of-Pocket } \\
\text { Cost of Out- } \\
\text { Patients }\end{array}$ & $\begin{array}{c}\text { Foregone } \\
\text { Earnings }\end{array}$ & TOTAL COST & \begin{tabular}{c|} 
Cost to \\
Government: \\
Provision of \\
Social \\
Insurance
\end{tabular} & \begin{tabular}{|c} 
Out-of-Pocket \\
Cost of \\
Hospital In- \\
Patients
\end{tabular} & $\begin{array}{l}\text { Out-of-Pocket } \\
\text { Cost of Out- } \\
\text { Patients }\end{array}$ & $\begin{array}{c}\text { Foregone } \\
\text { Earnings }\end{array}$ & TOTAL COST \\
\hline Bronchitis & $11,880,832$ & 985,868 & $1,603,912$ & 684,976 & $15,155,588$ & $9,012,543$ & 747,858 & $1,216,693$ & 519,608 & $11,496,702$ & $7,661,092$ & 635,715 & $1,034,247$ & 441,691 & $9,772,746$ \\
\hline Respiratory tract infection & $4,085,374$ & 285,976 & 551,526 & 228,535 & $5,151,411$ & $6,313,760$ & 441,963 & 852,358 & 353,191 & $7,961,272$ & $3,336,668$ & 233,567 & 450,450 & 186,653 & $4,207,338$ \\
\hline Influenza & $4,954,646$ & 346,825 & 668,877 & 258,964 & $6,229,313$ & $1,236,654$ & 86,566 & 166,948 & 64,636 & $1,554,804$ & \begin{tabular}{ll|}
$4,479,963$ \\
\end{tabular} & 313,597 & 604,795 & 234,154 & $5,632,510$ \\
\hline Chicken pox & $3,785,762$ & 265,003 & 511,078 & 205,661 & $4,767,504$ & $3,909,379$ & 273,657 & 527,766 & 212,376 & $4,923,177$ & $2,229,834$ & 156,088 & 301,028 & 121,135 & $2,808,085$ \\
\hline Measles & $7,008,192$ & 571,551 & 946,106 & 402,927 & $8,928,776$ & $7,391,453$ & 602,808 & 997,846 & 424,962 & $9,417,069$ & $4,147,859$ & 338,278 & 559,961 & 238,476 & $5,284,573$ \\
\hline Typhoid fever & $10,965,509$ & 767,586 & $1,480,344$ & 605,230 & $13,818,668$ & $10,144,236$ & 710,097 & $1,369,472$ & 559,900 & $12,783,705$ & $8,340,560$ & 583,839 & $1,125,976$ & 460,348 & $10,510,724$ \\
\hline \begin{tabular}{|l|} 
Diarrhoea \\
\end{tabular} & $4,723,229$ & 385,202 & 637,636 & 271,556 & $6,017,623$ & $6,533,679$ & 532,853 & 882,047 & 375,645 & $8,324,224$ & $3,657,362$ & 298,275 & 493,744 & 210,275 & $4,659,656$ \\
\hline \begin{tabular}{|l} 
Leptospirosis \\
\end{tabular} & $2,502,752$ & 320,502 & 337,872 & 156,974 & $3,318,099$ & $1,766,648$ & 226,237 & 238,498 & 110,805 & $2,342,187$ & $1,641,293$ & 210,183 & 221,575 & 102,943 & $2,175,993$ \\
\hline \begin{tabular}{|l|} 
Dengue \\
\end{tabular} & $4,263,317$ & 347,694 & 575,548 & 245,114 & $5,431,672$ & $4,292,518$ & 350,075 & 579,490 & 246,793 & $5,468,875$ & $3,044,146$ & 248,265 & 410,960 & 175,019 & $3,878,389$ \\
\hline \begin{tabular}{|l|} 
Hypertension \\
\end{tabular} & $4,610,076$ & $\begin{array}{ll}375,974 \\
\end{array}$ & 622,360 & 265,050 & $5,873,461$ & $4,478,673$ & 365,257 & 806,161 & 257,495 & $5,907,586$ & $2,283,109$ & 319,655 & 529,134 & 225,347 & $3,357,245$ \\
\hline Heart diseases & $1,857,171$ & 490,515 & 250,718 & 111,225 & $2,709,629$ & $1,822,130$ & 529,091 & 153,742 & 109,126 & $2,614,089$ & $1,540,718$ & 447,378 & 207,997 & 92,272 & $2,288,365$ \\
\hline \begin{tabular}{|c|} 
Total \\
\end{tabular} & $60,636,860$ & $5,142,696$ & $8,185,976$ & $3,436,210$ & $77,401,742$ & $56,901,673$ & $4,866,461$ & $7,791,021$ & $3,234,537$ & $72,793,691$ & $42,362,604$ & $3,784,840$ & $5,939,866$ & $2,488,314$ & $54,575,623$ \\
\hline
\end{tabular}

Table 4-25. Summary of Cost Implications of Flood-Induced Diseases, by Scenario and by Specific Disease, 2014 (in PhP), All Urban Areas in the Philippines

\begin{tabular}{|c|c|c|c|c|c|c|c|c|c|c|c|c|c|c|c|}
\hline \multirow[b]{2}{*}{ Disease } & \multicolumn{5}{|c|}{ Scenario 1} & \multicolumn{5}{|c|}{ Scenario 2} & \multicolumn{5}{|c|}{ Scenario 3} \\
\hline & \begin{tabular}{c|} 
Cost to \\
Government: \\
Provision of \\
Social Insurance
\end{tabular} & \begin{tabular}{|c|} 
Out-of-Pocket \\
Cost of Hospital \\
In-Patients
\end{tabular} & $\begin{array}{l}\text { Out-of-Pocket } \\
\text { cost of out- } \\
\text { Patients }\end{array}$ & $\begin{array}{l}\text { Foregone } \\
\text { Earnings }\end{array}$ & TOTAL COST & $\begin{array}{c}\text { Cost to } \\
\text { Government: } \\
\text { Provision of } \\
\text { Social Insurance }\end{array}$ & $\begin{array}{c}\text { Out-of-Pocket } \\
\text { Cost of Hospital } \\
\text { In-Patients }\end{array}$ & $\begin{array}{l}\text { Out-of-Pocket } \\
\text { Cost of out- } \\
\text { Patients }\end{array}$ & $\begin{array}{l}\text { Foregone } \\
\text { Earnings }\end{array}$ & TOTAL COST & $\begin{array}{l}\text { Cost to } \\
\text { Government: } \\
\text { Provision of } \\
\text { Social Insurance }\end{array}$ & \begin{tabular}{|c|} 
Out-of-Pocket \\
Cost of Hospital \\
In-Patients
\end{tabular} & $\begin{array}{l}\text { Out-of-Pocket } \\
\text { cost of out- } \\
\text { Patients }\end{array}$ & $\begin{array}{l}\text { Foregone } \\
\text { Earnings }\end{array}$ & TOTAL COST \\
\hline \begin{tabular}{|l|} 
Bronchitis \\
\end{tabular} & \begin{tabular}{ll|}
$357,876,829$ \\
20,26875
\end{tabular} & \begin{tabular}{ll|}
$29,696,511$ \\
961,23
\end{tabular} & $48,313,372$ & \begin{tabular}{|l|l|}
$19,702,750$ \\
, 57260
\end{tabular} & $\begin{array}{ll}455,589,461 \\
501001\end{array}$ & $\begin{array}{ll}271,477,644 \\
19,1927 \\
\end{array}$ & $22,527,132$ & $\begin{array}{ll}36,649,482 \\
2,67,892\end{array}$ & \begin{tabular}{ll|}
$14,946,081$ \\
\end{tabular} & $345,600,339$ & $230,768,976$ & $\begin{array}{ll}9,149,140 \\
\end{array}$ & $31,153,812$ & $\begin{array}{ll}12,704,883 \\
\end{array}$ & $293,776,811$ \\
\hline Respiratory tract infection & $123,060,475$ & $\begin{array}{l}8,614,233 \\
\end{array}$ & 613,164 & $\begin{array}{l}6,573,620 \\
, 3,925\end{array}$ & \begin{tabular}{ll|l}
$154,861,492$ \\
0,2002
\end{tabular} & $\begin{array}{ll}190,184,370 \\
2,2070\end{array}$ & $\begin{array}{ll}13,312,906 \\
30,50\end{array}$ & \begin{tabular}{|l|l|}
$25,674,890$ \\
$, 03,90$
\end{tabular} & $\begin{array}{ll}10,159,230 \\
0520\end{array}$ & $239,331,396$ & $100,507,802$ & $\begin{array}{l}7,035,546 \\
\end{array}$ & $13,568,553$ & $\begin{array}{l}, 368,905 \\
, 72,2\end{array}$ & $126,480,807$ \\
\hline Influenza & \begin{tabular}{ll|}
$149,244,841$ \\
190,1
\end{tabular} & $\begin{array}{ll}10,447,139 \\
, 29,9\end{array}$ & $\frac{148,054}{20,201}$ & $7,448,895$ & \begin{tabular}{ll|l}
$187,288,928$ \\
18,22023
\end{tabular} & \begin{tabular}{ll|}
$37,250,738$ \\
\end{tabular} & $2,607,552$ & $\begin{array}{r}, 028,850 \\
\end{array}$ & $1,859,206$ & $46,746,345$ & $134,946,357$ & $9,446,245$ & $18,217,758$ & $6,735,249$ & $169,345,609$ \\
\hline Chicken pox & $114,035,490$ & \begin{tabular}{ll|}
$7,982,484$ \\
\end{tabular} & 394,791 & \begin{tabular}{r|}
$5,915,654$ \\
\end{tabular} & $143,328,420$ & 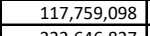 & $8,243,137$ & \begin{tabular}{ll|}
$15,897,478$ \\
\end{tabular} & $6,108,818$ & $148,008,531$ & $67,167,497$ & $4,701,725$ & $9,067,612$ & $3,484,351$ & $84,421,185$ \\
\hline \begin{tabular}{|l|} 
Measles \\
\end{tabular} & $211,102,177$ & \begin{tabular}{ll|l}
$17,216,386$ \\
\end{tabular} & $28,498,794$ & $11,589,853$ & $268,407,209$ & $222,646,827$ & $18,157,907$ & $30,057,322$ & \begin{tabular}{ll|}
$12,223,673$ \\
\end{tabular} & $283,085,728$ & $124,942,638$ & $\begin{array}{ll}10,189,666 \\
\end{array}$ & $16,867,256$ & \begin{tabular}{ll|l|}
$6,859,554$ \\
\end{tabular} & $158,859,114$ \\
\hline \begin{tabular}{|l|l|} 
Typhoid fever \\
\end{tabular} & $330,305,272$ & $23,121,369$ & $44,591,212$ & $17,408,925$ & $415,426,778$ & $305,566,736$ & $21,389,672$ & $41,251,509$ & $16,105,066$ & $384,312,983$ & $251,236,045$ & $17,586,523$ & $33,916,866$ & $13,241,537$ & $315,980,970$ \\
\hline \begin{tabular}{|l|} 
Diarrhoea \\
\end{tabular} & $142,274,071$ & $11,603,127$ & $19,207,000$ & $7,811,078$ & $180,895,275$ & $196,808,800$ & $16,050,693$ & $26,569,188$ & $10,805,123$ & $250,233,804$ & $110,167,794$ & $8,984,707$ & $14,872,652$ & $\begin{array}{ll}6,048,391 \\
\end{array}$ & $140,073,545$ \\
\hline Leptospirosis & $75,388,399$ & $\begin{array}{ll}9,654,218 \\
\end{array}$ & $\begin{array}{l}10,177,434 \\
\end{array}$ & $4,515,213$ & $99,735,264$ & $53,215,340$ & $\begin{array}{l}6,814,742 \\
\end{array}$ & $\begin{array}{l}, 184,071 \\
\end{array}$ & $3,187,210$ & $70,401,363$ & $49,439,349$ & $6,331,190$ & $6,674,312$ & $2,961,055$ & $65,405,906$ \\
\hline Dengue & $128,420,491$ & $\begin{array}{l}10,473,301 \\
\end{array}$ & $17,336,766$ & $7,050,494$ & $163,281,052$ & $\begin{array}{l}129,300,083 \\
\end{array}$ & \begin{tabular}{|l|l|}
$10,545,036$ \\
\end{tabular} & $17,455,511$ & $7,098,785$ & $164,399,416$ & $91,696,370$ & $7,478,275$ & $12,379,010$ & $5,034,280$ & $116,587,934$ \\
\hline $\begin{array}{l}\text { Hypertension } \\
\end{array}$ & $138,865,651$ & $\begin{array}{ll}11,325,154 \\
\end{array}$ & $18,746,863$ & $7,623,950$ & $176,561,617$ & $\begin{array}{l}134,907,485 \\
\end{array}$ & \begin{tabular}{ll|}
$11,002,347$ \\
\end{tabular} & $24,283,347$ & $7,406,640$ & $177,599,819$ & $118,064,262$ & $9,628,702$ & $15,938,675$ & $6,481,920$ & $150,113,559$ \\
\hline \begin{tabular}{|l} 
Heart diseases \\
\end{tabular} & \begin{tabular}{|l|l|}
$55,942,077$ \\
\end{tabular} & \begin{tabular}{|l|l|}
$14,775,395$ \\
\end{tabular} & $7,552,180$ & $3,199,282$ & $81,468,935$ & $\begin{array}{r}54,886,566 \\
\end{array}$ & $\begin{array}{l}15,937,387 \\
\end{array}$ & $\begin{array}{l}4,631,054 \\
\end{array}$ & $3,138,918$ & $78,593,925$ & $46,409,812$ & $\begin{array}{l}13,475,9996 \\
\end{array}$ & $\begin{array}{l}6,265,325 \\
\end{array}$ & $2,654,140$ & $\begin{array}{l}68,805,272 \\
\end{array}$ \\
\hline \begin{tabular}{|c|} 
Total \\
\end{tabular} & $1,826,515,772$ & 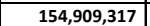 & \begin{tabular}{l|l}
$246,579,629$ \\
\end{tabular} & \begin{tabular}{|l|l|l|}
$98,839,713$ \\
\end{tabular} & $2,326,844,431$ & $1,714,003,687$ & $146,588,510$ & $234,682,702$ & $\begin{array}{ll}93,038,750 \\
\end{array}$ & $2,188,313,649$ & $1,325,346,901$ & $\begin{array}{ll}14,007,713 \\
\end{array}$ & \begin{tabular}{ll|l}
$178,921,832$ \\
\end{tabular} & $71,574,266$ & $1,689,850,712$ \\
\hline
\end{tabular}


Table 4-26. Average Cost of Disease per Household (for CDO) or Family (for the Philippines), by Disease, 2014

\begin{tabular}{|l|r|r|r|r|}
\hline \multirow{2}{*}{ Disease } & \multicolumn{2}{c|}{$\begin{array}{c}\text { Floodplains of Cagayan } \\
\text { de Oro }\end{array}$} & \multicolumn{2}{c|}{ Philippines } \\
\cline { 2 - 5 } & \multicolumn{1}{c}{ PhP } & \multicolumn{1}{c|}{ USD } & \multicolumn{1}{c|}{ PhP } & \multicolumn{1}{c|}{ USD } \\
\hline Bronchitis & 3,298 & 74 & 3,267 & $\mathbf{7 4}$ \\
\hline Respiratory tract infection & 2,414 & 54 & 2,390 & 54 \\
\hline Influenza & 1,698 & 38 & 1,682 & 38 \\
\hline Chicken pox & 3,293 & 74 & 3,262 & 73 \\
\hline Measles & 4,111 & 93 & 4,072 & 92 \\
\hline Typhoid fever & 3,252 & 73 & 3,221 & 73 \\
\hline Diarrhoea & 1,644 & 37 & 1,629 & 37 \\
\hline Leptospirosis & 3,584 & 81 & 3,552 & 80 \\
\hline Dengue & 3,289 & 74 & 3,257 & 73 \\
\hline Hypertension & 2,466 & 56 & 2,443 & 55 \\
\hline Heart diseases & 6,988 & 157 & 6,949 & 157 \\
\hline Weighted Average Cost per Household & $\mathbf{3 , 2 7 6}$ & $\mathbf{7 4}$ & $\mathbf{3 , 2 4 8}$ & $\mathbf{7 3}$ \\
\hline
\end{tabular}




\title{
Chapter 5
}

\section{Measurement of Economic Welfare Risk and Resilience of the Philippine Regions}

\begin{abstract}
Using an economic model to assess welfare risk and resilience to disasters, this paper systematically tackles the questions: 1) How much asset and welfare risks does each region face from riverine flood disasters? 2) How resilient is each region to riverine flood disasters? and 3) What are the available interventions per region to strengthen resilience to riverine flood disasters and what will be their benefit? We study the 18 regions of the Philippines to demonstrate the channels through which macroeconomic asset and output losses from disasters translate to consumption and welfare losses at the microeconomic level. Apart from the prioritization of regions based on resilience and welfare risk, we identify a menu of policy options ranked according to their level of effectiveness in increasing resilience and reducing welfare risk from riverine floods. While there are similarities in the ranking of policies among regions with comparable levels of resilience and welfare risk, the ranking of priorities varies for different regions. This suggests that there are region-specific conditions and drivers that need to be integrated into policies and development processes so that these conditions are effectively addressed. Overall, the results indicate that reduction of adverse disaster impacts, including welfare losses, and reduction of poverty are generally complementary development agenda. Thus, there is a need to ensure an integrated approach in addressing poverty and economic disaster welfare risk.
\end{abstract}




\subsection{Introduction}

Among the consequences of damages to assets due to disasters are losses in output and income that, in turn, result in consumption and welfare ${ }^{71}$ losses (Hallegatte et al., 2016a, 2016c). These losses of welfare are often not reported, nor even quantified. The scant empirical literature on welfare impacts is often cross-national or focused on one limited area within a country (e.g. a particular city or province or district, etc). We aim to fill these gaps by conducting an intra-national assessment of the welfare impacts of and resilience to riverine floods.

We study the Philippine regions, all of which are prone to riverine floods caused by heavy rainfall and by the presence of many river systems across the country ${ }^{72}$. The country is one of the most at-risk to different hazards worldwide (UNU-EHS, 2014). The centralized system of allocation of fiscal resources; the integrated nature of development planning, investment programming, and budgeting; and, the decentralized system of governance make the country a suitable test-case to demonstrate the practical usefulness of the economic model we use and of our assessment outputs to inform policy decisions.

In this study, we answer the following broad questions: 1) How much asset and welfare risk does each region face from riverine flood disasters? 2) How resilient is each region to riverine flood disasters? 3) What are the available interventions per region to strengthen resilience to riverine flood disasters and what will be their benefit?

\footnotetext{
71 "Welfare" in Economics approximates "well-being" in daily parlance. It is defined in the Oxford Dictionary of Economics as the "state of well-being of an individual or a society. The level of welfare measures the degree of contentment of an individual or a society" (Black et al., 2009).

${ }^{72}$ The Philippines has a total of 18 major river basins, with a drainage area of more than 1,000 square kilometres, and 421 principal river basins (PAGASA-DOST, 2012).
} 
We use the economic model by Hallegatte (2014) that extends the usual hazard-exposure-vulnerability disaster risk model into an economic welfare disaster risk model (henceforth, the Model). The Model accounts for the fact that assets damaged during a disaster ultimately cause adverse impacts on the welfare of affected individuals (Hallegatte et al., 2016a). The Model quantifies welfare risk ${ }^{73}$, which is the annual welfare losses expressed as the equivalent consumption losses, by adding socioeconomic resilience as a fourth component of hazard-exposure-vulnerability disaster risk model (Hallegatte et al., 2017). Socioeconomic resilience, or simply resilience under the Model, is defined as the economy's ability to minimize people's welfare losses consequent to asset losses brought by a disaster (Hallegatte, 2014). This definition is considered as "one part of the ability to resist, absorb, accommodate and recover in a timely and efficient manner to asset losses (the qualitative definition of resilience from the United Nations)" (Hallegatte, Bangalore, \& Vogt-Schilb, 2016b).

The Model had been applied empirically to a city and cross-national assessments. The Model was first empirically applied to Mumbai City and to 90 countries for a single hazard assessment (i.e. flood), and to 117 countries for a multi-hazard assessment (Hallegatte, 2014; Hallegatte et al., 2016a, 2016b, 2016c). For our application of the Model to the Philippine regions, we adopt with a number of modifications the estimation algorithm and assumptions used in the single hazard application for 90 countries in Hallegatte et al. (2016a). As needed, we use alternative proxy indicators and make appropriate adjustments to the assumptions to better reflect the specific circumstances of the Philippine regions ${ }^{74}$.

\footnotetext{
${ }^{73}$ Risk to welfare, expected welfare losses, and annual welfare losses are alternative terms referring to welfare risk.

${ }^{74}$ The specific adjustments we make are indicated in appropriate parts in Sections 5.4 Model, Dataset, and Descriptive Statistics.
} 
A cross-national assessment has limited value for making actual policy decisions, though it provides important general insights on the drivers of welfare risk and resilience. First, because there is no single global policymaking authority that is in charge of identifying priority countries and priority policies within each country, and of funding these priorities for each country. ${ }^{75}$ Second, because the costs of policy options are likely to differ across countries, thereby making the cross-national comparison of benefits generated from the assessment less meaningful. Meanwhile, an assessment specific to a subnational area (such as a particular city) likewise has a limited usefulness in typical contexts where resources are largely centrally determined and allocated. Results of such assessment cannot provide insights on the level of priority that must be given to this specific area relative to the other places.

Thus, our subnational assessment, with an intra-national spatial disaggregation (i.e. regions) and analysis has greater practical significance for policy-making. One, because there is a single policy-making authority across regions. Second, because costs are likely to be similar across these regions, the prioritization of policies based on benefits we compute are more useful than those in cross-country analysis. Through this assessment, we take advantage of the Model's systematic assessment of welfare risk and resilience to disasters, and further demonstrate how the Model can be adjusted to be of greater usefulness to policy-making, and at the same time add value to the development process of our study area.

In sum, our main contribution to the model is in terms of demonstrating the Model's flexibility (i.e how it can be modified to a given context), and demonstrating at what level of analysis it is most suitable and practicable.

75 At best, there are the multilateral and aid organizations which may have a global reach but with different development foci and agendas. 
Our final outputs are the prioritization of regions based on estimated resilience and welfare risk, and policy cards for each of the 18 regions of the country. The former can be useful for national development planning given the imperative to allocate resources efficiently at various subnational levels amidst the limits of the country's fiscal resources to fund its many development needs. The latter has at least two purposes: one, as a tool to track regional level progress; and, two as a menu of policy options prioritized according to their effectiveness in reducing asset and welfare risk, and increasing resilience per region. The prioritized policy options can be used as guide for investment programming and budgeting.

This paper is organized into six sections. Section 5.2 provides a quick review of literature on the factors affecting resilience, while Section 5.3 provides a brief background on Philippine development and riverine flood disasters. Section 5.4 presents further details on the Model, as well as the data and assumptions we use. Section 5.5 discusses the results, while Section 5.6, the general implications and caveats.

\subsection{Literature Review}

There is now a significant economic literature that aims to measure the follow-on economic impacts of disasters typically in either the short-run (months to several years) or long-run (at least 3 to 5 years). These studies also attempt to understand the factors that influence these impacts, thereby also providing insights on the determinants of economic resilience to disaster.

In a cross-country study, Felbermayr and Gröschl (2014) find substantial reduction in GDP per capita in the aftermath of disasters, with the low to middle income countries incurring greater declines. Further, greater financial and trade openness, as well as better institutions, facilitate the 
reconstruction thereby preventing large declines in GPD per capita. These are largely consistent with earlier empirical work. Noy (2009) finds that countries with higher income per capita, greater trade openness, and higher literacy rates, higher levels of public spending, and better institutions are able to withstand the initial impacts of disasters, and cope better. He attributes this to the capacity for resource mobilization to implement the necessary reconstruction. Likewise, Loayza, Olaberría, Rigolini, and Christiaensen (2012) find that greater trade openness is positively associated with growth.

Unlike Felbermayr and Gröschl (2014), Noy (2009) find that while an increase in asset damage results in reduced output growth among developing countries, the opposite is seen for developed countries. A similar finding is seen at the subnational level. An assessment of economic impacts among the provinces of Vietnam reveals that areas with higher levels of development, and those that have better access to funds for reconstruction from the central government experience a consequent shortrun growth spurt in the disaster aftermath (Noy \& Vu, 2010). These are consistent with the earlier cross-country findings of Cuaresma et al. (2008) that countries with high level of development benefit from capital upgrading for assets damaged during a disaster.

Hochrainer (2009) uses a counterfactual to the observed post-disaster output level in the medium-term and in the long-term (five years). Similarly, he finds evidence of negative (but small) consequences of the disaster on the capital stock and therefore on macroeconomic output. Inflows of remittances and aid reduce the adverse macroeconomic consequences. He finds that a disaster with damage to the capital stock of above a value of $1 \%$ of GDP would overwhelm the internal capacity of the 
country to self -finance post-disaster reconstruction needs, hence the importance of aid.

In an attempt to determine welfare changes due to the occurrences of disasters, Mechler (2009) measures the corresponding changes in consumption, instead of the usual changes in GDP76. Results for a crosscountry analysis reveal that asset losses do not cause significant changes in consumption. However, by narrowing the sample to low-income countries only, asset losses do adversely alter consumption. Further, results show that inflows of regular and post disaster aid likewise do not result in significant changes in consumption, except among low-income countries.

Meanwhile, von Peter, von Dahlen, and Saxena (2012) provide robust evidence on the influence of insurance in post disaster dynamics of countries. On top of the immediate damage to assets, there are likewise output losses incurred for several years following the disaster. By disaggregating the total losses into uninsured losses and insured losses, they show that these macroeconomic costs are largely due to uninsured losses. Interestingly, insured losses either do not have adverse impacts on economic activities, or result in positive impacts. ${ }^{77}$ Small and low-income countries experience quicker recovery when losses are insured, but incur more negative economic impacts otherwise.

At the firm level, Poontirakul, Brown, Noy, Seville, and Vargo (2016) study the role of commercial insurance among the firms affected by the 2011 earthquake in Christchurch, New Zealand. While there is no clear role of

\footnotetext{
${ }^{76}$ In assessing the welfare impact of disasters, indicators of production and outputs, such as GDP and its variants, are commonly used as a proxy for welfare, though consumption is arguably a better proxy (Mechler, 2009). In general, production only indicates how much is made available, while consumption indicates how much is actually used (consumed). It therefore better captures the economic concepts of utility and standard of living. From a Utilitarian perspective, consumption is what matters most, and not output and production (Hallegatte \& Przyluski, 2010).

77 The authors find that for geologic hazards (such as volcanic eruptions and earthquakes), insurance offsets the adverse impacts, while among hydrometeorological hazards (such as floods and storms), insurance
} 
insurance on firm recovery in the short-term, ${ }^{78}$ there are however evident positive effects in the medium-term. This is particularly true among firms that received their insurance claim payments promptly.

It is noted however that while insurance facilitates recovery, access to market insurance is limited mainly to high-income countries, and to the better off sectors of society. Often the poor only have access, if at all, to publicly funded social insurance mechanisms that often offer limited or inadequate coverage.

External sources of funds and assistance, such as aid, remittances, social protection, and insurance, are likewise critical for household-level postdisaster recovery. Arouri et al. (2015) undertook a household level study in Vietnam to determine the effects of disasters on household welfare, and the characteristics of households and communities that made them resilient to the adverse disaster impacts. Internal remittances are found to be an important contributor of household resilience to floods, storms and droughts. Likewise, access to finance-such as microfinancing, international remittances and social allowances - positively affect resilience. Households in communes with either a more equal distribution of expenditure or a higher level of average per capita expenditure are also better able to respond to the shock (Arouri et al., 2015).

These findings on the importance of access to finance are further supported by a study by Hudner and Kurtz (2015) among families affected by Typhoon Haiyan in the Philippines. Savings and loans, despite through informal schemes, make families feel that they are better able to cope or be resilient. Further, they find that social capital is positively associated with resilience. This is widely supported by the finding of Aldrich (2015) in his

78 The authors note that this could either be due to the limits of their dataset or the effectiveness of insurance provider in the immediate aftermath. 
study on strength of networks and communities in East Asia in the aftermath of disasters. On the other hand, Ravago and Mapa (2014) find that households affected by Typhoon Haiyan that undertook pre-cautionary measures, including asset accumulation, savings and informal insurance, have higher probability of recovery. Post-disaster coping actions such as dissaving and borrowing likewise facilitate recovery.

Among households affected by landslides in Uganda, Mertens et al. (2016) find that those with fewer assets (measured in terms of land) experience more severe impacts on income relative to those with more assets. Results also suggest that households sought external and/or alternative sources of income to offset income losses due to the landslides. Households that experienced a landslide in the previous year were more likely to get a job in other farms or engage in self-employment activities.

Overall, the results of the above empirical studies indicate that a high level of socio-economic development, whether at the national, subnational, or at the household level, reduces adverse economic impacts and improves resilience. While there is no clear agreement on the direction of impact of asset damage on macroeconomic output using a sample of low and highincome countries, there is apparent evidence that developing countries incur adverse impacts. Policies and actions that are most effective in minimizing follow-on economic impacts and spillover effects are mainly about adequate access to funds to speed up the reconstruction, rehabilitation, and subsequent economic recovery.

We operationalize the insights outlined above into our assessment, while at the same time addressing a gap in the empirical literature. No assessment simultaneously covers both macroeconomic and microeconomic aspects of 
this challenge ${ }^{79}$. The inclusion of both macroeconomic and microeconomic considerations in assessing resilience is one of the key advantages of the Model we use. Importantly, the Model applies economic theory and economic insights from related theoretical and empirical literature on the channels through which disaster asset losses at the macroeconomic level lead to welfare losses at the microeconomic level. Further, the Model takes into account important considerations that are relevant in the context of the Philippines, such as socioeconomic heterogeneity, in order to measure the disparity in welfare risk, with a specific focus on losses for the poor.

\subsection{Philippine Development and Riverine Flood Disasters}

The Philippines is an archipelago comprising of 18 regions that are grouped into three major island groups: Luzon, Visayas and Mindanao (Figure 5-1). As of 2015, the country has a projected population of over 101 million (PSA, 2016a). With a GNI per capita of USD3,550 in 2015, the Philippines is classified by the World Bank as a lower middle-income country (WB, 2016).

Several aspects of the country's physical and socio-economic characteristics influence its exposure, vulnerability, and resilience to disasters. Natural hazards occur frequently given the country's geographic, geologic and meteorological setting. It is located along the Pacific Ring of Fire and along the Pacific typhoon belt, thus making it prone to various geologic and hydrometeorologic hazards.

A number of highly destructive riverine floods in the country occurred in recent years:

\footnotetext{
${ }^{79}$ The focus of studies employing econometric methods on either the macro level or micro level of inquiry is likely due to the complexity of using a single econometric model to capture both levels. Adding to this is the difficulty of putting together useful macro and micro level datasets. Other useful methods that allow for macro-micro analysis include computable general equilibrium (as proposed in Rose (2004a) and Rose and Krausmann (2013)), partial equilibrium analysis (as in Hallegatte (2014)), and other mathematical algorithms.
} 
- In September 2009, the Marikina River ${ }^{80}$, rose 23 meters as Tropical Storm $^{81}$ (TS) Ketsana poured a rainfall volume that surpassed the country's forty-year record high (Abon, David, \& Pellejera, 2011). ${ }^{82}$

- Also in September 2009, Typhoon Parma likewise brought massive riverine floods in the national capital and in its neighbouring provinces (GOP, 2009). The combined damage and loss brought by these two tropical cyclones (Ketsana and Parma) reached USD4.38 billion, equivalent to 2.7\% of the country's GDP in 2009 (GOP, 2009).

- In December 2011, Tropical Storm Washi that poured a month's worth of rain in just 24 hours in the Northern Mindanao region, brought substantial swelling in four river basins traversing four provinces (NEDA, 2012; TCAGP, 2014). The majority of the 1,258 deaths and USD48 million in damage to properties were due to the resulting floods (NDRRMC, 2012b).

\footnotetext{
${ }^{80}$ Marikina River is the largest river system in the country's National Capital Region.

${ }^{81}$ In the Philippines, a typhoon is a tropical cyclone with a maximum wind speed of above 118 kilometres per hour (kph), while a tropical storm has a maximum wind speed of $64 \mathrm{kph}$ to $118 \mathrm{kph}$. A third classification is tropical depression, which has a maximum wind speed of $63 \mathrm{kph}$ (PAGASA, undated).

${ }^{82}$ In 2012, the same river swelled 20.6 meters up due to torrential southwest monsoon rains, again resulting in much devastation (Heistermann et al., 2013; Marueñas, 2015).
} 
Figure 5-1. The 18 Regions of the Philippines

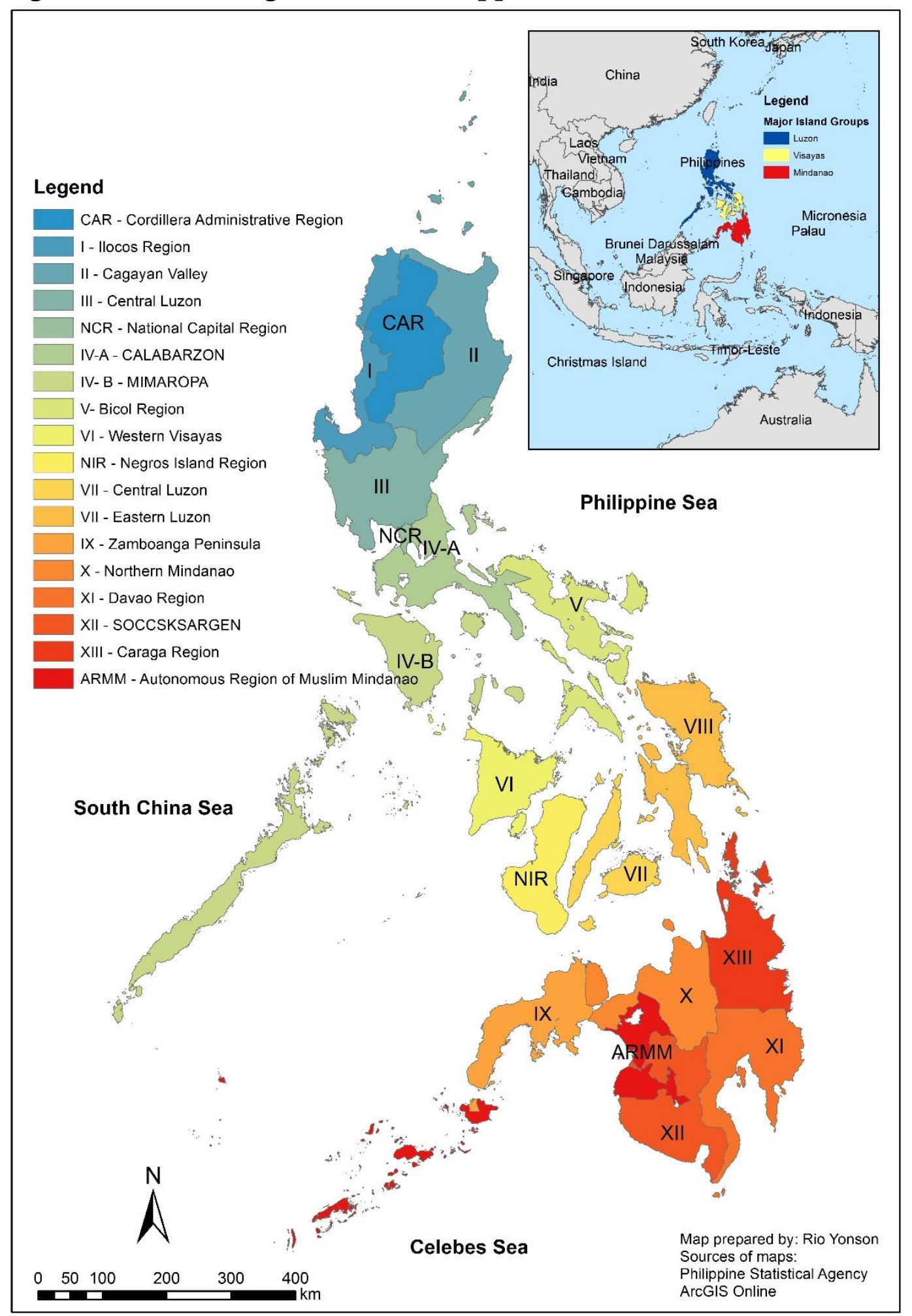

Typhoon Bopha in 2012, and Typhoon Haiyan in 2013 passed the PAR with unprecedented strength in the respective exposed areas in the central and 
southern part of the Philippines. Accompanied with other hazards such as riverine floods, landslides, and storm surges, these tropical cyclones became the most lethal and destructive in the country in these years. Typhoon Haiyan left a staggering trail of 6,092 deaths, while Typhoon Bopha claimed 1,258 lives (NDRRMC, 2014). Moreover, they were the most costly disaster events in the country in the said years (NDRRMC, 2014). Yonson et al. (2016) show that death toll from tropical cyclones in the Philippines is mostly because of water and not wind damage.

A critical and persisting development concern of the country is poverty, which is also deemed an important underlying factor for hazard exposure, vulnerability, and resilience. As of 2015, poverty incidence among population and among families was $26.3 \%$ and $22.3 \%$, respectively. Without access to land, poor people crowd and build makeshift houses in informal settlements that are hazard prone, including along the rivers and coastal areas (Gaillard, 2008; Gaillard et al., 2007; Ginnetti et al., 2013; WB-EASPR, 2003).

Apart from being a driver of disasters, poverty in the Philippines is likewise a consequence of disasters, whether natural or human-induced (ADB, 2007). Regions V and VIII, the poorest regions in Luzon and Visayas, respectively, lie along the eastern coastline where tropical cyclones first enter the Philippines (NEDA, 2014). These regions have experienced some of the worst disasters in Philippine history.

The rapid population growth and unplanned urbanization of the country have also been taking a toll in terms of increasing risk to disasters. ${ }^{83}$ High

\footnotetext{
${ }^{83}$ The Philippine population grew at an average of 2.69\% during the period 1950-2010 higher than the averages for South East Asia, the whole of Asia and the World (UN, 2014). Urban population grew much faster, driven mainly by migration of people from rural areas. During the period 1950 - 1990, urban population grew at an annual average of $4.47 \%$, also higher than the averages for South East Asia, the whole of Asia and the World (UN, 2014). Thereafter, urban annual population growth rate slowed down, ranging from 1.12 to $2.21 \%$ from 1990 to 2010.
} 
levels of urban poverty resulted in greater hazard exposure and vulnerability. Recognizing the gravity of the impact of disasters on the poor, the country expanded its conditional cash transfer program to offer postdisaster assistance to affected poor families. Specifically in 2012, the Modified Conditional Cash Transfer was implemented to provide cash grants for children's education and the health needs of families in difficult situations including those affected by disasters (DSWD, 2013).

The huge historical annual losses of lives and properties, along with the projected incremental damage due to climate change, depict the glaring reality that the Philippines has yet to match the increasing intensity of hazards and gravity of disaster impacts with heightened effectiveness in prevention and mitigation measures. For countries where there is certainty of hazard recurrence, it is imperative to supplement actions to reduce exposure and vulnerability with interventions that increase peoples' capacity to cope (Hallegatte et al., 2017).

It is towards this end of identifying context-specific interventions to strengthen people's ability to avoid welfare losses and increase resilience that we conduct this study. Our final research outputs can be easily integrated into the existing efforts of mainstreaming disaster risk reduction and management, and climate change adaptation in the development process.

\subsection{Model, Dataset, and Descriptive Statistics}

\subsubsection{Economic Welfare Disaster Risk Model}

This section is largely based on Hallegatte (2014), Hallegatte et al. (2016a), Hallegatte et al. (2016b), and (Hallegatte et al., 2017). Modifications made for the Philippine application in terms of estimation algorithm and 
assumptions are indicated either in the footnote or integrated into the main text $^{84}$

The Model operationalizes the quantification of welfare risk ${ }^{85}$ by adding socioeconomic resilience as a fourth component into the typical hazardexposure-vulnerability disaster risk model, as follows:

Welfare Risk $=\frac{(\text { Hazard }) x(\text { Exposure }) x(\text { Vulnerability })}{(\text { Socioeconomic Resilience })}=\frac{\text { Expected Asset Losses }}{\text { Socioeconomic Resilience }} \quad$ Equation 1

where the definitions of hazard, exposure, and vulnerability of assets are aligned with the definitions of UNISDR (2009) as follows: Hazard refers to a natural phenomenon that may cause damage to assets, and quantitatively expressed in terms of the probability for the hazard to occur and its intensity; Exposure refers to assets located in hazard-prone areas; and, Vulnerability refers to the characteristics of assets that make them be adversely affected by the hazard, and is quantitatively expressed as the proportion of asset that is lost as a result of the disaster (Hallegatte et al., 2017). Socioeconomic resilience is quantitatively defined as:

Socioeconomic Resilience $=\frac{\text { Asset Losses }}{\text { Welfare Losses }} \quad$ Equation 2

The analysis in the Model takes off from the classical production function where capital and labour are the factors of production, $\mathrm{Y}=\mathrm{f}(\mathrm{K}, \mathrm{L})$. When a disaster occurs, the economy incurs damage to capital or asset losses, $\Delta K$. This consequently leads to a decline in production capacity, and, therefore, the economy incurs output losses, $\Delta Y .{ }^{86}$

\footnotetext{
${ }^{84}$ Modifications in the equation and/or algorithm are typically explained in the footnote to avoid disruption of the flow of the discussion of the Philippine application. Assumptions, either modified or adopted from the Hallegatte et al (2016a), are indicated in the main text

${ }^{85}$ Henceforth, we use welfare risk or risk to welfare to refer to economic welfare disaster risk.

86 We note that asset losses and output losses are alternative typologies of economic costs that are, to an extent, distinct from the usual direct damage and indirect loss typology used by the ECLAC. Specifically, asset losses here refer to reduction in the value of the stock of assets or capital, while output losses refer to the reduction in the income flow (Hallegatte, 2014). Thus, this typology of economic costs is consistent with the damages to stocks and flows of Rose (2004a) rather than with the ECLAC direct damage and indirect loss typology.
} 
Figure 5-2 is a simplified illustration of losses in output consequent to the damage on assets brought by disasters, and the return to the baseline output over time after the completion of reconstruction. In this illustration, the shock due to the disaster occurs at $t_{0}$. The immediate result is the reduction in the stock of capital. Due to the disruption in production, output drastically falls:

$\Delta Y\left(t_{0}\right)=\mu \Delta K$

Equation 3

where $\Delta Y$ is output losses, $\Delta K$ is the damage to capital or asset losses, and $\mu$ is the average productivity of capital. It is noted that the Model uses average productivity of capital instead of the marginal productivity of capital that is typically used in the assessment of output losses. ${ }^{87}$

\section{Figure 5-2. Reconstruction Dynamics and Total Output Losses}

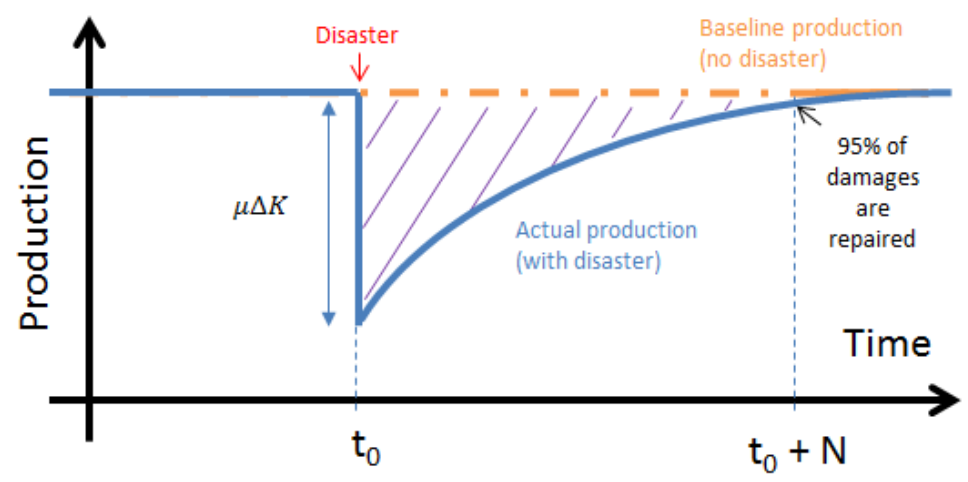

Source: Hallegatte et al. (2016b)

By how much output continues to decline in the aftermath depends mainly on the reconstruction dynamics. With the assumption that output losses are exponentially reduced to zero and $95 \%$ of the losses is repaired

\footnotetext{
87 This is because the use of marginal productivity of capital underestimates the output losses (Hallegatte et al., 2016c). This can be due to any or a combination of the following reasons, among others: damaged assets may generate positive externalities, thus making the damaged assets to be valued more by the society than by owner of the assets; non-marginal shocks affects the structure of the economy and the relative prices of goods; presence of further effects from the damaged assets that prevent the other unaffected assets to produce at pre-disaster levels (Hallegatte et al., 2016c).
} 
exponentially in $\mathrm{N}$ years, output losses are likewise reduced exponentially. Thus, post-disaster output losses at year $\mathrm{t}$ is:

$\Delta Y(t)=\mu \Delta K e^{-\frac{t-t_{0}}{N / 3}}$

Equation $4^{88}$

where $\Delta Y(t)$ is the output losses at a post-disaster time $\mathrm{t} ; \mathrm{N}$ is the time it takes to repair $95 \%$ of the damaged assets; and, $\Delta K$, and $\mu$ are as defined earlier. At year $\mathrm{t}_{0}+\mathrm{N}$, Equation 4 is equal to $\Delta Y\left(t_{0}+N\right)=\mu \Delta K e^{-3}$, or $\Delta Y\left(t_{0}+N\right)=\mu \Delta K(0.05)$, which is equivalent to $\Delta Y\left(t_{0}+N\right)=0.05 \Delta Y\left(t_{0}\right)$. That is, after $\mathrm{N}$ years of reconstruction from the year of the disaster, the output level has returned to $95 \%$ of its pre-disaster level.

Overall, the net present value (NPV) of output losses, $\widetilde{\Delta Y}$, is as follows:

$\widetilde{\Delta Y}=\int_{t_{0}}^{+\infty} \mu \Delta K e^{-\frac{t-t_{0}}{N / 3}} e^{-\rho\left(t-t_{0}\right)} d t=\mu \Delta K \frac{N}{\rho N+3}$

Equation $5^{89}$

where $\rho$ is the discount rate; and, $\Delta K, \mu$ and $\mathrm{N}$ are as defined earlier.

The losses in macroeconomic outputs result in losses in aggregate consumption equal to the NPV of cost to reconstruct the damaged capital, and the NPV of output losses, as follows:

$\widetilde{\Delta C}=\int_{t_{0}}^{+\infty}(\left(\mu \Delta K e^{-\frac{t-t_{0}}{N / 3}}+\Delta K e^{-\frac{t-t_{0}}{N / 3}} \frac{3}{N}\right) e^{-\rho t} d t=\Delta K \overbrace{\frac{\mu+3 / N}{\rho+3 / N}}^{\Gamma} \quad$ Equation $6^{90}$

${ }^{88}$ Equation 4 is a modified version of Equation 5 in Hallegatte et al. (2016c), $\Delta Y(t)=(1+\alpha) \mu \Delta K e^{-\frac{t-t_{0}}{N / 3}}$, where $(1+\alpha)$ represents "ripple effects". These effects represent the situation where the damaged assets made some other assets (that were not affected by the disaster) less productive in the aftermath of the disaster, such as in the case of closure of an entire road segment as a result of a damaged part of that segment (Hallegatte et al., 2016c).

${ }^{89}$ Equation 5 is a modified version of Equation 6 in Hallegatte et al. (2016c), $\widetilde{\Delta Y}=\int_{t_{0}}^{+\infty} \mu \Delta K e^{-\frac{t-t_{0}}{N / 3}} e^{-\rho\left(t-t_{0}\right)} d t=(1+$ a) $\mu \Delta K \frac{N}{\rho N+3}$ which includes ripple effects.

90 Equation 6 is a modified version of Equation 7 in Hallegatte et al. (2016c), $\widetilde{\Delta C}=\int_{t_{0}}^{+\infty}\left(\left(\mu \Delta K e^{-\frac{t-t_{0}}{N / 3}}+\right.\right.$ $\left.\Delta K e^{-\frac{t-t_{0}}{N / 3}} \frac{3}{N}\right) e^{-\rho t} d t=(1+\alpha) \Delta K \overbrace{\frac{\mu+3 / N}{\rho+3 / N}}^{\Gamma}$ which includes ripple effects. 
where $\widetilde{\Delta C}$ is the NPV of consumption losses integrated over N years; and, $\Delta K, \mu, \rho$, and $\mathrm{N}$ are as defined earlier. $\Gamma$ is an amplifying factor that indicates that NPV of the flow of consumption losses across $\mathrm{N}$ years to reconstruct $95 \%$ of the asset damage are greater than damage to capital multiplied by the average productivity of capital.

The Model assesses welfare impacts by translating the macroeconomic assessment indicated in Equations 1 to 6 into a microeconomic assessment. It takes into account socioeconomic heterogeneity to capture the disparity in welfare losses among the poor and the non-poor. This entails decomposing exposure and vulnerability into those of poor and non-poor families, i.e., into exposure and vulnerability for the poor and for the nonpoor families. Further, families are categorized into the "directly affected" and "not directly affected" (Hallegatte et al., 2016c). The former are those who experienced the disaster first hand, while the latter are those who have been affected through risk sharing mechanism, which in this analysis is proxied by the private transfers and the government social protection program (Hallegatte et al., 2016c). Table 5-1 below shows how the exposure for each of the four categories of families are computed.

Table 5-1. Exposure by Category of Families

\begin{tabular}{|l|c|c|}
\hline & Directly affected & Not directly affected \\
\hline Poor & $n_{p}^{a}=p_{h} f_{p}^{a} n$ & $n_{p}^{n}=p_{h}\left(1-f_{p}^{a}\right) n$ \\
\hline Non-poor & $n_{r}^{a}=\left(1-p_{h}\right) f_{r}^{a} n$ & $n_{r}^{n}=\left(1-p_{h}\right)\left(1-f_{r}^{a}\right) n$ \\
\hline
\end{tabular}

Source: Table 1 in Hallegatte et al. (2016c)

where $p_{h}$ is poverty incidence; $n$ is the total number of families; $n^{a}$ and $n^{n}$ is the number of families directly affected and not directly affected, respectively, with the subscripts $p$ and $r$ indicating whether poor or non- 
poor; and, $f_{p}^{a}$ is a fraction of poor families affected by disaster to the number of poor families in the province ${ }^{91}$, and $f_{r}^{a}$ is for the non-poor.

By how much consumption declines in the event of a disaster depends on the families' pre-disaster and post-disaster sources of income, including access to protective mechanisms as these affect the ability of affected families to cope with the disaster impacts. Income comes from labour using assets that are located where the family resides; and, from transfers or risk sharing mechanisms that are diversified at the national level. Considering these, the consumption of poor and non-poor families is computed as follows:

$c_{i}=\overbrace{\left(1-\lambda_{i}\right) c_{i}}^{c_{i}^{l}}+\overbrace{\lambda_{i} c_{i}}^{c_{i}^{d}}$

where $i$ indicates whether the family is poor $(i=p)$ or non-poor $(i=r) ; c_{i}^{l}$ is the consumption using income from labour, $c_{i}^{d}$ is the consumption using the transfers received; $\lambda_{i}$ is the share of family income from transfers or risk sharing mechanisms, $1-\lambda_{i}$ is the share on family income from assets used.

The Model assumes that over the short-term, consumption is linearly determined by the stock of assets as follows:

$c_{i}=\mu(\overbrace{\left(1-\lambda_{i}\right) k_{i}}^{k_{i}^{l}}+\overbrace{\lambda_{i} k_{i}}^{k_{i}^{d}})$

Equation 8

where $k_{i}$ is the capital used by the poor $\left(k_{p}\right)$ or the non-poor $\left(k_{r}\right)$, whether the capital is located local $\left(k_{i}^{l}\right)$ or diversified at the national level $\left(k_{i}^{d}\right)$; and $\mu$ is the average productivity of capital. Equation 8 implies that consumption

${ }^{91} f_{p}^{a}$ is derived from poverty exposure differential, $P E=\frac{f_{p}^{a}}{f^{a}}-1$, where PE is set at $20 \%$. Poverty exposure differential (originally poverty exposure bias (Hallegatte et al., 2016b)) is measure the exposure of the poor relative to the overall exposure of families (Hallegatte et al., 2016b). 
losses in the aftermath of a disaster is proportional to asset losses. It is noted that the Model makes the simplifying assumption that when a family is affected by a disaster, all of the capital used for generating income are likewise affected.

The extent of damage to capital used depends on the physical vulnerability of the assets used by the poor $\left(V_{p}\right)$ and by the non-poor $\left(V_{r}\right)$. It is assumed that assets used by the poor have greater vulnerability than the assets used by the non-poor. The vulnerability of capital diversified at the national level, whether among the poor or non-poor, are assumed equal to the vulnerability of capital of the non-poor. Table 5-2 summarizes how the capital or asset losses for each of the four categories of families are computed, where all variables are as defined earlier.

Table 5-2. Asset Losses by Category of Families

\begin{tabular}{|l|c|c|}
\hline & \multicolumn{1}{|c|}{ Directly affected } & Not directly affected \\
\hline Poor & $\Delta k_{p}^{a}=V_{p}\left(1-\lambda_{p}\right) k_{p}+f_{p}^{a} V_{r} \lambda_{p} k_{p}$ & $\Delta k_{p}^{n}=f_{p}^{a} V_{r} \lambda_{p} k_{p}$ \\
\hline Non-poor & $\Delta k_{r}^{a}=V_{r}\left(1-\lambda_{r}\right) k_{r}+f_{r}^{a} V_{r} \lambda_{r} k_{r}$ & $\Delta k_{r}^{n}=f_{r}^{a} V_{r} \lambda_{r} k_{r}$ \\
\hline
\end{tabular}

Source: Table 2 in Hallegatte et al. (2016c)

The macroeconomic consumption losses shown in Equation 6 is translated into the microeconomic level as follows:

$$
\widetilde{\Delta c_{i}}=\Gamma \Delta k_{i}
$$

Equation 9

where $\Gamma$ is as defined earlier in Equation 6. Substituting the formula for the computation of asset losses for each category of family shown in Table 5-2 into Equation 9 results in the formula for computing the NPV of consumption losses by category of families shown in Table 5-3 below. 
Table 5-3. NPV of Consumption Losses by Category of Families (without scale-up of protective mechanisms)

\begin{tabular}{|l|c|c|}
\hline & Directly affected & Not directly affected \\
\hline Poor & $\widetilde{\Delta c_{p}^{a}}=\Gamma V_{p}\left(1-\lambda_{p}\right) k_{p}+\Gamma f_{p}^{a} V_{r} \lambda_{p} k_{p}$ & $\widetilde{\Delta c_{p}^{n}}=\Gamma f_{p}^{a} V_{r} \lambda_{p} k_{p}$ \\
\hline Non-poor & $\widetilde{\Delta c_{r}^{a}}=\Gamma V_{r}\left(1-\lambda_{r}\right) k_{r}+\Gamma f_{r}^{a} V_{r} \lambda_{r} k_{r}$ & $\widetilde{\Delta c_{r}^{n}}=\Gamma f_{r}^{a} V_{r} \lambda_{r} k_{r}$ \\
\hline
\end{tabular}

Source: Table 3 in Hallegatte et al. (2016c)

In the aftermath of a disaster, the adequacy of protective mechanisms such as transfers, social protection, remittances or insurance largely influence the capacity of affected families to smooth their consumption (Hallegatte et al., 2016b), particularly among the poor who are faced with binding financial constraints. Thus, with the scaled-up provision of these protective mechanisms in response to the disaster, the NPV of consumption losses for each category of families are as shown in Table 5-4.

Table 5-4. NPV of Consumption Losses with Scaled-Up Social Protection by Category of Families

\begin{tabular}{|l|c|c|}
\hline & \multicolumn{1}{|c|}{ Directly affected } & Not directly affected \\
\hline Poor & $\widetilde{\Delta c_{p}^{a}}=\Gamma V_{p}\left(1-\overline{\lambda_{p}}\right) k_{p}+\Gamma f_{p}^{a} V_{r} \overline{\lambda_{p}} k_{p}$ & $\widetilde{\Delta c_{p}^{n}}=\Gamma f_{p}^{a} V_{r} \overline{\lambda_{p}} k_{p}$ \\
\hline Non-poor & $\widetilde{\Delta c_{r}^{a}}=\Gamma V_{r}\left(1-\overline{\lambda_{r}}\right) k_{r}+\Gamma f_{r}^{a} V_{r} \overline{\lambda_{r}} k_{r}$ & $\widetilde{\Delta c_{r}^{n}}=\Gamma f_{r}^{a} V_{r} \overline{\lambda_{r}} k_{r}$ \\
\hline
\end{tabular}

The set of formulas in Table 5-4 differs from that in Table 5-3 by $\overline{\lambda_{p}}$ and $\overline{\lambda_{r}}$, which captures the scaled-up provision of protective mechanisms. Specifically, $\overline{\lambda_{p}}=1-\left(1-\lambda_{p}\right)\left(1-\sigma_{p}\right)$ and $\overline{\lambda_{r}}=1-\left(1-\lambda_{r}\right)\left(1-\sigma_{r}\right)$, where $\sigma_{p}$ and $\sigma_{r}$ is the proportion of losses of the directly affected poor and nonpoor families, respectively, that is transferred to the rest of the families elsewhere in the country.

The consumption losses of the poor and non-poor are translated into welfare losses of the poor and non-poor through the application of 
distributional weights. Given the higher marginal utility of income and consumption among the poor, it is assumed that consumption losses among the poor carry more weight than the losses in consumption among the nonpoor. Welfare in the region is computed as follows:

$W=n_{p} w\left(\widetilde{c_{p}}\right)+n_{r} w\left(\widetilde{c_{r}}\right)$

Equation 10

where $w(\tilde{c})$ is the constant relative risk aversion welfare function ${ }^{92}$ that links the NPV of consumption with the welfare of the affected family; $\left(\widetilde{c_{p}}\right)$ and $\left(\widetilde{c_{p}}\right)$ is the NPV of consumption of the poor and non-poor families, respectively; and, $n_{p}$ and $n_{r}$ are as defined earlier in Table 5-1. Welfare loss from consumption losses is then computed as the change in welfare prior to and after the disaster for all four categories of families:

$$
\begin{aligned}
\Delta W= & n_{p}^{a}\left(w\left(\widetilde{c_{p}}\right)-w\left(\widetilde{c_{p}}-\widetilde{\Delta c_{p}^{a}}\right)\right)+n_{p}^{n}\left(w\left(\widetilde{c_{p}}\right)-w\left(\widetilde{c_{p}}-\widetilde{\Delta c_{p}^{n}}\right)\right) \\
& +n_{r}^{a}\left(w\left(\widetilde{c_{r}}\right)-w\left(\widetilde{c_{r}}-\widetilde{\Delta c_{r}^{a}}\right)\right)+n_{r}^{n}\left(w\left(\widetilde{c_{r}}\right)-w\left(\widetilde{c_{r}}-\widetilde{\Delta c_{r}^{n}}\right)\right) \quad \text { Equation } 11
\end{aligned}
$$

where $w\left(\widetilde{c_{p}}\right)$ and $w\left(\widetilde{c_{p}}-\widetilde{\Delta c_{p}^{a}}\right)$ is the pre- and post-disaster welfare, respectively, of the poor; $w\left(\widetilde{c_{r}}\right)$ and $w\left(\widetilde{c_{r}}-\widetilde{\Delta c_{r}^{a}}\right)$ is the pre- and post-disaster welfare, respectively, of the non-poor; and, $n_{p}$ and $n_{r}$ are as defined earlier.

We note that the global model, either in Hallegatte et al. (2016a) or in Hallegatte et al. (2016b), also considers welfare losses from poverty traps. The rationale is that not all poor people have the capacity to smooth consumption over time through insurance (either market insurance or selfinsurance through savings) and access to credit (Hallegatte et al., 2016a). While this is valid particularly in the context of the Philippines, we drop

\footnotetext{
${ }_{92} w(\tilde{c})=\frac{\tilde{c}^{1-\eta}-1}{1-\eta} \quad$ where $\eta$ is the constant that measures risk aversion. We adopt the assumption that $\eta=1.5$, thereby putting greater weight on the consumption losses of the poor (Hallegatte et al., 2016b).
} 
this from the estimation given the absence of data on either savings or insurance.

Once welfare loss is determined, socioeconomic resilience is computed using Equation 2, and welfare risk is computed simply as the product of hazard (probability of occurrence in a year) and welfare loss, as follows:

Welfare Risk $=$ Hazard $x$ Welfare Loss

Equation $12^{93}$

\subsubsection{Data and Assumptions}

Our choice of indicators is guided by those used in the global model, which are among the indicators found to be robustly related to disaster risk and resilience in the empirical literature. As needed, we use alternative proxy indicators and make appropriate adjustments to the assumptions to better reflect the specific circumstances of the Philippine regions. For data not readily available from Philippine sources, we utilize the data and/or adopt the simplifying assumptions made in the global application (Hallegatte et al., 2016a). The estimation algorithm used in the global application ${ }^{94}$ was accordingly modified to suit the regional level application in the Philippines.

\subsubsection{Hazard}

We use the protection level for flood hazards expressed in terms of the return period of the associated rainfall volume. We compute the probability for the protection level to be exceeded, and use it as the indicator for hazard in Equation 12. We adopt the widely-used simplifying assumption that when the flood protection is exceeded, the flood experienced is similar to that experienced without any protection (Hallegatte et al., 2016b; Jongman,

\footnotetext{
${ }^{93}$ Equation 1 simplifies to Equation 12.

${ }_{94}$ The algorithm for the global application can be found in github.com/adrivsh/resilience_indicator_public/ (Hallegatte et al., 2016b)
} 
Ward, \& Aerts, 2012). As in the global application, we use data from FLOPROS, which stands for Flood Protection Standards, a database on flood protection expressed in terms of return period at various spatial scales (Scussolini et al., 2016).

\subsubsection{Exposure of assets used}

In the absence of spatial data on assets, we estimate asset exposure from the spatial distribution of the population. To do this, we overlay the population map from WorldPop with the flood hazard map from GLOFRIS. WorldPop provides population estimates per $100 \mathrm{~m}$ square grid ${ }^{95}$. GLOFRIS, which stands for Global Flood with IMAGE Scenarios, provides quick risk assessment on river floods (Winsemius et al., 2015).

As shown in Table 5-1, the computed population exposure is disaggregated into the exposure for poor and for non-poor families using the assumed poverty exposure differential of $20 \%$ and regional level poverty incidence among families. The disaggregated exposure rate is then applied to the number of poor and non-poor families to obtain the number of exposed poor and non-poor families. Poverty data is from the Philippines' 2012 Full Year Official Poverty Statistics, and the number of families is from the 2012 Family Income and Expenditure Survey (FIES) (PSA, 2012b, 2013).

\subsubsection{Socioeconomic Vulnerability and Resilience}

Data for each variable on socioeconomic vulnerability and resilience are likewise disaggregated into the poor and non-poor. Except for the data on poverty, the rest of the socioeconomic variables we use are from the 2012 FIES. Income is based on data on family income per region. In terms of transfers or shared income, we use the percentage of income from other sources and other receipts to the average regional family income.

95 The dataset is downloaded from www.worldpop.org.uk. 
Meanwhile, we assume that scaled-up social protection (i.e. diversified income) is $5 \%$ of regional average income in the aftermath of disasters. ${ }^{96}$.

Due to the absence of a comprehensive dataset on inventory of assets and their respective users in the Philippines, the vulnerability of the assets used by families is estimated based on housing structures. We use the data of houses classified according to construction materials used for roof and outer wall: 1) "strong/mixed but predominantly strong materials"; 2) "light/mixed but predominantly light materials"; and, 3) "salvaged/mixed but predominantly salvaged materials" (PSA, 2012b). These are then matched to a damage function that assigns the following percentage of damage to flood-affected assets: high $-10 \%$, medium $-30 \%$, and low- $70 \%$, (Hallegatte et al., 2016b; Hallegatte \& Przyluski, 2010).

Further, we adopt the assumption that access to early warning systems reduce asset losses by $20 \%$. This is because families have some time to prepare and undertake some mitigation actions to protect their assets as they are forewarned. As a proxy indicator for access to early warning systems, we use the proportion of families with access to mobile phone, landlines, and internet services ${ }^{97}$.

We compute the country-level average productivity of capital as the quotient of the output and total reproducible capital from the World Penn Table (Feenstra, Inklaar, \& Timmer, 2015) estimated at 32\% in 2012. We use this uniform value across all 18 regions, i.e., $\mu=32 \%$. Meanwhile, we assume that $95 \%$ of the damaged capital is reconstructed after three years (i.e., $\mathrm{N}=3$ ).

\footnotetext{
${ }^{96}$ The global model uses ASPIRE data as proxy of asset diversification, and an indicator under the fifth priority action under the Hyogo Framework for Action (on availability of fund to finance disaster response and recovery). Thus, the algorithm for the global model was adjusted to suit the data used in our Philippine application.

97 The global model uses data from the reports of countries along their progress towards attaining the priority actions under Hyogo Framework for Action, particularly the second priority action that is on early warning systems for various hazards (Hallegatte et al., 2016c). Thus, Philippines algorithm for this part is a modified version used in the global application.
} 
We use the Philippines' social discount rate of 15\% (ICC, 2012) in discounting the streams of income and consumption over the 3-year period of reconstruction, i.e. $\rho=15 \%$.

\subsubsection{Descriptive statistics}

Table 5-5 below shows the descriptive statistics of the input indicators used in the assessment. All values are for the whole year of 2012, and are at the regional level, unless otherwise stated.

\section{Table 5-5. Descriptive Statistics}

\begin{tabular}{|l|r|r|r|r|}
\hline \multicolumn{1}{|c|}{ Variable } & \multicolumn{1}{c|}{ Mean } & Std. Dev & \multicolumn{1}{c|}{ Min } & \multicolumn{1}{c|}{ Max } \\
\hline Number of families, regional average & $1,190,319$ & 784,374 & 375,065 & $3,082,475$ \\
\hline Average family income, region (in PhP `000) & 235 & 59 & 130 & 379 \\
\hline Average family income, poor (in PhP `000) & 88 & 11 & 71 & 113 \\
\hline Average family income, non-poor (in PhP `000) & 263 & 49 & 167 & 386 \\
\hline Poverty incidence (\%) & 19.7 & 11.9 & 2.6 & 48.7 \\
\hline Exposure, poor (\%) & 3.3 & 2.3 & 0.5 & 9.2 \\
\hline Exposure, non-poor (\%) & 2.7 & 1.8 & 0.5 & 7.1 \\
\hline Protection (years) (\%) & 9 & 3.9 & 6 & 24 \\
\hline Asset vulnerability, poor (\%) & 21.6 & 4.5 & 14.4 & 30.8 \\
\hline Asset vulnerability, non-poor (\%) & 14.3 & 2.8 & 11.1 & 19.7 \\
\hline Access to early warning, poor (\%) & 6 & 2.7 & 2.1 & 12.1 \\
\hline Access to early warning, non-poor (\%) & 17.3 & 4.1 & 7.8 & 23.7 \\
\hline Social transfers, poor (\%) & 13 & 3.1 & 6.3 & 19.4 \\
\hline Social transfer, non-poor (\%) & 19.6 & 4.7 & 8.7 & 28.4 \\
\hline
\end{tabular}

Note: Exchange rate in 2012 is PhP1 = USD 0.0243.

Mean is the national average or the weighted mean of the regional values (expect for the number of families).

On average, there are 1.2 million families per region. Across regions, there is wide heterogeneity in terms of the number of families, which range from 375 thousand (Cordillera Administrative Region, CAR) to over 3 million families (National Capital Region, NCR).

The average family income across the regions gives an indication of the disparity in the level of development within the country. Average family income in the regions ranges from a low of PhP130 thousand or USD3,159 
(ARMM) to a high of PhP379 thousand or USD9,210 (NCR). ${ }^{98}$ Average family income at the national level is PhP235 thousand (or USD5,711).

Among poor families, average income ranges from PhP71 thousand or USD 1,725 (Negros Island Region) to PhP113 thousand or USD2,746 (NCR). That of non-poor families ranges from PhP167 thousand or USD4,058 (ARMM) to PhP386 thousand or USD9,380 (NCR). The average family income of the poor is PhP88 thousand (USD2,138), only a little over a third of the average income of non-poor families (PhP263 thousand or USD6,391), a glaring manifestation of the highly unequal distribution of income among families in the country. ${ }^{99}$

Poverty incidence among families has remained high at 19.7\% in 2012. Across regions, poverty incidence among families ranges from a low of $2.6 \%$ (NCR) to a high of $48.7 \%$ (ARMM).

The estimated exposure rate to riverine flood hazards among poor families ranges from $0.5 \%$ to $9.2 \%$ across regions, while that among non-poor, from $0.5 \%$ to $7.1 \%$. Average exposure is $3.3 \%$ among poor families, and $2.7 \%$ among non-poor families. ${ }^{100}$ Meanwhile, hazard protection among the regions range from an equivalent return period of 7 years to 24 years for the

\footnotetext{
${ }^{98}$ Family income values in Table 5-1 are expressed in their US dollar equivalent using the exchange rate in 2012 of PhP1 = USD 0.0243 .

${ }^{99}$ In 2015, the Gini coefficient of the Philippines was 0.4439 (PSA, 2015a). It is interesting to note that the regions that have the highest income disparity between the poor and non-poor are also the largest in terms of economic size. In the National Capital Region, which contributes about a third of the country's GDP, the average annual income of non-poor families is 3.4 times that of poor families. In Region IV-A, which is contiguous to NCR and makes the second highest contribution to GDP, the non-poor families' average income is 3.23 times that of the non-poor. Both NCR and the Region IV-A are in the Luzon island group. Similarly, Region VII, where the country's second largest city (Cebu City) is also located and which is located in the Visayas, the average family income of the non-poor is 3.29 times that of the poor. Region X where the country's fourth largest city (Cagayan de Oro City) is located Mindanao, the average income of non-poor families is 3.18 times that of poor families. The extent of income disparity in family income is same as that for the Cordillera Administrative Region (CAR) in Luzon.

${ }^{100}$ As in the protection level, exposure rate was generated per province and averaged to the regional level. For provinces without generated data, exposure is set equal to $5 \%$, the lowest exposure rate across provinces that have data.
} 
rainfall volume associated with riverine floods. ${ }^{101}$ Across regions, average protection is equivalent to a 9-year rainfall return period.

Asset vulnerability among poor families ranges from $14.4 \%$ to $30.8 \%$, while that of non-poor families, ranges from $11.1 \%$ to $19.7 \%$. Average asset vulnerability is $21.6 \%$ for poor families and $14.3 \%$ for non-poor families. Among the poor families, access to early warning services ranges from $2.1 \%$ to $12.1 \%$ across regions, while among non-poor families, access ranges from $7.8 \%$ to $23.7 \%$. Average access among the poor is only about a third that of the non-poor (6\% vs $17.3 \%$ ). Meanwhile, among the non-poor, an average of $19.6 \%$ of the family income comes from social transfers; among the poor, the average is $13 \%$.

\subsection{Results and Discussions}

\subsubsection{Asset Risk, Welfare Risk, and Resilience}

Table 5-6 below shows the three main outputs from the model: asset risk, welfare risk, and resilience. Asset risk and welfare risk are per family, and are expressed as a percentage of the regional average annual income per family. Across regions, asset risk ranges from $0.01 \%$ to $0.62 \%$, while welfare risk ranges from $0.02 \%$ to $1.75 \%$.

Region I has both the lowest estimated asset risk and welfare risk. This can be largely attributed to the region's hazard protection level that is equivalent to a 24-year hazard return period. This is the highest among the regions, and is almost three times the national average. Furthermore, among the regions, Region I has the third lowest exposure rate, both among the poor and non-poor families. The region is also among the five least poor

101 Protection level was generated per province and averaged to the regional level. For provinces without generated data, protection level is set equal to the lowest protection level across provinces that have data. 
regions, as measured by poverty incidence. So, it has the lowest hazard, as well as low exposure and low vulnerability.

Meanwhile, Region VIII has both the highest estimated asset and welfare risk. Among the contributory factors are as follows: highest level of exposure both among the poor and non-poor families across 18 regions, second highest poverty incidence, and second lowest protection level.

Table 5-6. Asset Risk, Welfare Risk, and Resilience (\%) ${ }^{102}$

\begin{tabular}{|l|r|r|r|}
\hline \multicolumn{1}{|c|}{ Region } & Asset Risk & $\begin{array}{c}\text { Welfare } \\
\text { Risk }\end{array}$ & Resilience \\
\hline NCR - National Capital Region & 0.12 & 0.07 & 165 \\
\hline Region IVA - CALABARZON & 0.07 & 0.07 & 100 \\
\hline Region III - Central Luzon & 0.03 & 0.03 & 88 \\
\hline CAR - Cordillera Administrative Region & 0.02 & 0.03 & 83 \\
\hline Region I - Ilocos Region & 0.01 & 0.02 & 61 \\
\hline Region VI - Western Visayas & 0.35 & 0.58 & 60 \\
\hline Region VII - Central Visayas & 0.27 & 0.46 & 59 \\
\hline Region II - Cagayan Valley & 0.04 & 0.08 & 56 \\
\hline Region XI - Davao Region & 0.18 & 0.38 & 47 \\
\hline Region X - Northern Mindanao & 0.23 & 0.52 & 45 \\
\hline Region XIII - Caraga Region & 0.20 & 0.46 & 44 \\
\hline Region IVB - MIMAROPA & 0.53 & 1.21 & 44 \\
\hline Negros Island Region & 0.18 & 0.45 & 39 \\
\hline Region V - Bicol Region & 0.22 & 0.56 & 39 \\
\hline Region IX - Zamboanga Peninsula & 0.14 & 0.39 & 36 \\
\hline Region VIII - Eastern Visayas & 0.62 & 1.75 & 35 \\
\hline Region XII - SOCCSKARGEN & 0.09 & 0.27 & 34 \\
\hline ARMM - Autonomous Region of Muslim Mindanao & 0.32 & 1.05 & 31 \\
\hline
\end{tabular}

Given the range of values for asset and welfare risks, resilience across regions ranges from a low of $31 \%$ to a high of $165 \%$. Only two of the 18 regions reached at least a 100\% resilience level: National Capital Region (NCR) and Region IV-A. The NCR is the most resilient at $165 \%$. This implies that the region's post-disaster support is, on average, more than enough to

102 Table 5-7 in the appendix shows the values of the variables and parameters used, alongside the results of a number of key steps in the estimation process. 
offset the losses incurred by the affected families in NCR. As such, affected families in NCR may even be able to rebuild their lives to a better state than that prior to the disaster. Moreover, the region also has a very low poverty incidence of only $2.62 \%$. Not surprisingly, Region IV-A, which is adjacent to the NCR, has a resilience level of $100 \%$, indicating that asset risk is just a little above welfare risk. Region IV-A is next to the NCR in terms of lowest poverty incidence.

Of the bottom five regions in terms of estimated resilience, three are in the southern Mindanao island group, and one region each in the Visayas and Luzon groups. The ARMM that is located in Mindanao has the lowest resilience with $31 \%$. This means that for every peso in asset losses translates to over three pesos in welfare losses. Practically what the NCR has in abundance, the ARMM has little of. Almost half of the families in the ARMM are poor, with poverty incidence of $48.70 \%$. As noted earlier, the average income in ARMM is just over a third that of NCR's, and less than two thirds of the national average. Furthermore, the ARMM has the lowest access to social protection, where the levels of access among the region's poor $(6.29 \%)$ and non-poor $(8.71 \%)$ families are less than half of the national average access to social protection among poor families (13.33\%), and nonpoor families $(19.34 \%)$.

Region XII that is also located in Mindanao has the second lowest estimated resilience, at $34 \%$. Over a third of the total number of families in the region are poor. Average income of families is less than half that of the NCR, and substantially lower than the average across regions.

It is worthwhile to note that all six Mindanao regions have welfare risks that are more than double the asset risks, thus resilience of each is less than $50 \%$. Relative to regions elsewhere in the country, Mindanao experiences fewer disasters brought by natural hazards. However, relative to Luzon and 
Visayas, Mindanao is lagging behind in terms of access to economic and social services.

Further, we note that there are regions whose level of resilience is similar but due to different reasons. For instance, Eastern Visayas and Zamboanga Peninsula have comparable resilience levels of 35\% and 36\%, respectively. However, the former is due mainly to high poverty and exposure, while the latter is mainly due to high poverty and asset vulnerability. This implies that each region, while having comparable resilience to another, will likely require different policies and corresponding measures to strengthen resilience to disasters.

\subsubsection{Priority Regions}

We attempt to provide broad yet useful inputs into the various stages of the development planning cycle in the Philippines. Particularly after the passage of the country's landmark laws on climate change adaptation (CCA), and on disaster risk reduction and management (DRRM) in 2009 and 2010, respectively, the country has been intensifying its efforts to integrate CCA and DRRM into each stage of the planning cycle. Our results add value into each of these stages by ensuring disaster welfare impacts and resilience can be considered.

Our results can be used to determine the regions that are in most need for development interventions to reduce/avoid welfare losses and strengthen resilience. Given the limits of the Philippines' fiscal resources for many of its development needs, there is need to direct resources to areas where they will yield the greatest net benefits.

We categorize the regions based on two criteria. The first is based on the estimated resilience, and the second is based on estimated welfare risk. We adopt three tiers per categorization, namely: low, medium, and high. We 
use quantiles that divides the range of values of resilience and welfare risk into intervals with unequal size but with equal number of regions per tier. The results are shown in Figures 5-3 and 5-4. There are six regions with low level of resilience: one in Luzon (Region V), two in Visayas (Region VIII and NIR), and 3 in Mindanao (ARMM, Region IX and Region XII). There are five regions with high level of resilience, all of which are in Luzon. Meanwhile, there is one region per island group that has high welfare risk. The five regions with high resilience are also the same regions with low welfare risk.

Based on these categorization results, we identify regions that may be given the highest and the lowest priority in terms of reducing welfare losses and improving resilience to disasters. ${ }^{103}$ Figure 5-5 shows as High Priority those regions with both low resilience and high welfare risk. Low Priority regions are those with both high level of resilience and low welfare risk.

Three regions are High Priority: Regions V in Luzon, Region VIII in Visayas, and ARMM in Mindanao. A distinct common characteristic of these regions is that they are among the country's poorest regions. The ARMM and Region VIII are the two poorest regions, measured in terms of poverty incidence. Region $\mathrm{V}$ is the poorest in the country, measured in terms of number of poor families. These regions may be considered as the top priority regions for building and/or strengthening disaster resilience.

Meanwhile, five regions have the ideal combination of low welfare risk and high resilience, and, thus may be given the lowest level of priority. These regions are NCR, CAR, I, III, and IV-A. All five regions belong to the northern Luzon. Their relatively better hazard protection makes them more resilient than the rest of the regions despite the greater frequency of tropical cyclones that cause riverine floods in the northern part of the country.

103 A finer categorization of regions is presented in Appendix B. 
We undertake both qualitative and quantitative examination of the robustness of our prioritization results above. As a first test, we compare our results with the categorization of provinces as contained in the country's national development plan ${ }^{104}$ (NEDA, 2014). We note that as part of the efforts to mainstream DRR and CCA into the development process, the country's national development plan categorized provinces based on vulnerability and risk to disasters. Provinces were likewise categorized according to poverty incidence given that poverty persists, thus poverty eradication remains a major development goal.

We find that provinces in Regions $\mathrm{V}$ and VIII, two of the regions we identified as High Priority, are included in the Category 3 provinces, which the national plan indicated as among those that face the greatest risk of disasters. We note, however, that our findings reveal that ARMM, which is one of the country's poorest, also faces great adverse disaster impacts in terms of welfare losses. This can be considered as an added-value of our analysis. Likewise, we find that half of the Category 2 provinces (or provinces with the highest poverty incidence) are located in the three High Priority regions we identified (i.e. Region V, Region VIII, and ARMM).

It has been argued earlier that resilience is significantly associated with poverty incidence. Thus, we would expect that areas where there is high concentration of poverty are also areas where there is greater need for resilience building. To check this, we conduct a spatial statistical analysis using finer-grained data, i.e. provincial values. We use the Hot Spots Analysis tool of GIS to identify regions where there is significant clustering of provinces with high incidence of poverty (hot spots), and low incidence

104 This refers to the Medium-Term Philippine Development Plan, 2011-2016. At the time that this study was started in early 2015, the said plan underwent a mid-term review in 2014. It is due to be updated again by the end of 2016; thus, the results of our assessment approach can be used to the said updating. 
of poverty (cold spots). ${ }^{105}$ This is important because we use as our level of analysis the regions in the Philippines that formed from the aggregation of provinces. At times the higher-level aggregation (in this case, the regions) masks the differences in the lower spatial units (in this case, the provinces) that comprise it.

Figure 5-6 shows the Hot Spots Analysis result for poverty incidence. It can be gleaned that all provinces in ARMM are Hot Spots for poverty at the $99 \%$ confidence, and the provinces in Region VIII are Hot Spot at either 95\% or $90 \%$ confidence. We note that these are also two of the three regions that posted the highest welfare risk and lowest resilience across all regions, and which we classified as High Priority regions.

We see that the provinces in Region X are Hot Spots either at the $99 \%$ or 95\% confidence level, and the Province of Davao del Norte in Region XI is a Hot Spot at $90 \%$ confidence. Both of these regions have medium level of socioeconomic resilience.

Meanwhile, the districts ${ }^{106}$ of NCR, and the provinces in Region III are all Cold Spots for poverty at the 99\% confidence, and provinces in Region IVA are Cold Spots either at the $99 \%$ or $95 \%$ confidence. Cold spots are where there is significant clustering of provinces with low incidence of poverty. We note that these Cold Spots shown in Figure 5-6 are three of the five Low Priority regions we identified.

Overall, our results show that regions with the lowest resilience and highest welfare risk are also the country's poorest regions, either in terms of incidence of poverty or number of poor persons. On the other hand, regions

\footnotetext{
105 For a province to be a statistically significant poverty hot spot (cold spot), it must have high (low) poverty incidence and be surrounded by provinces with high (low) poverty incidence.

106 The National Capital Region do not have provinces, only districts. Like the provinces, districts comprise of cities and municipalities. A province is one of the administrative divisions in the Philippines, and is ran by a governor. A district is created for the purpose of representation to the House of Representatives.
} 
with highest resilience and lowest welfare risk are the country's most socioeconomically-advanced regions. These results suggest that poverty reduction and disaster risk reduction, including through resilience building, are connected rather than discrete development concerns. Thus, development planning that addresses poverty, economic welfare, and disaster risk in an integrated manner translates to greater effectiveness in addressing each concern, as well as greater efficiency in resource use. 
Figure 5-3. Categorization of Regions According to Resilience

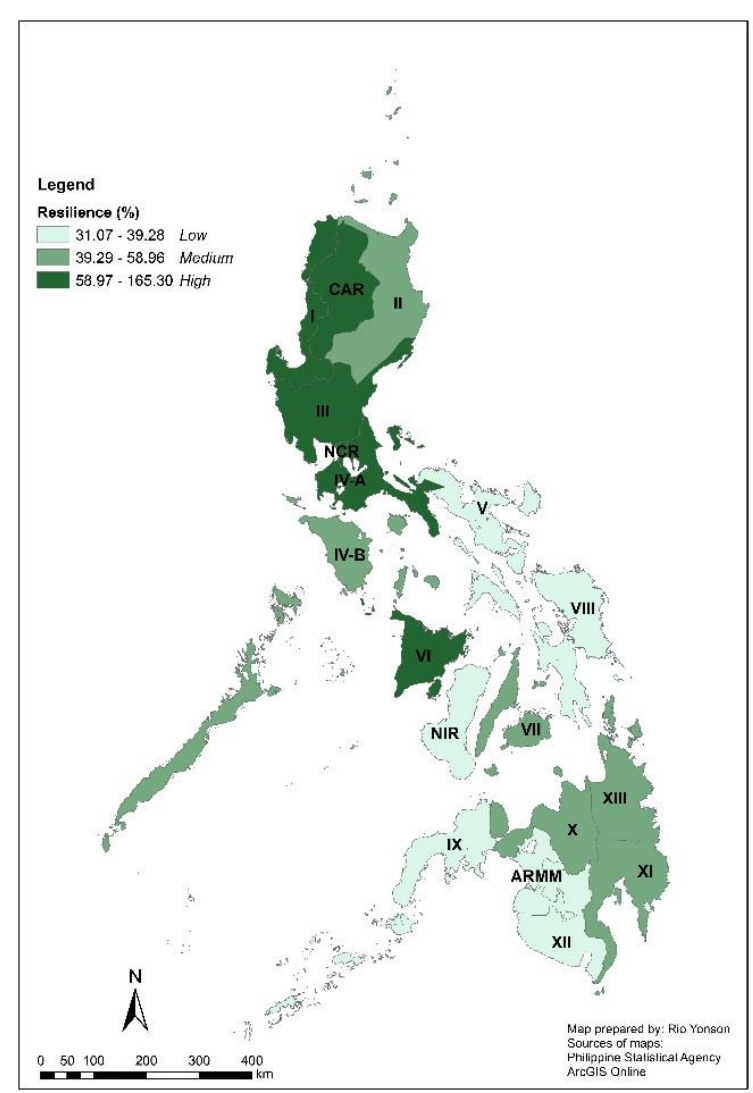

Figure 5-4. Categorization of Regions According to Welfare Risk

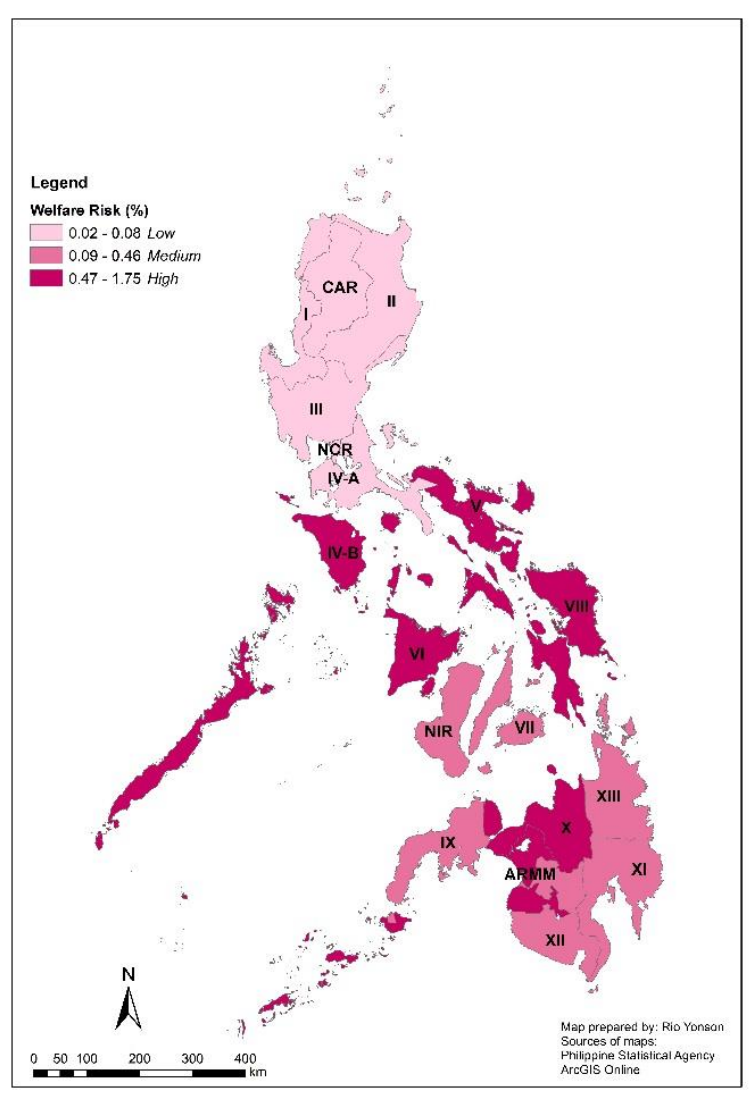


Figure 5-5. Prioritization of Regions, Based on Resilience Figure 5-6. Hot Spot Analysis of Provincial Level of and Welfare Risk Poverty Incidence
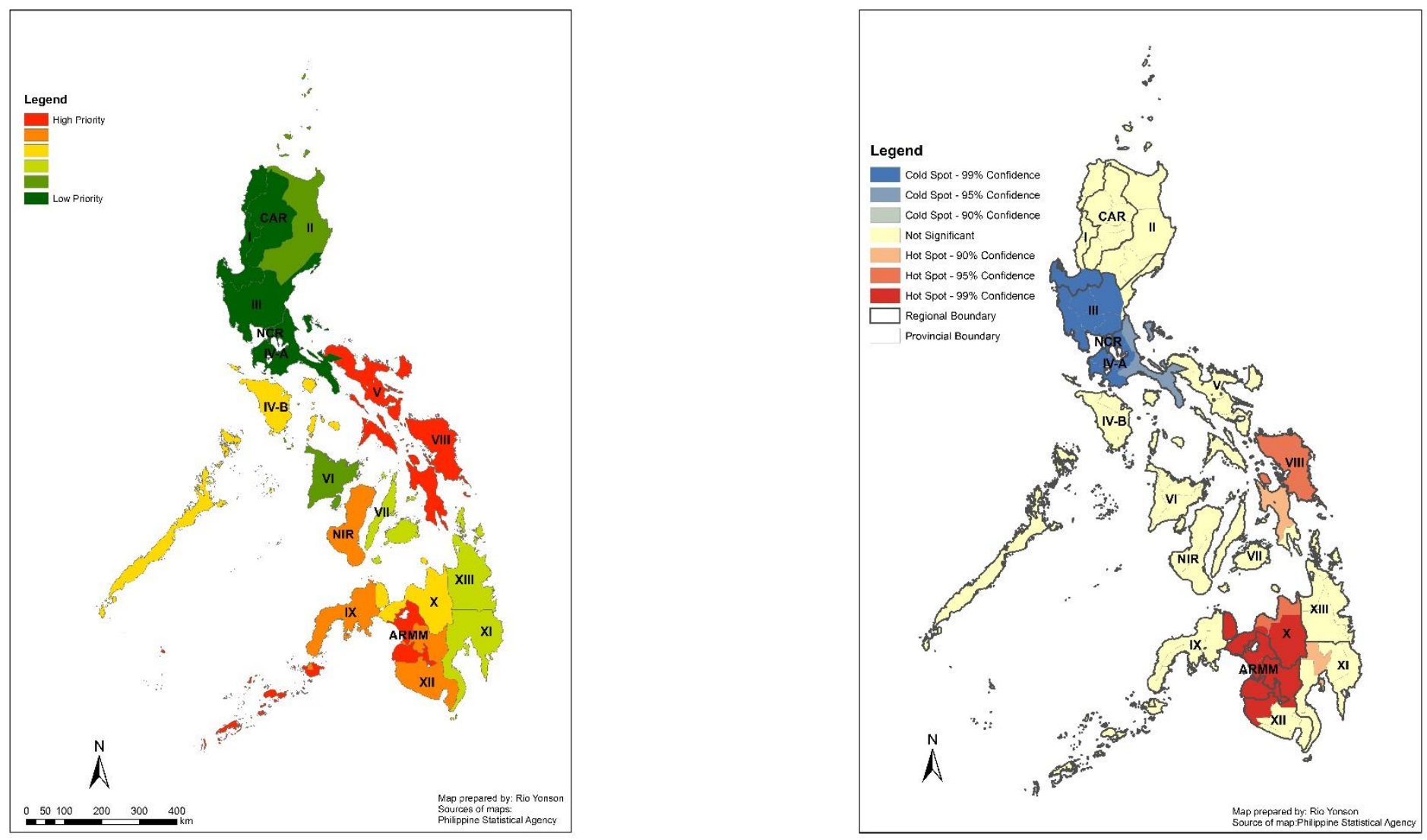


\subsubsection{Policy Experiments}

We undertake policy experiments to provide a systematically derived basis for the prioritization of alternative policy options within each region, and across regions. We adjust, one at a time, the value of selected input variables from their respective values under the base case scenario presented in Sections 5.5.1 and 5.5.2.

- Hazard Protection

- Protection level equivalent to one year higher than the current level

- Exposure

- $10 \%$ reduction in the exposure of poor families

- $10 \%$ reduction in the exposure of non-poor families

- Vulnerability and Resilience

- $5 \%$ reduction in the asset vulnerability of poor families

- $5 \%$ reduction in the asset vulnerability of non-poor families

- Time to reconstruct is shorter by 1 year

- $1 \%$ reduction in poverty incidence

- $10 \%$ increase in access to early warning among poor families

- $10 \%$ increase in access to early warning among non-poor families

- $5 \%$ increase in reactivity to early warning

- $5 \%$ increase in social protection for poor families

- $5 \%$ increase in social protection for non-poor families

- $15 \%$ increase in the scale-up of social protection for poor families

- $15 \%$ increase in the scale-up of social protection for nonpoor families

- $10 \%$ increase in income of poor families

- $10 \%$ increase in income of non-poor families

- $10 \%$ increase in average income of families

The outputs are policy cards for each of the 18 regions of the Philippines. The policy card has at least two purposes: one, as a tool to track regional level progress; and, two as menu of policy options prioritized according to 
their effectiveness in reducing asset and welfare risk, and increasing resilience per region.

In Section 5.5.3.2, we also use the assessment approach to determine in which regions a particular policy alternative will yield the greatest and least impacts in terms of reduction in welfare and asset losses. Unlike in a crossnational assessment, our intra-national analysis allows us to safely assume that the costs of implementing these policies from one region to another are comparable. Thus, even if we do not measure these costs, it makes sense to discuss which regions will benefit the most from each policy alternative. We measure benefits (or the gains) in terms of reduction in asset losses and welfare losses.

\subsubsection{Within Each Region}

We perform the exercise for each region to estimate the effect of the policy alternatives on total regional welfare losses and asset losses. For brevity, we focus our analysis on one of High Priority (ARMM), and on one Low Priority (NCR) region presented in Section 5.5.2. The policy cards of the regions are juxtaposed in Figures 5-7 and 5-8. The policy cards for the rest of the regions are found in the Appendices.

For ARMM, it is the $10 \%$ reduction in the exposure of poor families that consistently yield the highest reduction in welfare losses and asset losses, respectively. Meanwhile, for NCR it is the $10 \%$ reduction in the exposure of non-poor families that yield the highest gains in terms of reduction in both asset and welfare losses.

Similarly, we find that for ARMM, between reducing asset vulnerability of the poor and of the non-poor, it is the former that results in greater reduction in welfare losses. The same situation is observed for the other High Priority Regions, such as Regions VIII and V. 
The converse is seen for NCR, where it is the reduction in asset vulnerability that generates greater reduction in welfare losses, as well as in asset losses. This is also observed for CAR and Region IV-A, which like NCR are Low Priority Regions.

We also see that while the $10 \%$ reduction in exposure among the poor and the non-poor are the two top gain-yielding policy alternatives for ARMM, it is the $10 \%$ reduction in exposure among the non-poor families and the $5 \%$ reduction in the asset vulnerability for non-poor families that are the top two policies for NCR. In fact, across all regions, it is only the NCR that has $5 \%$ reduction asset vulnerability within the first two among the policy alternatives; the rest of the regions have $10 \%$ exposure of the poor and the non-poor as the top two.

The above results together suggest that while there are similarities in the ranking of policies among regions with comparable levels of resilience and welfare risk, we find that the ranking of priorities vary from one region to another. This suggests that there are region-specific conditions that influence welfare impacts and resilience. Thus, the need for region-specific policies and interventions, as well. 


\section{Figure 5-7. Policy Cards for a High Priority Region: ARMM}

Exposure of poor families $(-10 \%)$

Exposure of nonpoor families $(-10 \%)$

Asset vulnerability for poor families $(-5 \%)$

Protection (+1 yr)

Asset vulnerability for nonpoor families(-5\%)

Time to reconstruct $(-1 \mathrm{yr})$ Scale-up of social protection for poor households $(+15 \%)$ Access to early warning for poor families $(+10 \%)$ Social protection for poor families $(+5 \%)$ Poverty incidence $(-1 \%)$ Access to early warning for nonpoor families $(+10 \%)$ Scale-up of social protection for nonpoor families $(+15 \%)$ Reactivity to early-warnings ( $+5 \%$ ) Social protection for nonpoor families $(+5 \%)$

Average income of poor families $(+10 \%)$ Average income of nonpoor families $(+10 \%)$ Average income in the region $(+10 \%)$

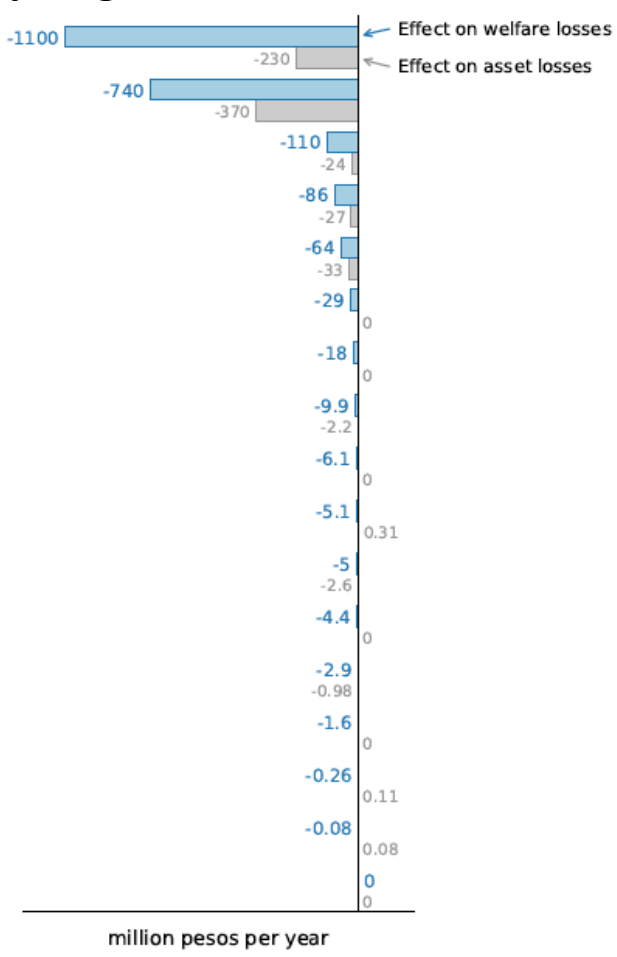

\section{Figure 5-8. Policy Cards for the Low Priority Regions: NCR}

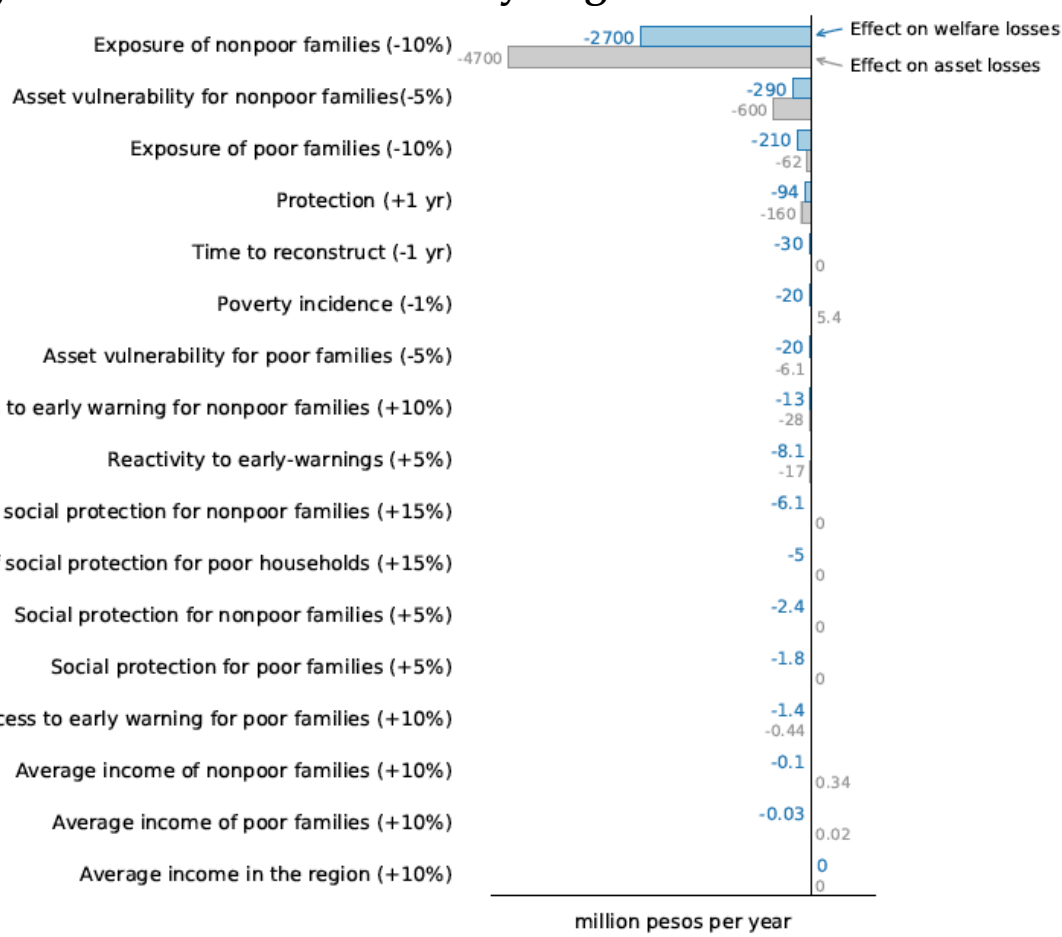




\subsubsection{Across Regions}

We also use the assessment approach to determine in which regions a particular policy alternative will yield the greatest and least impacts in terms of reduction in welfare and asset losses. Unlike in a cross-national assessment, our intra-national analysis allows us to safely assume that the costs of implementing these policies from one region to another are comparable. Thus, even if we do not measure these costs, it makes sense to discuss which regions will benefit the most from each policy alternative. We measure benefits (or the gains) in terms of reduction in asset losses and welfare losses.

\subsection{Reduction in exposure by $10 \%$}

It can be gleaned from Figure 5-9 that across the regions, a 10\% reduction of exposure among the poor families results in reduction in annual welfare losses ranging from PhP170 million (CAR and Region I) to PhP1.9billion (Region VIII), and asset losses from PhP31 million (Region I) to PhP300 million (Region VIII). On the other hand, reducing exposure among the non-poor by $10 \%$ results in reduction in welfare losses ranging from PhP360 million (CAR) to PhP2.7 billion (NCR).

Compared with the results for the non-poor, we see that for the poor families, there is a wider difference between the reduction in asset losses and welfare losses. This is because the poor have very few assets, hence it is expected that reduction in asset losses will be much lower than the reduction in welfare losses. It is also noted that among the non-poor, the reduction in asset losses is greater than the reduction in welfare losses. The reverse is true among the poor.

Moreover, the comparison of magnitude of effects between reducing exposure among the poor and exposure among the non-poor reveals that 
the latter yields a higher total reduction in welfare losses across regions (PhP1.9 Billion vs PhP2.7 billion). However, it will be recalled that despite the high incidence of poverty, there are still more non-poor families. Thus, when expressed on a per family basis, there is greater reduction in welfare losses when exposure of the poor is reduced, than exposure of the non-poor.

\subsection{Reduction in asset vulnerability by $5 \%$}

Reducing by $5 \%$ the asset vulnerability of the poor reduces welfare losses and asset losses in Region VIII by PhP340 million and PhP54 per year, respectively, the highest across all regions (Figure 5-10). As poor families have very few assets, the reduction in asset losses is considerably lower than the reduction in welfare losses. The next eight regions that follow Region VIII have comparable reductions in welfare losses, though the reduction in each region is notably less than half of that in Region VIII.

On the other hand, reducing by $5 \%$ the asset vulnerability for non-poor families benefits NCR the most, both in terms of reductions in asset losses and welfare losses. Expectedly, given a much larger asset base, the reduction in asset losses in NCR of PhP600 million per year is substantially higher than those in the rest of the regions, which range from PhP8.7 million per year (CAR) to PhP220 million per year (Region VIII).

\subsection{Increase in average income by $10 \%$}

Meanwhile, as shown in Figure 5-11, a 10\% increase in the average income of the poor again benefits Region VIII the most, and followed by Region IVB. Interestingly, we find that ARMM, which has the highest poverty incidence among the regions, is only the $9^{\text {th }}$ to gain. This reflects the fact that many of the ARMM's poor earn very low incomes such that a $10 \%$ income increase does not translate to welfare gains comparable to other areas with high poverty incidence. Nonetheless, within ARMM, the reduction in 
welfare losses largely offsets the increase in asset losses. The gains in welfare (absolute value of reduction in welfare losses is PhP0.26 million per year) is double that of the value of the asset losses (PhP0.11 million pesos per year).

Meanwhile, a 10\% increase in the average income of the non-poor will likewise benefit Region VIII the most. The least to gain in either of the policy alternatives of reducing exposure are CAR and Regions I, II and III. It will be recalled that all these are under the Low Priority regions identified earlier in Section 5.5.2.

\subsection{Reduction in poverty incidence by $1 \%$}

Figure 5-12 shows the result of implementing a uniform 1\% decline in poverty incidence in each of the 18 regions. Expectedly, such policy will have the greatest impact in terms of reducing welfare losses in Region VIII, as the region has one of the highest poverty incidence and number of poor families.

Interestingly, despite having the lowest poverty incidence and number of poor families, NCR stands to gain next in terms of highest reduction in welfare losses and ARMM is only the $13^{\text {th }}$. As shown in Figure 5-8 earlier, a $1 \%$ reduction in poverty incidence in NCR will yield welfare gains of PhP20 million pesos compared to just PhP5.1 million for ARMM as shown in Figure 5-9. This indicates that while poverty is prevalent in ARMM (much more than in NCR), there are other factors that have greater influence on disaster consequences. 
Figure 5-9. Reduction in Exposure by 10\%

Region VIII - Eastern Visayas ${ }^{-1900}$ Exposure of poor families (-10\%) Effect on welfare losses

Region XII - SOCCSKARGEN

Region XI - Davao Region

Region V - Bicol Region

Region VII - Central Visayas

Region X - Northern Mindanao

ARMM - Autonomous Region of Muslim Mindanao

Region IVB - MIMAROPA

Negros Island Region

Region IX - Zamboanga Peninsula

Region VI - Western Visayas

Region III - Central Luzon

Region XIII - Caraga Region

Region IVA - CALABARZON

Region II - Cagayan Valley

NCR - National Capital Region

CAR - Cordillera Administrative Region

Region I - llocos Region

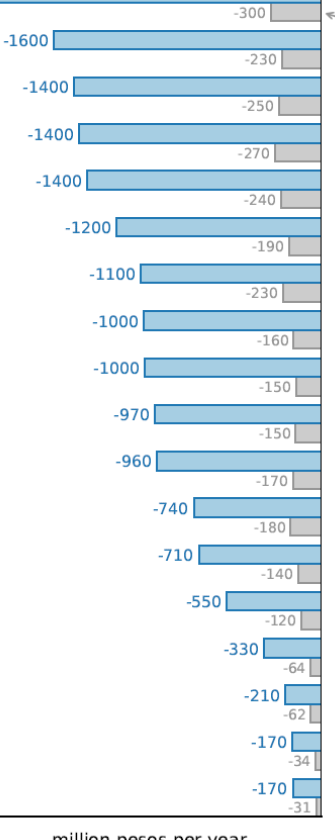

million pesos per year
Exposure of nonpoor families (-10\%) Region III - Central Luzo

Region IVA - CALABARZON

Region VII - Central Visayas

Region XI - Davao Region

Region VI - Western Visaya

Region IVB - MIMAROPA

Region V - Bicol Region

Region VIII - Eastern Visayas

Region X - Northern Mindanao

Region XII - SOCCSKARGEN

Negros Island Region

Region IX - Zamboanga Peninsula

ARMM - Autonomous Region of Muslim Mindana

Region II - Cagayan Valley

Region XIII - Caraga Region

Region I - llocos Region

CAR - Cordillera Administrative Region

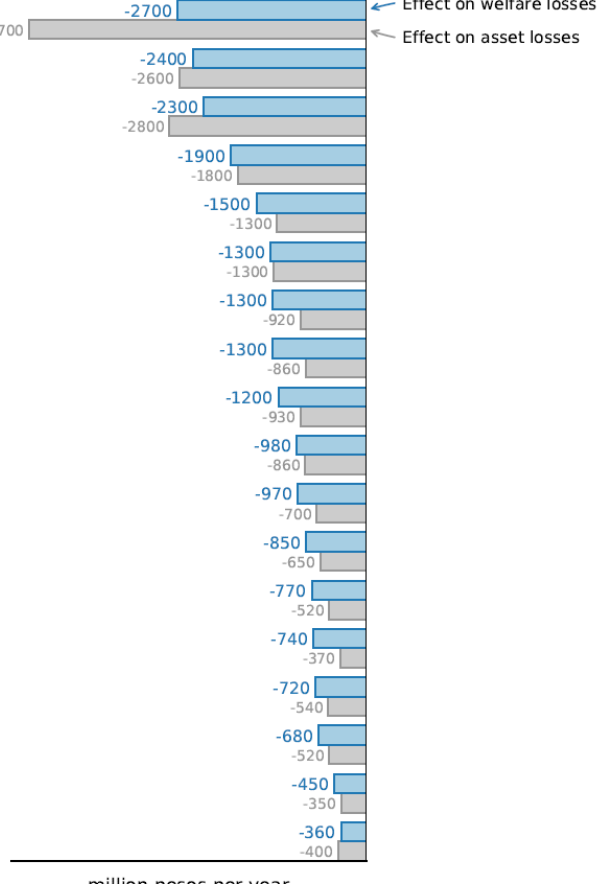

million pesos per year 
Figure 5-10. Reduction in Asset Vulnerability by 5\%

Asset vulnerability for poor families $(-5 \%$

Region VIII - Eastern Visayas ${ }^{-340}$

Region X - Northern Mindanao

Region VII - Central Visayas

ARMM - Autonomous Region of Muslim Mindanao

Region V - Bicol Region

Region IVB - MIMAROPA

Region VI - Western Visayas

Region XI - Davao Region

Negros Island Region

Region XII - SOCCSKARGEN

Region IX - Zamboanga Peninsula

Region XIII - Caraga Region

Region IVA - CALABARZON

NCR - National Capital Region Region III - Central Luzon Region II - Cagayan Valley Region I - llocos Region

CAR - Cordillera Administrative Region

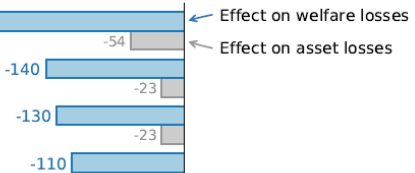

$- 1 1 0 \longdiv { - 2 4 }$

$- 1 1 0 \longdiv { \square } - 2 3$

$-10$

$- 9 0 \longdiv { \square }$$$
-84
$$$$
-55 \stackrel{-12}{-8.1}
$$

$-55$

$-50 \lcm{-9.9}$

$-35 \square$

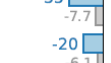

-20
-6.1
-12
-2.9
-10

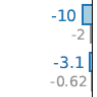

million pesos per year

Asset vulnerability for nonpoor families(-5\%)

Region VIII - Eastern Visayas

Region VII - Central Visayas

Region IVA - CALABARZON

Region IVB - MIMAROPA

Region VI - Western Visayas

Region X - Northern Mindanao

Region XI - Davao Region

Region V - Bicol Region

Negros Island Region

ARMM - Autonomous Region of Muslim Mindanao

Region III - Central Luzo

Region XIII - Caraga Region

Region IX - Zamboanga Peninsula

Region XII - SOCCSKARGEN

Region II - Cagayan Valley

Region I - llocos Regio

CAR - Cordillera Administrative Region

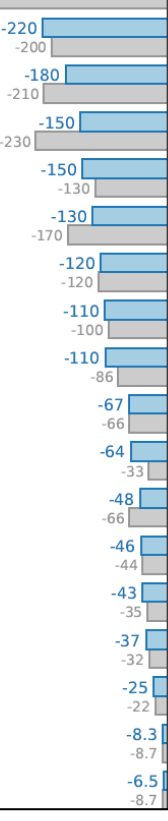

million pesos per year 


\section{Figure 5-11. Increase in Family Income by 10\%}

Average income of poor families ( $+10 \%)$ Region VIII - Eastern Visayas ${ }^{-1.2}$ Effect on welfare losses

Region IVB - MIMAROPA

Region X - Northern Mindanao

Region VII - Central Visayas

Region V - Bicol Region

Region VI - Western Visayas

Negros Island Region

Region XI - Davao Region

ARMM - Autonomous Region of Muslim Mindanao

Region IX - Zamboanga Peninsula

Region XII - SOCCSKARGEN

Region XIII - Caraga Region

Region IVA - CALABARZON

NCR - National Capital Regio

Region III - Central Luzon

Region II - Cagayan Valley

Region I - llocos Region

CAR - Cordillera Administrative Regio

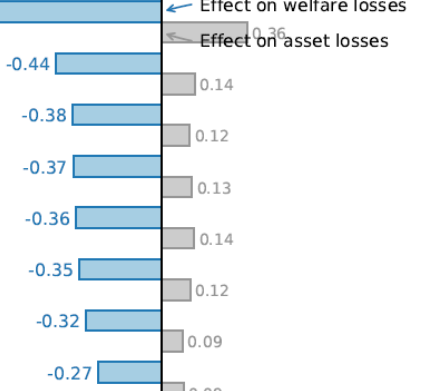

Average income of nonpoor families $(+10 \%)$ Region VIII - Eastern Visayas ${ }^{-0.2}$ — Effect on welfare losses

Region IVB - MIMAROPA Region VII - Central Visayas

Region VI - Western Visayas

Region V - Bicol Region

NCR - National Capital Region

Region XI - Davao Region

Region X - Northern Mindanao

ARMM - Autonomous Region of Muslim Mindanao

Region IVA - CALABARZON

Negros Island Region

Region IX - Zamboanga Peninsula

Region XIII - Caraga Region

Region XII - SOCCSKARGEN

Region III - Central Luzon

Region II - Cagayan Valley

Region I - llocos Region

CAR - Cordillera Administrative Region

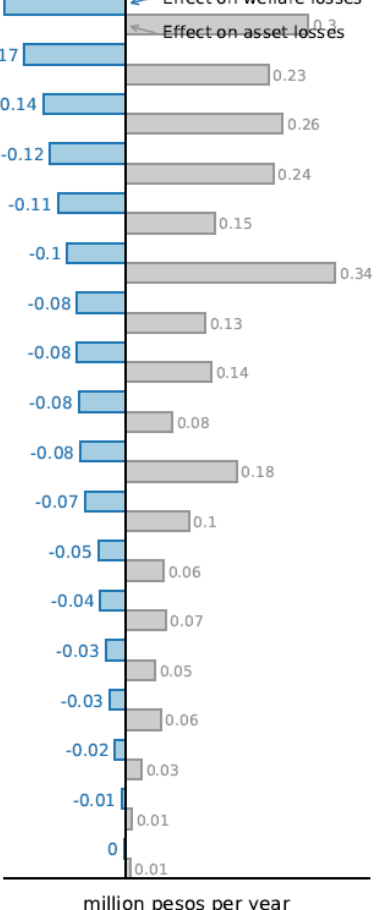

million pesos per year 
Figure 5-12. Reduction in Poverty Incidence by 1\%

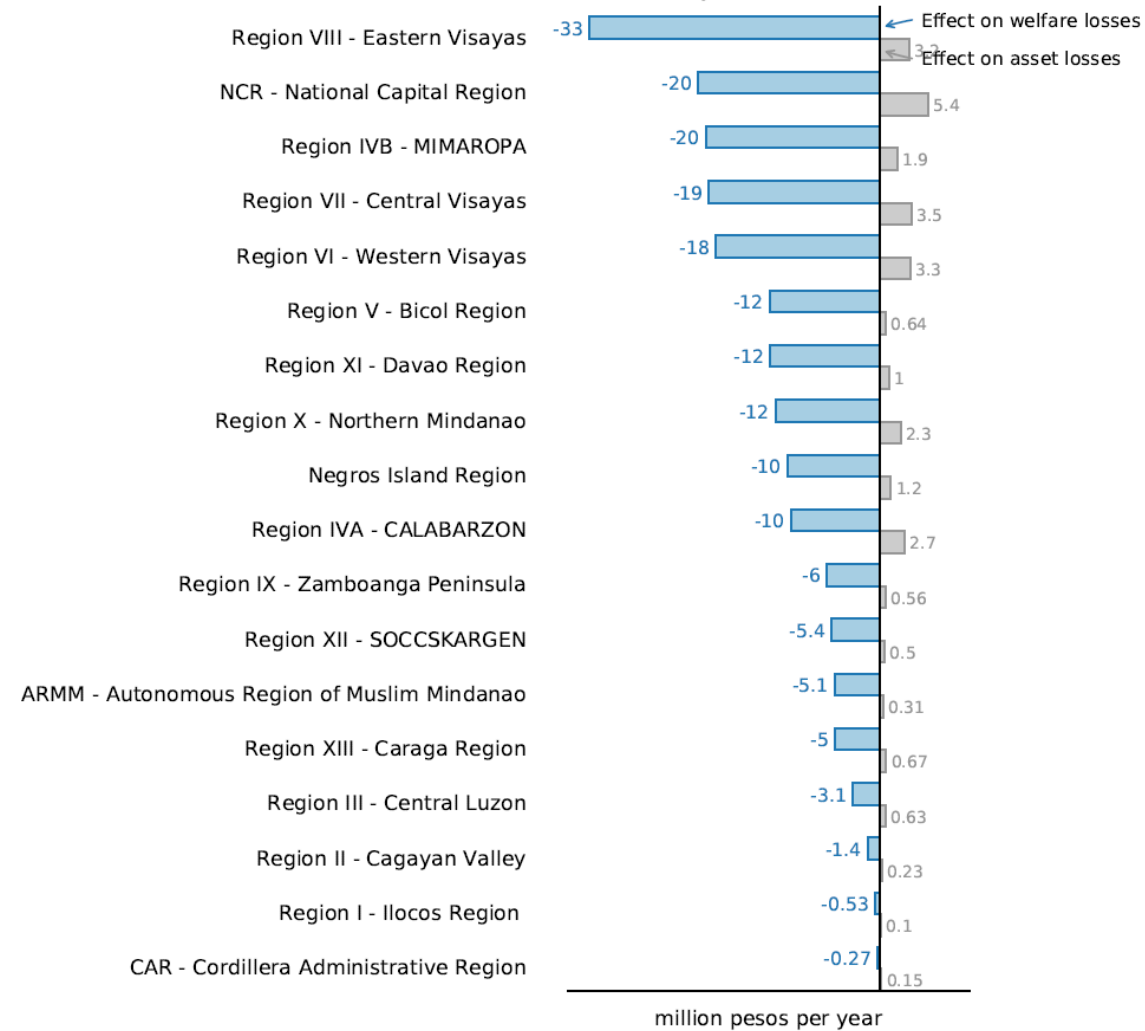

\subsection{Increase in social transfers by $10 \%$}

Increasing pre-disaster social transfers for poor families will reduce postdisaster welfare losses but will not have any impact on asset losses. It is this diversification in income source and risk sharing mechanism that reduce the impact on welfare (Hallegatte et al., 2017).

As shown in Figure 5-13, increasing the social transfers to the poor brings the largest welfare gains again to Region VIII. Region IVB second highest gain, but welfare reduction is less than half of that for Region VIII. The Cordillera Administrative, which is among the least poor regions, stands to gain the least.

In terms of increasing social transfers for the non-poor, Regions IVB and VIII which are expected to gain the most have about the same reduction in 
welfare losses. It is noted however that gains from increasing social transfers for the non-poor results in much lower gains in welfare than from increasing social transfers to the poor.

\subsection{Provision of scaled-up protection by $15 \%$}

Likewise, scaling up social protection does not translate to any reductions in assets losses given the ex post nature of the provision of assistance. However, there are some important gains in terms of welfare particularly when these are directed towards the poor. Scaling up social protection by $15 \%$ of regional income translates to welfare gains for Region VIII amounting to PhP110 (Figure 5-14). For the rest of the regions, welfare gains ranges from $\mathrm{PhP} 0.35$ million to $\mathrm{PhP} 48$ million.

On the other hand, scaling up assistance to non-poor families by the same percentage results in much lower gains in welfare and assets. Region IV-B benefits the most, is again closely followed by Region VIII. 


\section{Figure 5-13. Increase in Social Protection by $10 \%$}

Social protection for poor families $(+5 \%)$

Region VIII - Eastern Visayas
Region IVB - MIMAROPA
Region V - Bicol Region
Region VII - Central Visayas
Region VI - Western Visayas
Region X - Northern Mindanao
Negros Island Region
Region XI - Davao Region
Region XII - SOCCSKARGEN
IX - Zamboanga Peninsula
Region XIII - Caraga Region
Region IVA - CALABARZON
NCR - National Capital Region
Region III - Central Luzon
Region II - Cagayan Valley
Region I - Ilocos Region

Social protection for nonpoor families $(+5 \%)$

Region IVB - MIMAROPA -3.8 Region VIII - Eastern Visayas Region VI - Western Visayas Region VII - Central Visayas WCR - National Capital Region Region V - Bicol Region ARMM - Autonomous Region of Muslim Mindanao Region XI - Davao Region Region X - Northern Mindanao Region IVA - CALABARZON Negros Island Region Region IX - Zamboanga Peninsula Region XIII - Caraga Region Region XII - SOCCSKARGEN Region III - Central Luzon Region II - Cagayan Valley Region I - llocos Region CAR - Cordillera Administrative Region

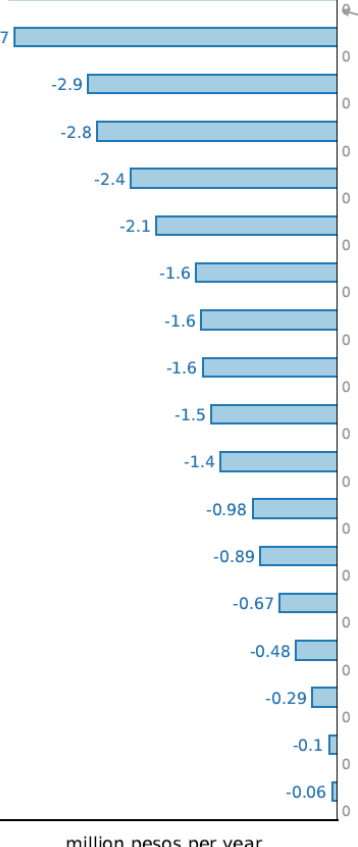

million pesos per year 
Figure 5-14.Provision of scale-up protection by $15 \%$ of income

Scale-up of social protection for poor households $(+15 \%)$

Region IVB - MIMAROPA

Region $V$ - Bicol Region

Region VII - Central Visaya

Region VI - Western Visayas

Region XI - Davao Regio

Region X - Northern Mindanao

Negros Island Regio

Region XII - SOCCSKARGEN

Region IX - Zamboanga Peninsula

ARMM - Autonomous Region of Muslim Mindana

Region XIII - Caraga Region

Region IVA - CALABARZO

NCR - National Capital Region

Region III - Central Luzon

Region II - Cagayan Valley

Region I - llocos Region

CAR - Cordillera Administrative Region

million pesos per year

3

$-32 \square$

$-32 \square$

$-20 \square$

$-18 \square$

$-7.6$

-5 -

$-3.4$

$-2.34$

$-0.66$

$-0.35$
Scale-up of social protection for nonpoor families $(+15 \%)$

Region IVB - MIMAROPA -9.1 - Effect on welfare losses

Region VIII - Eastern Visayas

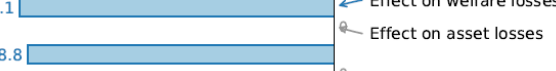

Region VII - Central Visayas

Region VI - Western Visayas

NCR - National Capital Region

Region V - Bicol Region

ARMM - Autonomous Region of Muslim Mindanao

Region XI - Davao Region

Region X - Northern Mindanao

Region IVA - CALABARZON

Negros Island Region

Region IX - Zamboanga Peninsula

Region XIII - Caraga Region

Region XII - SOCCSKARGEN

Region III - Central Luzon

Region II - Cagayan Valley

Region I - llocos Region

CAR - Cordillera Administrative Region

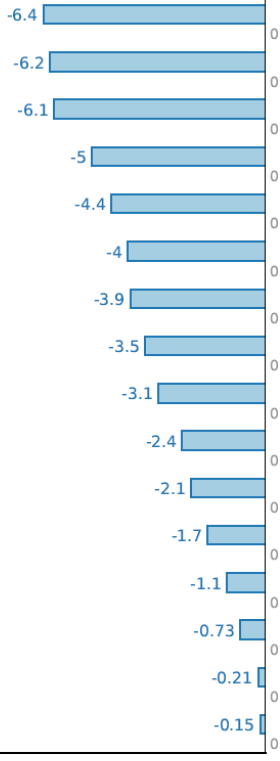

million pesos per year 
From the above results, it is clear that Region VIII will stand to gain the most in terms of various interventions to affect any of the components of the welfare risk among the poor. Even for several policies for the non-poor (such as increasing the income, increasing the social protection, scale-up of protection, increasing access to early warning, reducing asset vulnerability for non-poor), Region VIII is one of the top regions expected to experience the highest reduction in welfare loss, or equivalently, the highest gains in welfare.

\subsection{Conclusions and Caveats}

This work extends the usual assessment of disaster impacts on assets by conducting an analysis of the consequent welfare impacts at the subnational level. The estimate for welfare losses along with the estimate for asset losses allows for a quantified measure of resilience to disasters. Together, these quantified impacts enable the prioritization of policy alternatives depending on the main region-specific factors that drive asset and welfare losses.

Region I has the lowest estimated asset risk and welfare risk, due to high hazard protection level, low exposure, and poverty incidence. At the opposite end is Region VIII due to high exposure both among the poor and non-poor families, high poverty incidence, and low protection level. Meanwhile, the NCR is the most resilient, while ARMM is the least resilient. The findings about these latter two regions best demonstrates the importance of risk sharing and income diversification though social transfer and public post-disaster support to minimize or avoid adverse impacts of disasters on welfare. 
The categorization of regions based on estimated resilience, and estimated welfare risk suggest that Regions V and VIII, and ARMM may be considered as the top priority in terms of allocation of national public resources for strengthening disaster resilience to minimize the impacts of flood disasters on welfare. On the other hand, NCR, CAR, and Regions I, III, and IV-A may be given the lowest level of priority.

The policy experiment within each region and the comparison of results across regions reveal evident similarities in the ranking of policies among regions with comparable levels of resilience and welfare risk. Nonetheless, the ranking of priorities varies for different regions. Not surprisingly, for a majority of the policy alternatives, it is Region VIII that is expected to benefit the most. Apart from being one of the socioeconomically disadvantaged, it is also one of the regions that experienced some of the worst disaster impacts in recent decades.

Overall, our results indicate that reduction of adverse disaster impacts, including welfare losses, and reduction of poverty are generally complementary development agenda. Thus, this suggests the need to ensure an integrated approach in addressing poverty and economic disaster welfare risk.

We note some caveats. Given the limits of available data, this study covers only riverine floods. As the Philippines and its regions are also prone to other geologic and hydrometeorologic hazards, a multiple hazard analysis will be desirable. While we expect that regional levels of resilience under the multi-hazard assessment will be lower than those presented here, we expect very similar ranking of regions for other hazards as those shown in this current paper. 
Another limitation of the study is that we also did not account for disasterinduced mortality and morbidity, which, despite being non-economic, also have obvious impacts on the welfare and resilience of the affected family members and other people in the community. Furthermore, we excluded from the analysis the long-term welfare impacts, such as poverty traps or intergenerational poverty (Karim \& Noy, 2016; van Den Berg, 2010). Extensions to our current assessment to address the above limitation can be readily undertaken with access to needed data, and this forms part of our future research agenda. 
Appendices 
Table 5-7. Variables, Parameters, Results 107

\begin{tabular}{|c|c|c|c|c|c|c|c|c|c|}
\hline \multirow[b]{2}{*}{ Region } & \multicolumn{9}{|c|}{ Variables and Parameters } \\
\hline & Population & $\begin{array}{c}\text { Poverty } \\
\text { incidence }\end{array}$ & $\begin{array}{c}\text { Average } \\
\text { income in the } \\
\text { region }\end{array}$ & $\begin{array}{c}\text { Average } \\
\text { income of } \\
\text { poor families }\end{array}$ & $\begin{array}{c}\text { Average } \\
\text { income of } \\
\text { non-poor } \\
\text { families }\end{array}$ & $\begin{array}{c}\text { Exposure, } \\
\text { poor family }\end{array}$ & $\begin{array}{c}\text { Exposure, non } \\
\text { poor family }\end{array}$ & $\begin{array}{c}\text { Asset } \\
\text { vulnerability } \\
\text { (poor } \\
\text { families) }\end{array}$ & $\begin{array}{c}\text { Asset } \\
\text { vulnerability } \\
\text { (non-poor } \\
\text { families) }\end{array}$ \\
\hline NCR - National Capital Region & $2,917,149$ & 0.03 & 379 & 113 & 386 & 0.0350 & 0.0280 & 0.1781 & 0.1114 \\
\hline Region IVA - CALABARZON & $3,082,475$ & 0.08 & 284 & 92 & 298 & 0.0226 & 0.0196 & 0.1738 & 0.1191 \\
\hline Region III - Central Luzon & $2,385,869$ & 0.10 & 259 & 99 & 276 & 0.0064 & 0.0060 & 0.1975 & 0.1196 \\
\hline CAR - Cordillera Administrative Region & 375,065 & 0.17 & 257 & 89 & 284 & 0.0050 & 0.0050 & 0.1443 & 0.1152 \\
\hline Region I - llocos Region & $1,104,774$ & 0.14 & 204 & 84 & 223 & 0.0072 & 0.0064 & 0.1823 & 0.1293 \\
\hline Region VI - Western Visayas & 942,539 & 0.21 & 222 & 81 & 259 & 0.0592 & 0.0482 & 0.2704 & 0.1824 \\
\hline Region VII - Central Visayas & $1,278,500$ & 0.21 & 218 & 81 & 254 & 0.0441 & 0.0363 & 0.2261 & 0.1531 \\
\hline Region II - Cagayan Valley & 771,071 & 0.17 & 195 & 86 & 217 & 0.0119 & 0.0105 & 0.1858 & 0.1291 \\
\hline Region XI - Davao Region & $1,077,750$ & 0.25 & 194 & 81 & 230 & 0.0300 & 0.0239 & 0.2426 & 0.1462 \\
\hline Region X - Northern Mindanao & 976,204 & 0.33 & 190 & 76 & 242 & 0.0483 & 0.0395 & 0.1976 & 0.1418 \\
\hline Region XIII - Caraga Region & 531,930 & 0.32 & 180 & 86 & 224 & 0.0350 & 0.0280 & 0.2399 & 0.1689 \\
\hline Region IVB - MIMAROPA & 638,074 & 0.24 & 179 & 76 & 210 & 0.0657 & 0.0534 & 0.3078 & 0.1968 \\
\hline Negros Island Region & 960,545 & 0.31 & 173 & 71 & 222 & 0.0443 & 0.0353 & 0.2693 & 0.1741 \\
\hline Region V - Bicol Region & $1,165,107$ & 0.32 & 162 & 85 & 199 & 0.0435 & 0.0339 & 0.2596 & 0.1692 \\
\hline Region IX - Zamboanga Peninsula & 771,667 & 0.34 & 162 & 74 & 206 & 0.0306 & 0.0245 & 0.2845 & 0.1828 \\
\hline Region VIII - Eastern Visayas & 901,897 & 0.37 & 166 & 75 & 218 & 0.0917 & 0.0706 & 0.2493 & 0.1630 \\
\hline Region XII - SOCCSKARGEN & 987,958 & 0.37 & 163 & 73 & 213 & 0.0183 & 0.0148 & 0.2607 & 0.1621 \\
\hline ARMM - Autonomous Region of Muslim Mindanao & 557,166 & 0.49 & 130 & 96 & 167 & 0.0472 & 0.0349 & 0.2182 & 0.1945 \\
\hline
\end{tabular}

${ }^{107}$ A more detailed presentation of the estimation process can be found in the appendix of the online version of this chapter, located in: https://sites.google.com/site/noyeconomics/research/naturaldisasters 
Continuation of Table 5-7. Variables, Parameters, Results

\begin{tabular}{|c|c|c|c|c|c|}
\hline \multirow[b]{2}{*}{ Region } & \multicolumn{5}{|c|}{ Variables and Parameters } \\
\hline & $\begin{array}{l}\text { Access to early } \\
\text { warning for poor } \\
\text { families }\end{array}$ & $\begin{array}{l}\text { Access to early } \\
\text { warning for non-poor } \\
\text { families }\end{array}$ & $\begin{array}{l}\text { Avoided losses with } \\
\text { early warning system } \\
\text { (EWS) }\end{array}$ & $\begin{array}{l}\text { Social transfers for } \\
\text { poor families }\end{array}$ & $\begin{array}{l}\text { Social transfers for } \\
\text { non-poor families }\end{array}$ \\
\hline NCR - National Capital Region & 0.066174 & 0.237085 & 0.2 & 0.1233 & 0.1467 \\
\hline Region IVA - CALABARZON & 0.056548 & 0.217606 & 0.2 & 0.1056 & 0.2018 \\
\hline Region III - Central Luzon & 0.028142 & 0.154878 & 0.2 & 0.1267 & 0.2243 \\
\hline CAR - Cordillera Administrative Region & 0.045747 & 0.156712 & 0.2 & 0.1231 & 0.1622 \\
\hline Region I - Ilocos Region & 0.028726 & 0.103161 & 0.2 & 0.1346 & 0.2656 \\
\hline Region VI - Western Visayas & 0.021142 & 0.134344 & 0.2 & 0.1579 & 0.2838 \\
\hline Region VII - Central Visayas & 0.060833 & 0.177022 & 0.2 & 0.1348 & 0.2312 \\
\hline Region II - Cagayan Valley & 0.030700 & 0.078110 & 0.2 & 0.0979 & 0.1611 \\
\hline Region XI - Davao Region & 0.092403 & 0.184171 & 0.2 & 0.1036 & 0.1568 \\
\hline Region X - Northern Mindanao & 0.046791 & 0.188088 & 0.2 & 0.1224 & 0.1639 \\
\hline Region XIII - Caraga Region & 0.081892 & 0.154434 & 0.2 & 0.1535 & 0.1953 \\
\hline Region IVB - MIMAROPA & 0.090333 & 0.133815 & 0.2 & 0.1574 & 0.1996 \\
\hline Negros Island Region & 0.081523 & 0.182859 & 0.2 & 0.1380 & 0.2408 \\
\hline Region V - Bicol Region & 0.073916 & 0.137342 & 0.2 & 0.1939 & 0.1998 \\
\hline Region IX - Zamboanga Peninsula & 0.121129 & 0.174615 & 0.2 & 0.1846 & 0.1802 \\
\hline Region VIII - Eastern Visayas & 0.049552 & 0.154824 & 0.2 & 0.1571 & 0.2097 \\
\hline Region XII - SOCCSKARGEN & 0.087492 & 0.176603 & 0.2 & 0.1221 & 0.1710 \\
\hline ARMM - Autonomous Region of Muslim Mindanao & 0.069146 & 0.093597 & 0.2 & 0.0629 & 0.0871 \\
\hline
\end{tabular}


Continuation of Table 5-7. Variables, Parameters, Results

\begin{tabular}{|c|c|c|c|c|c|c|c|}
\hline \multirow[b]{2}{*}{ Region } & \multicolumn{7}{|c|}{ Varaiables and Parameters } \\
\hline & $\begin{array}{c}\text { Effective scale } \\
\text { up for poor } \\
\text { families }\end{array}$ & $\begin{array}{c}\text { Effective scale } \\
\text { up for non- } \\
\text { poor families }\end{array}$ & $\begin{array}{l}\text { Time to } \\
\text { reconstruct }\end{array}$ & Discount rate & $\begin{array}{c}\text { Average } \\
\text { Productivity } \\
\text { of capital }\end{array}$ & $\begin{array}{c}\text { Elasticity of } \\
\text { utility }\end{array}$ & $\begin{array}{c}\text { Hazard } \\
\text { (protection) }\end{array}$ \\
\hline NCR - National Capital Region & 0.05 & 0.05 & 3 & 0.15 & 0.32 & 1.5 & 7.67 \\
\hline Region IVA - CALABARZON & 0.05 & 0.05 & 3 & 0.15 & 0.32 & 1.5 & 10.82 \\
\hline Region III - Central Luzon & 0.05 & 0.05 & 3 & 0.15 & 0.32 & 1.5 & 8.13 \\
\hline CAR - Cordillera Administrative Region & 0.05 & 0.05 & 3 & 0.15 & 0.32 & 1.5 & 7.63 \\
\hline Region I - Ilocos Region & 0.05 & 0.05 & 3 & 0.15 & 0.32 & 1.5 & 23.65 \\
\hline Region VI - Western Visayas & 0.05 & 0.05 & 3 & 0.15 & 0.32 & 1.5 & 8.18 \\
\hline Region VII - Central Visayas & 0.05 & 0.05 & 3 & 0.15 & 0.32 & 1.5 & 6.52 \\
\hline Region II - Cagayan Valley & 0.05 & 0.05 & 3 & 0.15 & 0.32 & 1.5 & 10.26 \\
\hline Region XI - Davao Region & 0.05 & 0.05 & 3 & 0.15 & 0.32 & 1.5 & 6.51 \\
\hline Region X - Northern Mindanao & 0.05 & 0.05 & 3 & 0.15 & 0.32 & 1.5 & 7.86 \\
\hline Region XIII - Caraga Region & 0.05 & 0.05 & 3 & 0.15 & 0.32 & 1.5 & 7.91 \\
\hline Region IVB - MIMAROPA & 0.05 & 0.05 & 3 & 0.15 & 0.32 & 1.5 & 6.64 \\
\hline Negros Island Region & 0.05 & 0.05 & 3 & 0.15 & 0.32 & 1.5 & 11.85 \\
\hline Region V - Bicol Region & 0.05 & 0.05 & 3 & 0.15 & 0.32 & 1.5 & 9.42 \\
\hline Region IX - Zamboanga Peninsula & 0.05 & 0.05 & 3 & 0.15 & 0.32 & 1.5 & 11.11 \\
\hline Region VIII - Eastern Visayas & 0.05 & 0.05 & 3 & 0.15 & 0.32 & 1.5 & 6.56 \\
\hline Region XII - SOCCSKARGEN & 0.05 & 0.05 & 3 & 0.15 & 0.32 & 1.5 & 9.27 \\
\hline ARMM - Autonomous Region of Muslim Mindanao & 0.05 & 0.05 & 3 & 0.15 & 0.32 & 1.5 & 7.78 \\
\hline
\end{tabular}


Continuation of Table 5-7. Variables, Parameters, Results

\begin{tabular}{|c|c|c|c|c|c|c|c|c|c|c|}
\hline \multirow[b]{2}{*}{ Region } & \multicolumn{10}{|c|}{ Key Results } \\
\hline & $\begin{array}{c}\text { Average asset } \\
\text { losses per family } \\
\text { in the event of a } \\
\text { flood disaster }\end{array}$ & $\begin{array}{l}\text { Average welfare } \\
\text { losses in the } \\
\text { event of a flood } \\
\text { disaster }\end{array}$ & \begin{tabular}{|c|} 
Average \\
consumption \\
losses in the \\
event of a flood \\
disaster, poor \\
family \\
\end{tabular} & $\begin{array}{c}\text { Average } \\
\text { consumption } \\
\text { losses in the } \\
\text { event of a flood } \\
\text { disaster, non- } \\
\text { poor family } \\
\end{array}$ & $\begin{array}{c}\text { Average asset } \\
\text { losses across } \\
\text { familes in the } \\
\text { event of a flood } \\
\text { disaster }\end{array}$ & $\begin{array}{c}\text { Expected welfare } \\
\text { losses per capita } \\
\text { due to natural } \\
\text { flood disasters }\end{array}$ & $\begin{array}{l}\text { Total expected } \\
\text { welfare losses } \\
\text { due to natural } \\
\text { flood disasters }\end{array}$ & Welfare risk & Resilience & Risk to assets \\
\hline NCR - National Capital Region & 3.55262199 & 0.0000347 & 52 & \begin{tabular}{|r|}
105 \\
\end{tabular} & $1,351,895$ & 0.2804 & 817,844 & 0.07 & 165.30 & 0.12 \\
\hline Region IVA - CALABARZON & 2.00671471 & 0.0000325 & 42 & 81 & 571,605 & 0.1857 & 572,291 & 0.07 & 99.88 & 0.07 \\
\hline Region III - Central Luzon & 0.57948246 & 0.0000107 & 51 & 74 & 170,033 & 0.0812 & 193,742 & 0.03 & 87.76 & 0.03 \\
\hline CAR - Cordillera Administrative Region & 0.44313032 & 0.0000086 & 33 & 79 & 21,788 & 0.0701 & 26,282 & 0.03 & 82.90 & 0.02 \\
\hline Region I - Ilocos Region & 0.53193969 & 0.0000141 & 39 & 62 & 24,846 & 0.0370 & 40,830 & 0.02 & 60.85 & 0.01 \\
\hline Region VI - Western Visayas & 6.32394142 & 0.0001697 & 55 & 100 & 729,112 & 1.2837 & $1,209,915$ & 0.58 & 60.26 & 0.35 \\
\hline Region VII - Central Visayas & 3.87822225 & 0.0001063 & 47 & 87 & 761,057 & 1.0096 & $1,290,757$ & 0.46 & 58.96 & 0.27 \\
\hline Region II - Cagayan Valley & 0.84875275 & 0.0000246 & 43 & 69 & 63,803 & 0.1486 & 114,605 & 0.08 & 55.67 & 0.04 \\
\hline Region XI - Davao Region & 2.26535344 & 0.0000781 & 51 & 82 & 375,036 & 0.7418 & 799,527 & 0.38 & 46.91 & 0.18 \\
\hline Region X - Northern Mindanao & 3.47952497 & 0.0001251 & 39 & 83 & 432,003 & 0.9839 & 960,454 & 0.52 & 44.98 & 0.23 \\
\hline Region XIII - Caraga Region & 2.89131957 & 0.0001051 & 51 & 88 & 194,554 & 0.8223 & 437,432 & 0.46 & 44.48 & 0.20 \\
\hline Region IVB - MIMAROPA & 6.25263047 & 0.0002316 & 58 & 97 & 600,815 & 2.1577 & $1,376,792$ & 1.21 & 43.64 & 0.53 \\
\hline Negros Island Region & 3.64549929 & 0.0001500 & 49 & 85 & 295,504 & 0.7832 & 752,295 & 0.45 & 39.28 & 0.18 \\
\hline Region V - Bicol Region & 3.30526838 & 0.0001382 & 52 & 79 & 408,736 & 0.9070 & $1,056,709$ & 0.56 & 38.68 & 0.22 \\
\hline Region IX - Zamboanga Peninsula & 2.50433115 & 0.0001123 & 50 & 89 & 173,948 & 0.6250 & 482,264 & 0.39 & 36.07 & 0.14 \\
\hline Region VIII - Eastern Visayas & 6.72943599 & 0.0003068 & 47 & 83 & 925,386 & 2.8938 & $2,609,932$ & 1.75 & 35.46 & 0.62 \\
\hline Region XII - SOCCSKARGEN & 1.36481321 & 0.0000648 & 49 & 82 & 145,479 & 0.4323 & 427,113 & 0.27 & 34.06 & 0.09 \\
\hline ARMM - Autonomous Region of Muslim Mindanao & 3.27550490 & 0.0001704 & 58 & 87 & 234,470 & 1.3545 & 754,658 & 1.05 & 31.07 & 0.32 \\
\hline
\end{tabular}




\section{Figure 5-15. Policy Card: National Capital Region}

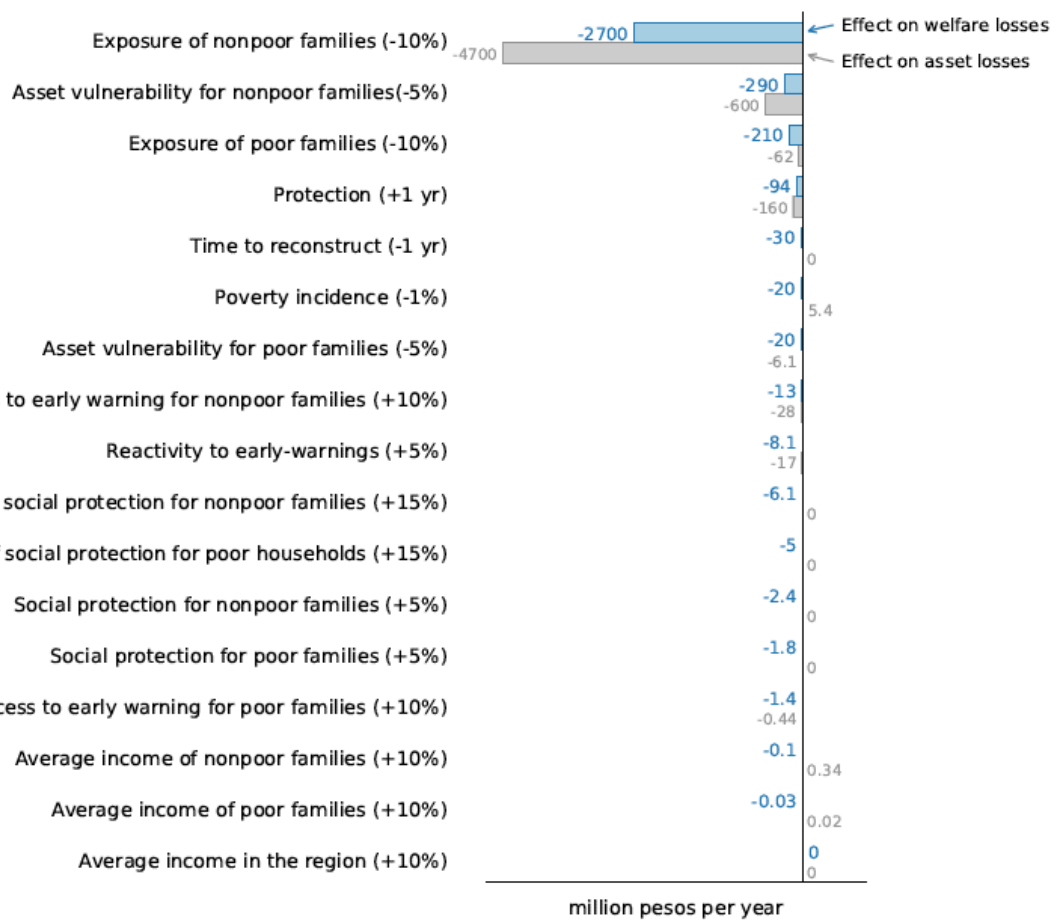

\section{Figure 5-16. Policy Card: Cordillera Administrative Region}

Exposure of nonpoor families $(-10 \%)$

Exposure of poor families (-10\%)

Asset vulnerability for nonpoor families(-5\%)

Protection (+1 yr)

Asset vulnerability for poor families $(-5 \%)$

Time to reconstruct $(-1 \mathrm{yr})$

Scale-up of social protection for poor households $(+15 \%)$

Access to early warning for nonpoor families $(+10 \%)$

Poverty incidence $(-1 \%)$

Access to early warning for poor families $(+10 \%)$

Scale-up of social protection for nonpoor families $(+15 \%)$

Reactivity to early-warnings ( $+5 \%$ )

Social protection for poor families $(+5 \%)$

Social protection for non poor families $(+5 \%)$

Average income of poor families $(+10 \%)$

Average income of nonpoor families $(+10 \%)$

Average income in the region $(+10 \%)$

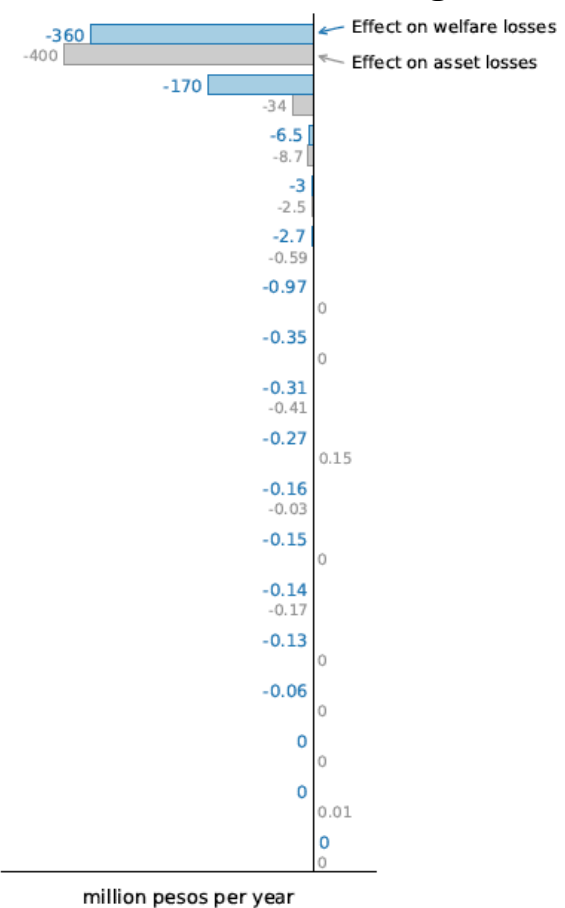


Figure 5-17. Policy Card: Region I - Ilocos Region

Exposure of nonpoor families (-10\%)

Exposure of poor families (-10\%)

Asset vulnerability for nonpoor families(-5\%)

Asset vulnerability for poor families $(-5 \%)$

Protection (+1 yr)

Time to reconstruct $(-1 \mathrm{yr})$

Scale-up of social protection for poor households $(+15 \%)$

Poverty incidence $(-1 \%)$

Access to early warning for nonpoor families $(+10 \%)$

Social protection for poor families $(+5 \%)$

Access to early warning for poor families $(+10 \%)$

Scale-up of social protection for nonpoor families (+15\%)

Reactivity to early-warnings ( $+5 \%$ )

Social protection for non poor families $(+5 \%)$

Average income of poor families $(+10 \%)$

Average income of nonpoor families $(+10 \%)$

Average income in the region $(+10 \%)$

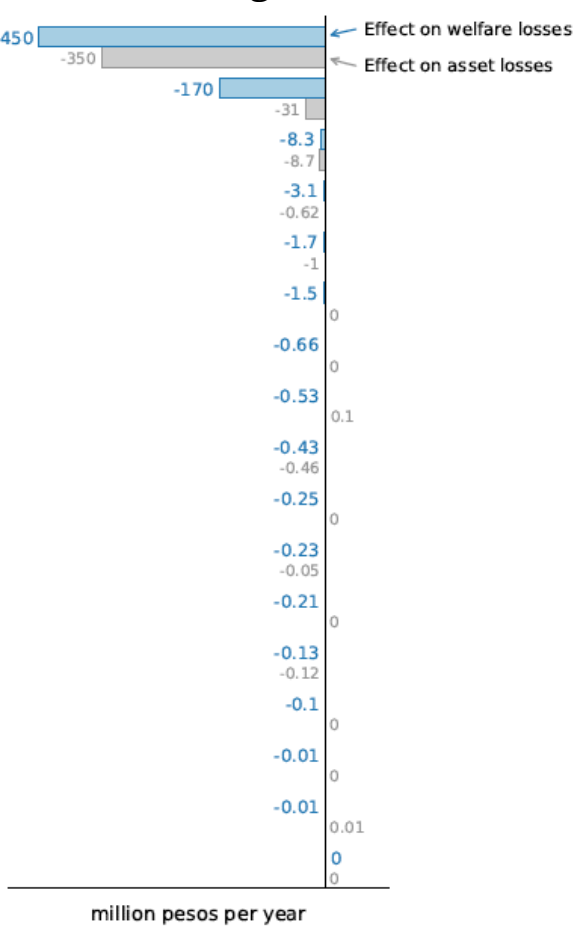

Figure 5-18. Policy Card: Region II - Cagayan Valley

Exposure of nonpoor families (-10\%)

Exposure of poor families (-10\%)

Asset vulnerability for nonpoor families(-5\%)

Asset vulnerability for poor families $(-5 \%)$

Protection (+1 yr)

Time to reconstruct $(-1 \mathrm{yr})$

Scale-up of social protection for poor households $(+15 \%)$

Poverty incidence $(-1 \%)$

Access to early warning for nonpoor families $(+10 \%)$

Social protection for poor families $(+5 \%)$

Access to early warning for poor families $(+10 \%)$

Scale-up of social protection for nonpoor families (+15\%)

Reactivity to early-warnings ( $+5 \%)$

Social protection for non poor families $(+5 \%)$

Average income of poor families $(+10 \%)$

Average income of nonpoor families $(+10 \%)$

Average income in the region $(+10 \%)$

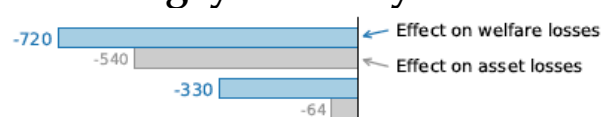

million pesos per year 


\section{Figure 5-19. Policy Card: Region III - Central Luzon}

Exposure of nonpoor families (-10\%)

Exposure of poor families (-10\%)

Asset vulnerability for nonpoor families(-5\%)

Protection (+1 yr)

Asset vulnerability for poor families $(-5 \%)$

Time to reconstruct $(-1 \mathrm{yr})$

Scale-up of social protection for poor households $(+15 \%)$

Poverty incidence $(-1 \%)$

Access to early warning for nonpoor families $(+10 \%)$

Social protection for poor families $(+5 \%)$

Scale-up of social protection for nonpoor families $(+15 \%)$

Reactivity to early-warnings ( $+5 \%$ )

Access to early warning for poor families $(+10 \%)$

Social protection for non poor families $(+5 \%)$

Average income of nonpoor families $(+10 \%)$

Average income of poor families $(+10 \%)$

Average income in the region $(+10 \%)$

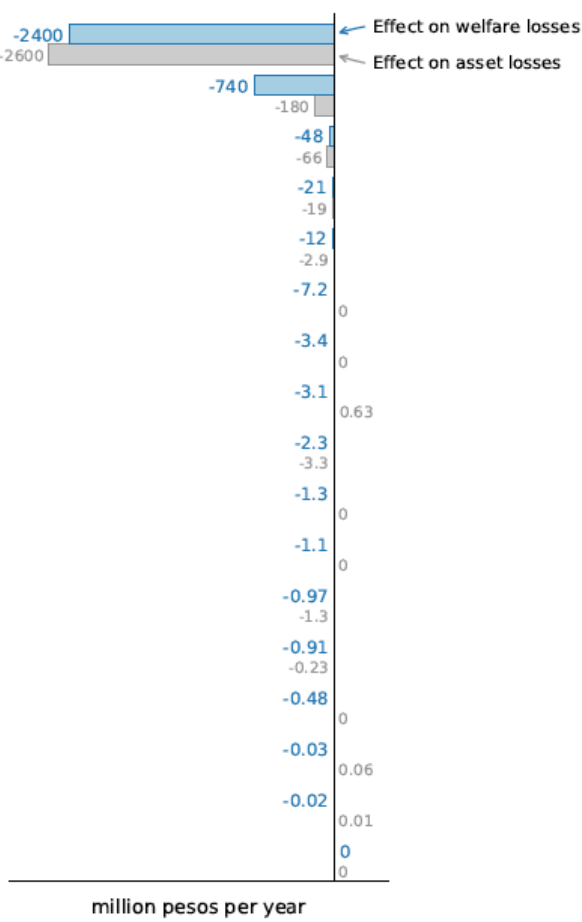

\section{Figure 5-20. Policy Card: Region IVA - CALABARZON}

Exposure of nonpoor families (-10\%)

Exposure of poor families (-10\%)

Asset vulnerability for nonpoor families(-5\%)

Protection (+1 yr)

Asset vulnerability for poor families $(-5 \%)$

Time to reconstruct $(-1 \mathrm{yr})$

Poverty incidence (-1\%)

Scale-up of social protection for poor households (+15\%)

Access to early warning for nonpoor families $(+10 \%)$ Reactivity to early-warnings ( $+5 \%$ ) Scale-up of social protection for nonpoor families (+15\%) Social protection for poor families $(+5 \%)$ Access to early warning for poor families $(+10 \%)$ Social protection for non poor families $(+5 \%)$ Average income of nonpoor families (+10\%) Average income of poor families $(+10 \%)$ Average income in the region $(+10 \%)$ 
Figure 5-21. Policy Card: Region IVB - MIMAROPA

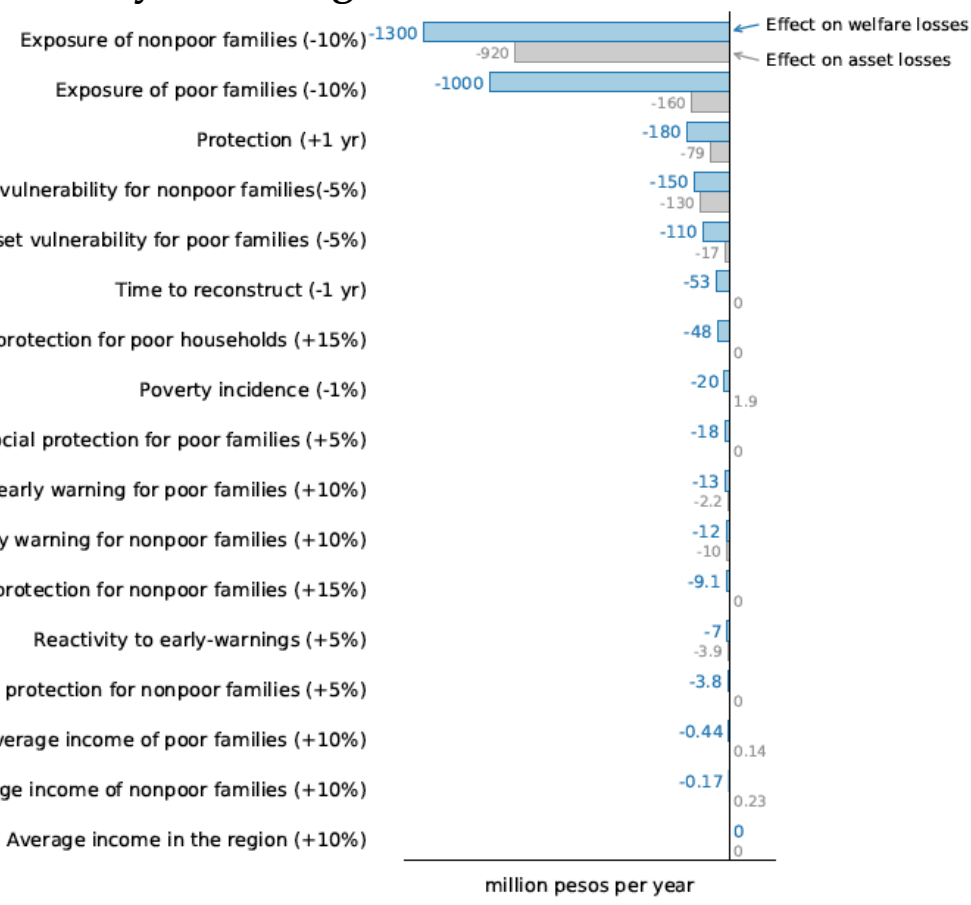

Scale-up of social protection for poor households $(+15 \%)$

Poverty incidence $(-1 \%)$

Social protection for poor families $(+5 \%)$

Access to early warning for poor families $(+10 \%)$

Access to early warning for nonpoor families $(+10 \%)$

Scale-up of social protection for nonpoor families $(+15 \%)$

Reactivity to early-warnings $(+5 \%)$

Social protection for non poor families $(+5 \%)$

Average income of poor families $(+10 \%)$

Average income of nonpoor families $(+10 \%)$

Average income in the region $(+10 \%)$

million pesos per year

\section{Figure 5-22. Policy Card: Region V - Bicol Region}

Exposure of poor families (-10\%) Exposure of nonpoor families (-10\%) Asset vulnerability for poor families (-5\%) Asset vulnerability for nonpoor families(-5\%) Protection (+1 yr)

Time to reconstruct $(-1 \mathrm{yr})$ Scale-up of social protection for poor households $(+15 \%)$ Social protection for poor families $(+5 \%)$ Poverty incidence $(-1 \%)$

Access to early warning for poor families $(+10 \%)$ Access to early warning for nonpoor families $(+10 \%)$ Scale-up of social protection for nonpoor families $(+15 \%)$ Reactivity to early-warnings ( $+5 \%$ ) Social protection for nonpoor families $(+5 \%)$

Average income of poor families $(+10 \%)$ Average income of nonpoor families $(+10 \%)$ Average income in the region $(+10 \%)$

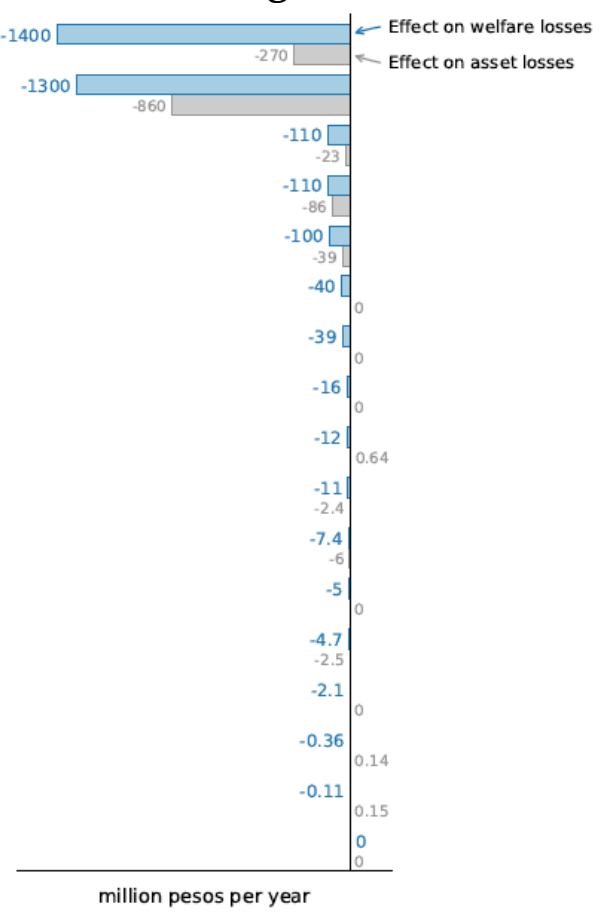




\section{Figure 5-23. Policy Card: Region VI - Western Visayas}

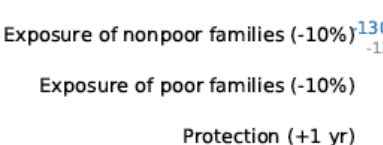

Asset vulnerability for nonpoor families(-5\%)

Asset vulnerability for poor families $(-5 \%)$

Time to reconstruct $(-1 \mathrm{yr})$

Scale-up of social protection for poor households $(+15 \%)$

Poverty incidence $(-1 \%)$

Social protection for poor families $(+5 \%)$

Access to early warning for poor families $(+10 \%)$

Access to early warning for nonpoor families $(+10 \%)$

Scale-up of social protection for nonpoor families $(+15 \%)$

Reactivity to early-warnings ( $+5 \%)$

Social protection for non poor families $(+5 \%)$

Average income of poor families $(+10 \%)$

Average income of nonpoor families $(+10 \%)$

Average income in the region $(+10 \%)$

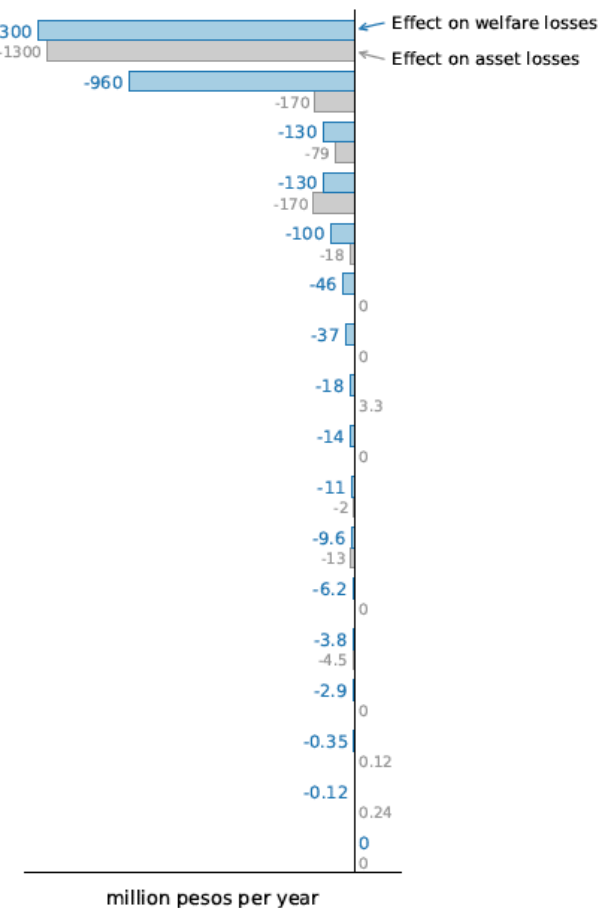

\section{Figure 5-24. Policy Card: Negros Island Region}

Exposure of poor families (-10\%) Exposure of nonpoor families (-10\%)

Asset vulnerability for poor families $(-5 \%)$ Asset vulnerability for nonpoor families(-5\%)

Protection (+1 yr)

Scale-up of social protection for poor households $(+15 \%)$

Time to reconstruct $(-1 \mathrm{yr})$

Social protection for poor families $(+5 \%)$

Poverty incidence $(-1 \%)$

Access to early warning for poor families $(+10 \%)$

Access to early warning for nonpoor families $(+10 \%)$

Reactivity to early-warnings ( $+5 \%$ )

Scale-up of social protection for nonpoor families (+15\%)

Social protection for non poor families $(+5 \%)$

Average income of poor families $(+10 \%)$

Average income of nonpoor families $(+10 \%)$

Average income in the region $(+10 \%)$

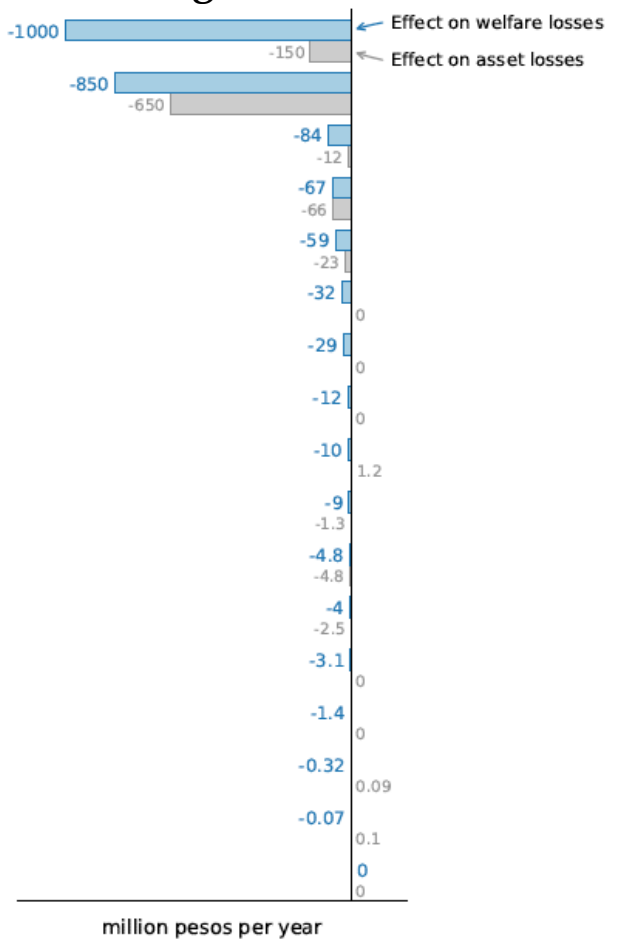




\section{Figure 5-25. Policy Card: Region VII - Central Visayas}

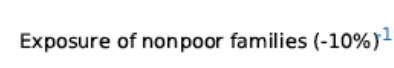

Exposure of poor families (-10\%)

Asset vulnerability for nonpoor families(-5\%)

Protection (+1 yr)

Asset vulnerability for poor families $(-5 \%)$

Time to reconstruct (-1 yr)

Scale-up of social protection for poor households $(+15 \%)$

Poverty incidence $(-1 \%)$

Social protection for poor families $(+5 \%)$

Access to early warning for poor families $(+10 \%)$

Access to early warning for nonpoor families $(+10 \%)$

Reactivity to early-warnings ( $+5 \%$ )

Scale-up of social protection for nonpoor families (+15\%)

Social protection for nonpoor families $(+5 \%)$

Average income of poor families $(+10 \%)$

Average income of nonpoor families $(+10 \%)$

Average income in the region $(+10 \%)$

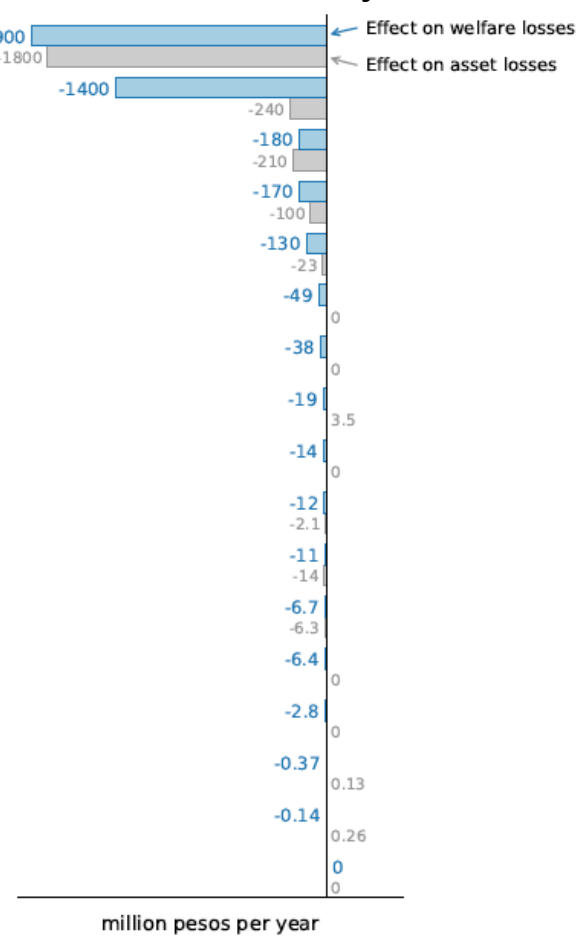

\section{Figure 5-26. Policy Card: Region VIII - Eastern Visayas}

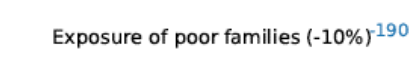

Exposure of nonpoor families (-10\%)

$$
\text { Protection (+1 yr) }
$$

Asset vulnerability for poor families $(-5 \%)$

Asset vulnerability for nonpoor families(-5\%)

Scale-up of social protection for poor households (+15\%)

Time to reconstruct $(-1 \mathrm{yr})$

Social protection for poor families $(+5 \%)$

Access to early warning for poor families (+10\%)

Poverty incidence $(-1 \%)$

Access to early warning for nonpoor families $(+10 \%)$

Reactivity to early-warnings ( $+5 \%)$

Scale-up of social protection for nonpoor families $(+15 \%)$

Social protection for non poor families $(+5 \%)$

Average income of poor families $(+10 \%)$

Average income of nonpoor families $(+10 \%)$

Average income in the region $(+10 \%)$

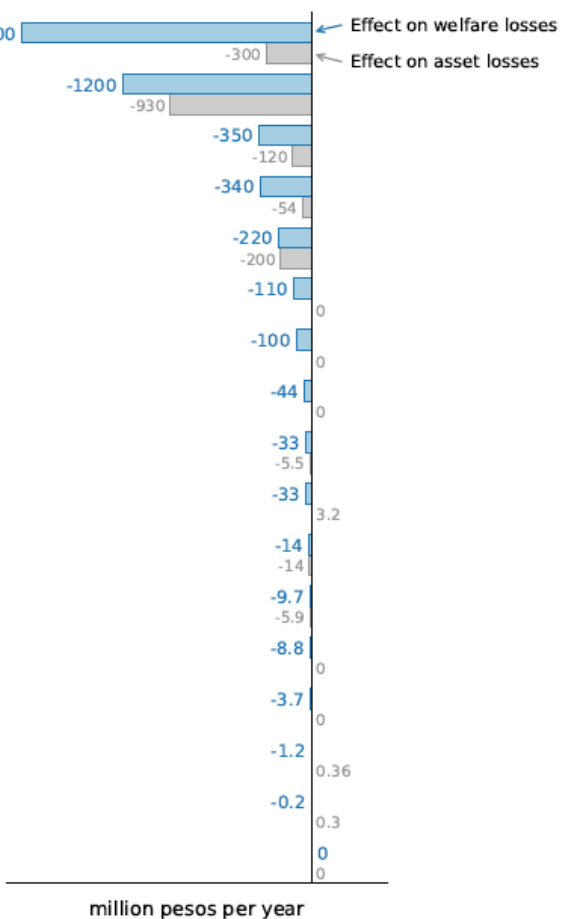


Figure 5-27. Policy Card: Region IX - Zamboanga Peninsula

Exposure of poor families $(-10 \%)^{-9}$

Exposure of nonpoor families (-10\%)

Asset vulnerability for poor families (-5\%)

Asset vulnerability for nonpoor families(-5\%)

Protection (+1 yr)

Scale-up of social protection for poor households $(+15 \%)$

Time to reconstruct (-1 yr)

Social protection for poor families $(+5 \%)$

Poverty incidence $(-1 \%)$

Access to early warning for poor families $(+10 \%)$

Access to early warning for nonpoor families (+10\%)

Reactivity to early-warnings ( $+5 \%$ )

Scale-up of social protection for nonpoor families $(+15 \%)$

Social protection for nonpoor families $(+5 \%)$

Average income of poor families $(+10 \%)$

Average income of nonpoor families $(+10 \%)$

Average income in the region $(+10 \%)$

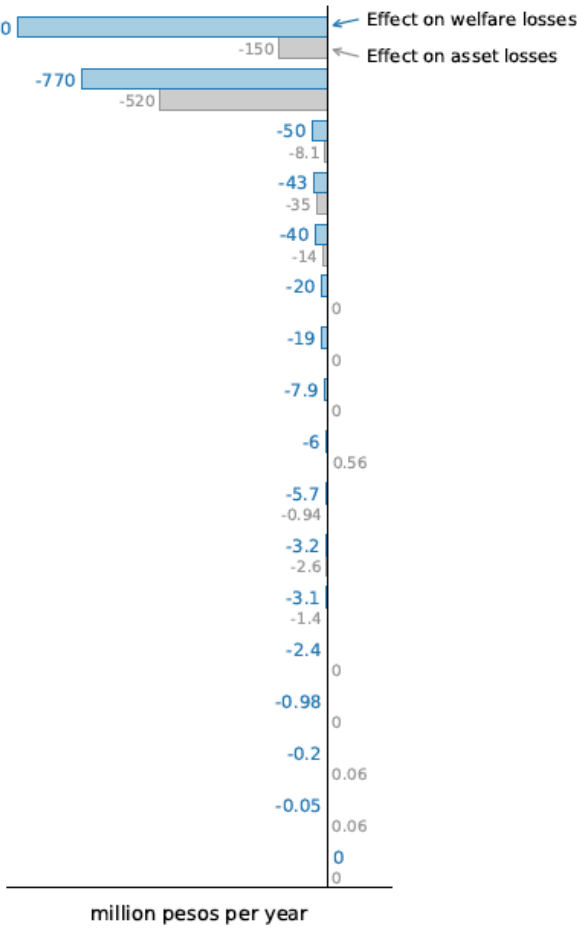

Figure 5-28. Policy Card: Region X- Northern Mindanao

Exposure of poor families $(-10 \%)^{200}$

Exposure of nonpoor families (-10\%)

Asset vulnerability for poor families (-5\%)

Asset vulnerability for nonpoor families(-5\%)

Protection (+1 yr)

Time to reconstruct $(-1 \mathrm{yr})$

Scale-up of social protection for poor households $(+15 \%)$

Social protection for poor families $(+5 \%)$

Poverty incidence $(-1 \%)$

Access to early warning for poor families $(+10 \%)$

Access to early warning for nonpoor families $(+10 \%)$

Reactivity to early-warnings ( $+5 \%$ )

Scale-up of social protection for nonpoor families $(+15 \%)$

Social protection for nonpoor families $(+5 \%)$

Average income of poor families $(+10 \%)$

Average income of nonpoor families $(+10 \%)$

Average income in the region $(+10 \%)$

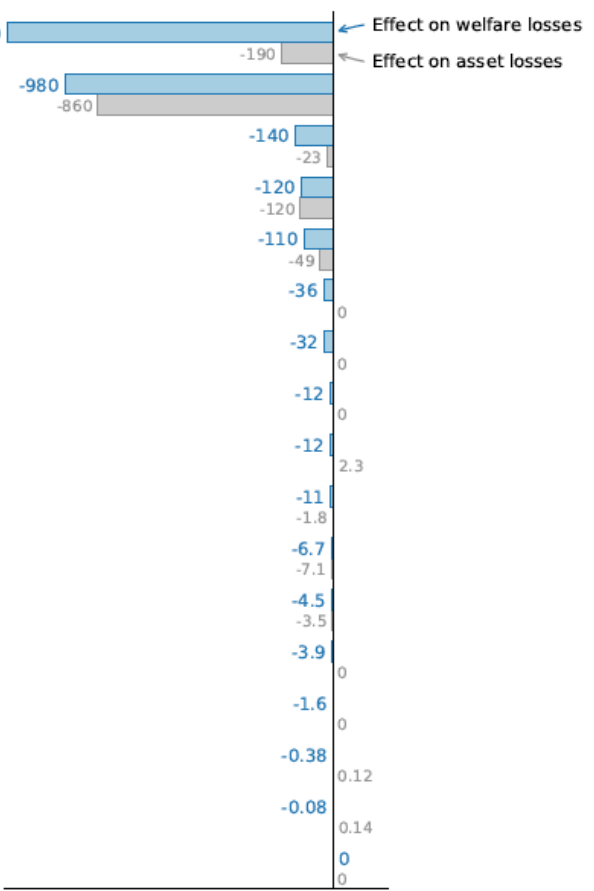

million pesos per year 


\section{Figure 5-29. Policy Card: Region XI - Davao Region}

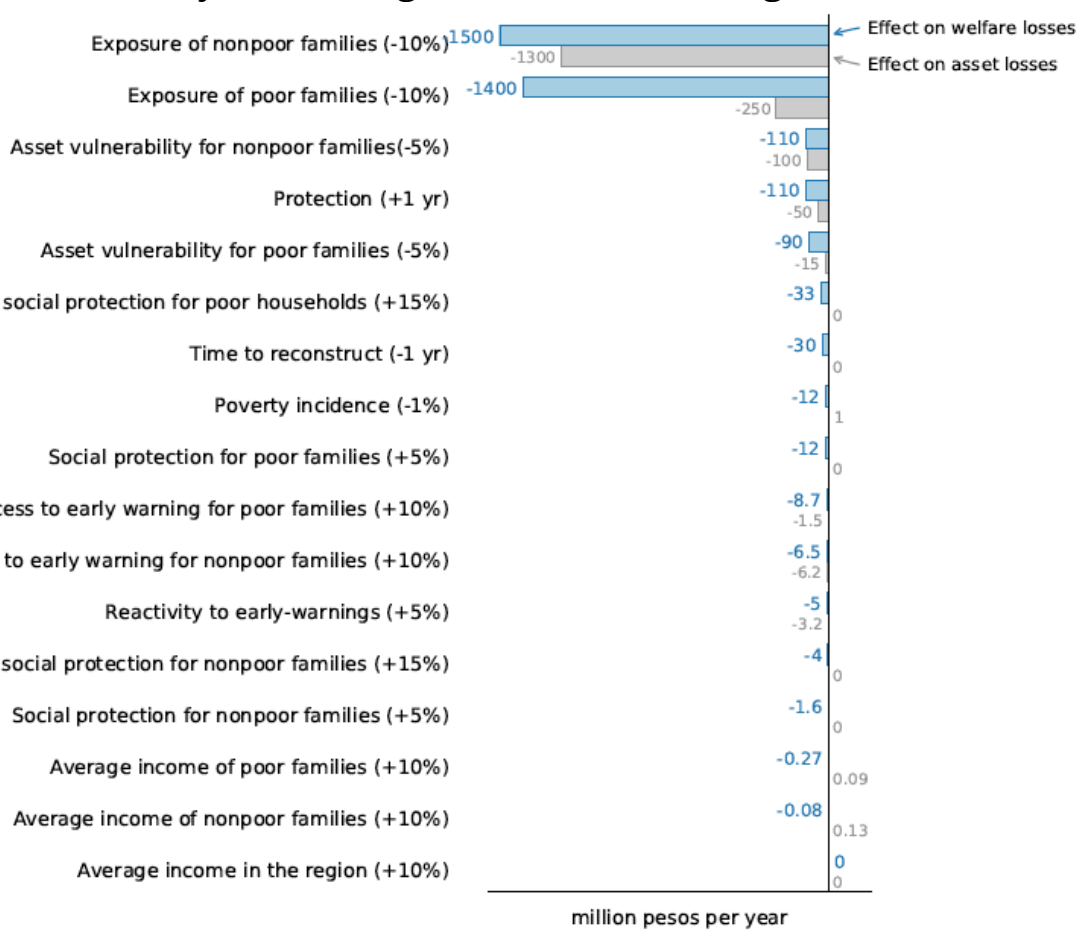

\section{Figure 5-30. Policy Card: Region XII - SOCCSAKARGEN}

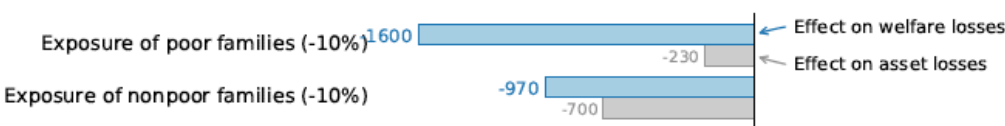

Asset vulnerability for poor families $(-5 \%)$

$$
\text { Protection (+1 yr) }
$$

Asset vulnerability for nonpoor families(-5\%)

Scale-up of social protection for poor households (+15\%)

Time to reconstruct $(-1 \mathrm{yr})$

Social protection for poor families $(+5 \%)$

Access to early warning for poor families $(+10 \%)$

Poverty incidence $(-1 \%)$

Access to early warning for nonpoor families $(+10 \%)$

Reactivity to early-warnings ( $+5 \%$ )

Scale-up of social protection for nonpoor families (+15\%)

Social protection for non poor families $(+5 \%)$

Average income of poor families $(+10 \%)$

Average income of nonpoor families $(+10 \%)$

Average income in the region $(+10 \%)$

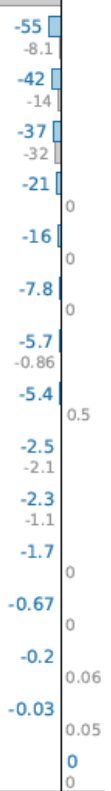

million pesos per year 
Figure 5-31. Policy Card: Region XIII - CARAGA Region

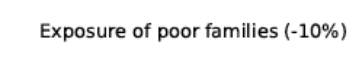

Exposure of nonpoor families (-10\%)

Asset vulnerability for poor families $(-5 \%)$

Protection (+1 yr)

Asset vulnerability for nonpoor families(-5\%)

Time to reconstruct (-1 yr)

Scale-up of social protection for poor households $(+15 \%)$

Social protection for poor families $(+5 \%)$

Poverty incidence $(-1 \%)$

Access to early warning for poor families $(+10 \%)$

Access to early warning for nonpoor families $(+10 \%)$

Reactivity to early-warnings ( $+5 \%$ )

Scale-up of social protection for nonpoor families $(+15 \%)$

Social protection for non poor families $(+5 \%)$

Average income of poor families $(+10 \%)$

Average income of nonpoor families $(+10 \%)$

Average income in the region $(+10 \%)$

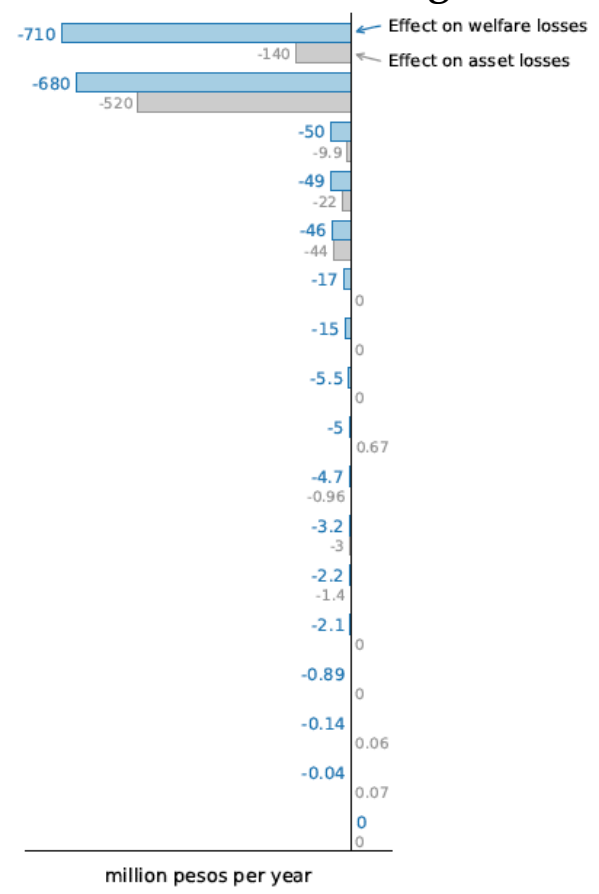

Figure 5-32. Policy Card: ARMM - Autonomous Region of Muslim Mindanao

$$
\begin{aligned}
& \text { Exposure of poor families }(-10 \%) \\
& \text { Exposure of nonpoor families }(-10 \%)
\end{aligned}
$$

Asset vulnerability for poor families $(-5 \%)$

Protection $(+1 \mathrm{yr})$

Asset vulnerability for nonpoor families $(-5 \%)$

Time to reconstruct $(-1 \mathrm{yr})$

Scale-up of social protection for poor households $(+15 \%)$

Access to early warning for poor families $(+10 \%)$

Social protection for poor families $(+5 \%)$

Poverty incidence $(-1 \%)$

Access to early warning for nonpoor families $(+10 \%)$

Scale-up of social protection for nonpoor families (+15\%)

Reactivity to early-warnings ( $+5 \%$ )

Social protection for non poor families $(+5 \%)$

Average income of poor families $(+10 \%)$

Average income of nonpoor families $(+10 \%)$

Average income in the region $(+10 \%)$

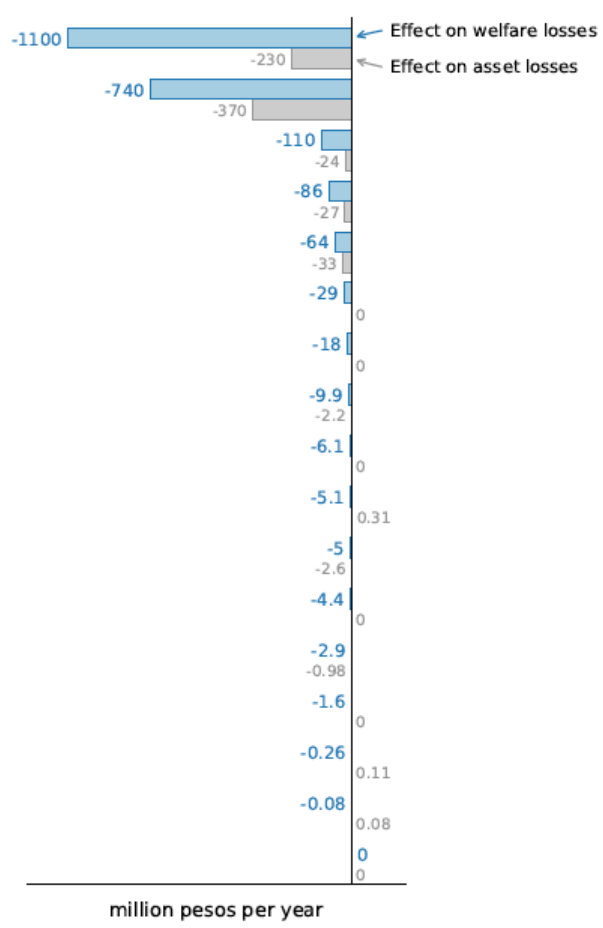




\section{Chapter 6}

\section{Conclusion}

This thesis is an endeavour to measure disaster risk and impacts, and identify the socio-economic, as well as demographic, geographic, and physical factors affecting vulnerability and resilience. In general, economic vulnerability and economic resilience, interacting with the hazard and the exposure of populations, assets, and economic systems are considered critical determinants of the disaster risk and resulting disaster impacts.

The goal of this endeavour is to produce research outputs that can be readily applied for policy decisions. The findings and implications of the empirical studies are summarized below. 


\subsection{Determinants of Tropical Cyclone Fatalities}

The results of the assessment in Chapter 3 provide strong quantitative evidence of the linkage between several aspects of development and disaster-related fatalities, even in a country where tropical cyclone exposure is high. Economic and social development, as well as good local governance reduce disaster fatalities, while unplanned urbanization is associated with more fatalities.

A province's level of economic development, as proxied by income per capita, is negatively associated with fatalities. This indicates that higher income allows people to secure themselves from harm. In contrast, poverty, which is positively associated with fatalities, is a manifestation of people's lack of access to safe shelters and from settlements in hazard-free areas. Poverty also forces people to forgo investments in human capital, particularly health and education, which are likewise critical in building people's capacity to survive cyclones.

Good local governance is associated with fewer disaster-related fatalities. Increased effectiveness in generating local revenues means increased ability to provide public goods and services, including the provision of services for public safety (such as early warning systems), as well as access to universal public basic education, and expanded and better quality public health services, particularly among the poor.

The positive and statistically significant coefficient for built-up density on disaster fatalities indicate that amidst unplanned and rapid urbanization, vulnerabilities are generated and exposure to hazards increased. This finding points to the need for better land use planning that integrates DRRM, along with intensified enforcement of these plans and related laws and systems, such as zoning ordinances, water code, building code, and 
forestry code, as well as weather forecasting and monitoring, and early warning systems.

Exposure, topography, and tropical cyclone strength are likewise important determinants of fatalities. Crucially, tropical cyclone fatalities appear to be influenced much more by socioeconomic vulnerability and exposure, than by the hazard itself. For instance, the effect of poverty incidence on fatalities is almost three times that of rainfall volume.

\subsection{Relationship of Floods and Diseases in Urban Areas}

The results in Chapter 4 provide evidence of the positive and significant association between floods and 11 of the 13 diseases covered in the analysis. Flood exposure has a positive and statistically significant influence on bronchitis, respiratory tract infection, chicken pox, measles, typhoid fever, diarrhoea, leptospirosis, dengue, hypertension, and heart diseases. Flood height is positively associated with bronchitis, influenza, and leptospirosis; and, flood duration with bronchitis, influenza, and typhoid fever. However, there is no evidence of such association between any of these flood-related variables and either tuberculosis or malaria.

Spatial analysis shows that the density of diseases varies across areas. This suggests that flood exposure and flood characteristics combine together with area-specific socioeconomic conditions that may generate different incidence of diseases.

The analysis of the cost of disease to households relative to their average income suggests some important implications for household well-being. Households below or just above the poverty line have no means to smooth consumption, and may need to forego other needs (such as education) to prioritize their food needs and afford the medical expenses. Among those already in subsistence poverty, their subsequent attempts to smooth 
consumption and provide for the medical needs of sick members, may be financed by borrowing and selling of productive assets. These dynamics may eventually make them extremely poor, or even fall into a poverty trap. Among the non-poor, the combined consequences of foregone earnings and out-of-pocket medical costs may cause some of them to fall into poverty.

These estimates can serve as an initial reference for the evaluation of the costs and benefits of alternative measures to avert disaster-induced diseases. Further, these may also serve as useful inputs for discussions on the expansion and/or redesign of the current social welfare program and social health insurance, and other policies aimed at ensuring people's safety from disasters, diseases, and poverty.

\subsection{Resilience of Regions to Riverine Floods}

The assessment in Chapter 5 demonstrates the importance of socioeconomic resilience to minimize the microeconomic welfare impacts that result from macroeconomic asset losses. The assessment uses the estimates for welfare losses and asset losses to come up with a quantified measure of resilience to disasters. Together, these quantified impacts enable the prioritization of policy alternatives depending on the main region-specific factors that drive asset and welfare losses.

Results show that Region I has the lowest estimated asset risk and welfare risk, due to high hazard protection level, low exposure, and poverty incidence. At the opposite end is Region VIII due to high exposure both among the poor and non-poor families, high poverty incidence, and low protection level. Meanwhile, the NCR is the most resilient, while ARMM is the least resilient. The findings about these latter two regions best demonstrates the importance of risk sharing and income diversification 
through social transfer and public post-disaster support to minimize or avoid adverse impacts of disasters on welfare.

The categorization of regions based on estimated resilience, and estimated welfare risk suggest that Regions $\mathrm{V}$ and VIII, and ARMM may be considered as the top priority in terms of allocation of national public resources for strengthening disaster resilience to minimize the impacts of flood disasters on welfare. On the other hand, NCR, CAR, and Regions I, III, and IV-A may be given the lowest level of priority. The prioritization of regions based on estimated resilience and welfare risk can be useful for national development planning given the imperative to allocate resources efficiently at various subnational levels amidst the limits of the country's fiscal resources to fund its many development needs.

The policy experiment within each region and the comparison of results across regions reveal evident similarities in the ranking of policies among regions with comparable levels of resilience and welfare risk. Nonetheless, the ranking of priorities varies for different regions. Not surprisingly, for a majority of the policy alternatives, it is Region VIII that is expected to benefit the most. Apart from being one of the socioeconomically disadvantaged, it is also one of the regions that experienced some of the worst disaster impacts in recent decades. Overall, the results indicate that reduction of adverse disaster impacts, including welfare losses, and reduction of poverty are generally complementary development agenda. Thus, this suggests the need to ensure an integrated approach in addressing poverty and economic disaster welfare risk. The policy card per region may serve as a tool to track regional level progress and as a menu of policy options prioritized according to their effectiveness in reducing asset and welfare risk, and increasing resilience per region. The prioritized policy options can be used as guide for investment programming and budgeting. 


\section{References}

Abon, C. C., David, C. P. C., \& Pellejera, N. E. B. (2011). Reconstructing the Tropical Storm Ketsana flood event in Marikina River, Philippines. Hydrol. Earth Syst. Sci., 15(4), 1283-1289. doi:10.5194/hess-15-12832011

ADB. (2009a). Poverty in the Philippines: causes, constraints and opportunities. Asian Development Bank. Mandaluyong City, Philippines.

ADB. (2009b). Poverty in the Philippines: Causes, Constraints, and Opportunities. Mandaluyong City, Philippines: Asian Development Bank.

ADB. (2014). Republic of the Philippines National Urban Assessment. Mandaluyong City, Philippines: Asia Development Bank.

ADB (Ed.) (2007). Philippines: Critical Development Constraints. Metro Manila, Philippines: Asian Development Bank.

Adger, W. N. (1999). Social Vulnerability to Climate Change and Extremes in Coastal Vietnam. World Development, 27(2), 249-269. doi:http://dx.doi.org/10.1016/S0305-750X(98)00136-3

Ahern, M., Kovats, R. S., Wilkinson, P., Few, R., \& Matthies, F. (2005). Global Health Impacts of Floods: Epidemiologic Evidence. Epidemiologic Reviews, 27(1), 36-46. doi:10.1093/epirev/mxi004

Albala-Bertrand, J. M. (1993). Political Economy of Large Disasters. Oxford, United Kingdom: Clarendon Press.

Aldrich, D. P. (2015). Social Capital in Post Disaster Recovery: Strong Networks and Communities Create a Resilient East Asian Community. In D. P. Aldrich, S. Oum, \& Y. Sawada (Eds.), Resilience and Recovery in Asian Disasters: Community Ties, Market Mechanisms, and Governance (pp. 19-34). Tokyo: Springer Japan.

Alexander, D. E. (2013). Resilience and disaster risk reduction: an etymological journey. Nat. Hazards Earth Syst. Sci., 13(11), 2707-2716. doi:10.5194/nhess-13-2707-2013

Alwang, J., Siegel, P., \& Jorgensen, S. (2001). Vulnerablity: A View from Different Disciplines. Washington D.C.: The World Bank.

Anbarci, N., Escaleras, M., \& Register, C. A. (2005). Earthquake fatalities: the interaction of nature and political economy. Journal of Public Economics, $89(9-10)$,

1907-1933. doi:http://dx.doi.org/10.1016/j.jpubeco.2004.08.002

Angeon, V., \& Bates, S. (2015). Reviewing Composite Vulnerability and Resilience Indexes: A Sustainable Approach and Application. World Development, 72 , 140-162. doi:http:/ / dx.doi.org/10.1016/j.worlddev.2015.02.011 
Antilla-Hughes, J. K., \& Hsiang, S. M. (2013). Destruction, Disinvestment, and Death: Economic and Human Losses Following Environmental Disaster. University of San Francisco; University of California, Berkeley; National Bureau of Economic Research (NBER). Retrieved from ssrn.com/abstract $=2220501$

Arouri, M., Nguyen, C., \& Youssef, A. B. (2015). Natural Disasters, Household Welfare, and Resilience: Evidence from Rural Vietnam. World Development, 70, 59-77. doi:http:/ / dx.doi.org/10.1016/j.worlddev.2014.12.017

Balisacan, A. M., \& Hall, H. (2006). The Dynamics of Regional Development: The Philippines in East Asia.

Ballesteros, M. M. (2010). Linking Poverty and the Environment: Evidence from Slums in Philippine Cities Philippine Institute for Development Studies Discussion Paper (Vol. 2010-33, pp. 31).

Bankoff, G., Frerks, G., \& Hilhorst, D. (2004). Mapping Vulnerability: Disasters, Development and People. London: Earthscan.

Beccari, B. (2016). A Comparative Analysis of Disaster Risk, Vulnerability and Resilience Composite Indicators. PLoS Currents, 8. doi:doi: 10.1371/currents.dis.453df025e34b682e9737f95070f9b970.

Birkmann, J. (2006). Measuring vulnerability to promote disaster-resilient societies: Conceptual frameworks and definitions. In J. Birkmann (Ed.), Measuring vulnerability to natural hazards :towards disaster resilient societies. New York: United Nations University.

Birkmann, J. (2007). Risk and vulnerability indicators at different scales: Applicability, usefulness and policy implications. Environmental Hazards, 20-31. doi:http:/ / dx.doi.org/10.1016/j.envhaz.2007.04.002

Black, J., Hashimzade, N., \& Myles, G. (2009). Oxford Dictionary of Economics: Oxford University Press.

Blaikie, P., Cannon, T., Davis, I., \& Wisner, B. (1994). At risk : natural hazards, people's vulnerability, and disasters London; New York: Routledge.

BLGF. (2014). Local Government Unit Financial Data: Statement of Income and Expenditure of Provinces, Cities and Municipalities. Retrieved from http:/ / www.blgf.gov.ph/\#

Bohle, H. G. (2001, 2/2001). Vulnerability and Criticality: Perspectives from Social Geography. Newsletter of the International Human Dimensions Programme on Global Environmental Change, pp. 1-7.

Bonds, M. H., Keenan, D. C., Rohani, P., \& Sachs, J. D. (2010). Poverty trap formed by the ecology of infectious diseases Proceedings of the Royal Society B, 277(1685), 1185-1192. doi:10.1098/rspb.2009.1778

Briguglio, L. (2004). Economic vulnerability and resilience: concepts and measurements. In L. Briguglio \& E. J. Kisanga (Eds.), Economic Vulnerability and Resilience of Small States: Malta: Islands and Small 
States Institute of the University of Malta, London: Commonwealth Secretariat.

Briguglio, L., Cordina, G., Farrugia, N., \& Vella, S. (2009). Economic Vulnerability and Resilience: Concepts and Measurements. Oxford Development Studies, 37(3), 229-247.

Briguglio, L., \& Galea, W. (2003). Updating the Economic Vulnerability Index Occasional Chapters on Islands and Small States. Malta: Islands and Small States Institute of the University of Malta.

Bruneau, M., Chang, S. E., Eguchi, R. T., Lee, G. C., O'Rourke, T. D., Reinhorn, A. M., . . . Winterfeldt, D. v. (2003). A Framework to Quantitatively Assess and Enhance the Seismic Resilience of Communities. Earthquake Spectra, 19(4), 733-752. doi:doi:10.1193/1.1623497

BSP. (2014). Economic and Financial Statistics Retrieved from: http://www.bsp.gov.ph/statistics/efs_ext3.asp

Cardona, O., Aalst, M. K. v., Birkmann, J., Fordham, M., McGregor, G., Perez, R., . . Sinh, B. T. (2012). Determinants of risk: exposure and vulnerability Managing the Risk of Extreme Events and Disasters to Advance Climate Change Adaptation. Cambridge University Press, Cambridge UK, and New York, NY, USA: Intergovernmental Panel on Climate Change (IPCC).

Carroll, B., Balogh, R., Morbey, H., \& Araoz, G. (2010). Health and social impacts of a flood disaster: responding to needs and implications for practice. Disasters, 34(4), 1045-1063. doi:10.1111/j.14677717.2010.01182.x

Carter, M. R., Little, P. D., Mogues, T., \& Negatu, W. (2007). Poverty Traps and Natural Disasters in Ethiopia and Honduras. World Development, 35(5),

835-856.

doi:http:/ / dx.doi.org/10.1016/j.worlddev.2006.09.010

Caruso, G., \& Miller, S. (2015). Long run effects and intergenerational transmission of natural disasters: A case study on the 1970 Ancash Earthquake. Journal of development economics, 117, 134-150. doi:http://dx.doi.org/10.1016/j.jdeveco.2015.07.012

Cavallo, E., \& Noy, I. (2011). Natural Disasters and the Economy--A Survey. International Review of Environmental and Resource Economics, 5(1), 63102. doi:http://www.irere.net

Corpuz, A. G. (2013). Land Use Policy Impacts on Human Development in the Philippines. Philippines: UNDP.

Correia, F. N., Santos, M. A., \& Rodrigues, R. R. (1987). Engineering Risk in Regional Drought Studies. In L. Duckstein \& E. Plate (Eds.), Engineering Reliability and Risk in Water Resources (Vol. 124, pp. 6186): Springer Netherlands. 
Cuaresma, J. C., Hlouskova, J., \& Obersteiner, M. (2008). Natural disasters as creative destruction? Evidence from developing countries. Economic Inquiry, 46(2), 214-226.

Cutter, S. L., Barnes, L., Berry, M., Burton, C., Evans, E., Tate, E., \& Webb, J. (2008). A place-based model for understanding community resilience to natural disasters. Global Environmental Change, 18(4), 598-606. doi:http:// dx.doi.org/10.1016/i.gloenvcha.2008.07.013

Cutter, S. L., Boruff, B. J., \& Shirley, W. (2003). Social Vulnerability to Environmental Hazards. Social Science 4, 84(2), 242-261. doi:http://dx.doi.org/10.1111/1540-6237.8402002

Dacy, D. C., \& Kunreuther, H. K. (1969). The Economics of Natural Disasters. New York, United States: Free Press.

Davidson, R., \& Shah, H. (1997). An Urban Earthquake Disaster Risk Index. Stanford: The John A. Blume Earthquake Engineering Center, Department of Civil Engineering.

De Groeve, T., Poljansek, K., \& Vernaccini, L. (2015). Index for Risk Management - INFORM Concepts and Methodology (Version 2015). Luxemberg: Joint Research Center of the European Commission.

Del Ninno, C., Dorosh, P. A., Smith, L. C., \& Roy, D. K. (2001). The 1998 Floods in Bangladesh: Disaster Impacts, Household Coping Strategies, and Response (pp. 134). Washington, D.C.: International Food Policy Research Institute.

DSWD. (2013). DSWD's Modified CCT helps families with special needs survive life's daily grind. Manila Philippines: Department of Social Welfare and Development.

ECLAC, \& WB. (2003). Handbook for Estimating the Socio-Economic and Environmental Effects of Disaster (ECLAC Handbook). Santiago, Chile: United Nations-Economic Commission for Latin America and the Caribbean (UN-ECLAC), International Bank for Reconstruction and Development (The World Bank).

Feenstra, R. C., Inklaar, R., \& Timmer, M. P. (2015). The Next Generation of the Penn World Table. American Economic Review, 105(10), 3150-3182.

Felbermayr, G., \& Gröschl, J. (2014). Naturally negative: The growth effects of natural disasters. Journal of development economics, 111, 92-106. doi:http://dx.doi.org/10.1016/j.jdeveco.2014.07.004

Gaillard, J. (2008). Alternative paradigms of volcanic risk perception: The case of Mt. Pinatubo in the Philippines. Journal of Volcanology and Geothermal Research, 172(3-4), 315-328. doi:http://dx.doi.org/10.1016/j.jvolgeores.2007.12.036

Gaillard, J. (2010). Vulnerability, capacity and resilience: Perspectives for climate and development policy. Journal of International Development, 22(2), 218-232. doi:10.1002/jid.1675 
Gaillard, J. (2011). People's Response to Disasters in the Philippines: Vulnerability, Capacities and Resilience. New York: Paalgrave Macmillan.

Gaillard, J., Liamzon, C. C., \& Villanueva, J. D. (2007). 'Natural' disaster? A retrospect into the causes of the late-2004 typhoon disaster in Eastern Luzon, Philippines. Environmental Hazards, 7(4), 257-270. doi:10.1016/j.envhaz.2006.11.002

GFDRR. (2014). Damage, Loss and Need Assessment - Tools and Methodology. 2014(27 July).

Ginnetti, J., Dagondon, B., Villanueva, C., Enriquez, J., F.T., T., Bacal, C., \& Carcellar, N. (2013). Disaster-induced Internal Displacement in the Philippines: The Case of Tropical Storm Washi/Sendong. Norway.

Goerg, G. M., Patterson-Lomba, O., Hébert-Dufresne, L., \& Althouse, B. M. (2014). Escaping the poverty trap: modeling the interplay between economic growth and the ecology of infectious disease.

GOP. Pantawid Pamilyang Pilipino Program. Philippines: Goverment of the Philippines.

GOP. (1975). Presidential Decree No. 705: Revising Presidential Decree No. 389, Otherwise Known As the Forestry Reform Code of the Philippines. Manila, Philippines: Government of the Philippines.

GOP. (1983). An Act Enacting the Local Government Code. Manila, Philippines: Government of the Philippines.

GOP. (1991). Local Government Code of the Philippines. Manila, Philippines: Government of the Philippines Retrieved from http://www.dilg.gov.ph/PDF_File/reports_resources/DILG-

Resources-201162-99c00c33f8.pdf.

GOP. (2009). Typhoons Ondoy and Pepeng: Post-Disaster Needs Assessment. Metro Manila, Philippines: Goverment of the Philippines.

Grünewald, F., \& Boyer, B. (2013) Lessons Learnt on Typhoons in the Philippines. Urgence Rehabilitation Developpement.

Guha-Sapir, D., Hoyois, P., \& Below, R. (2012). Annual Disaster Statistical Review 2011: The Numbers and Trends. Brussels, Belgium: Centre for Research on the Epidemiology of Disasters (CRED), Institute of Health and Society (IRSS), Universite Catholique de Louvain.

Guha-Sapir, D., Hoyois, P., \& Below, R. (2013). Annual Disaster Statistical Review 2012: The Numbers and Trends. Brussels, Belgium: Centre for Research on the Epidemiology of Disasters (CRED), Institute of Health and Society (IRSS), Universite Catholique de Louvain.

Guha-Sapir, D., Hoyois, P., \& Below, R. (2014). Annual Disaster Statistical Review 2013: The Numbers and Trends. Brussels, Belgium.

Hallegatte, S. (2014). Economic Resilience: Definition and Measurement Policy Research Working Paper (Vol. WPS6852). Washington DC: World Bank Group. 
Hallegatte, S., Bangalore, M., \& Vogt-Schilb, A. (2016a). Assessing Socioeconomic Resilience to Floods in 90 Countries Policy Research Working Paper (Vol. WPS7663). Washington DC, USA: World Bank.

Hallegatte, S., Bangalore, M., \& Vogt-Schilb, A. (2016b). Socioeconomic resilience : multi-hazard estimates in 117 countries Policy Research Working Paper (Vol. WPS7886). Washington DC, USA: World Bank Group.

Hallegatte, S., Bangalore, M., \& Vogt-Schilb, A. (2016c). Socioeconomic Resilience to Floods in 90 Countries: Supplementary Material Policy Research Working Paper. Washington DC, USA: World Bank Group.

Hallegatte, S., \& Przyluski, V. (2010). The Economics of Natural Disasters: Concepts and Methods Policy Research Working Paper (Vol. WPS5507). Washington DC, USA: World Bank Group.

Hallegatte, S., Vogt-Schilb, A., Bangalore, M., \& Rozenberg, J. (2017). Unbreakable : Building the Resilience of the Poor in the Face of Natural Disasters. Climate Change and Development. Retrieved from Washington DC: http://hdl.handle.net/10986/25335

Heistermann, M., Crisologo, I., Abon, C. C., Racoma, B. A., Jacobi, S., Servando, N. T., ... Bronstert, A. (2013). Brief communication "Using the new Philippine radar network to reconstruct the Habagat of August 2012 monsoon event around Metropolitan Manila". Nat. Hazards Earth Syst. Sci., 13(3), 653-657. doi:10.5194/nhess-13-6532013

Hochrainer, S. (2009). Assessing the Macroeconomic Impacts of Natural Disasters: Are there Any? (Vol. WPS4968). Washington DC, USA: The World Bank.

Holling, C. (1973). Resilience and Stability of Ecological Systems. Annual Review of Ecology and Systematics.

Hudner, D., \& Kurtz, J. (2015). Do Financial Services Build Disaster Resilience? Examining the Determinants of Recovery from Typhoon Yolanda in the Philippines: Mercy Corps.

ICC. (2012). ICC Project Evaluation Procedures and Guidelines. Philippines:

National Economic and Development Authority (NEDA), Investment Coordinating Council (ICC).

IFPRI. (2015). International Food Policy Research Institute. Retrieved from http:/ / www.ifpri.org/publications?keyword=\&ds_year\%25255Bm in $\% 25255 \mathrm{D}=\& d s \_y e a r \% 25255 \mathrm{Bmax} \% 25255 \mathrm{D}=\&$ sort_by $=d s \_y e a r$

IPCC. (1996). Climate Change 1995. Retrieved from Great Britain: https://www.ipcc.ch/ipccreports/sar/wg_I/ipcc_sar_wg_I_full_r eport.pdf

IPCC. (2001). Climate Change 2001: Impacts, Adaptation, and Vulnerability. Retrieved from Cambridge, UK: http://www.ipcc.ch/ipccreports/tar/wg2/index.htm 
IPCC. (2014). Climate Change 2014: Impacts, Adaptaion, and Vulnerability. Retrieved from Geneva, Switzerland: https://ipccwg2.gov/AR5/images/uploads/WGIIAR5-

IntegrationBrochure_FINAL.pdf

Israel, D., \& Briones, R. (2014). Disasters, Poverty, and Coping Strategies: The Framework and Empirical Evidence for Micro/Household Data - Philippines Case PIDS Discussion Paper Series. Manila, Philippines: Philippine Institute for Development Studies.

Jacobsen, K. (2008). Global health and global aging (Vol. 45, pp. 1370). Middletown: American Library Association dba CHOICE.

Jongman, B., Ward, P. J., \& Aerts, J. C. J. H. (2012). Global exposure to river and coastal flooding: Long term trends and changes. Global $\begin{array}{llll}\text { Environmental } \quad \text { Change, 22(4), 823-835. } & \text {. }\end{array}$ doi:http://dx.doi.org/10.1016/j.gloenvcha.2012.07.004

Jose, S. R. G. (2012). Preliminary Examination of Existing Methodologies for Allocating and Tracking National Government Budget for Disaster Risk Reduction (DRR) in the Philippines: ADB and UNISDR.

JRC-EC. (2014). INFORM Results and User Guide (2014 Beta Version). Luxemberg: Joint Research Center of the European Commission.

Kahn, M. E. (2005). The Death Toll from Natural Disasters: The Role of Income, Geography, and Institutions. Review of Economics and Statistics, $\quad 87(2)$ 271-284. doi:http://dx.doi.org/10.1162/0034653053970339

Karim, A., \& Noy, I. (2016). Poverty and Natural Disasters-A Qualitative Survey of the Empirical Literature. The Singapore Economic Review, 61(1).

Kates, R. W. (1971). Natural Hazard in Human Ecologica Perspective: Hypothesis and Models. Economic Geography, 47(438-451).

Kellenberg, D. K., \& Mobarak, A. M. (2008). Does rising income increase or decrease damage risk from natural disasters? Journal of urban economics, 63(3),

doi:http://dx.doi.org/10.1016/i.jue.2007.05.003

Kondo, H., Seo, N., Yasuda, T., Hasizume, M., Koido, Y., Ninomiya, N., \& Yamamoto, Y. (2002). Post-flood--infectious diseases in Mozambique. Prehospital and disaster medicine, 17(3), 126. doi:10.1017/S1049023X00000340

Kouadio, I., Aljunid, S., Kamigaki, T., Hammad, K., \& Oshitani, H. (2012). Infectious diseases following natural disasters: prevention and control measures (Vol. 10, pp. 95-104). London: Informa Healthcare Expert Reviews Ltd.

Kunii, O., Nakamura, S., Abdur, R., \& Wakai, S. (2002). The impact on health and risk factors of the diarrhoea epidemics in the 1998 Bangladesh floods. Public Health, 116(2), 68-74. doi:http://dx.doi.org/10.1038/sj.ph.1900828 
Lamond, J. E., Joseph, R. D., \& Proverbs, D. G. (2015). An exploration of factors affecting the long term psychological impact and deterioration of mental health in flooded households. Environmental Research, 140,

325-334.

doi:http://dx.doi.org/10.1016/j.envres.2015.04.008

Leal Filho, W. (2016). Climate Change and Health Improving Resilience and Reducing Risks. In U. M. Azeiteiro, F. t. Alves, \& SpringerLink (Eds.), Climate Change Management (1st ed. 2016.. ed.): Cham : Springer International Publishing : Imprint: Springer.

Lewis, J. (1999). Development in Disaster-Prone Places: Studies in Vulnerability. London: IT Publications.

LGU-CDO. (2014a). 2014 Socioeconomic Profile of Cagayan de Oro City. Cagayan de Oro City, Philippines: Local Government of Cagayan de Oro City.

LGU-CDO. (2014b). Comprehensive Development Plan of Cagayan de Oro, 2014-2019. Cagayan de Oro City, Philippines: Local Government Unit of Cagayan de Oro City.

LGU-CDO. (2016). Vulnerability and Adaptation Assessment Report. Cagayan de Oro City, Philippines: Local Government Unit of Cagayan de Oro City, UN-Habitat, World Food Program.

Liongson, L., Tabios, G., \& Castro, P. (Eds.) (2000). . (2000). Pressure of Urbanization: Flood Control and Drainage in Metro Manila. Quezon City, Philippines: University of the Philippines - Center for Integrated Development Studies.

Liu, A., Tan, H., Zhou, J., Li, S., Yang, T., Wang, J., . . Shi, W. (2006). An epidemiologic study of posttraumatic stress disorder in flood victims in Hunan China. Canadian Journal of Psychiatry, 51(6), 350-354.

Loayza, N. V., Olaberría, E., Rigolini, J., \& Christiaensen, L. (2012). Natural Disasters and Growth: Going Beyond the Averages. World Development, $\quad 40(7), \quad 1317-1336$. doi:http://dx.doi.org/10.1016/j.worlddev.2012.03.002

Marueñas, M. (2015). 23,000 residents evacuated as Marikina River continues to swell. GMA News Online. Retrieved from http://www.gmanetwork.com/news/story/268665/news/metro manila/23-000-residents-evacuated-as-marikina-river-continues-toswell

Maryam, B., Zain, A. S., Amyn, B., Nida Shahab, B., Sidra, A., Javeria, F., \& Beg, M. A. (2012). Infectious diseases in the aftermath of monsoon flooding in Pakistan. Asian Pacific Journal of Tropical Biomedicine, 2(1), 76-79. doi:10.1016/S2221-1691(11)60194-9

Matthew, S., Jennie, M., Hugo, B., Charles, B., Alison, S., \& Cynthia, J. (2016). Vector-control response in a post-flood disaster setting, Honiara, Solomon Islands, 2014. Western Pacific Surveillance and Response, 7(1), 38-43. doi:10.5365/wpsar.2015.6.3.004 
Mechler, R. (2009). Disaster and Economic Welfare: Can National Savings Help Explain Post-disaster Changes in Consumption? Policy Research Working Paper (Vol. WPS4988). Wahington DC, USA: The World Bank.

Mertens, K., Jacobs, L., Maes, J., Kabaseke, C., Maertens, M., Poesen, J., . . Vranken, L. (2016). The direct impact of landslides on household income in tropical regions: A case study from the Rwenzori Mountains in Uganda. Science of The Total Environment, 550, 10321043. doi:http://dx.doi.org/10.1016/j.scitotenv.2016.01.171

Mileti, D. S. (1999). Disasters by design a reassessment of natural hazards in the United States. Washington, D.C.: Joseph Henry Press.

Miller, F., H. Osbahr, E. Boyd, F. Thomalla, S. Bharwani, G. Ziervogel, . . . Nelson, D. (2010). Resilience and vulnerability: complementary or conflicting concepts? Ecology and Society, 15(3), 11.

Moret, W. (2014). Vulnerability Assessment Methodologies: A Review of Literature. United States: United States Agency for International Development.

NDRRMC. (2012a). Final Report on the Effects and Emergency Manangement re Tropical Storm Sendong (Washi) (pp. 36). Metro Manila, Philippines: National Disaster Risk Reduction and Management Council.

NDRRMC. (2012b). SitRep No. 29 re Effects of Tropical Storm "Sendong" (WASHI) and Status of Emergency Response Operations As of 5 January 2012. Metro Manila, Philippines: National Disaster Risk Reduction and Management Council.

NDRRMC. (2014). Tropical Cyclones and Their Effects, 2005-2013.

NEDA. (2005). Regional Development Plan of Northern Mindanao. Cagayan de Oro City, Philippines: National Economic and Development Authority.

NEDA. (2007). Guidelines on Provincial/Local Planning and Expenditure Management. Manila, Philippines: National Economic and Development Authority and the Asian Development Bank.

NEDA. (2008). Mainstreaming Disaster Risk Reduction in Subnational Development and Land Use/Physical Planning in the Philippines. Manila, Philippines: National Economic and Development Authority, United Nations Development Programme, European Commission Humanitarian Aid.

NEDA. (2012). Strategic Action Plan for the Reconstruction and Rehabilitation of Areas Affected by TS Sendong. Cagayan de Oro, Philippines: NEDA.

NEDA. (2014). Philippine Development Plan Midtem Update. Metro Manila, Philippines: NEDA from http:/ / www.neda.gov.ph/2013/10/21/philippine-developmentplan-2011-2016/. 
NMC. (2005). Natural Hazard Mitigation Saves: An Independent Study to Assess the Future Savings from Mitigation Activities Report to U.S. Congress on behalf of the National Institute of Building Sciences (Vol. 2). Washington, DC: Multihazard Mitigation Council.

Nomura, S., Parsons, A. J. Q., Hirabayashi, M., Kinoshita, R., Liao, Y., \& Hodgson, S. (2016). Social determinants of mid- to long-term disaster impacts on health: A systematic review. International Journal of Disaster Risk Reduction, 16, 53-67. doi:10.1016/j.ijdrr.2016.01.013

Nordhaus, W. D., \& Tobin, J. (1972). Is Growth Obsolete? Economic Research: Retrospect and Prospect (Vol. 5): NBER.

Noy, I. (2009). The macroeconomic consequences of disasters. Journal of development economics, 88(2), 221-231. doi:http:/ / dx.doi.org/10.1016/j.jdeveco.2008.02.005

Noy, I., \& duPont, W. (2016). The long-term consequences of natural disasters: A summary of the literature SEF Working Paper, 02/2016. doi:http://hdl.handle.net/10063/4981

Noy, I., \& Vu, T. B. (2010). The economics of natural disasters in a developing country: The case of Vietnam Journal of Asian Economics (Vol. 21, pp. 345-354).

Noy, I., \& Yonson, R. (2016). A Survey of the Theory and Measurement of Economic Vulnerability and Resilience to Natural Hazards Victoria University Working Paper (Vol. 03/2016). Wellington, New Zealand: Victoria University of Wellington.

NRC. (2005). Improved Seismic Monitoring--Improved Decision-Making: Assessing the Value of Reduced Uncertainty. Washington, DC: National Research Council.

NRC. (2011). National Earthquake Resilience: Research, Implementation and Outreach. Washington, DC: National Research Council.

NRC. (2012). Disaster Resilience: A National Imperative. Washington, DC: National Research Council.

O'Keefe, P., Westgate, K., \& Wisner, B. (1976). Taking the naturalness out of natural disasters. Nature, 260(5552), 566-567.

PAGASA-DOST. (2012). Flood Hazard and Risk in the Philippines. Paper presented at the Caucus on Climate Scnarios and Flood Risk Assessment, Metro Manila, Philippines.

PAGASA. (2011). Climate Change in the Philippines. Manila: Philippine Atmospheric, Geophysical, Astronomical Services

PAGASA. (2014). List of Tropical Cyclone in the Philippine Area of Responsibility, 1980-2013.

PAGASA. (undated). Tropical Cyclone. Retrieved from http://www.pagasa.dost.gov.ph/learning-tools/tropical-cyclonelearning?showall=1\&limitstart $=$

Peduzzi, P. (2006). The Disaster Risk Index: Overview of a quantitative approach. In J. Birkmann (Ed.), Measuring vulnerability to natural 
hazards: towards disaster resilient societies (pp. 171-181). New York United Nations University.

Peduzzi, P., Dao, H., Herold, C., \& Mouton, F. (2009). Assessing global exposure and vulnerability towards natural hazards: the Disaster Risk Index. Natural Hazards and Earth System Sciences, 9(4), 1149-1159.

Pelling, M. (2003). The vulnerability of cities: natural disasters and social resilience London, United Kingdom: Earthscan Publications Ltd.

Pelling, M. (2006). Review of global risk index projects: Conclusions for subnational and local approaches. In J. Birkmann (Ed.), Measuring vulnerability to natural hazards: towards disaster resilient societies (pp. 151-170). New York United Nations University.

PHDN. (2013). 2012/2013 Philippine Human Development Report. Manila, Philippines: Philippine Human Development Network.

Pimm, S. L. (1984). The complexity and stability of ecosystems. Nature, 307(5949), 321. doi:10.1038/307321a0

Poontirakul, P., Brown, C., Noy, I., Seville, E., \& Vargo, J. (2016). The role of commercial insurance in post-disaster recovery: Quantitative evidence from the 2011 Christchurch earthquake. SEF Working Paper, 01/2016.

Porio, E. (2011). Vulnerability, Adaptation, and Resilience to Floods and Climate Change-Related Risks among Marginal, Riverine Communities in Metro Manila. Asian Journal of Social Science, 39, 425445.

PSA. (2012a). The 2010 Census of Population and Housing Reveals the Philippine Population at 92.34 Million. Retrieved from http://web0.psa.gov.ph/

PSA. (2012b). 2012 Family Income and Expenditure Survey. Metro Manila, Philipines: Philippine Statistics Agency.

PSA. (2013). 2012 Full Year Official Poverty Statistics.

PSA. (2015a). 2015 Family Income and Expenditure Survey. Metro Manila, Philipines: Philippine Statistics Agency.

PSA. (2015b). Gross Regional Domestic Product - Data and Charts. Retrieved from: http://nap.psa.gov.ph/grdp/datacharts.asp

PSA. (2015c). List of Provinces in the Philippines. Retrieved from www.nscb.gov.ph/activestats/psgc/listprov.asp

PSA. (2016a). Highlights of the Philippine Population 2015 Census of Population. Retrieved from https://psa.gov.ph/content/highlights-philippine-population2015-census-population

PSA. (2016b). Highlights of the Philippine Population 2015 Census of Population. In P. S. Agency (Ed.). Manila, Philippines: Philippines Statistical Agency.

PSA. (2016c). Population of Region X - Northern Mindanao (Based on the 2015 Census of Population)2016-075. Retrieved from 
https://psa.gov.ph/content/population-region-x-northernmindanao-based-2015-census-population

Raschky, P. A. (2008). Institutions and the losses from natural hazards. Natural Hazards and Earth System Sciences(8), 627-634.

Ravago, M.-L., \& Mapa, D. (2014). Eastern Visayas after Yolanda: Evidence from Household Survey (Vol. 2014-05): Philippine Center for Economic Development.

Rose, A. (2004a). Defining and measuring economic resilience to disasters. Disaster Prevention and Management: An International Journal, 13(4), 307-314. doi:doi:10.1108/09653560410556528

Rose, A. (2004b). Economic Principles, Issues, and Research Priorities in Hazard Loss Estimation. In Y. Okuyama \& S. Chang (Eds.), Modeling Spatial and Economic Impacts of Disasters. Heidelberg: Springer.

Rose, A. (2007). Economic Resilience to Natural and Man-Made Disasters: Multi-Disciplinary Origins and Contextual Dimensions. Environmental Hazards, 7(4), 383-395.

Rose, A. (2009a). Economic Resilience to Disasters Published Articles $\mathcal{E}$ Papers. United States: CREATE Research Archive.

Rose, A. (2009b). Economic Resilience to Disasters. United States: CREATE Research Archive.

Rose, A. (2011). Resilience and sustainability in the face of disasters. Environmental Innovation and Societal Transitions, 1(1), 96-100. doi:http://dx.doi.org/10.1016/j.eist.2011.04.003

Rose, A., \& Krausmann, E. (2013). An economic framework for the development of a resilience index for business recovery. International Journal of Disaster Risk Reduction, 5, 73-83. doi:http://dx.doi.org/10.1016/j.ijdrr.2013.08.003

Ruger, J. P., Jamison, D. T., Bloom, D. E., \& Canning, D. (2012). Health and the Economy. In M. H. Merson, R. E. Black, \& A. J. Mills (Eds.), Global Health: Diseases, Programs, Systems, and Policies (Third ed.). USA: Jones \& Bartlett Learning.

Scussolini, P., Aerts, J. C. J. H., Jongman, B., Bouwer, L. M., Winsemius, H. C., de Moel, H., \& Ward, P. J. (2016). FLOPROS: an evolving global database of flood protection standards. Nat. Hazards Earth Syst. Sci., 16(5), 1049-1061. doi:10.5194/nhess-16-1049-2016

Shepherd, A., Mitchell, T., Lewis, K., Lenhardt, A., Jones, L., Scott, L., \& Muir-Wood, R. (2013). The Geography of Poverty, Disasters and Climate Extreme in 2030. London, United Kingdom: Overseas Development Institute.

Strobl, E. (2012). The economic growth impact of natural disasters in developing countries: Evidence from hurricane strikes in the Central American and Caribbean regions. Journal of development economics, 97(1), 130-141. doi:http:// dx.doi.org/10.1016/j.jdeveco.2010.12.002 
TCAGP. (2014). River Basin and Flood Modeling and Flood Hazard Assessment for the Rivers in the Cities of Cagayan de Oro and Iligan. Manila, Philippines: Training Center for Applied Geodesy and Photogrammetry (TCAGP), College of Engineering, University of the Philippines.

Thywissen, K. (2006). Core terminology of disaster reduction. In J. Birkmann (Ed.), Measuring vulnerability to natural hazards: towards disaster resilient societies. New York: United Nations University.

Toya, H., \& Skidmore, M. (2007). Economic development and the impacts of natural disasters. Economics Letters, 94(1), 20-25. doi:http://dx.doi.org/10.1016/j.econlet.2006.06.020

UN. (2014). World Urbanization Prospects: The 2014 Revision: United Nations, Department of Economic and Social Affairs, Population Division.

UN. (2015a). Sendai Framework for Disaster Risk Reduction 2015-2030: United Nations.

UN. (2015b). Transforming Our World: the 2030 Agenda for Sustainable Development

UNDP-BCPR. (2004). A Global Report: Reducing Disaster Risk, A Challenge for Development. New York: United Nations Development Programme - Bureau of Crisis Prevention and Recovery.

UNDP-DHA. (1994). Vulnerability and Risk Assessment: Disaster Management Training Programme.

UNDRO. (1979). Natural Disasters and Vulnerbality Analysis Rerport of Expert Group Meeting. Geneva: United Nations Disaster Relief

UNDRO. (1992). An Overview of Disaster Management. 2nd.

UNISDR. (2005). Hyogo Framework for Action 2005-2015: Building the resilience of nations and communities to disasters: United Nations Office for Disaster Risk Reduction.

UNISDR. (2009). UNISDR Terminology on Disaster Risk Reduction. Geneva, Switzerland: United Nations International Strategy for Disater Reduction.

UNISDR. (2013). From Shared Risk to Shared Value -The Business Case for Disaster Risk Reduction Global Assessment Report on Disaster Risk Reduction. Geneva, Switzerland: United Nations International Strategy for Disaster Reduction (UNISDR).

UNISDR. (2015a). Disaster Risk Reduction and Resilience in the 2030 Agenda for Sustainable Development: UN Office for Disaster Risk Reduction.

UNISDR. (2015b). Fact sheet: Health in the Context of the Sendai Framework for Disaster Risk Reduction. Geneva, Switzerland: United Nations International Strategy for Disaster Reduction - The United Nations Office for Disaster Risk Reduction. 
UNU-EHS. (2014). World Risk Report 2014 Focus: The City as Risk Area: United Nations University for Environment and Human Security.

van Den Berg, M. (2010). Household income strategies and natural disasters: Dynamic livelihoods in rural Nicaragua. Ecological Economics, 69(3), 592-602.

Vijayachari, P., Sugunan, A., \& Shriram, A. (2008). Leptospirosis: an emerging global public health problem. Journal of Biosciences, 33(4), 557-569. doi:10.1007/s12038-008-0074-z

Villagran de Leon, J. C. (2006). Vulnerability: A Conceptual and Methodological Review. Germany: UNU Institute for Environment ad Human Society (UNU-EHS).

von Peter, G., von Dahlen, S., \& Saxena, S. (2012). Unmitigated disasters? New evidence on the macroeconomic cost of natural catastrophes. BIS Working Papers, (394).

Wamsler, C. (2006). Mainstreaming risk reducting in urban planning and housing: a challenge for international aid organizations. Disasters, 30(2), 151-177.

Watson, J. T., Gayer, M., \& Connolly, M. A. (2007). Epidemics after natural disasters. Emerging Infectious Diseases, 13(1), 1. doi:10.3201/eid1301.060779

Watson, J. T., Gayer, M., \& Connolly, M. A. (2007). Epidemics after Natural Disasters. Emerging Infectious Diseases, 13(1). doi:https://dx.doi.org/10.3201/eid1301.060779.

Watts, M. J., \& Bohle, H. G. (1993). The Space of Vulnerability: The Causal Structure of Hunger and Famine. Progress in Human Geography, 17(1), 43-67.

WB-EASPR. (2003). Natural Disaster Risk Management in the Philippines: Enhancing Poverty Alleviation Through Disaster Reduction: World Bank - East Asia and Pacific Region, Rural Development.

WB. (2014). Philippine Economic Update Pursuing Inclusive Growth through Sustainable Reconstruction and Job Creation. Philippines: World Bank, Philippine Country Office, East Asia and Pacific Region.

WB. (2016, 07/01/2016). New country classifications by income level.

Westen, C., \& Kingma, N. (2009). Vulnerability Asessment Vulnerability Assessment: Disastance Education Course Guidebook: United Nations University - ITC School of Disaster Geoinformation Management.

WHO. (2003). Climat Change and Human Health: Risks and Responses. Summary. Geneva, Switzerland: Word Health Organization.

WHO. (2009). WHO Guide to Identifying the Economic Consequences of Disease and Injury. Switzerland: World Health Organization.

Winsemius, H., B. Jongman, T. Veldkamp, S. Hallegatte, M. Bangalore, a., \& Ward, P. J. (2015). Disaster Risk, Climate Change, and Poverty: Assessing the Global Exposure of Poor People to Floods and Droughts. Policy Research Working Paper, 7480. Retrieved from 
Wisner, B., Blaikie, P., Cannon, T., \& Davis, I. (2004). At risk : natural hazards, people's vulnerability, and disasters (Second ed.). London; New York: Routledge.

Wisner, B., Gaillard, J., \& Kelman, I. (Eds.). (2012). The Routledge Handbook of Hazards and Disaster Risk Reduction. Great Britain: Routledge.

Yang, L., Wang, X., Huang, K., \& Wang, D. (2015). Anomalous Tropical Cyclone Activity In The Western North Pacific In August 2014. Bulletin of the American Meteorological Society, 96(12), S120-S126.

Yonson, R., Gaillard, J., \& Noy, I. (2016). The Measurement of Disaster Risk: An Example from Tropical Cyclones in the Philippines SEF Working Paper (Vol. 04/2016). Wellington, New Zealand: Victoria University of Wellington. 